\title{
Forensic DNA Profiling of Bacterial Communities in Soil
}

\section{Rachel Parkinson}

\author{
A thesis \\ submitted to the Victoria University of Wellington \\ in partial fulfilment of the \\ requirements for the degree of \\ Master of Science \\ in Cell and Molecular Biosciences.
}

Victoria University of Wellington

2004 


\section{ABSTRACT}

Soil is frequently encountered as trace evidence in forensic science case-work, but because of the limitations of current analytical techniques, this evidence is rarely utilised. A technique has been developed that allows comparisons of soil samples to be made, based on molecular analysis of the bacterial communities living in the soil. This project assesses the practicality of using this technique, known as 16S rDNA T-RFLP community profiling, for forensic soil analysis, by refining the basic methodology and performing a preliminary evaluation of its reproducibility and utility. Initial difficulties associated with generating profiles from soil samples have been overcome through methodology improvement, and the technique has been found to be effective for generating simple, visual profiles that clearly demonstrate differences between soil samples. Soil bacterial community DNA profiling is likely to be a powerful yet simple forensic tool, providing the ability to routinely use soil as associative evidence.

The potential for using the same technology to develop a time since death or post mortem interval (PMI) estimation tool was also investigated. This study monitored the changes in the soil bacterial community beneath decomposing human cadavers and pig carcasses and showed that community change is dynamic and progressive. These changes are caused by fluctuations in specific bacterial species populations that are able to utilise organic breakdown products released from the body over time. Release of the body's natural microflora into the underlying soil may also contribute to an altered bacterial community. This project has demonstrated that the soil microbial community clearly changes over the course of decomposition, and potential exists for development of a PMI estimation tool based on soil bacterial community succession. 


\title{
Acknowledgments
}

I would like to express my sincere thanks to my fantastic team of supervisors: Dr Jacqui Horswell-Sutherland, Dr Steve Cordiner and Dr Geoff Chambers. Special thanks go to Jacqui who was my day to day supervisor and whose door was always open for help, advice or just someone to chat with. Thanks also to my unofficial supervisor Bjorn Sutherland for forensic advice and on occasion murdering me!

I would also like to thank Dr Steph Watson for her brilliant molecular biology expertise; Dr Phil Carter and Marilyn Grubner for PCR and Genescan help; Dr Tom Speir for soil expertise and for reading, reading and re-reading; Andrew and Natalie for putting up with me in the office; Dr David Stirling for his rocket science (we'll miss you : $)$ ); Dr Rod Lea for loads of stats advice, and the rest of the staff at ESR Kenepuru for being so supportive. Many thanks to everyone.

\begin{abstract}
Also thanks to Dr Arpad Vass from Oak Ridge National Laboratories for his soil samples and help, and to Terry Eberhardt from the University of Auckland for her soil samples and pig data.
\end{abstract}

Thank you to my family who have had great trouble explaining to other people what I'm researching and why anyone would want to; and finally, special thanks go to my partner, Jeremy, who put up with me having a research topic which led to rather unusual dinner conversations that thoroughly grossed out his friends and family. His efforts in producing 'Profile Wizard' are also very much appreciated. 


\section{TABLE OF CONTENTS}

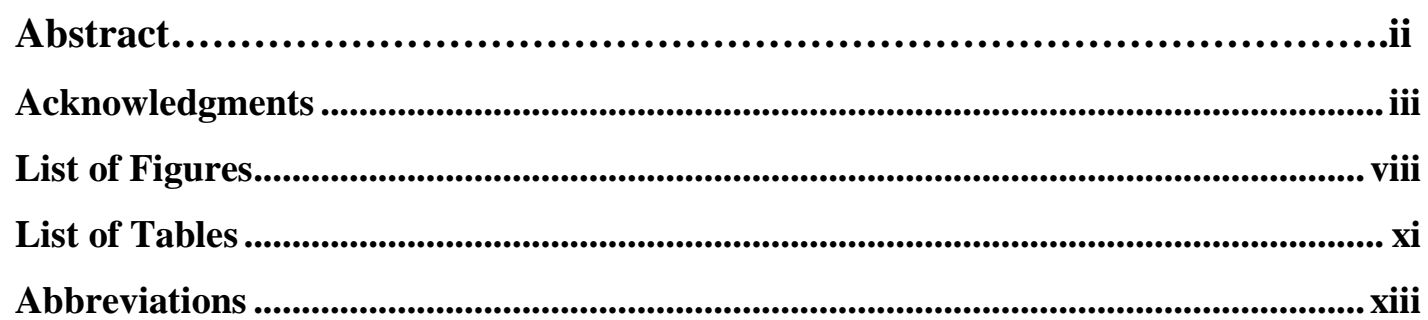

1 INTRODUCTION $\ldots \ldots \ldots \ldots \ldots \ldots \ldots \ldots \ldots \ldots \ldots \ldots \ldots \ldots \ldots \ldots \ldots \ldots \ldots \ldots \ldots \ldots \ldots \ldots \ldots \ldots \ldots$

1.1 The Need for and Potential of this Research................................................... 3

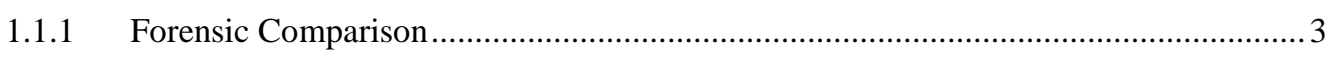

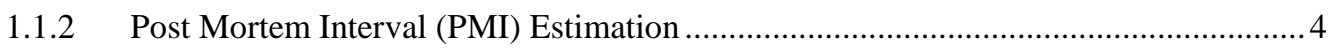

$1.2 \quad$ Aims of the Project ..................................................................................... 6

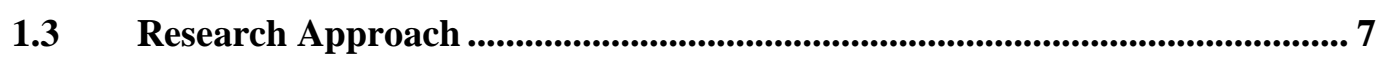

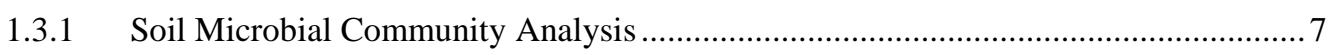

1.3.2 Developmental and Testing Approach ……………...........................................

\section{BACKGROUND AND LITERATURE REVIEW .....................11}

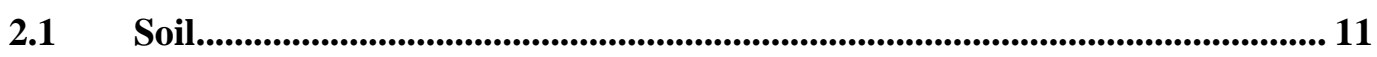

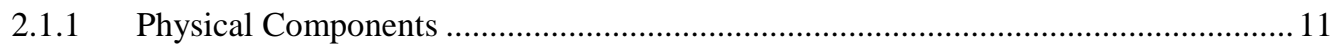

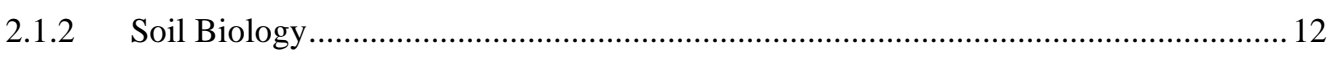

2.1.3 Soil Microbial Diversity ……............................................................................ 16

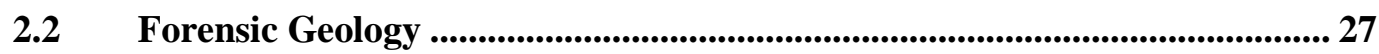

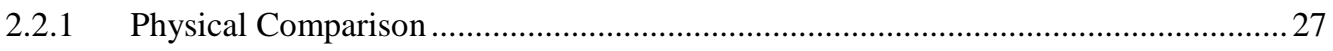

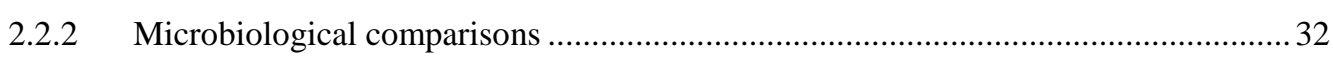

2.3 Molecular Analysis of Microbial Communities .................................................... 34

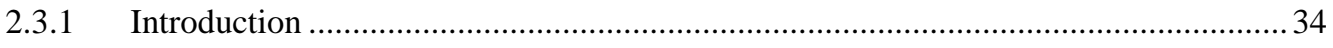

2.3.2 Culture-Independent Approaches for Studying Soil Microbial Communities.......... 34

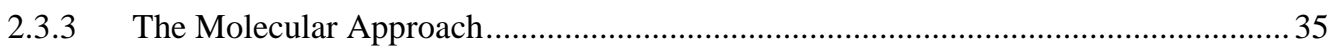

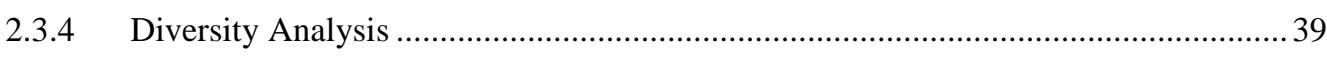

2.4 Post Mortem Interval Estimation .............................................................. 46

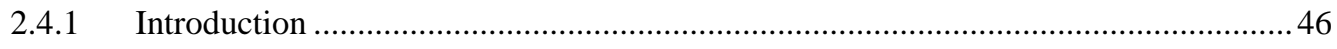

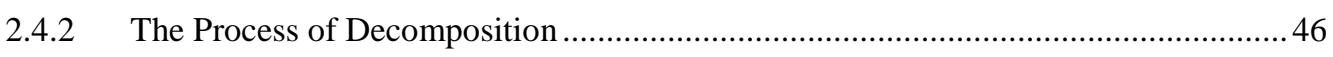

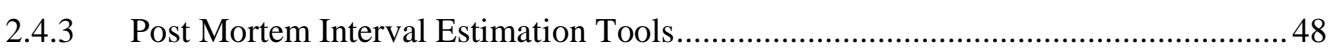

2.4.4 Post Mortem Microbiology .................................................................................... 52 
3.1 Introduction ........................................................................................................... 54

3.2 Soil DNA Profiling Method...................................................................................... 55

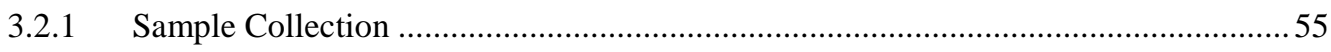

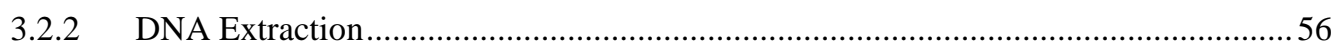

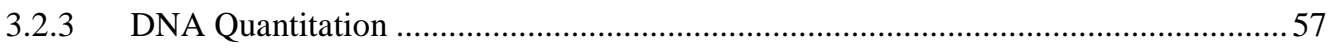

3.2.4 Amplification of 16S rRNA genes …………………........................................... 57

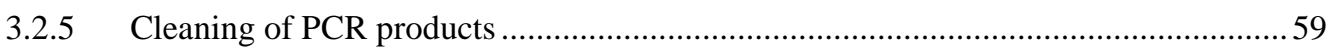

3.2.6 Restriction Enzyme Digestion of PCR Products .......................................................59

3.2.7 Fragment Detection \& Profile Generation...............................................................5

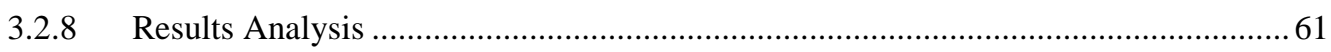

4 TECHNICAL SURVEY OF ANALYTICAL METHODOLOGY .......63

$4.1 \quad$ Introduction ............................................................................................................... 63

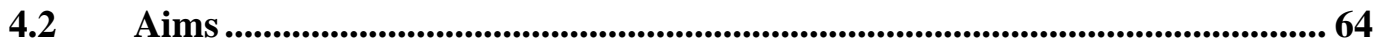

4.3 Methods ............................................................................................................................... 64

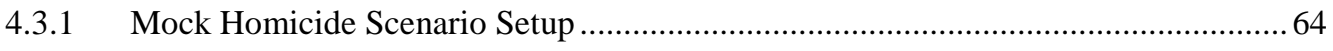

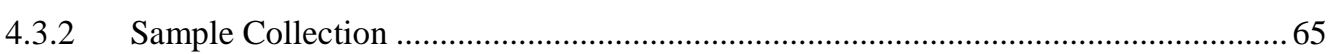

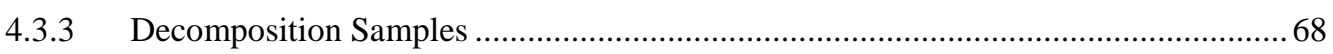

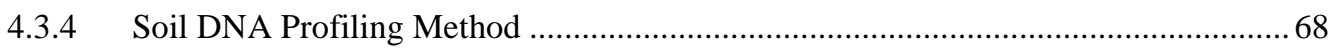

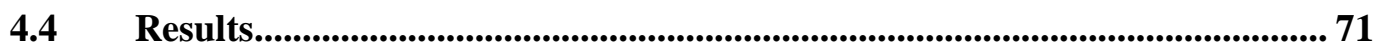

4.4.1 Soil Recovery and DNA extraction .............................................................. 71

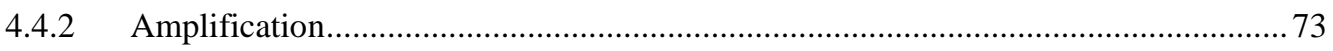

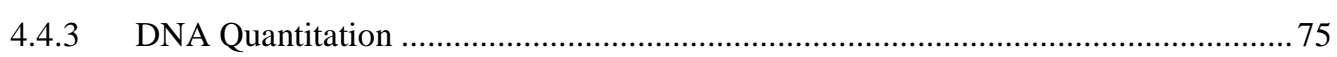

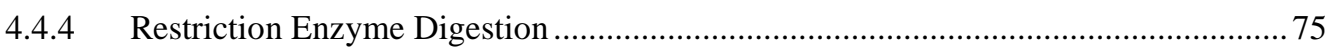

4.4.5 Fragment Detection \& Profile Generation.................................................................. 76

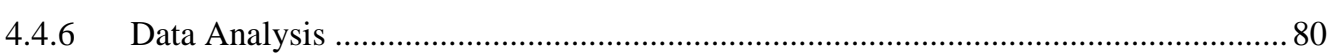

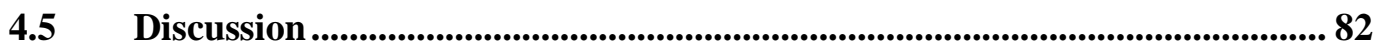

5 METHOD DEVELOPMENT ..............................................85

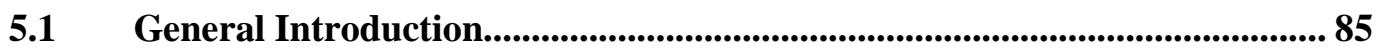

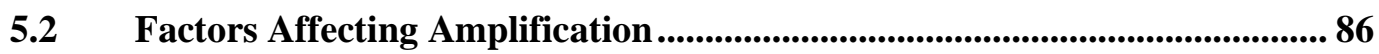

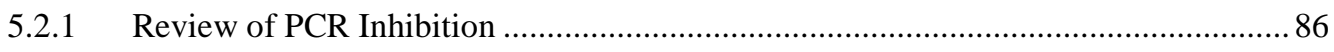

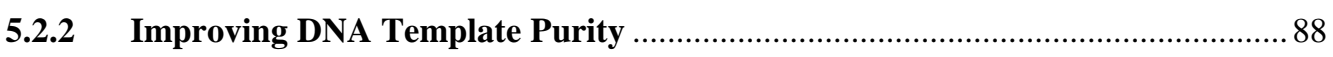

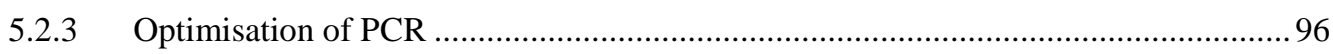


5.3 Fragment Detection and Profile Generation................................................ 104

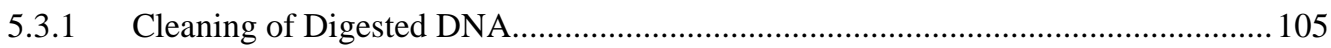

5.4 Data Analysis of Profiles ..................................................................................... 106

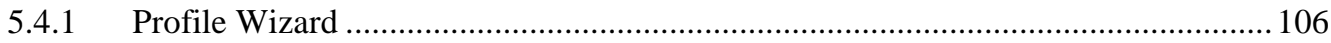

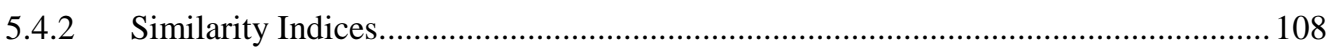

$5.5 \quad$ Sample Storage ................................................................................................ 114

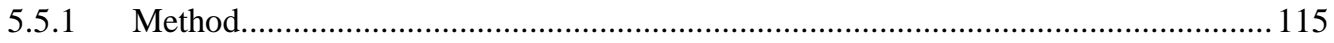

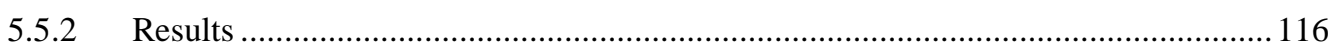

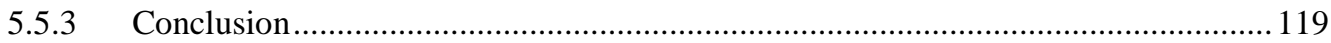

5.6 Other Improvements .............................................................................................. 120

5.6.1 Restriction Enzyme Digestion ............................................................................... 120

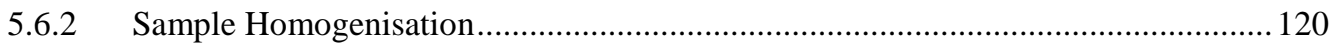

5.6.3 Minimum Soil Sample Size Required to Generate a Profile .................................... 123

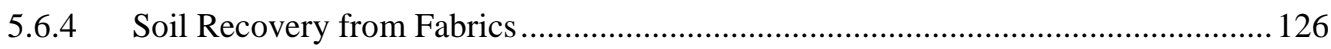

5.7 Conclusions .................................................................................................................... 129

6 REPRODUCIBILITY AND SPATIAL VARIATION ............134

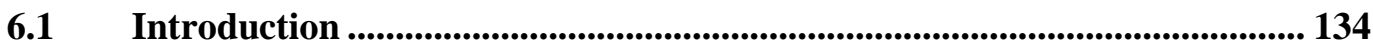

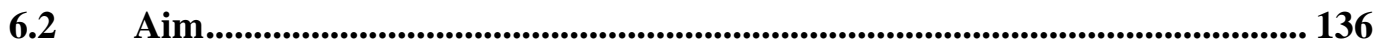

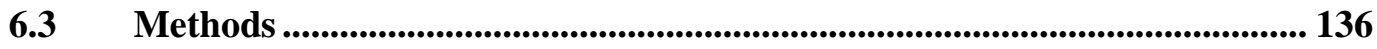

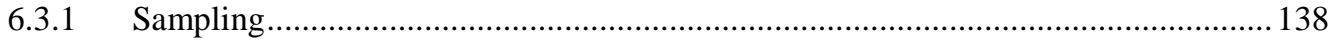

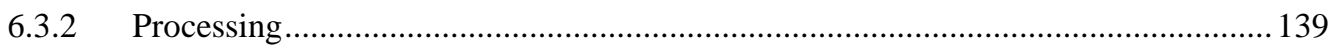

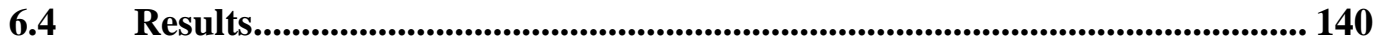

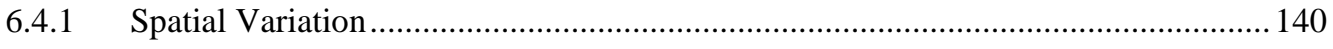

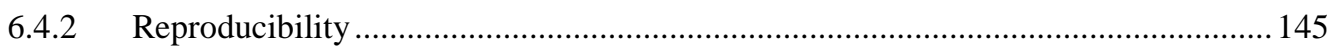

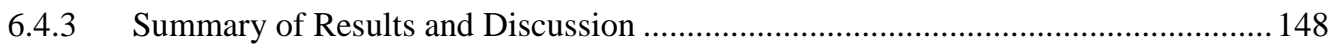

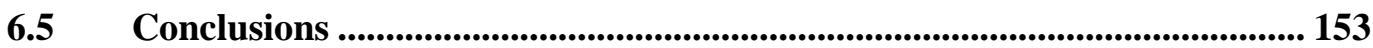

7 POST MORTEM INTERVAL ESTIMATION..........................156

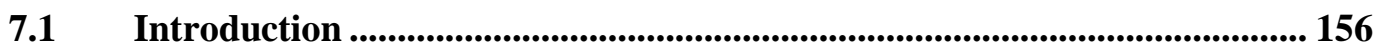

7.2 Surface Exposure Decomposition Experiment ................................................. 157

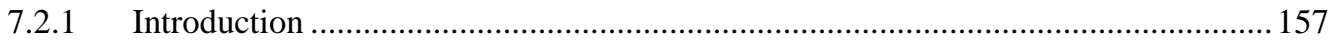

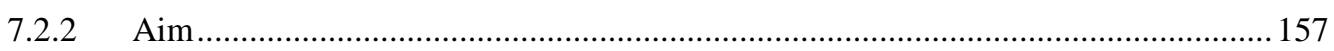

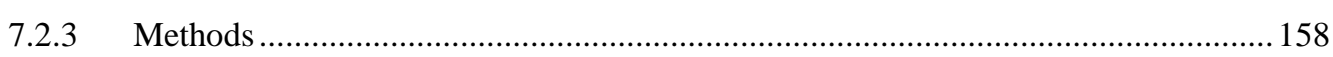

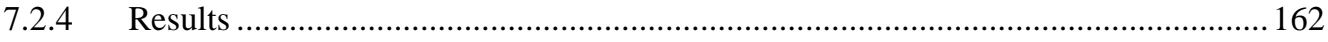




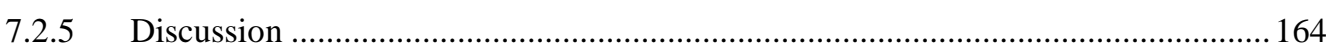

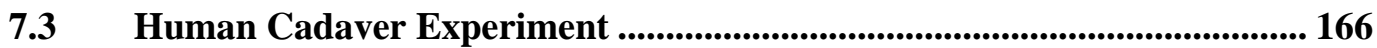

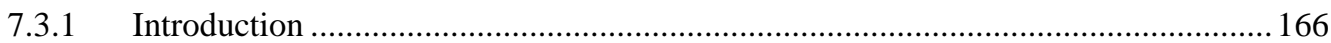

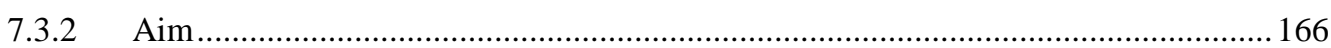

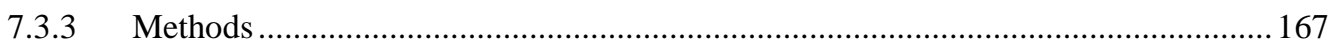

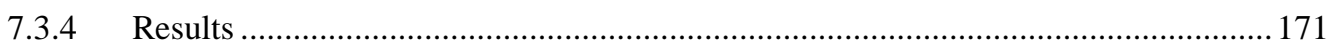

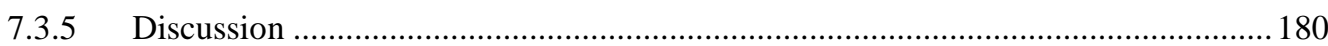

7.4 Grave Burial Experiment ................................................................................... 191

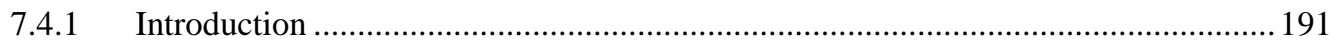

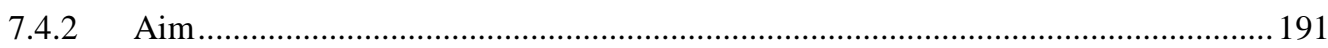

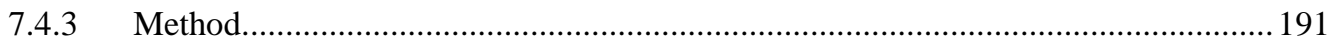

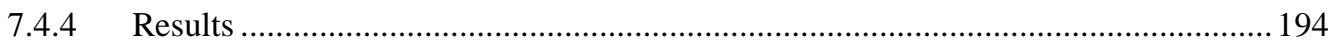

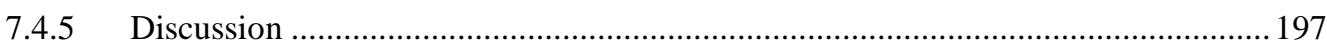

7.5 Conclusions ................................................................................................................ 201

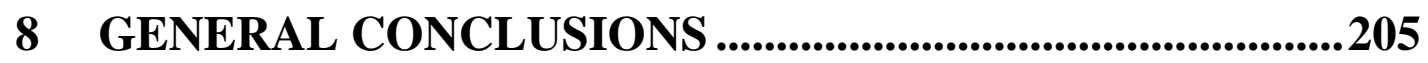

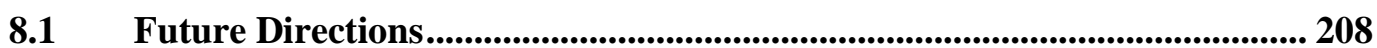

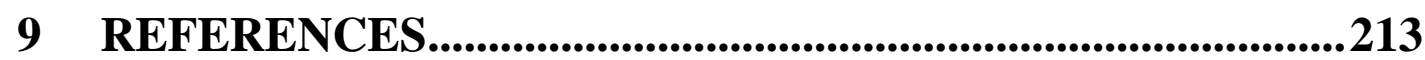

Appendix 1: Method Protocols ......................................................................................... 228

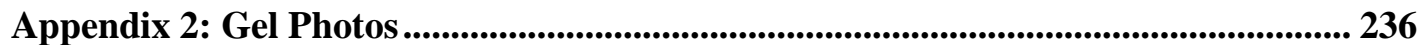




\section{List of Figures}

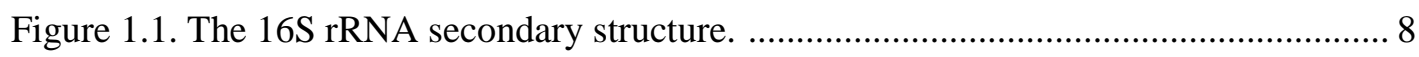

Figure 1.2. Overview of terminal restriction fragment generation. ................................... 9

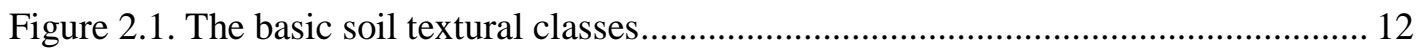

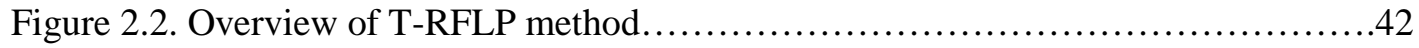

Figure 2.3. The five basic stages of decomposition, ........................................................ 47

Figure 2.4. Insect succession on a pig carcass in New Zealand.......................................... 49

Figure 2.5. Flow diagram for determining time since death in cumulative degree hours

$(\mathrm{CDH})$ using the ratios of biochemical biomarkers in muscle tissue................................... 51

Figure. 3.1. The steps involved in the basic soil DNA profiling methodology. ................ 55

Figure 3.2. Example of graphically displayed T-RFLP profile data...................................... 61

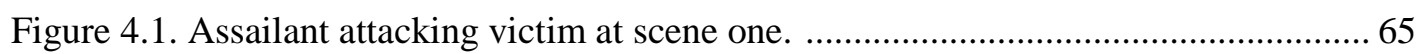

Figure 4.2. Assailant and victim at scene two..................................65

Figure 4.3. Sample sites at scene one marked with collection tubes. ..................................65

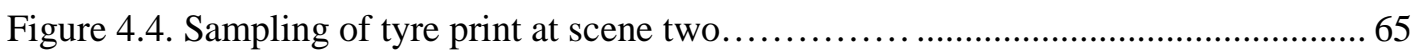

Figure 4.5. Collection of samples from assailant's right shoe (A), from the vehicle side

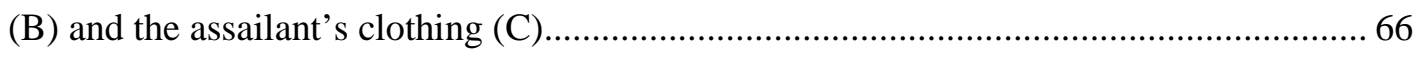

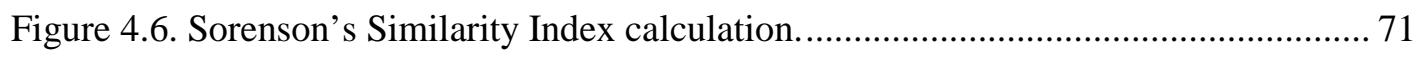

Figure 4.7. Profiles from samples from scene one of the homicide scenario. ..................... 78

Figure 4.8. Profiles from scene two of homicide scenario................................................. 79

Figure 4.9. Profiles from successfully amplified decomposition samples........................... 79

Figure 5.1. Hypothetical model structure of humic acid (Stevenson, 1982) ....................... 87

Figure 5.2. Two profiles that were identified as being of poor quality.............................. 104

Figure 5.3. Profiles of two samples previously producing poor quality profiles.............. 105

Figure 5.4. Screenshot of Profile Wizard displaying sample A32 …............................... 107

Figure 5.5. Screenshot of Profile Wizard displaying a comparison.................................. 108

Figure 5.6. Equation for the Common Area Index calculation......................................... 111

Figure 5.7. Equation for the Peak Percentage Index calculation ....................................... 112

Figure 5.8. Mean similarity between samples collected at the same site and at different

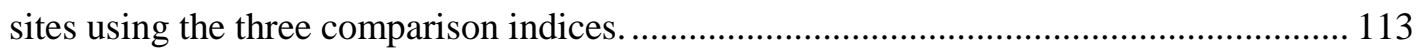

Figure 5.9. The correlation between the CAI and PPI comparisons................................ 113

Figure 5.10. Profiles from: control, oven dried, freeze dried and air dried samples.......... 118

Figure 5.11. Profiles from the three replicate control samples ........................................ 121 
Figure 5.12. Profiles from the replicate sub-samples ground with liquid nitrogen. 122

Figure 5.13. Profiles from the sub-samples not ground with liquid nitrogen. 122

Figure 5.14. Amount of DNA recovered from soil samples of varying sizes. 124

Figure 5.15. Profiles generated using different amounts of the same soil sample. 125

Figure 5.16. Fabric squares used for soil recovery experiment. 127

Figure 5.17. Example of soil stain on a $10 \mathrm{~cm}^{2}$ square of fabric type 2.......................... 127

Figure 5.18. Amount of soil recovered from stains on various fabrics. 128

Figure 6.1. Location A: Hutt River Bank. 137

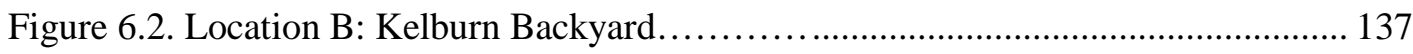

Figure 6.3. Location C: Porirua Field....................................................................... 137

Figure 6.4. Location D: Rotorua Backyard........................................ 137

Figure 6.7. Mean CAI values for each group of samples $10 \mathrm{~cm}$ apart............................. 141

Figure 6.8. Profiles from samples A1.1 - A1.3 ……..................................................... 141

Figure 6.9. Profiles from samples A3.1 - A3.3 ……….................................................. 142

Figure 6.10. Example of the sites $10 \mathrm{~m}$ apart at each location........................................... 143

Figure 6.11. Genetic Analyser replicate profiles and CAI similarity index values........... 145

Figure 6.12. Digestion replicate profiles and CAI similarity index values........................ 146

Figure 6.13. PCR replicate profiles and CAI similarity index values................................ 146

Figure 6.14. Extraction replicate profiles and CAI similarity index values....................... 147

Figure 7.1. Experimental setup for the pig at the grass site............................................ 161

Figure 7.2. Experimental setup for the pig at the sand site ............................................ 161

Figure 7.3. Experimental setup for the pig at the bush site...........................161

Figure 7.4. The CAI values between samples collected from the same sampling

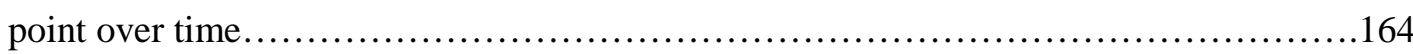

Figure 7.5. An area of the Anthropological Research Facility ....................................... 167

Figure 7.6. Profiles from the fresh stage of body A (samples A1 - A9) .......................... 172

Figure 7.7. Profiles from the bloat and decay stages of body A (A10 - A18)................... 173

Figure 7.8. Profiles from samples collected at the dry stage of body A (A20 - A31)........ 174

Figure 7.9. Profiles from the dry stage of body A continued (A32 - A36) ......................... 175

Figure 7.10. Profiles from fresh stage of body B (B1 \& B2) .......................................... 176

Figure 7.11. Profile from bloat/decay stage of body B (B6-B10)..................................... 176

Figure 7.12. Profiles from dry stage of body B ( B11-B23) .......................................... 177

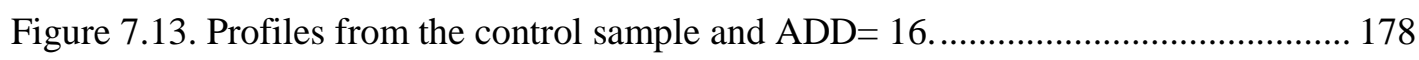

Figure 7.14. Profiles from the control sample collected near body B and ADD $=0 \ldots \ldots \ldots 178$

Figure 7.15. Number of peaks in body A profiles over time............................................. 179 
Figure 7.16. Example of results from the Microbial Community Analysis 2 website. .... 187

Figure 7.17. Empty pig grave. ............................................ 192

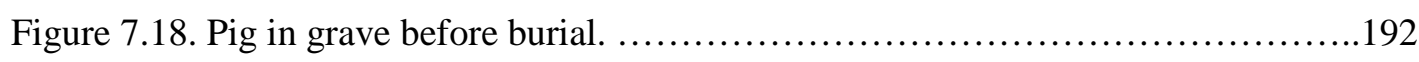

Figure 7.19.Investigator taking core samples of the grave using an auger....................... 192

Figure 7.20. Flies were attracted to the opening in the grave created by the auger........... 192

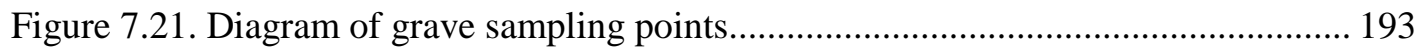

Figure 7.22. Profiles from control samples collected from the pig grave at burial............ 194

Figure 7.23. Profiles from samples collected from the pig grave six months of burial. .... 196 


\section{List of Tables}

Table 2.1. Summary of commonly used 16S rDNA bacterial community analysis techniques. 40 Table 2.2. Summary of microbial community diversity analysis techniques that do not use $16 \mathrm{~S}$ rDNA.

Table 4.1. Samples collected from the homicide scenario scenes. 67

Table 4.2. AmpliTaq Gold PCR recipe. 69

Table 4.3. AmpliTaq Gold thermocycling regime. 69

Table 4.4. HotStarTaq DNA polymerase PCR recipe. ............................................................... 70

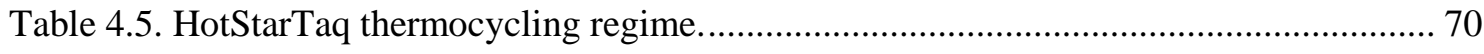

Table 4.6. The amount of soil used for DNA extraction and the amount of DNA extracted...... 72

Table 4.8. Total number of peaks and number of peaks over 100 fluorescence units ................ 77

Table 4.9. Sorenson's Similarity Index for homicide scenario samples...................... 81

Table 4.10. Similarity Index values between decomposition sample profiles............................ 81

Table 5.1. Soil samples used for DNA extraction method modification testing.. 90

Table 5.2. Ten extra decomposition samples used to test the DNAzol and plant DNAzol steps during extraction 94

Table 5.4. FastStart DNA Polymerase PCR recipe...................................................................... 98

Table 5.5. FastStart DNA Polymerase thermocycling regime...................................................... 98

Table 5.6. Results of FastStart DNA Polymerase ........................................................................ 99

Table 5.7. Accuprime Taq DNA Polymerase PCR recipe....................................................... 100

Table 5.8. Accuprime Taq DNA Polymerase thermocycling regime. ...................................... 100

Table 5.9. Results of Accuprime Taq PCR using template DNA from the test panel samples. 101 Table 5.10. Summary of alternative polymerase enzymes' PCR success in amplifying target DNA already tested with HotStarTaq. 101

Table 5.11. The test panel of samples used with BSA added to the PCR reaction. 102

Table 5.12. The number of replicates profiled at each time period for each storage condition. 116 Table 5.14. The mean CAI values (and standard deviation) between replicate profiles from each soil portion. 119

Table 5.15. Fabric items soil was applied to. 120

Table 6.1. Location and classification of the four soils sampled. 138

Table 6.2 Common Area Index similarity values between samples collected $10 \mathrm{~cm}$ apart...... 141

Table 6.3. Common Area Index similarity values between samples collected $20 \mathrm{~cm}$ apart..... 142

Table 6.4. CAI values for samples collected $10 \mathrm{~m}$ apart at each location. 143 
Table 6.5. CAI values for samples collected $10 \mathrm{~m}$ apart at each location.

Table 6.6. Mean CAI values for inter-location variation.

Table 6.7. Summary of the CAI values and Coefficient of Variance for the inter-location and intra-location sample comparisons and for replicates at each stage of the methodology.

Table 7.1 Success of the DNA extraction and PCR steps for controls and samples from the grass, bush and sand sites.

Table 7.2. Details about the cadavers used in the human decomposition study. 170

Table 7.3. CAI comparison values for the profiles from samples collected from the pig grave after six months of burial. 


\section{Abbreviations}

ADDs - Accumulative Degree Days

BSA - Bovine Serum Albumin

CAI - Common Area Index

CDHs - Cumulative Degree Hours

CTAB - Cetyl Tri-Methyl Ammonium Bromide

DGGE - Denaturing Gradient Gel Electrophoresis

DNA - Deoxyribonucleic Acid

dsDNA - double stranded DNA

ESR Ltd - Institute of Environmental Science \& Research Ltd.

FAME - Fatty Acid Methyl Ester analysis

PCR - Polymerase Chain Reaction

PMI - Post Mortem Interval

PPI - Peak Percentage Index

rDNA - ribosomal Deoxyribonucleic acid

RFU - Relative Fluorescence Units

RNA - Ribonucleic Acid

rRNA - ribosomal Ribonucleic Acid

SI - Sorenson’s Similarity Index

T-RF - Terminal Restriction Fragment

T-RFLP - Terminal Restriction Fragment Length Polymorphism 


\section{INTRODUCTION}

Soil is known to be a highly complex and dynamic medium with considerable variability in its components and composition (Marumo et al., 1995). This variability can have significant impacts on the living soil microbial community, making it unique in any given soil. Bacteria are a major component of the soil biota, with an estimated $10^{9}$ bacterial cells per gram of soil (Harris, 1994). In the past, analysis of the diversity of soil micro-organisms has been limited by traditional culturing techniques, as these allow only a fraction of all the organisms present to be isolated (Ward et al., 1990), with the proportion of cells that can be cultured being as little as $1 \%$ of the total population seen with direct microscopy (Amann et al., 1995 ). Recent developments in molecular biological techniques have enabled the study of the bacterial community in its entirety, bypassing the need for culturing. Direct characterisation of bacterial community diversity is now possible, using straightforward techniques based on conserved genes (Fisher and Triplett, 1999). Fifty-two major lineages or phyla within the domain Bacteria have now been identified using molecular techniques. Only 26 of those have previously cultivated representatives (Rappe and Giovannoni, 2003). Molecular technology has opened many doors for novel research and has been applied to numerous environments including marine and fresh waters (Donachie et al., 2002), soils (Buckley and Schmidt, 2001), composts (Buckley and Schmidt, 2001; Nogales et al., 2001; LaMontagne et al., 2002), and landfills (Huang et al., 2002). Many of these studies have focused on perturbations of natural microbial communities by contaminants and pollutants (Nogales et al., 2001), or by other factors such as cultivation (Buckley and Schmidt, 2001) or deforestation (Borneman and Triplett, 1997). Other studies have examined previously uncharacterised microbial communities, such as the natural 
microflora of insect midguts (Broderick et al., 2004), or acidic hydrothermal streams on active volcanic sites (Donachie et al., 2002).

The project detailed in this thesis investigates the potential for using molecular bacterial community analysis for a novel and applied purpose; evidential analysis of soils in forensic science. Utilising the molecular diversity of bacterial communities in soil for forensic science is a relatively new concept and could prove to be a valuable tool for criminal investigation (Horswell et al., 2002). A molecular 'snapshot' is taken of the bacterial community in a given soil sample at a particular time and this generates a DNA profile or 'community fingerprint' unique to the particular sample. Profiles from different samples can then be compared and their similarities calculated. This method of comparison of soils could be used by forensic scientists to determine whether soil samples found in disparate locations or on materials (e.g. clothing, tyres, shoes), may have originated from the same location.

A further potential application for this technology in forensic science is as a method for determining time since death, or the post mortem interval (PMI) of bodies found on or in soil. This application is based on the theory that a bacterial succession occurs in the soil under a corpse during decomposition in response to the nutrients released from the body. The few previous studies that have attempted to utilise bacterial communities for PMI estimation relied on isolating and culturing the bacterial species involved. This proved to be extremely difficult because of the large numbers of bacterial species involved in decomposition, and the approach was abandoned (Vass, 2001). With the development of molecular techniques that bypass the need for bacterial culturing, this research direction can again be explored. 


\subsection{The Need for and Potential of this Research}

The field of forensic science has experienced huge technological advances in recent decades. This is demonstrated by the development of forensic human DNA profiling, the use of which has grown exponentially in the 15 years since its inception (Walsh, 2004). Continued research into innovative techniques and ideas is required for continued growth of forensic science and to help police improve the rate of resolution of crimes. The application of the molecular techniques used in this project to the forensic purpose is innovative and holds significant potential for forensic science by providing another 'tool in the toolbox' for crime scene investigators.

\subsubsection{Forensic Comparison}

Soil is frequently encountered as trace evidence in forensic situations. It may be found adhering to clothing, vehicle tyres and interiors, the tread of footwear and on carpets. Traditional forensic soil analysis techniques use abiotic or physical characteristics to characterise soils. These include colour comparison, particle size distribution, particle size distribution and mineral examination (Marumo et al., 1995). Forensic palynology, the analysis of pollen and spores as legal evidence, has also been successfully used for soil analysis, particularly in New Zealand, which leads the world in the use of palynology as evidence in a court of law (Mildenhall, 1990; Horrocks and Walsh, 1998a). A number of traditional soil analysis techniques are restricted in their use by the size of sample required (Andrasko, 1981), which presents analytical problems because soil samples recovered in forensic situations are often less than $100 \mathrm{mg}$, sometimes as little at $0.5 \mathrm{mg}$ (Raeside, 1974). All of the above techniques also have the major disadvantage of requiring trained and experienced scientists to conduct the analyses and interpret comparisons. In small countries, such as New Zealand, there is 
not enough routine forensic analysis to warrant full-time employment of specialised forensic soil scientists or palynologists by forensic laboratories. Consultant scientists may be called upon occasionally for particular cases, but often soil evidence simply cannot be used because of the cost of securing specialist opinion. Up to five percent of forensic cases have soil involved as trace evidence but the costs involved currently restrict soil analysis to only serious assault and homicide cases (S. Cordiner, ESR Ltd., pers. comm.). Development of a simple analysis method that can utilise soil trace evidence and that can be performed by laboratory staff with basic molecular biology training would prove very useful for criminal investigation. By comparing soil samples, and providing a likelihood of these samples originating from the same source, results could be used as associative evidence in court.

The potential for using the microbial component of soil for forensic comparison was originally identified by Thornton (1986) who recognised that microbes can offer information about the specific local environment that sustains them. More recently, the ability to compare forensic soil samples using molecular bacterial analysis was demonstrated by Horswell et al. (2002), but it was recognised that further development and evaluation of the utility and reliability of the technique was required if it was to be used for routine forensic comparison. Some of this development and evaluation has been carried out as part of this project, as a contribution to the advancement of this analytical technique.

\subsubsection{Post Mortem Interval (PMI) Estimation}

Determining the time elapsed since a person has died, or the PMI, is an essential aspect of forensic investigation. Establishing the time since death aids homicide investigators 
by providing a time frame in which to concentrate their inquiries and, thereby, can help to convict a murderer, break an alibi or eliminate a suspect (Gerberth, 1996). The more recent the death, the more accurate the estimation is, as the time of death can be narrowed to a fairly limited time frame. The changes that occur in a body after death can be reliably used to estimate the PMI up to 24 hours following death, and together with information on environmental conditions, can provide rough estimations for slightly longer periods. Early post mortem changes which can be used include body temperature, degree of onset of rigor mortis and livor mortis, and biochemical changes within the body (Svensson et al., 1981). Forensic entomology is a commonly used method for estimating the PMI after longer periods of time. Necrophilous insects arrive quickly at an exposed body and in a relatively predictable and well documented sequence (Pickering and Bachman 1996). The life cycles of these insects can be used by experienced entomologists to estimate time since death (Goff, 2000). As with the currently used soil comparison methods, these techniques, while being extremely useful, have the limitation of requiring extensive experience and knowledge in the field. Forensic scientists are constantly looking to improve PMI estimations, and the potential for using bacterial community profiling technology as a new direction for this is evident. It may be possible to compare soil sample profiles where the PMI is unknown, with profiles from soil communities under bodies at known decompositional stages.

Decomposition is a well documented, predictable sequence of events beginning at the moment of death. Gut microflora begin to break down internal tissues, releasing gases as by-products of metabolism. These gases collect within the abdominal cavity, bloating the body. When the body reaches capacity, the cavity can rupture and gas and fluids begin to seep from body openings into the underlying soil (Goff, 2000). The 
decomposition fluids can influence the populations of soil-dwelling organisms in the area beneath the body as they may be utilised as substrates for growth, or may act as inhibitors to growth. As decomposition progresses and the substrates the body releases change, the structure of the soil bacterial community may be significantly altered. Potentially, the body microflora, which are released during decomposition may further impact the community, as may other bacterial species introduced by visiting insects and scavengers (Vass, 2001).

Using this succession of changes in the soil bacterial community as a PMI estimation technique is an entirely new concept, and although it is still in a preliminary investigative stage, it could appreciably contribute to the field of forensic science, providing scientists with another tool for estimating time of death. With improved methods for more accurate PMI estimation, police may be able to solve homicides more quickly, saving time and expense.

\subsection{Aims of the Project}

The aims of this research project are to: establish the reliability and utility of using DNA analysis of soil microbial communities for forensic purposes; and to provide a preliminary evaluation of the potential of using the bacterial community DNA profiling technology as a means of estimating the PMI. 


\subsection{Research Approach}

\subsubsection{Soil Microbial Community Analysis}

The research approach applied in this project is based on the preliminary work by Horswell et al. (2002). It uses the 16S ribosomal RNA (rRNA) gene and terminal restriction fragment length polymorphism (T-RFLP) analysis (Liu et al., 1997) as the basis for DNA profile generation. The 16S rRNA genes encode functional RNA molecules which make up part of the bacterial ribosome. Ribosomes are the protein synthesizing ribozyme machines of the cell and are comprised of two subunits. These are large complexes of proteins and ribosomal ribonucleic acids (rRNAs). In bacteria, there are three different rRNA molecules; the $16 \mathrm{~S}$ rRNA which is part of the small subunit, and the $5 \mathrm{~S}$ and $23 \mathrm{~S}$ rRNAs which are part of the large subunit.

The 16S rRNA molecule is conserved across all known bacterial species because of its important function, but its gene has nine regions of high variability interspersed between less variable regions (Van de Peer et al., 1996). Some regions are highly evolutionarily constrained due to the essential functions of these stretches (Ward et al., 1992). Less conserved regions have been able to change during evolution without negatively impacting on the organism. Different bacterial species and even strains of a species can have very dissimilar 16S rRNA sequences (Amann et al., 1990), although often, if species are phenotypically closely related, their 16S rRNA sequences are similar (Ward et al., 1992). This variability between bacterial species can be used to assess the diversity of the bacterial community living within soil samples. 


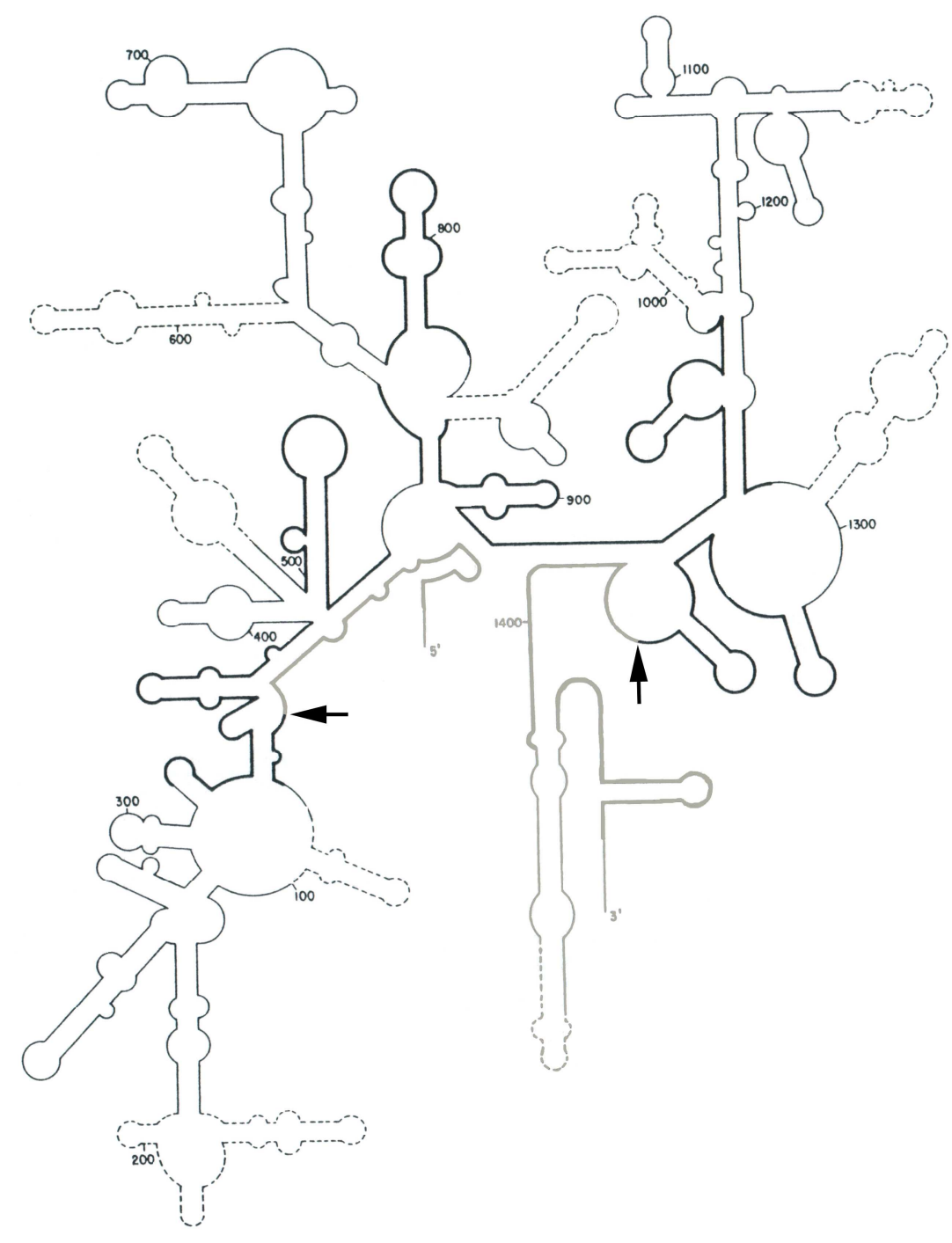

Figure 1.1. The 16S rRNA secondary structure. Primary sequence with near universal conservation (thick lines), intermediate conservation (normal lines) and hypervariability (dashed lines) is shown (Ward et al., 1992). Arrows and black lines indicate the region of the gene amplified by polymerase chain reaction (PCR). The grey regions at the $3^{\prime}$ and 5' ends are not amplified.

In the T-RFLP method, a portion of the $16 \mathrm{~S}$ rRNA gene containing eight of the nine hypervariable regions is amplified using the polymerase chain reaction (PCR). The $16 \mathrm{~S}$ rRNA genes from all of the bacteria in the soil community are amplified, resulting in gene copies of a similar length but with different internal sequences. A fluorescently labelled primer is used to allow later detection of the DNA. The PCR products are then cleaved with a restriction enzyme that recognises and cleaves DNA at particular 
sequences. In the variable regions, restriction sites occur in different places resulting in different length fragments (Figure 1.2). The more diverse the bacterial community in a sample, the greater the range of resulting fragments.
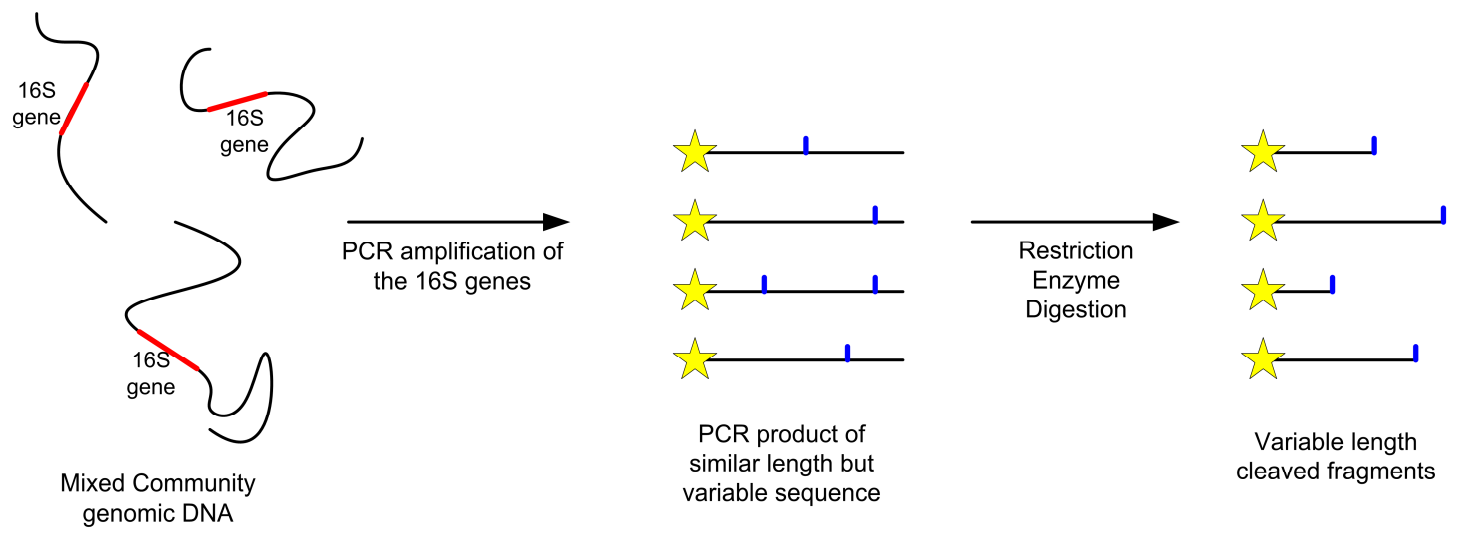

Figure 1.2. Overview of terminal restriction fragment generation. The community DNA is extracted and the 16S genes amplified using fluorescently labelled primers. The PCR products are cut with a restriction enzyme to yield different length fragments.

The end, or terminal fragments are analysed and the size and frequency of each fragment assessed to produce a profile or 'fingerprint' of the whole bacterial community in a soil sample. Profiles of different samples can then be compared to assess the level of similarity or difference. A similarity index can be used to calculate a numerical measure of the similarity between two profiles, and profiles can be visually compared.

\subsubsection{Developmental and Testing Approach}

An important part of this research project was to review and further develop the existing profiling protocol. There are known problems associated with molecular applications of soil analysis, with compounds such as humic acids which inhibit PCR being difficult to remove from DNA preparations (Yeates and Gillings, 1998; Yeates et al., 1998). These problems were encountered in the initial development of the protocol, as were 
difficulties with profile comparison techniques (J Horswell, ESR Ltd., pers. comm.). Increasing the reliability of the PCR is necessary if soil bacterial DNA profiling is to be accepted as a routine forensic technique. Horswell et al. (2000) used a simple similarity index known as the Sorenson's Index that calculated a measure of similarity between two profiles based on presence or absence of profile peaks. Because of the simplicity of this index it was felt that a more sophisticated approach should be sought, one that uses all of the available profile data, such as peak heights (Horswell et al., 2002). In order to identify any other areas that needed modification, a mock crime scenario was used to sample soil in a "realistic" forensic setting. This provided samples of the size likely to be encountered in forensic casework, and in realistic places on clothing and vehicles. Modifications to the profiling protocol were made where required and the reproducibility and practicality of the technique as a forensic tool examined.

The possibility of using the profiling technique as a PMI estimation tool was examined in a preliminary study profiling soil from under decomposing pigs and under human cadavers. Soil samples from under decomposing pigs were provided from a concurrent MSc project carried out by Terry Eberhardt (University of Auckland/ESR) documenting the entomological succession on pig carcasses in the New Zealand environment. The samples from under human cadavers were collected as part of a study into human decomposition at the Anthropological Research Facility, University of Tennessee, USA and supplied by Dr Arpad Vass (Oak Ridge National Laboratories, USA). Dr Vass developed, from this study, a novel technique for estimating time since death based on ratios of volatile fatty acids released from the decomposing body into the underlying soil (Vass et al., 1992). The donated pig and human samples were used to determine whether changes could be seen in the soil bacterial community over the course of decomposition. 


\section{BACKGROUND AND LITERATURE REVIEW}

\subsection{Soil}

Soil is a chemically, physically and biologically complex and dynamic medium consisting of inorganic and organic components distributed between liquid and gas phases (Andrasko, 1981; Stotzky, 1997). The specific composition of soil varies widely due to the presence of these components in varying proportions at different geographical locations (Liesack et al., 1997). Spatial variation in soil composition is also influenced by the topography of the particular area, by climate, vegetation and human activity (Prosser, 1997).

\subsubsection{Physical Components}

In general, approximately $95 \%$ of the solid components of soil are inorganic mineral particles. Organic soils, e.g. peats, can have considerably less (5-60\%) mineral particles, but the average soil is primarily composed of inorganic minerals (Andrasko, 1981). The smallest of these mineral particles are defined as clays $(<0.002 \mathrm{~mm}$ diameter), the intermediate size as silt $(0.002-0.05 \mathrm{~mm}$ diameter $)$ and the coarser particles, as sand (0.05-2 $\mathrm{mm}$ diameter) and stones (> $2 \mathrm{~mm}$ diameter) (Murray and Tedrow, 1992).

The organic component of soil is by far the smallest, and rarely exceeds $5 \%$ by volume (Andrasko, 1981). It consists of: the living, active microbiota and plant root systems; animal, plant and microbial residues in various stages of decay; and humus, a heterogenous complex of organic residues which is largely resistant to decay. 


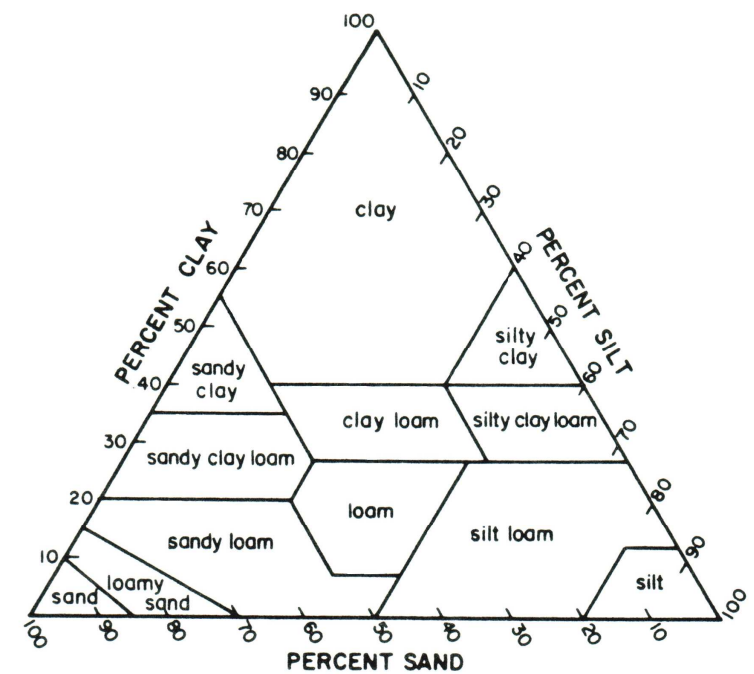

Figure 2.1. The percentages of clay, silt and sand in the basic soil textural classes

(Murray and Tedrow, 1992).

Water makes up about $20-30 \%$ of the average soil volume and is essential to the survival of the soil microbial community and plant life (Wood, 1995). Associated with the soil water is the soil atmosphere, or gaseous component of soil. The $\mathrm{CO}_{2}$ content of the soil atmosphere is generally higher than that of $\mathrm{O}_{2}$ because of microbial metabolism and the slow diffusion rate of these gases. In addition to these, other gases such as $\mathrm{CH}_{4}$ and $\mathrm{CO}$, and volatiles (e.g. short-chain organic acids, aldehydes, alcohols, esters) are also present in the soil atmosphere (Stotzky, 1997). The water content and atmosphere of soil are inversely related because these fluids can occupy the same interstitial spaces within the soil matrix.

\subsubsection{Soil Biology}

The organisms that live in soil range from the microscopic flora (bacteria and fungi), through to the macrofauna (earthworms, millipedes, insects and molluscs). Often, these soil inhabitants form relationships between each other and also with plants. These relationships can help support life in the soil. 
Bacteria are the most numerous component of the soil microbial population. It has been estimated that there may be as many as $10^{9}$ bacterial cells per gram of soil (Harris, 1994) and that half of the total biomass on earth consists of bacteria located in the top two to three centimetres of the soil (Thornton, 1986). It is widely accepted that the majority of soil bacteria, possibly as many as $99 \%$, cannot be cultured using traditional laboratory media based techniques (Amann et al., 1995). This is due to the complex nature of the environments that soil provides, which is not easily simulated in the laboratory. The most common culturable soil bacterial genera are Arthrobacter, Pseudomonas and Bacillus (Killham, 1994).

Soil bacteria often show morphological and physiological adaptations that allow them to utilise the soil habitat more effectively. One such example is the presence of a thick mucilaginous capsule surrounding the bacterial cell which is not found in laboratory grown isolates of the same species (Killham, 1994). This capsule protects the bacterium from desiccation, from potentially toxic compounds, and may affect adhesion to soil particles (Riley et al., 2001). Many soil bacteria exhibit the ability to slow their metabolism in response to low levels of available carbon and nutrients, and then increase it when nutrient levels rise (Wood, 1995). This adaptation allows the persistence of microbial species over time, as soil is predominantly nutritionally poor (Stotzky, 1997).

Bacteria have many varied functions within soil. Heterotrophic bacteria, or those which derive energy from organic carbon, are the most numerous members of the soil community, and they carry out decomposition of animal, plant and microbial residues (Killham, 1994). Nitrogen fixation is also performed by heterotrophs, mainly the Rhizobium family which inhabits legume root nodules. The chemoautotrophic bacteria 
in soil, those which derive energy by oxidation of inorganic substances, are largely nitrifiers and sulphur oxidisers.

Soil microbial populations can be divided into two distinct classes in terms of their response to nutrients. This idea was first proposed by Winogradsky (1949) who described the classes as autochthonous and zymogenous microbial populations. Autochthonous populations are the indigenous soil organisms that 'tick over' and are most competitive at low substrate concentrations. Their populations persist actively in the soil for long periods of time and are present at relatively constant levels. They use the soil carbon sources that are more resistant to degradation, such as complex organic matter. The genus Arthrobacter is an example of autochthonous soil microbes that are able to maintain their presence in soil, even when readily available carbon is limiting. The zymogenous soil microbial populations are not a significant component of the soil microbial community under normal conditions, but proliferate when substrates such as plant or animal residues are introduced into the soil. They are capable of rapid multiplication and can often revert to resistant spore structures once the substrate is exhausted. Some saprophytic (decomposer) fungi are zymogenous, particularly those known as the "sugar fungi", which can only utilise simple sugars, and are not able to degrade more complex organic compounds (Thorn, 1997). The soil microbial population may not be as sharply divided as Winogradsky proposed, but it is likely that these general groups really do exist within the soil community (Killham, 1994). Competition between organisms for nutrients is likely to lead to specialisation in terms of rate of growth and substrate utilisation. The zymogenous population may respond to readily available substrates such as simple sugars, while the autochthonous may use the more complex, less readily available substrates such as cellulose. 
Actinomycetes are a component of the soil microbial community that are bacteria, but have a mycelial morphology, resembling fungi. Actinomycetes have the ability to degrade an enormous array of carbonaceous substrates including recalcitrant polymers such as chitin, celluloses and hemicelluloses (Wood, 1995).

Fungi are significant contributors to the biomass of the soil microbiota. The number of fungi present can vary widely through differing soil conditions, but an average population is in the order of 10-20 million individual colony forming units per gram of soil (Griffin, 1972). One role of soil fungi is decomposition of organic matter, ranging from simple sugars to the most resistant polymers such as lignin and complex humic acids. Of equal importance is the role fungi play in forming symbioses, known as mycorrhizae, with the roots of plants. The majority of plants have these associations, in which the fungus provides nutrients and protection from drought stress and plant pathogens (Killham, 1994). Fungi are more tolerant of acid soils than bacteria, so under these conditions fungi are predominant in decomposition processes (Thorn, 1997).

Algae also form an important part of the soil microbial community. Being photoautotrophic and using sunlight as an energy source, they are largely restricted to parts of the soil that are penetrated by sunlight. They are often primary colonisers on bare surfaces because they are not reliant on organic soil matter, but synthesise their own carbon compounds through the Calvin Cycle of photosynthesis. Algae are thought to play important roles in soil formation and in maintaining structural stability in degraded soils. They range in numbers from 100,000 to three million per gram of soil (Lund, 1967). 
Soil contains a rich variety of protozoa that are predators of the microbial population. There can be up to 10 million protozoa per gram of soil (Bardgett and Griffiths, 1997). They primarily inhabit the top $15-20 \mathrm{~cm}$ of soil where microbes are most plentiful. Protozoa may also have some involvement in the primary decomposition of soil organic matter although their ecological significance is not well understood (Killham, 1994).

The larger fauna living in soil comprise oligochaetes (earthworms), nematodes, arthropods (millipedes, centipedes and mites) and molluscs (slugs and snails). The main ecological role of the larger fauna (meso/mega-fauna) is the processing and mixing of the soil. They contribute to organic material decomposition and also to the vertical and horizontal mixing of organic material through their burrowing activity (Wood, 1995; Griffiths and Bardgett, 1997).

\subsubsection{Soil Microbial Diversity}

There is little doubt that soils from different locations vary widely in composition (Wood, 1995; Prosser, 1997; Stotzky, 1997). It is also clear that microbial communities vary considerably between soils (Liesack et al., 1997; Zhou et al., 2002). Microbial diversity has been demonstrated not only between different sampling sites, but also within sites. This is due to localised variations in the soil environment that influence the population at this level (Killham, 1994). Many factors can influence the microbial diversity within soil, most of which affect nutrient availability or the physico-chemical properties of the soil.

\subsubsection{Physical Soil Properties}

The physical structure and chemical properties of a given soil itself affect the microbial community it contains, as do local environmental factors. The water /atmosphere 
content, clay content, $\mathrm{pH}$ and temperature contribute strongly to the heterogeneity of microbial communities in soil (Liesack et al., 1997).

\subsection{Available Water / Atmosphere}

Perhaps the most important abiotic factor that affects microbes is the supply of water. The water content/atmosphere ratio of soils can vary widely, and within a given soil, fluctuates in response to rainfall and temperature. The physical composition of the soil also affects the amount of available water. Clays and organic matter retain water, whereas sand and silt allow rapid drainage to the local water table. Moisture content and oxygen availability are inextricably linked, with plant roots and aerobic microbes relying on a correct balance of both for survival (Stotzky, 1997). In situations where water content is too low, both plant and microbial life are reduced. If the proportion of water in a soil is too high, oxygen is reduced and only anaerobic life can be supported. The rate of decomposition is greatly reduced in anaerobic soils, resulting in high organic content. Some plants, such as rice (Oryza sativa) are able to grow in fully anaerobic conditions by using internal air spaces, like a series of small tunnels, through which air is collected and passed down to the root cells (Colmer, 2003). For this reason, flooded paddy-fields are often used for growing rice, as weed species and pathogens cannot tolerate the lack of soil oxygen.

\subsection{Clay Minerals}

Clay is an important factor in soil water levels, and plant and microbial nutrient supply. The proportion and type of clay minerals present can profoundly influence microbial activity, by modifying physicochemical characteristics of microhabitats such as $\mathrm{pH}$, nutritional status, the activity of toxic substances as well as water availability (Killham, 1994; Stotzky, 1997). Clay minerals retain water in soil by its attraction to the charged 
surfaces of the clay mineral structures. Sand and silt do not retain water well against the pull of gravity, and as microbes are all dependant on an adequate water supply, the presence of clay in a soil is essential for microbial communities to survive (Stotzky, 1997). Clay minerals are mainly negatively charged at normal soil $\mathrm{pH}$ values and thus also tend to attract nutrient cations such as $\mathrm{NH}_{4}^{+}, \mathrm{Ca}^{2+}, \mathrm{Mg}^{2+}$ and $\mathrm{K}^{+}$. These are important plant nutrients, so the ability of clays to bind these makes them more available for plant growth and reduces leaching from the soil (Tucker, 1999). Conversely, organic molecules such as proteins, amino acids, polysaccharides and nucleic acids, as well as toxic compounds can be bound by clay minerals, reducing their bioavailability (Stotzky, 1997).

The clay mineral content of soil plays an important part in forming microhabitats. These are small pockets or pores that may contain microbial communities that are very different from others nearby. Clay minerals also tend to coat larger sand and silt particles, which cluster together through electrostatic attraction to form microaggregates. These, in turn, cluster to form aggregates which are stabilised by organic matter and precipitated inorganic materials. The individual aggregates retain water, and cause the formation of individual microhabitats which are discontinuous with other nearby aggregates (Stotzky, 1997). Microhabitats are highly variable, primarily as a result of the heterogeneity of the surfaces and fluctuations in the types and concentrations of organic and inorganic solutes which penetrate them (Killham, 1994). The pockets of communities in soil microhabitats can exclude predators such as protozoa because of the small pore sizes, providing safe niches for groups of bacteria (Killham, 1994; Griffiths and Bardgett, 1997). 


\subsubsection{3 pH}

The acid-base balance of soil can have significant effects on microbial community structure. Different microbial groups have varying tolerances to ranges of $\mathrm{pH}$. Most soil bacteria and fungi prefer a neutral $\mathrm{pH}$, but their tolerances to acidic or alkali conditions vary considerably. Actinomycetes can tolerate high alkalinity with some streptomycetes even growing at a $\mathrm{pH}$ of 10 . Some sulphur-oxidising bacteria can tolerate a $\mathrm{pH}$ of 1 (Killham, 1994). Fungi predominate in acidic soils (below pH 5.5) whereas bacteria, including actinomycetes predominate in near-neutral or moderately alkaline soils (Stotzky, 1997). The low numbers of fungi found in alkaline soils is not because fungi are intolerant to these conditions, but because bacteria are efficient competitors at these $\mathrm{pH}$ values and prevent the proliferation of fungi. In contrast, the low numbers of bacteria in acidic soils are a result of their intolerance to the low $\mathrm{pH}$ values that fungi can tolerate, allowing the fungi to proliferate without competition (Wood, 1995).

The $\mathrm{pH}$ of soil also affects the solubility, availability and toxicity of mineral nutrients. Both microbial populations and plants are affected by this nutrient control. High $\mathrm{pH}$ adversely affects plants by reducing the availability of manganese and iron to their root systems. In some cases, low $\mathrm{pH}$ can increase availability of micronutrients such as manganese to the point of toxicity, which causes a decrease in carbon exudate from the roots. This decrease in substrate availability to the rhizosphere population results in a reduction in microbial numbers (Killham, 1994).

\subsection{Temperature}

The average soil temperature of a particular area will greatly influence the composition of the resident microbial population. Sub-freezing Antarctic soils have shown 
psychrophilic (low temperature tolerant) microbial activity, and thermophilic (high temperature tolerant) bacteria thrive in volcanic areas inhospitable to other life. The majority of soils worldwide contain predominantly mesophilic microbes which thrive in moderate temperatures (Stotzky, 1997).

The effect of seasonal temperature fluctuations have been shown to have some effect on soil microbial populations (Patra et al., 1990). Temperature tends to affect the microflora indirectly. Plants roots are particularly sensitive to changes in soil temperature, altering both the supply of carbon and exudation from the roots, and thus affecting the rhizosphere microflora. Microbial biomass has been found to increase in autumn months and decrease in summer months in some soils (Diaz-Ravina et al., 1994) but this may be correlated with changes in soil moisture levels rather than with temperature (Srivastava, 1992). In well established soil, the microbial populations seem to reach a stable equilibrium, in which seasonal fluctuations in abundance of individual species may occur, but the population composition as a whole is very resistant to change (Wood, 1995).

The degree to which soil temperatures change in response to diurnal solar heating is dependant on soil properties such as colour and water content, as well as vegetation cover and topography (eg slope, aspect). Surface temperature fluctuations of up to $35^{\circ}$ C can occur at the soil surface but this decreases rapidly with increasing depth (Wood, 1995).

Closely linked to temperature is sunlight, which is a property that only affects the distribution and activity of organisms on or very near the surface of the soil. Topography, aspect, soil type and vegetation cover affect the level of light a soil 
receives. Light primarily dictates the number of soil algae and photoautotrophic bacteria. Being restricted to the upper soil surface layer, these bacteria and algae are not large components of the total microbial biomass, but they do contribute to the overall diversity of soil community composition (Killham, 1994).

\subsubsection{Nutrient Availability}

In general, soil is a nutritionally poor, or oligotrophic, environment (Stotzky, 1997). Microbes are concentrated in 'hot spots' or niches within the soil where nutrient levels are highest and environmental conditions most suitable. Substrates are not uniformly distributed on the surface of soil, leading to localised zones of nutrients, and thus microbes. For example, nutrients from animal decomposition are restricted to the area where the body lies and fluids drain to. Nutrients are also provided by plants, so higher microbial activity is associated with vegetation.

\subsection{The Rhizosphere}

The rhizosphere is the area where soil microbes are most abundant. This is the area around plant roots, where microbes take advantage of nutrient rich root exudates. Soluble carbohydrates, organic acids, amino acids, fatty acids, sterols, vitamins and enzymes are 'leaked' from particular areas of the roots, and are readily used as substrates by the microbial population (Curl and Truelove, 1986). Particular groups of bacteria, collectively known as rhizobacteria, are especially stimulated by root exudates, and are found closely associated with the roots. The ratio of bacteria found in the rhizosphere to that in the bulk soil is $24: 1$ (Wood, 1995). The rhizosphere can be divided into two distinct parts: the endorhizosphere, the root surface and its mucous layer; and the ectorhizosphere, the rhizosphere-associated soil layer which extends a few millimetres from the root surface (Sorenson, 1997). The exact chemical 
composition of the nutrient-rich mucilage varies with root development and also between plant species, influencing the rhizobacterial population (Sorenson, 1997; Yang and Crowley, 2000). Despite the higher microbial numbers associated with the rhizosphere, microbial diversity within this area is greatly reduced compared with bulk soil because of the selective pressure provided by rhizodeposition of carbon (Killham, 1994). Only those species that can utilise the carbon most efficiently proliferate rapidly at the expense of those that are less competitive.

\subsection{Plant Species}

One of the most important factors affecting soil microbial population variation between sites is thought to be the plant species growing in the soil. This is thought to be due in part to variation in rhizosphere exudates from different plant species. Spatial variability in vegetation directly affects the spatial distribution of soil microbes. A number of important relationships exist between plants and microbes other than those in the rhizosphere, some specific to particular species, and others more universal. An example of a species specific relationship is that between Rhizobium and leguminous plants. The legume/Rhizobium interaction is a symbiosis, in which the rhizobia gain a habitat free of competition and a steady supply of carbon, and in exchange, the plant is supplied with fixed nitrogen.

The mycorrhizal relationship between plant roots and fungi is also important, as the vast majority, an estimated $80 \%$ of vascular plants are involved in such associations (Wood, 1995). The mycorrhiza can enhance the plant's uptake of nutrients (particularly phosphate), increase rootlet size and longevity and protect the root system from many pathogens. The fungus is provided with carbohydrate from the plant and a competition free habitat, which is often the only habitat available to it for growth. Colonisation is 
not host-pathogen specific, meaning that many fungal species can associate with a number of different plant species. The mycorrhiza may be in direct competition with the rhizosphere bacterial population, with both vying for root exudates (Marschner et al., 1997).

Whether soil type or vegetation type has the more significant impact on community structure is hotly debated. Grayston et al. (1996) and Miethling et al. (2000) both found that plants have a stronger effect, whereas Buyer et al. (2002) and Damastri et al. (1999) both found that soil type had a greater effect than plant species. Marschner et al. (2001) concluded that rhizosphere communities are affected by a complex interaction between soil type, plant species and root zone location, all of which have important effects.

\subsection{Soil Depth}

The number of bacteria found in soil has been shown to decrease with depth (Zhou et al., 2002). The vast majority are found in the top $10 \mathrm{~cm}$, with a 1000 -fold decrease in numbers at a depth of $135 \mathrm{~cm}$ (Wood, 1995). This is due to a reduction in nutrients, particularly carbon, quality and availability with depth. Organic matter is found mainly in the top horizons or layers of soil and reduces with increasing depth. Similarly, the concentration of plant roots decreases with depth, reducing the nutrients provided through exudates. Gram negative bacteria, fungi and protozoa tend to be proportionally higher in upper levels of the soil, while actinomycetes and Gram positive bacteria tend to dominate at depth (Fierer et al., 2003). This may be because many genera of Gram negative bacteria have high intrinsic growth rates and require greater organic substrate concentrations to survive. Gram positive bacteria have the ability to degrade complex carbon sources such as lignin and humic acids, but have slower growth rates than the 
Gram negative bacteria, competing more efficiently when nutrients are low (Burke et al., 2003).

Surface soils have a considerably higher microbial biomass than sub-surface soils, but the diversity within these two levels differs. Surface soils generally have more heterogeneous microbial populations, with deeper soils showing dominance of one or a few bacterial groups (Blume et al., 2002; Zhou et al., 2004). Two theories for the main cause of differences in biodiversity within a soil have been suggested. The first theory, spatial isolation, suggests that when microbial groups are isolated from each other, diversity can be maintained. Conversely, if microbes are able to interact, competition can occur, and the best adapted groups come to dominate (Zhou et al., 2004). The moisture level in soil dictates spatial isolation of microbial groups. Surface soils often have transient water films that are present after rainfall, but are rapidly drawn away from the surface by gravity. Deeper and less free-draining soils tend to have a more continuous water film, resulting in greater interaction and hence competition between microbes. The second theory is based on carbon availability (Wood, 1995). Variation in total carbon levels and variety of carbon types can prevent competition and allow maintenance of high diversity (Zhou et al., 2002). Where carbon availability is low, the bacterial group which utilises the carbon source best becomes dominant. Under very low carbon or water conditions, however, few bacterial species can exist and both microbial biomass and diversity will be decreased (Killham, 1994).

Under both theories, the biodiversity of surface soil will be altered if prolonged moisture content or carbon source input change occurs. If a single, simple carbon source was to become available, and interaction was possible, competition could lead to dominance of one or a few species (Zhou et al., 2004). This concept is in keeping with 
the idea of zymogenous microbial populations, which proliferate and dominate when a suitable carbon source becomes available, but quickly revert to dormancy when the carbon source is depleted (see section 2.1.2).

Plant diversity is affected by nutrient availability in a similar way. In soils with either high or low fertility, diversity is low. In a soil with intermediate fertility, diversity is high. This is thought to happen because highly fertile soils promote rapid growth of the most competitive individuals. As these plants grow they become even more efficient because of their size. Soils with very low fertility also have low diversity because, like soil microbes, those that can best utilise the limited resources dominate. The highest level of plant diversity is found in soils with intermediate fertility because this gives plants a more equal opportunity for growth in a more heterogeneous habitat (Zak et al., 2003).

\subsubsection{Human Activity}

Human activity can have a significant impact on soil microbial communities. Few soils worldwide are totally unaffected by humans. The land uses that go hand in hand with civilisation, such as agriculture, building development, waste disposal and mining all impact the soil. On a large scale, widespread acidification of soils has been accelerated by acid rain produced by the burning of fossil fuels. At more localised sites, increased salinity caused by poor agricultural irrigation techniques, high levels of heavy metals, fertilisers, pesticides and radioactivity are directly associated with human land use. The effects that these have on the soil community are complex and not well understood, although major differences in community composition have been displayed in many studies. The influence of heavy metals on soil microbial communities has been particularly widely studied, and they have been shown to reduce total biomass (Chander 
and Brookes, 1992), decrease species diversity (Frostegard et al., 1993), and impact heavily on microbial processes (Wuertz and Mergeay, 1997). The influences of human activities are most apparent when members of the soil ecosystem cannot tolerate the changed physico-chemical properties of the soil or are killed directly, either intentionally or via a non-target ecological effect. This upsets the balance of the biological community and causes shifts in the microbial community structure.

Micro-organisms that would not ordinarily be part of a particular soil community can also be introduced to the soil by human activity. This can be via the addition of organic materials to the soil, e.g. sewage sludge containing enteric pathogens such as Salmonella spp., or directly as an inoculant introduced to the soil for a specific purpose, e.g. to promote growth of an introduced crop species. Some Rhizobium species are commonly introduced to soils cropped with legumes to improve nitrogen availability and growth (Beauchamp and Hume, 1997). Biological control, using one organism to control another, is a further way the microbial community composition can be influenced. For example, Agrobacterium radiobacter can be introduced to soil to inhibit the growth of Agrobacterium tumefaciens, the pathogen that causes crown gall in roses and fruit trees (Whipps, 1997). The recent issue of the use of genetically modified organisms in agriculture has potential implications for soil microbial communities. The effects of transgenic plants on soil microbes are not yet fully understood, but there is evidence suggesting soil microbial communities can be altered by interaction with novel proteins, particularly in root exudates (Dunfield and Germida, 2004). Horizontal gene transfer between transgenic plants and soil micro-organisms also has the potential to impact on community composition if the transgene provides a selective advantage to the bacterium (Kowalchuk et al., 2003). 


\subsection{Forensic Geology}

Forensic geology is reputed to have been born when Sherlock Holmes, the great fictional supersleuth was said by Dr Watson in A Study in Scarlet to be able to:

“...tell at a glance different soils from each other. After walks (he) has shown me splashes upon his trousers, and told me by their colour and consistence in what part of London he had received them" (Conan Doyle, 1887).

By using this reasoning, Sir Arthur Conan Doyle's character was some years ahead of his time, as it was not until 1904 that soil evidence was first introduced into a murder enquiry in Germany by Georg Popp (Murray, 1982). Since then, geological evidence has been crucial in numerous cases around the world. One famous example was the determination of the origin of the balloon bombs which rained down on parts of the United States during the final years of World War II. Officials were puzzled as to where these bombs had come from. Bags of sand were attached to the balloons as ballast, so geologists were assigned the task of pinpointing the sand's origin. Through the combined efforts of many specialist geologists, two beaches near Ichinomiya in Japan were identified as likely candidates. It was later confirmed that close to 9,000 bombs had been launched from one of these sites, as well as another two sites nearby. An estimated 1,000 bombs reached the United States although the damage caused was minimal (McPhee, 1996).

\subsubsection{Physical Comparison}

Soil is frequently encountered as trace evidence at crime-scenes and current methods of forensic analysis rely on the soil's physical or abiotic properties (Marumo et al., 1995). These techniques however require comparatively large sample sizes, analytical expertise in the laboratory and experience in the field (Thornton, 1986; Marumo et al., 1995). 
They also rely heavily on expert opinion and the interpretation of results can be subjective. Consequently, they are not routinely carried out in many countries, including New Zealand.

Forensic palynology, the science of deriving legal evidence from pollen and spores, is commonly used in New Zealand, which may be the only country in the world that routinely does so (Mildenhall, 1990; Horrocks and Walsh, 1998b). Palynology has been used in a number of criminal cases in New Zealand, providing associative evidence or proving links between suspects and crime scenes, victims and objects, including illicit substances (Horrocks et al., 1998). Horrocks and Walsh (1999) were able to differentiate a crime scene and alibi scene only 7 metres apart (the suspect denied entering a particular alleyway but admitted being on a nearby driveway) because of the significantly different soil pollen representations at the two locations. This was possible because of the close proximity of two quite different localised areas, with very different vegetation. Isolated cases around the world have used palynology in recent years, including a murder investigation in the UK that combined palynology with soil mineralogical analysis. The soil found on a vehicle suspected of being used to move homicide victims was analysed to predict possible source areas, based on the soil type and vegetation likely to be nearby. This enabled a narrowing of the search area and the victims' bodies were subsequently found in an area very similar to that which was predicted (Brown et al., 2002).

Analytical techniques more widely used world-wide include colour analysis, density gradient distribution, mineral analysis and chemical analysis of soil samples (Murray, 1982). Colour analysis is usually the first examination carried out in the laboratory because if two samples are different colours, they are obviously different soil types and 
further testing is not required. If two samples differ in colour, it is likely that they will differ in other properties. Soil colour is determined by minerals and organic matter and can range from yellow to red to black. Precise colour descriptions can be made with the help of Munsell colour charts, or the two soils can be visually compared directly by the observer (Marumo et al., 1995). Direct microscopic examination is usually performed along with colour determination. Foreign materials such as fibres, paint chips, glass or metal fragments can be identified and preserved, and components such as plant matter or algal cells can also be observed (Raeside, 1974).

Density gradient distribution is the most traditional forensic soil comparison method. It has been used for over 50 years in forensic laboratories (Marumo et al., 1995). The technique involves applying a sample to a tube of layered liquids, usually tetrabromoethane (TBE) and ethanol mixed to varying densities, increasing from bottom to top. The soil particles settle to a level in the column where the liquid has the same density as that particle. The distribution of particles in the column is examined and can be compared with other samples treated the same way (Murray, 1982). The major problem with using density gradients is that samples from different localities often give very similar density gradient patterns, and that reproducibility of gradients can vary between laboratories (Marumo et al., 1995). Murray and Tedrow (1992), advise against the use of density gradient analysis for forensic analysis. They cite gradient preparation as a problem, but also maintain that geologic problems such as particles of different densities adhering to each other, or porous particles trapping air contribute to its unreliability.

Size distribution of soil particles can also be used as a comparison technique. Soil particles are separated based on their size, by being passed through a series of sieves 
with decreasing pore size, or by determining the rate of settling of the grains in a fluid (Murray, 1982). Marumo et al. (1995) however, found from experience that the technique is unreliable, particularly with small sample sizes.

Clay minerals cannot be examined using optical microscopy because of their small size, so techniques such as x-ray diffraction and transmission electron microscopy (TEM) have been used to identify the various clay minerals in samples (McAlister and Smith, 1995). Anion analysis using capillary electrophoresis has also been applied to forensic soil comparison (Cengiz and Sakul, 2001) as have x-ray fluorescence, petrographic (polarising) microscopy and atomic absorption spectrophotometry, among others (Murray and Tedrow, 1992). Chemical analysis of soils is often performed alongside mineral analysis (Murray, 1982). Chemical properties such as $\mathrm{pH}$, saccharide content and enzymatic characterisation of samples can be measured for comparison.

Cox et al. (2000) recently developed a method for analysis of soil organic matter using Fourier Transform Infrared Absorption Spectrometry (FTIR). This method involved collecting a spectrum of a soil sample that had been oxidatively pyrolysed so that all organic matter was degraded. The spectrum was subtracted from the spectrum of the same sample that contained the organic matter prior to pyrolysis. The resultant IR spectrum represented the organic portion of the sample. The FTIR method successfully discriminated four samples that were identical using colour comparison.

Continuous-flow isotope-ratio mass spectrometry (CF-IRMS) has been used recently as a forensic soil comparison method. Carbon and nitrogen isotopic ratios were analysed for soils recovered from footwear and this was shown to be able to discriminate between soils from different locations. Spatial variation over 20 metres and temporal 
variation over 2 years were also assessed and found to be within the range of natural sampling variation (Croft and Pye, 2003).

Phytoliths and diatoms have also been used in forensic soil analysis. Phytoliths are particles of plant opal, which are silica structures that accumulate in plants. When the plant dies, these structures are deposited in the soil. They are widely distributed in soils and accumulate, giving a history of the succession of plant communities in a soil (Raeside, 1974). Phytoliths vary in size, shape and colour and in some cases the genus, or even species, of plant that they originated from can be determined. Marumo and Yanai (1986) demonstrated that soils with identical mineralogical properties could be differentiated by comparing the phytolith morphologies present. Diatoms are photosynthetic algae that have a resistant silica cell wall. They are widely distributed in soils and are useful in forensic science because diatom communities are particularly sensitive to small changes in environmental factors such as nutrients, $\mathrm{pH}$, moisture, salinity and temperature (Raeside, 1974). Like phytoliths, the silica structures of diatoms are resistant to degradation and accumulate, preserving the diatom history of the soil. Analysis of these soil constituents is not routine because of the expertise required to distinguish the many morphologies of diatoms and phytoliths.

Numerous other soil properties have been suggested as candidates for forensic analysis. For example, comparison of soil moisture content has been proposed, as has differential thermal analysis, which compares the thermal properties of a sample with a control (Murray and Tedrow, 1992). These properties are not commonly considered for forensic analysis because of their low discriminatory power, but could be used in conjunction with other techniques. 
The commonly used techniques described above have been used to compare soil samples with some success for many years. Many techniques have the disadvantage of requiring years of expertise and experience before reliable comparisons can be made, and rely heavily on the opinions of the analyst. Other techniques require a greater amount of soil than is recovered for many forensic samples. A number of methods do not differentiate between soil samples conclusively and cannot be used as stand-alone analytical techniques. The development of a single comparison method that can definitively differentiate between samples, is accurate for small sample sizes and does not require expertise or specialised equipment to perform would be extremely beneficial. Minimising time and cost requirements would also be advantageous. A simple comparison tool that can be carried out by a non-specialist forensic laboratory would greatly enhance the use of forensic soil analysis. As most forensic laboratories are equipped to perform DNA analysis, a technique that utilises the living, microbiological component of soil could potentially provide such a tool.

\subsubsection{Microbiological comparisons}

The microbiological component of soils has largely been overlooked by the forensic community to date, primarily because of the limitations of culturing (as described in section 2.3.1). Thornton and McLaren (1975), first recognised that the living component of soil might be useful for forensic comparison. They suggested that the biochemical properties of soil, arising from the metabolic processes of specialised microbes within a soil, could impart a degree of uniqueness to a soil. By testing different soils from sites in close proximity, they proved that these samples could successfully be distinguished by their enzyme activity patterns. The main disadvantage 
of this approach is that changes in enzyme activity can be expected during drying and storage, although this can be minimised if all samples are treated in a similar manner.

More recently, Omelyanyuk et al. (1999) attempted to compare soils based on the microbial component using a multisubstrate testing method (MT). Their method is based on complete functional characterization of complex natural microbial communities, using intensity of assimilation of different sources of organic carbon, while observing the change of colour of tetrazolium salt from yellow to purple. Eleven carbon sources were used. This method was applied effectively to an actual forensic case study.

The development of molecular techniques for measuring microbial community diversity in soils provides the potential for developing soil comparison methods that are sensitive and robust enough to be used for forensic sample analysis, and to provide evidence which may be given in a court of law. This potential was first realised by Horswell et al. (2002) who used T-RFLP technology to profile soil bacterial communities for comparative forensic purposes. By setting up mock crime scenarios, Horswell et al. (2002) established that bacterial community DNA profiling can be used to compare soil samples of the size likely to be encountered in real forensic situations. Samples were collected from the sole of a boot, from the knees of denim jeans and from prints left by these objects in soil on the ground. They also observed that soil samples from the same site produced similar profiles, whereas the profiles obtained from samples from separate sites were significantly different. One site was re-sampled eight months after the initial sampling and the profile showed a high degree of similarity to the original sample. The use of molecular techniques to compare the microbiological component of forensic soil 
samples has the potential to be a simple yet definitive forensic tool that could be performed routinely by non-specialised forensic laboratories.

\subsection{Molecular Analysis of Microbial Communities}

\subsubsection{Introduction}

The structure of bacterial communities had been investigated for many years prior to the molecular era, using methods based on isolating and culturing bacteria. However, the proportion of environmental bacteria species that can be cultured in a laboratory may be as low as $1 \%$ of the total community (Amann et al., 1995), severely limiting the accuracy of diversity estimates and potentially introducing a massive bias when assessing community structure. Culturing methods are mostly biased towards selective enrichment of fast-growing bacteria adapted to high substrate concentrations (Smalla et al., 1998). Over the past decade, many new culture-independent techniques for studying

microbial populations have been developed, opening the lid of the "black box" of hidden microbial diversity (Tiedje et al., 1999). Many of these techniques allow the study of microbes using genetic information, thereby revolutionising environmental microbiology.

\subsubsection{Culture-Independent Approaches for Studying Soil Microbial Communities}

A number of approaches to the study of microbial communities can be taken that do not rely on culturing and isolating, including the use of microbial biomarkers. Biomarkers are specific biochemical constituents which are restricted to particular subsets of the microbial community. They can be used to obtain information about the composition of 
the community. One such technique is fatty acid methyl ester (FAME) profile analysis of soils. There are a great number of different kinds of fatty acids in the lipids of microorganisms and these are found in various combinations across different species. Many microbial isolates or taxa have unique FAME profiles. The procedure involves methylation of fatty acids followed by volatilisation, and analysis by gas chromatography. It has the advantage of rapidly characterising whole communities at a relatively low cost (Cavigelli et al., 1995). Ergosterol is also a commonly used biomarker. It is a prevalent sterol found in fungal membranes and has been used as an indicator of fungal biomass (Suberkropp et al., 1993).

Another approach is to examine a component of functional biodiversity, namely substrate utilisation. The Biolog system allows the potential utilisation of 95 substrates by the microbial community to be analysed. The more functionally diverse a community, the more substrates can be used, due to the collective action of many individual species (van Heerden et al., 2002).

The development of genetic or molecular techniques for studying microbial communities, however, has revolutionised microbiology and opened the door for widespread studies on diversity in natural microbial populations.

\subsubsection{The Molecular Approach}

The polymerase chain reaction (PCR) has rapidly become a fundamental biological technology by allowing the direct study of DNA and genes. Often described as 'molecular photocopying', PCR is a fast and inexpensive technique for amplifying or copying DNA of interest. Many molecular techniques require large amounts of DNA for analysis and PCR offers a rapid means of obtaining this. 
Molecular biology has opened the door for investigation of the community structure and diversity of micoorganisms. Functional gene analysis can provide information on the presence and diversity of a single physiological group. Ubiquitously distributed genes or DNA sequences can be used to infer phylogenetic relationships and diversity within and between all forms of life (Liesack et al., 1997). By far the most widely used genes are those that code for the RNA component of the small subunit of the cellular ribosomal machinery: the $16 \mathrm{~S}$ rRNA gene for prokaryotes and the $18 \mathrm{~S}$ rRNA for eukaryotes.

The use of ribosomal RNA genes has grown from the identification by Carl Woese (1987), that $16 \mathrm{~S}$ rDNA and its corresponding molecule in eukaryotes, 18S rDNA, can be used as a powerful phylogenetic marker molecule which allows calculation of evolutionary divergence times because of its clock-like mutation accumulation. Comparative analysis of the primary structure of these RNA genes resulted in the realisation that all forms of life are separated into the three currently recognised domains Bacteria, Archaea and Eukarya (Woese, 1987). Because of this, the 16S rRNA gene has the largest representation of any gene in the public databases (Maidak et al., 1999). The 16S rRNA gene has regions which are highly conserved, while other regions display considerable sequence variation even within closely related taxa (Ludwig and Schleifer, 1994). Universal PCR primers have been developed for the $16 \mathrm{~S}$ gene that are capable of amplifying genes from almost all known types of eubacteria (Schwieger and Tebbe, 1998). Other genes have been used in bacterial community studies, particularly genes involved with a specific metabolic activity, for example those associated with carbon dioxide fixation (Ueda et al., 1995) or mercury resistance (Bruce, 1997), but none to the extent of the rRNA genes. 
The rRNA approach to microbial community analysis requires bulk nucleic acid extraction from the environmental sample, followed by isolation of the rDNA. Early methods for isolating the rDNA involved shotgun cloning the bulk DNA as large fragments into vectors and screening the clones for rRNA genes (Schmidt et al., 1991), or by reverse transcription of extracted rRNA (Weller and Ward, 1989). The use of PCR, however, has superseded shotgun cloning, because of its technical simplicity and the small amounts of starting material required (Hugenholtz and Goebel, 2001).

\subsubsection{Drawbacks to the Molecular Approach}

The comparative analysis of the $16 \mathrm{~S}$ rRNA gene pool provides a very sophisticated tool for molecular based analysis of bacterial diversity in soil. This approach, however, does still have some methodological uncertainties. For example, bias might be introduced during the retrieval of nucleic acids from environmental samples. Many methods have been used to extract nucleic acids, but it is unknown whether any method recovers all of the naturally occurring DNA (Ward et al., 1992). Some procedures, particularly enzymatic lysis methods, are biased towards recovery of DNA from Gram-negative bacteria, which have a thinner cell wall than their Gram-positive counterparts. Mechanical lysis is more rigorous and is considered to give a more representative sample, although lower molecular weight DNA is recovered this way due to shearing of the DNA molecules (Ward et al., 1992). Conversely, DNA liberated from easily lysed organisms can become adsorbed to soil colloids, especially in clay soils, skewing the recovered DNA profile towards Gram-positive bacterial species (Frostegard et al., 1999). The size of cells may also affect DNA extraction efficiency. More et al. (1994) showed that small bacterial cells $(1.2$ to $0.3 \mu \mathrm{m})$ are more difficult to lyse than larger bacteria, and 50 to $70 \%$ of bacteria in non-rhizosphere soil are less that $0.5 \mu \mathrm{m}$ in size. Extracellular DNA in soil may also contribute to the total DNA extracted, as it can 
remain adsorbed to soil particles for long periods after the cell is lysed (Paget et al., 1992). Frostegard (1999), however found that only $6 \%$ of extracellular DNA added to soil before DNA extraction could be recovered, suggesting that the effect of extracellular DNA is minimal.

Bias associated with PCR must also be considered in bacterial community diversity analysis. Bacterial community $16 \mathrm{~S}$ rRNA analysis is widely regarded as a qualitative rather than quantitative technique, because PCR can result in differential amplification of community rDNAs, distorting the final template ratios away from the initial template ratios. This can be caused by a number of mechanisms including preferential denaturation of low GC containing sequences, template reannealing inhibition (Reysenbach et al., 1992), low template concentrations (Chandler et al., 1997a), and reannealing of single-stranded template molecules (Suzuki and Giovannoni, 1996). Another problem that has been reported is the formation of chimeric DNA molecules (recombinant DNA sequences of two or more different parent sequences in the sample). Chimeric sequences are thought to be caused by reannealing of the $3^{\prime}$ end of an incompletely synthesised rDNA product to a different template, which is synthesised to completion. Kopczynski et al. (1994), identified chimeric 16S rRNA products from PCR and cautioned that their detection is important when sequencing genes, as erroneous sequences may be entered into ribosomal databases, giving a false estimate of diversity.

Although not specifically related to PCR, operon heterogeneity and gene clusters complicate the interpretation of environmental genetic data (Hugenholtz and Goebel, 2001). The copy number of the $16 \mathrm{~S}$ gene can range between 1 and 14 in different bacterial species (Cole and Girons, 1994). These copies can have some variation 
between them, and this may artificially increase the diversity seen in a profile (Clayton et al., 1995). Coenye and Vandamme (2003), have shown that this variation is low in the 55 bacterial genomes they studied, with similarity between copies being between 100 and $98.74 \%$. Actinomycetes may have higher intragenomic variability, with differences of up to $6.5 \%$ being reported (Yap et al., 1999). Alternatively, a single sequence may represent more than one cellular lineage or species due to the highly conserved nature of the 16S rDNA (Stackebrandt and Goebel, 1994)

\subsubsection{Diversity Analysis}

Two main approaches have been taken to analyse bacterial community rRNA. The more traditional approach involves cloning extracted or copied rRNA molecules into vectors for sequencing. This approach is used when the sequence is required for clone identification. The effort and cost involved in cloning and sequencing however precludes the analysis of many samples as might be required when assessing temporal and spatial dynamics of populations in natural ecosystems. For this reason, various molecular "fingerprinting" techniques have become popular. These techniques are based on the principle of resolving the diversity of the amplified genes depending on their sizes or sequences. Numerous techniques have been developed that separate community $16 \mathrm{~S}$ rDNA based on various properties. Those most commonly used are outlined in Table 2.1. Many of these techniques are PCR based so are subject to the biases inherent with PCR. They are all, however, relatively simple and rapid and allow analysis of numerous samples which can then be compared. Other techniques which use areas of DNA other than the $16 \mathrm{~S}$ rRNA have also been used to analyse bacterial communities. These are outlined in Table 2.2. These techniques are not as popular as those based on 16S rDNA, but offer a different perspective on diversity because community separation is based on different properties of the DNA. 


\begin{tabular}{|c|c|c|c|c|}
\hline & Differentiation based on & Advantages & Disadvantages & Reference \\
\hline $\begin{array}{l}\text { Denaturing gradient gel } \\
\text { electrophoresis (DGGE) }\end{array}$ & $\begin{array}{l}\text { Melting temperature/ base } \\
\text { composition in denaturant } \\
\text { gradient }\end{array}$ & $\begin{array}{l}\text { Bands can be excised for } \\
\text { sequencing } \\
\text { Can hybridise profile with } \\
\text { probes }\end{array}$ & $\begin{array}{l}\text { PCR biases } \\
\text { PCR products larger than } 500 \mathrm{bp} \text { not separated } \\
\text { well } \\
\text { Different sequences can have similar melting } \\
\text { properties }\end{array}$ & $\begin{array}{l}\text { (Muyzer et al., } \\
1993 \text { ) }\end{array}$ \\
\hline $\begin{array}{l}\text { Temperature gradient gel } \\
\text { electrophoresis (TGGE) }\end{array}$ & $\begin{array}{l}\text { Melting temperature/ base } \\
\text { composition in temperature } \\
\text { gradient }\end{array}$ & $\begin{array}{l}\text { Bands can be excised for } \\
\text { sequencing } \\
\text { Can hybridise profile with } \\
\text { probes }\end{array}$ & $\begin{array}{l}\text { PCR biases } \\
\text { PCR products larger than } 500 \mathrm{bp} \text { not separated } \\
\text { well } \\
\text { Different sequences can have similar melting } \\
\text { properties }\end{array}$ & $\begin{array}{l}\text { (Heuer et al., 1997; } \\
\text { Ramirez-Saad et al., } \\
\text { 2003). }\end{array}$ \\
\hline $\begin{array}{l}\text { Single-strand conformation } \\
\text { polymorphism (SSCP) }\end{array}$ & $\begin{array}{l}\text { Single-stranded secondary } \\
\text { structure mobility }\end{array}$ & $\begin{array}{l}\text { Bands can be excised for } \\
\text { sequencing }\end{array}$ & $\begin{array}{l}\text { PCR biases } \\
\text { Only fragments between 150- } \\
400 \text { nucleotides can be used } \\
\text { Electrophoretic variables have strong influence }\end{array}$ & $\begin{array}{l}\text { (Schwieger and } \\
\text { Tebbe, 1998) }\end{array}$ \\
\hline $\begin{array}{l}\text { Amplified ribosomal DNA } \\
\text { restriction analysis (ARDRA) or } \\
\text { restriction fragment length } \\
\text { polymorphism (RFLP) analysis }\end{array}$ & Restriction fragment length & $\begin{array}{l}\text { Straightforward } \\
\text { No expensive equipment }\end{array}$ & $\begin{array}{l}\text { PCR biases } \\
\text { Diversity difficult to estimate due to multiple } \\
\text { fragments per gene copy }\end{array}$ & $\begin{array}{l}\text { (Cheneby et al., } \\
\text { 2000) }\end{array}$ \\
\hline $\begin{array}{l}\text { Length heterogeneity-PCR (LH- } \\
\text { PCR) }\end{array}$ & Gene fragment length & $\begin{array}{l}\text { Simple and rapid } \\
\text { Products can be excised } \\
\text { and sequenced }\end{array}$ & PCR biases & (Suzuki et al., 1998) \\
\hline $\begin{array}{l}\text { Terminal Restriction Fragment } \\
\text { Length Polymorphism } \\
\text { (T-RFLP) }\end{array}$ & Restriction fragment length & $\begin{array}{l}\text { Can be automated (high } \\
\text { resolution) } \\
\text { Potential to be quantitative } \\
\text { Standards allow controlled } \\
\text { comparison }\end{array}$ & $\begin{array}{l}\text { PCR biases } \\
\text { Cannot be sequenced without use of cloning. }\end{array}$ & $\begin{array}{l}\text { (Liu et al., 1997; } \\
\text { Osborn et al., 2000) }\end{array}$ \\
\hline $\begin{array}{l}\text { Ribosomal RNA-targeted nucleic } \\
\text { acid probes }\end{array}$ & Sequence & Not subject to PCR biases & $\begin{array}{l}\text { rRNA can be naturally low in abundance } \\
\text { Time consuming/complex } \\
\text { Some sequence knowledge required for probe } \\
\text { design }\end{array}$ & $\begin{array}{l}\text { (Amann and } \\
\text { Ludwig, 2000) }\end{array}$ \\
\hline
\end{tabular}

Table 2.1. Summary of commonly used 16S rDNA bacterial community analysis techniques. 


\begin{tabular}{|c|c|c|c|c|c|}
\hline & Gene used & $\begin{array}{l}\text { Differentiation based } \\
\text { on }\end{array}$ & Advantages & Disadvantages & Reference \\
\hline $\begin{array}{l}\text { Randomly } \\
\text { Amplified } \\
\text { Polymorphic } \\
\text { DNA (RAPD) }\end{array}$ & $\begin{array}{l}\text { Random } \\
\text { DNA }\end{array}$ & $\begin{array}{l}\text { Annealing of primers } \\
\text { in different places in } \\
\text { different genomes }\end{array}$ & $\begin{array}{l}\text { No sequence information } \\
\text { required at all }\end{array}$ & $\begin{array}{l}\text { Some questions raised over } \\
\text { reproducibility. } \\
\text { PCR biases } \\
\text { No phylogenetic information } \\
\text { can be inferred }\end{array}$ & (Wikstrom et al., 1999) \\
\hline $\begin{array}{l}\text { Ribosomal } \\
\text { intergenic spacer } \\
\text { analysis (RISA) }\end{array}$ & $\begin{array}{l}\text { Intergenic } \\
\text { spacer } \\
\text { (IGS) }\end{array}$ & Length polymorphism & $\begin{array}{l}\text { Can be automated } \\
\text { (ARISA) } \\
\text { Good phylogenetic } \\
\text { resolution. }\end{array}$ & $\begin{array}{l}\text { Limited IGS sequence data } \\
\text { available } \\
\text { PCR biases/ operon } \\
\text { heterogeneity }\end{array}$ & $\begin{array}{l}\text { (Fisher and Triplett, 1999; } \\
\text { Ranjard et al., 2000) }\end{array}$ \\
\hline $\begin{array}{l}\text { Total genomic } \\
\text { cross-DNA } \\
\text { hybridisation }\end{array}$ & Total DNA & $\begin{array}{l}\text { Reannealing between } \\
\text { two different samples } \\
\text { whole DNA }\end{array}$ & Not subject to PCR biases & $\begin{array}{l}\text { Does not give information on } \\
\text { relative abundance of individual } \\
\text { genomes } \\
\text { Requires large amounts of high } \\
\text { quality DNA }\end{array}$ & (Torsvik et al., 1990) \\
\hline $\begin{array}{l}\text { Whole DNA } \\
\text { fractionation }\end{array}$ & Total DNA & $\begin{array}{l}\text { Density gradient/ base } \\
\text { composition }\end{array}$ & Not subject to PCR biases & $\begin{array}{l}\text { Low taxon resolution } \\
\text { Requires large amounts of high } \\
\text { quality DNA }\end{array}$ & (Holben and Harris, 1995) \\
\hline $\begin{array}{l}\text { Low-molecular- } \\
\text { weight (LMW) } \\
\text { RNA analysis }\end{array}$ & $\begin{array}{l}\text { 5S rRNA } \\
\text { and tRNA }\end{array}$ & Length polymorphism & Not subject to PCR biases & $\begin{array}{l}\text { Rapid degradation of small } \\
\text { RNA molecules leading to gel } \\
\text { artefacts } \\
\text { Limited information in small } \\
\text { RNA }\end{array}$ & (Höfle and Brettar, 1996) \\
\hline
\end{tabular}

Table 2.2. Summary of microbial community diversity analysis techniques that do not use 16S rDNA. 


\subsubsection{Terminal Restriction Fragment Length Polymorphism (T-RFLP) Analysis}

Terminal Restriction Fragment Length Polymorphism (T-RFLP) analysis is one fingerprinting methodology that can incorporate automated genotyping systems for laser detection of fluorescently-labelled DNA fragments. As outlined briefly in section 1.3.1, the T-RFLP analysis technique involves the amplification of a gene of interest using fluorescent primers, followed by restriction endonuclease digestion, and automated analysis of the end or terminal restriction fragments. Because the $16 \mathrm{~S}$ rRNA genes from all of the bacteria in the soil community are amplified, the resulting PCR products are gene copies of a similar length but with different internal sequences. The PCR products are cleaved with a restriction enzyme that recognises and cleaves DNA at particular sequences. In the variable regions of the $16 \mathrm{~S}$ gene (see Figure 1.2), restriction sites occur in different places resulting in different length fragments. The more diverse the bacterial community in a sample, the greater the range of resulting fragments. The end, or terminal fragments are analysed and the size and frequency of each fragment assessed to produce a profile or 'fingerprint' of the whole bacterial community in a soil sample.

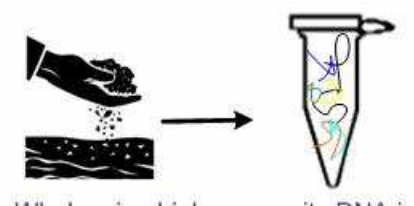

Whole microbial community DNA is extracted from the soil

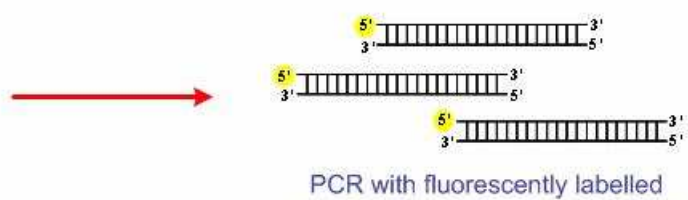

primers to amplify a region of the gene of interest

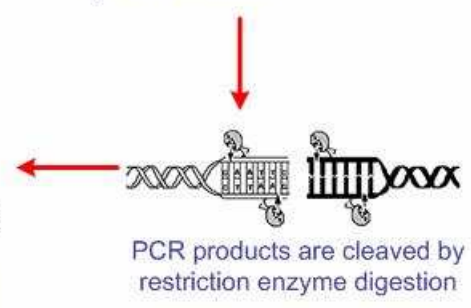
restriction enzyme digestion

The fluorescently labelled end fragments are separated and detected using the $A B \mid 310$ Genetic Analyser and an electropherogram generated

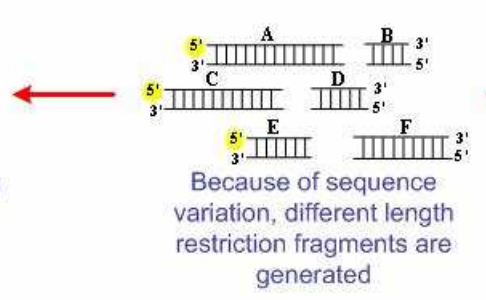

Figure 2.2. Overview of the T-RFLP method. 
Profiles of different samples can then be compared to assess the level of similarity or difference. A similarity index can be used to calculate a numerical measure of the similarity between two profiles, and profiles can be visually compared.

The T-RFLP method was originally developed by Avaniss-Aghajani et al. (1994) to identify Mycobacteria, but its potential to analyse variation between genes from a mixture of bacteria was first shown by Liu et al. (1997). Since then, T-RFLP analysis has been used in numerous studies to look at bacterial (Liu et al., 1998), archael (van der Maarel et al., 1998) and eukaryal (Marsh et al., 1998) populations in natural habitats, and has been identified as a reproducible and accurate tool for community fingerprinting (Egert and Friedrich, 2003). There are clear advantages for using TRFLP over many of the other molecular techniques presently in use (Tables 2.1 and 2.2), including the fact that direct reference to the sequence database can be used to derive phylogenetic inferences (Osborn et al., 2000). The DNA sequencing technology also has considerably higher resolution than the electrophoretic systems, and the output is digital, allowing for easy data handling (Marsh, 1999). The Ribosomal Database Project (http://rdp.cme.msu.edu/html/) offers an online T-RFLP analysis similarity coefficient calculation tool, that allows raw $16 \mathrm{~S}$ rDNA T-RFLP data to be input, and a measure of similarity, or similarity index, between two samples calculated (Maidak et al., 1999). Some aspects of T-RFLP can also be tailored to meet the particular requirements of the user although the $16 \mathrm{~S}$ rRNA gene is the most commonly used. Indeed, any gene of interest that has both conserved and diverse regions can be used. Osborn et al. (2000) evaluated T-RFLP analysis as a tool for the study of bacterial community structure and dynamics. They assessed the reproducibility and robustness of the method using both pristine (control) and PCB polluted soils. Little variability was observed between replications of various procedure steps although some variation 
was observed when using different DNA polymerase enzymes. Other experimental conditions including template DNA concentration, primer annealing temperature, number of PCR cycles, and restriction endonuclease concentration were also evaluated. Nine restriction endonucleases were investigated and three, AluI, HhaI and ThaI, were predicted to yield the highest number of different sized terminal restriction fragments. Osborn et al. (2000) concluded that T-RFLP analysis is a robust and reproducible methodology for analysis of bacterial community structure, and could be developed into a powerful tool in microbial ecology.

Despite the obvious advantages of T-RFLP analysis, some problems are associated with its use for bacterial community analysis. These include the biases caused by PCR, as well as other factors such as restriction enzyme digestion efficiency. The validity of using T-RFLP to quantify bacterial ribotypes, or fragments, giving an idea of the importance of that species in the community is currently questioned. Lueders and Friedrich (2003) maintain that quantitation is valid, as accurate template to product ratios have been seen using T-RFLP analysis. In contrast, other studies have documented unpredicted results from mixed populations. Egert and Friedrich (2003) investigated the occurrence of pseudo-terminal restriction fragments (pseudo T-RFs). These are restriction fragments that are present in a T-RFLP profile, but are caused by single-stranded amplicons, and cannot be digested by restriction endonucleases, giving false peaks. The height and area of the pseudo-T-RFs increases with the number of PCR cycles, indicating they are a PCR artefact. Extra T-RFs can occur because of partial digestion of the PCR products, but this can be overcome by increasing the amount of restriction enzyme. Egert and Friedrich (2003), hypothesize that singlestranded amplicons are formed by intrastrand annealing under the same conditions as template reannealing. These structures may prevent correct amplification by 
polymerases, leaving single stranded amplicons. To further complicate the problem, single stranded sequences can form local palindromic secondary structures that allow restriction enzymes to digest them. Restricting the number of PCR cycles to the minimum required will reduce the effect of pseudo-T-RFs, but is unlikely to eliminate them completely. Hence the presence of these peaks should be considered when evaluating species diversity in a mixed community using T-RFLP.

It must be recognised that many bacterial species have more than one copy of the $16 \mathrm{~S}$ rRNA gene, and that some T-RFs will also be common in size to many different organisms. Since T-RFLP relies on restriction sites, which can be located in the same place in the gene in more than one species, it has limited resolution for identifying specific phylogenetic groups within a complex community (Lee et al., 1996). Restriction enzymes that produce high numbers of T-RFs can be chosen, but some common sites between species are still likely. Despite the potential biases inherent in the T-RFLP method, it has still become a popular technique for bacterial community analysis. As long as these potential areas of concern are taken into consideration when assessing communities quantitatively, T-RFLP is a simple, reproducible and useful technique (Marsh, 1999). 


\subsection{Post Mortem Interval Estimation}

\subsubsection{Introduction}

Determination of time since death, or the post-mortem interval (PMI) is often essential in forensic cases, particularly homicides. It is, however, almost always a difficult task. The more recent the death, the simpler it is, as estimation can be narrowed to a fairly limited time range. A variety of tools can be used to estimate the PMI, depending on the stage of decomposition of the body. Physical changes in the body itself can be used early in decomposition, and for later stages, changes to the surrounding environment, such as vegetation growth, or the study of the insects which colonise the body (forensic entomology) can be useful.

\subsubsection{The Process of Decomposition}

Human decomposition begins approximately four minutes after death. Characteristic changes in the early post mortem period include the cooling of the body to ambient temperatures (algor mortis), the stiffening of muscles (rigor mortis) and the settling of blood due to gravity (livor mortis) (Clark et al., 1997). As cells are starved of the oxygen they require to live, carbon dioxide builds up, $\mathrm{pH}$ decreases and wastes accumulate, causing cells to rupture through a process called autolysis (Vass, 2001). This process begins in tissue with high enzyme activity such as the brain and liver and proceeds to all tissues of the body. The release of nutrient-rich cellular fluids during cell lysis promotes the beginning of a process known as putrefaction. The body's natural microflora begin to break down soft tissues, releasing gases as by-products of metabolism (Clark et al., 1997). These collect within the abdominal cavity, bloating the body. Gas and fluid accumulation purge from natural body openings or burst the skin, 
releasing decomposition compounds into the external environment (Vass, 2001). Active decay follows, and is characterised by heavy microbial and insect activity. By the end of this stage only approximately 10 percent by weight of the corpse remains. The skeleton and any remaining tissues continue to dry, and bone is slowly degraded through a process known as diagenesis (Galloway, 1997). The progression of decomposition can be divided into a rough sequence of stages: fresh, bloat, decay, postdecay or dry and skeletonisation (Goff, 2000).
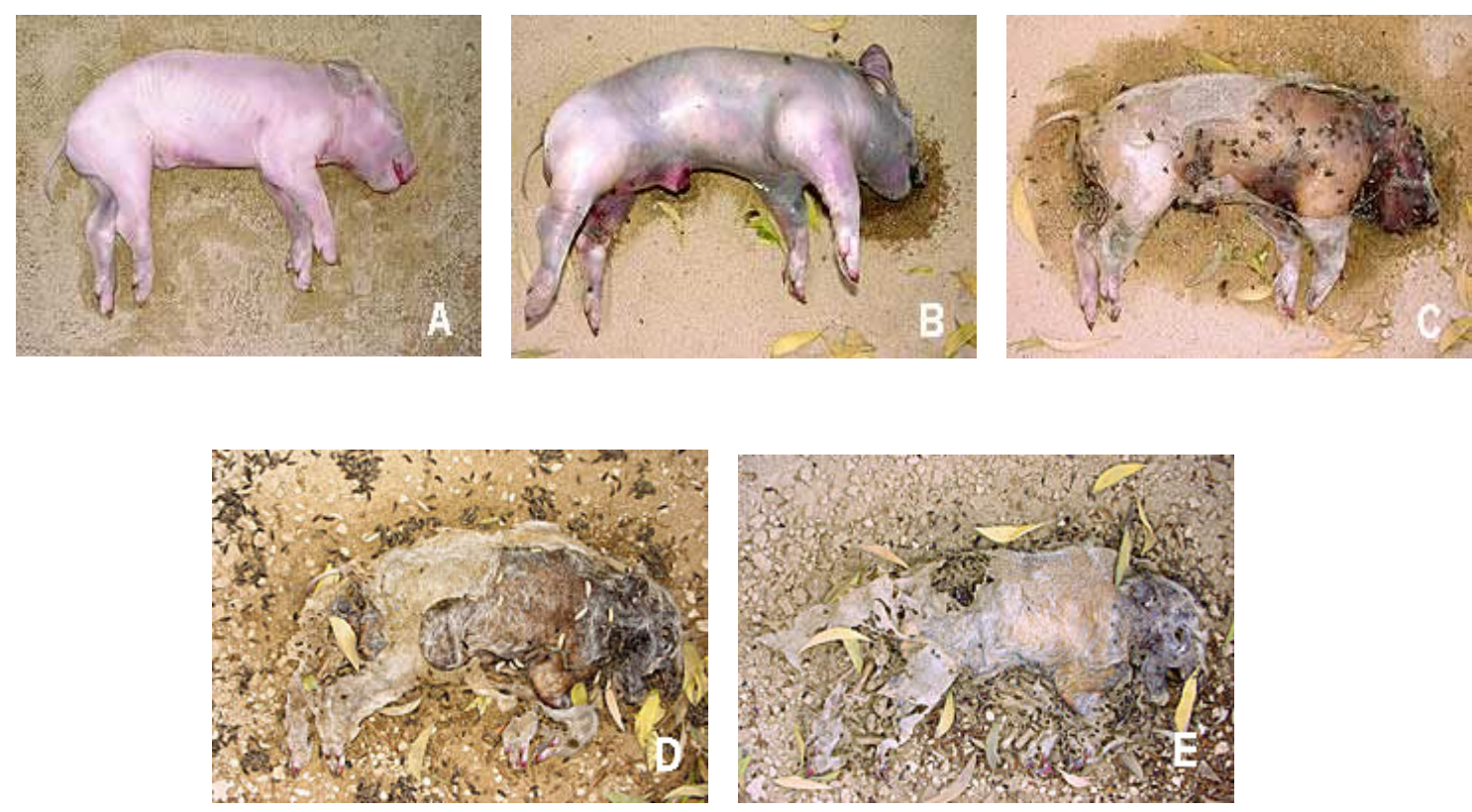

Figure 2.3. The five basic stages of decomposition: fresh (A), bloat (B), active decay $(C)$, post-decay or dry (D) and skeletonisation (E) (Australian-Museum, 2003)

The rate of decomposition is greatly affected by the environment. Conditions such as temperature, oxygen availability, exposure to sunlight and scavengers, humidity and $\mathrm{pH}$ must all be taken into consideration when estimating time since death. Whether a body is buried, submerged in water or left on the soil surface will affect factors such as temperature, insect access to the body and oxygen availability and so greatly affects the rate of decomposition. 


\subsubsection{Post Mortem Interval Estimation Tools}

The changes that occur to a body after death can be reliably used to estimate the PMI up to 24 hours following death. Early post mortem changes that can be used include body temperature, degree of onset of rigor mortis and livor mortis and biochemical changes within the body (Svensson et al., 1981). Examining the state of the gastric contents of a body can determine how much time elapsed between the last meal and the time of death, and if the time of the last meal is known, this can be used to estimate the time since death.

For longer term PMI estimation, reasonable determinations can be made solely by observation by a forensic investigator with experience, although assistance from scientific tools is helpful (Pickering and Bachman 1996). Forensic entomology is a commonly used method for estimating the post mortem interval, and one that can be used from the time of colonisation until after active decay is finished. The succession of insects that invade a corpse has been widely studied. Necrophilous insects arrive at an exposed body quickly and in a relatively predictable sequence (Goff, 2000) An example of such a process is shown in Figure 2.4. Knowledge of the lifecycles of bodycolonising insects can be used by experienced entomologists to estimate time since death (Pickering and Bachman 1996). 


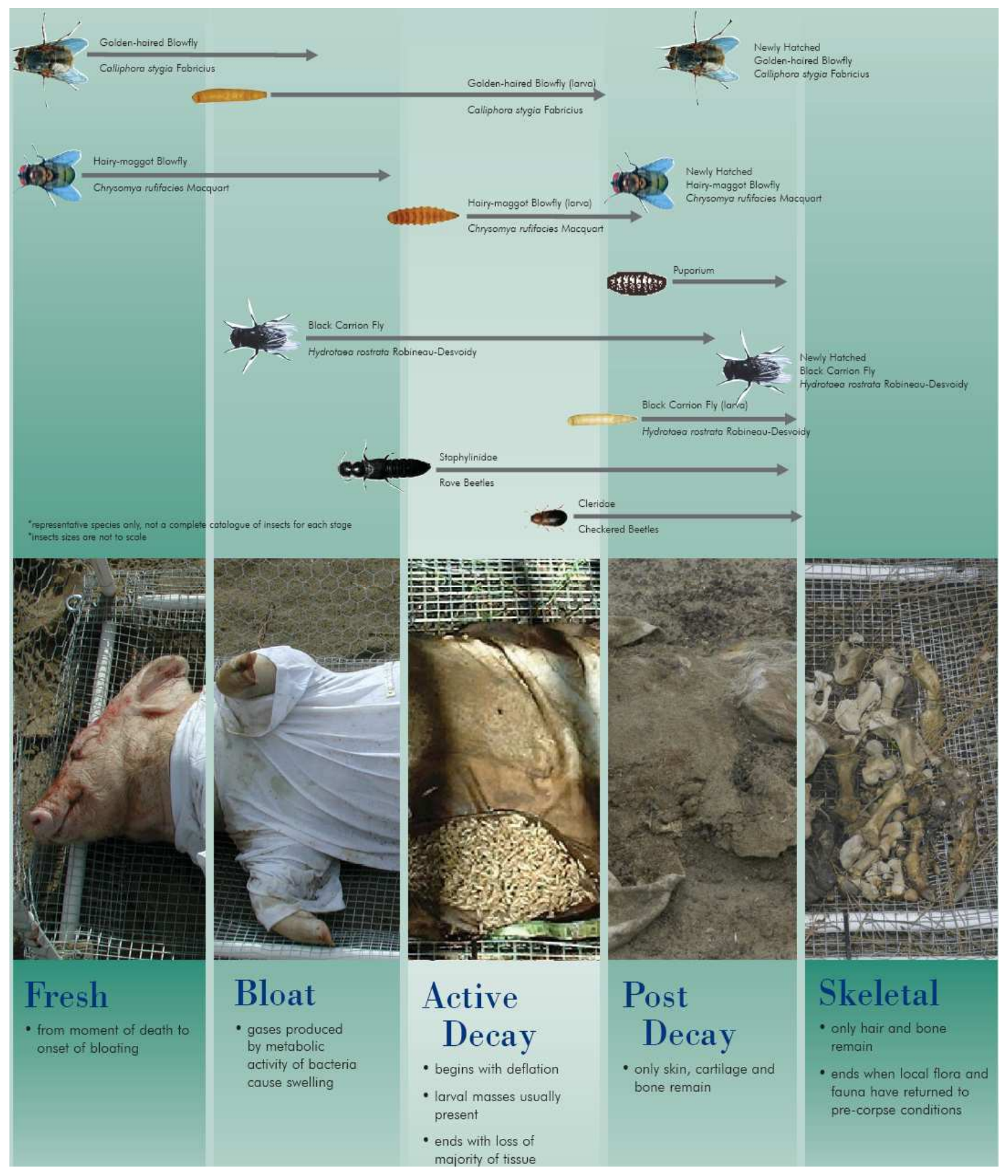

Figure 2.4. Insect succession on a pig carcass in New Zealand. The diagram shows representative species only and is not a complete catalogue of insects for each stage (Eberhardt and Elliot, 2004).

The vegetation found under and around a body can also be used as an indicator of how long a body has been exposed. Plants go through a defined growth cycle, so plants growing in or around a skeleton can indicate how long it has been there, as can the state of plant matter under a body. Plants in flower may be buried under the body, indicating the time of year of burial based on knowledge of when particular plant species flower. 
Growth comparisons can also be made with similar plants in the vicinity (Svensson et al., 1981).

Various innovative techniques have been investigated in recent years to aid in post mortem interval estimation and research continues into gaining a better understanding of these existing tools. Forensic entomology is the focus of much PMI estimation research with many studies undertaken worldwide (Malgorn and Coquoz, 1999; Amendt et al., 2000; Arnaldos et al., 2001; Myskowiak and Doums, 2002). Studies of biochemical and physical changes in the post mortem body are also continuing, often with the more traditional tools being improved by the application of newer technology. For example, determination of electrolyte concentrations (mainly potassium) in the vitreous humour of the human eye is one tool currently being upgraded. BocazBeneventi et al. (2002) have applied new electrolyte detection techniques including capillary zone electrophoresis (CZE) to quantitate these post mortem changes more accurately. Querido $(1998 ; 1999)$ recently looked at the potential of using electrical impedance of lateral abdominal skinfolds and scalps on rat cadavers as a PMI estimation tool, but found that individual variation made it unsuitable. Babapulle and Jayasundera (1993) found that the degeneration of white blood cells in cadavers could be used to estimate the PMI reasonably accurately up to 84 hours after death.

Volatile fatty acids, which are microbially produced degradation products of soft tissue, and various anions and cations were investigated by Vass et al. (1992) to estimate PMI for pre-skeletonised remains. Measurements of these decomposition products were made from soil samples taken from underneath bodies over time. The ratios of specific fatty acids were found to be predictive of the stage of decomposition with a reported accuracy of \pm 2 days. More recently, Vass et al. (2002) concentrated on identifying 
biomarkers in various organs of the body to develop a PMI estimation tool that is more accurate. Biomarkers such as amino acids, neurotransmitters and decompositional byproducts from various organs were studied and it was shown that each biomarker is found in a tissue for a specific period of time. By examining relative concentration ratios between different markers, the number of cumulative degree hours (CDHs) since death could be calculated (Figure 2.5). Cumulative degree hours are calculated by summing the average temperature $\left({ }^{\circ} \mathrm{C}\right)$ for each twelve hour period since death. The $\mathrm{CDH}$ gives a measure of the stage of decomposition irrespective of climatic conditions. By comparing data from a number of tissues, the time range could be narrowed to as little as $5 \mathrm{CDHs}$ (up to $1000 \mathrm{CDHs}$ or 3 weeks after death). The significant advantage of this technique is that variables such as the victim's weight do not need to be taken into consideration because the method is based on ratios between the biomarkers and not absolute values.

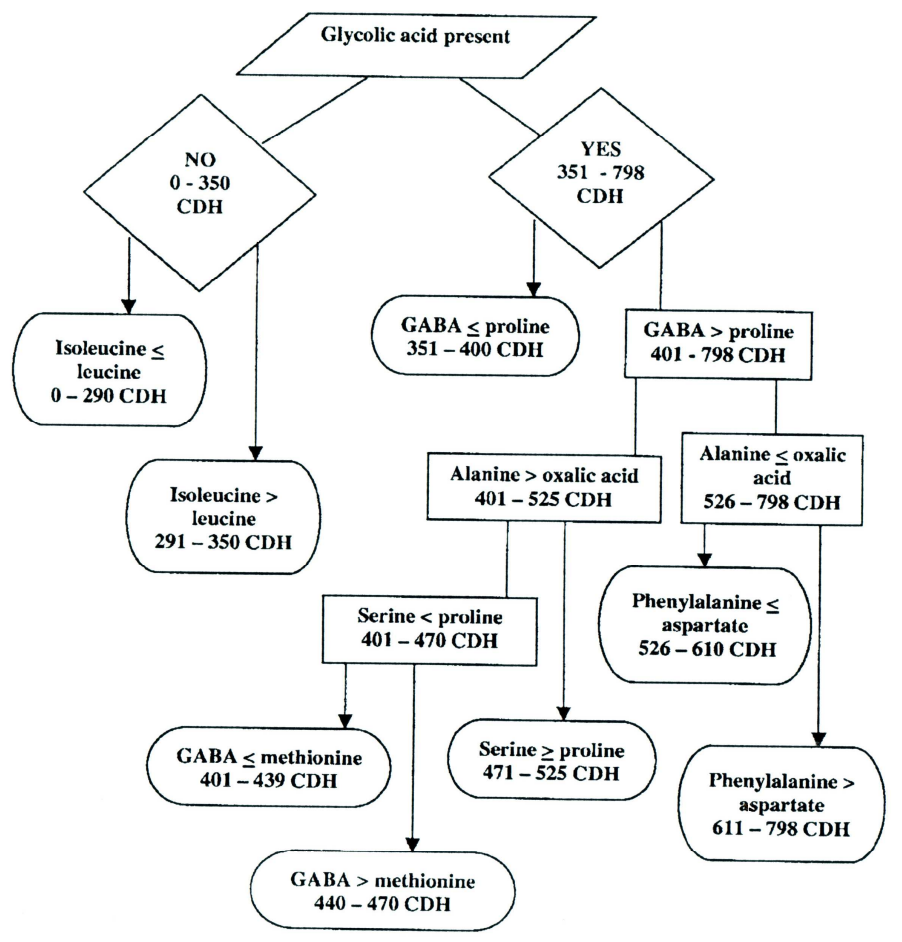

Figure 2.5. Flow diagram for determining time since death in cumulative degree hours $(\mathrm{CDH})$ using the ratios of biochemical biomarkers in muscle tissue (Vass et al., 2002). 
Carter and Tibbett (2003) recognised that certain fungal species that are associated with decomposition could be used as a PMI estimation tool. Known as post-putrefaction fungi, these species are commonly found in association with graves. The authors speculate that with better understanding of the fungal succession associated with cadavers, a PMI estimation tool could be developed.

For longer term PMI estimation, studies have included determining the decay rate of DNA in ribs (Perry et al., 1988) and using bone lipid, cholesterol and protein forming multiple regression equations for dating bones (Castellano et al., 1984). More recently it has been shown that certain radionuclides and trace elements in bones could potentially be used as a means of PMI estimation for skeletal remains (Swift et al., 2001).

\subsubsection{Post Mortem Microbiology}

The microbiology of death is not well defined. Attempts to better understand the microbial participants in the decomposition process have been made, but these studies were reliant on laboratory culture and isolation of individual bacterial species. This approach is greatly complicated by the extensive collection of bacterial species that participate in decomposition (Vass, 2001). The natural body microflora play an essential role in putrefaction, with both aerobic and anaerobic species involved. In a normal adult colon, endosymbionts consist of 96-99 \% anaerobes e.g., Bacteroides spp., anaerobic lactobacilli, clostridia, and anaerobic streptococci, and about 1-4 \% aerobes e.g., Gram negative coliforms, enterococci, and small numbers of Proteus spp., Pseudomonas spp. and others (Jawetz et al., 1982). Environmental micro-organisms including many species of fungi, amoebae, protozoa and bacteria also contribute to the 
decompositional process with further species being introduced by insects and scavengers (Vass, 2001).

The putrefactive changes that occur during decomposition are likely to affect not only the microbes in and on the body, but also the bacterial communities in the underlying soil. Decomposition products drain from the body into the underlying soil and influence the populations of soil-dwelling organisms in the area beneath the body. These changes can be long-term and become more significant as decomposition progresses (Goff, 2000). The microbial species associated with decomposition may be present for months or even years after death, depending on local conditions.

Hopkins et al. (2000) investigated the microbiological activity in soil from pig graves 430 days after burial. The grave soils contained more total carbon, microbial biomass carbon and total nitrogen, and showed increased rates of respiration and nitrogen mineralisation compared to control soils. The grave soils also had higher amino acid and $\mathrm{NH}_{4}{ }^{+}$concentrations, and reducing conditions.

Post mortem interval estimation is a complex but essential part of forensic investigation. Development of new tools that can aid in simpler, more accurate PMI estimations is ongoing. For the first time, in this project, the bacterial succession in soil under a decomposing corpse will be studied. This knowledge will contribute to the understanding of decomposition and the putrefactive process, and may help refine PMI estimation. 


\section{MATERIALS AND METHODS}

\subsection{Introduction}

The application of molecular microbiological techniques to forensic soil analysis is a relatively novel concept. Horswell et al. (2002) were successful in developing a method that was used to demonstrate the potential of this approach. During the initial establishment of this technique, it was recognised that further refinements would be required, if it were to be used routinely in forensic investigation. The primary remit of this project was to further develop and validate the existing soil bacterial community DNA profiling technique, and improve the profiling success rate for forensic soil samples. In addition, the potential for applying this technology to an alternative forensic problem, post mortem interval estimation, was also investigated. Because methodology development was a fundamental and substantial part of this project, the structure of this thesis is slightly unconventional. This chapter, Materials and Methods, outlines the basic process involved in profile generation. The following four chapters constitute the Results section. Chapter 4 - Technical Survey of Analytical Methodology, examines the basic methodology and identifies areas that were in need of refinement. Chapter 5 - Method Development, details the process and outcome of developing and refining the methodology. Spatial variation in the soil bacterial community and the contribution of variation by the methodology are examined in Chapter 6 - Reproducibility and Spatial Variation. Chapter 7 - Post Mortem Interval Estimation details the application of the soil bacterial DNA profiling technique to the problem of PMI estimation. 


\subsection{Soil DNA Profiling Method}

The basic soil DNA profiling method used here was that developed by Horswell et al. (2002), and involves the series of steps shown in Figure 3.1.

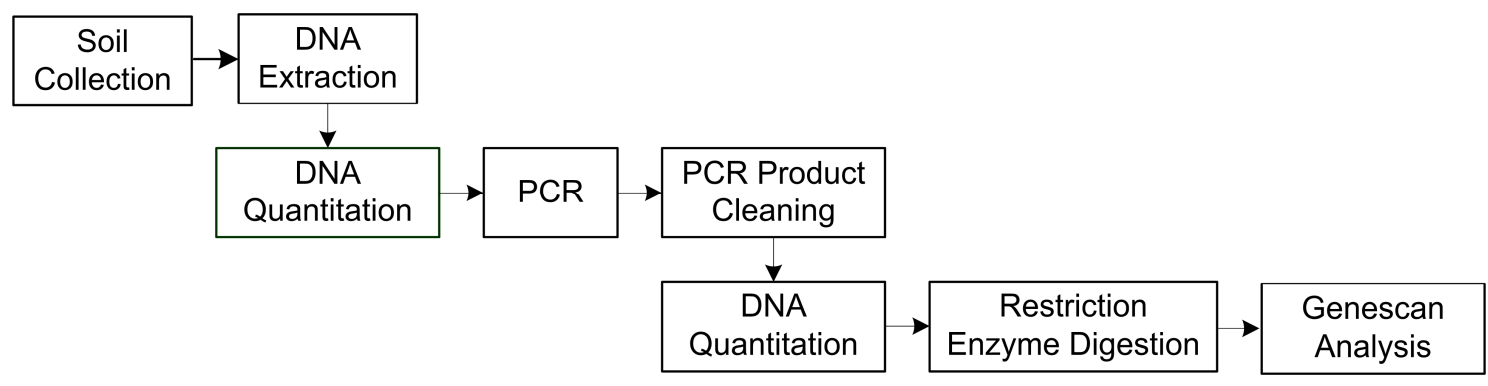

Figure. 3.1. The steps involved in the basic soil DNA profiling methodology.

The first step is soil collection, followed by extraction of the total soil bacterial community DNA. The amount of DNA extracted from the sample was then measured, and a specified quantity (20 ng) used for PCR amplification of a $1.3 \mathrm{~kb}$ region of bacterial $16 \mathrm{~S}$ rRNA genes. Fluorescently labelled synthetic oligonucleotide primers are used to facilitate automated detection of the amplified products. The mixture of amplified DNA products is then purified to remove PCR reagents that may affect later steps. The yield of DNA products is quantitated, and a $150 \mathrm{ng}$ aliquot digested with restriction endonuclease AluI. The resulting fluorescent DNA end fragments or terminal restriction fragments (T-RFs) are then quantitated using an ABI310 Genetic Analyser (Applied Biosystems). The T-RFLP profile data are collated and analysed using the GeneScan Analysis Software (Applied Biosystems).

\subsubsection{Sample Collection}

Soil was collected by scraping the surface of the sampling site (to the depth of about 10 $\mathrm{mm}$ ) with a clean metal spatula (previously rinsed with $80 \%$ ethanol and dried on a 
clean paper towel). For each sample, approximately one gram of soil was collected and each was put into a separate labelled, sterile $15 \mathrm{~mL}$ screw-top plastic centrifuge tube. The spatula was rinsed with ethanol after each sampling to ensure there was no contamination of subsequent samples. Soils stains on fabric were collected by excising the entire stained area, or part thereof, if the stained area was greater than $15 \mathrm{~cm}^{2}$. Soil was removed from the fabric by immersing it in $40 \mathrm{~mL}$ TE buffer $(10 \mathrm{mM}$ Tris-Cl, 1 mM EDTA, pH 7.5) for 1 hour at room temperature with shaking. The buffer and soil suspension was then centrifuged, the supernatant removed and the soil pellet air-dried.

If DNA extraction from the soil samples was not possible immediately after extraction, samples were stored at $4^{\circ} \mathrm{C}$ until required. Various storage methods were tested to determine the storage technique that allowed the least change in the soil bacterial community. The results are outlined in section 5.5 in Chapter 5.

\subsubsection{DNA Extraction}

Microbial DNA was extracted from $0.5 \mathrm{~g}$ soil using the FastDNA SPIN kit for Soil (QBIOgene) following the manufacturer's protocol (Appendix 1.1). When less than 0.5 $\mathrm{g}$ of soil was collected, the whole sample was used. The FastDNA SPIN kit uses a 'bead-beating' step that involves adding the sample and lysing buffer (from the kit) to a tube with fine glass beads and shaking vigorously with a Mini-BeadBeater (Biospec). This procedure physically shears the bacterial cells open and releases their cellular components. The liberated DNA is bound to a silica matrix and a number of wash steps are included to remove cell debris and contaminants before the DNA is eluted from the matrix in $50 \mu \mathrm{L}$ of sterile $\mathrm{dH}_{2} \mathrm{O}$. Because the FastDNA SPIN kit for Soil is a patented product, detailed information on the components is not supplied with the kit by its 
manufacturer. Various additions and modifications were made to this extraction process and are detailed in section 5.2.2 in Chapter 5.

\subsubsection{DNA Quantitation}

The amount of DNA extracted from each soil sample was measured using a PicoGreen dsDNA Quantitation Kit (Molecular Probes Inc.). This step is essential to enable a fixed amount of DNA to be put into each PCR. The concentration of DNA in each sample was also measured before restriction enzyme digestion, as DNA is lost during the PCR clean-up step and it is important to hold the amount of DNA constant for later comparisons between samples. A $1 \mu \mathrm{L}$ aliquot was taken from each DNA preparation and using the PicoGreen assay, the amount of DNA present estimated using a standard curve (Appendix 1.2). The Pico Green reagent is a dye, that, upon binding to double stranded DNA, exhibits a >1000-fold fluorescence enhancement. The fluorescence generated by this reaction was measured using a FLUOstar fluorescence plate reader and associated software (BMG LabTechnologies).

\subsubsection{Amplification of 16S rRNA genes}

A $1.3 \mathrm{~kb}$ target region of the bacterial $16 \mathrm{~S}$ rRNA genes present in the extracted DNA was amplified using PCR. Primer pair F63 (5' CAGGCCTAACACATGCAAGTC 3') and R1389 (5'ACGGGCGGTGTGTACAAG 3') were used as they facilitate amplification of most of the $16 \mathrm{~S}$ rRNA gene including all but one of the nine highly variable regions identified by Van de Peer et al. (1996) within the gene (refer Figure 1.1). Marchesi et al. (1998) identified this primer pair as being the most generally useful of all available 16S rDNA primer pairs, as they support PCR amplification of 16S rRNA genes from more bacterial species than any of the other primer sets tested. Osborn et al. (2000) also used 
this pair in their evaluation of T-RFLP as a technique for bacterial community profiling. A $5^{\prime}$ primer fluorescently labelled with 6-FAM phosphoramidite dye (Applied Biosystems) was used for later detection of the PCR product. In some protocols, both primers can be labelled with different dyes to generate more terminal restriction fragments (T-RFs). However, the $3^{\prime}$ end of the $16 \mathrm{~S}$ rRNA gene has been shown to produce fewer terminal restriction fragment variants than the $5^{\prime}$ end (Osborn et al., 2000). The higher number of $5^{\prime} \mathrm{T}-\mathrm{RF}$ variants may be a consequence of the length variation within the first three variable regions at the $5^{\prime}$ end of the gene (Suzuki et al., 1998). Horswell et al. (2002) demonstrated that labelling of only the $5^{\prime}$ end provided sufficient T-RFs for discrimination between soil samples. It has also been found that the PCR reaction is more likely to fail when both primers are labelled (J Horswell, ESR Ltd., pers. comm.), although a clear explanation for this failure is not apparent.

AmpliTaq Gold DNA polymerase (Applied Biosystems, Australia) was originally chosen for use in the PCR because it had previously been identified as successful for amplification of target DNA extracted from soil samples (J Horswell, ESR Ltd., pers. comm.). Following problems with AmpliTaq Gold, a different enzyme, HotStarTaq (Qiagen) detailed in section 4.3.4.2 was adopted for routine use. Other enzymes were also tested. The details of these enzymes and protocols are in Chapter 5, section 5.2.3.1. A Perkin-Elmer GeneAmp 2400 PCR machine was used for all amplifications.

A $3 \mu \mathrm{L}$ aliquot from each PCR reaction was run on a $2 \%$ agarose gel (Appendix 1.3) with a 100 bp ladder (Invitrogen) to check for successful amplification of the target DNA. The gel was stained with ethidium bromide and visualised using ultra-violet (UV) light. A digital photograph was taken of each gel. 


\subsubsection{Cleaning of PCR products}

A purification step was required after the PCR to remove any unused primers and other PCR components that could interfere with later detection of the DNA fragments and profile generation. For this purpose, the QIAquick PCR Purification Kit (Qiagen) procedure was followed (Appendix 1.4). Amplified products were cleaned and eluted in $50 \mu \mathrm{L}$ of elution buffer (10 mM Tris-Cl, $\mathrm{pH} 8.5)$.

\subsubsection{Restriction Enzyme Digestion of PCR Products}

Following the purification step, the PCR products were digested using the restriction enzyme AluI (Roche Molecular Biochemicals). This enzyme was selected because Osborn et al. (2000) tested nine 4 bp cutting restriction enzymes and identified AluI as one of three restriction enzymes which yielded the most T-RFs from soil samples using the primer pair F63 and R1389. A set amount of PCR product DNA (150 ng) was digested with $2 \mu \mathrm{L}$ (20 units) AluI, $1.5 \mu \mathrm{L}$ buffer A (10x stock) and $\mathrm{H}_{2} \mathrm{O}$ to a total volume of $15 \mu \mathrm{L}$. Digestions were incubated at $37^{\circ} \mathrm{C}$ for 3 hours, followed by restriction enzyme inactivation by heating to $65^{\circ} \mathrm{C}$ for 20 minutes. Buffer A contains at final $(1 \mathrm{x})$ concentration: Tris-acetate $33 \mathrm{mM}$, magnesium acetate $10 \mathrm{mM}$, potassium acetate $66 \mathrm{mM}$, dithiothreitol (DTT) $0.5 \mathrm{mM}, \mathrm{pH} 7.9$ at $37^{\circ} \mathrm{C}$. Modifications, including the addition of a cleanup step were made to this stage during method development (section 5.3.1).

\subsubsection{Fragment Detection \& Profile Generation}

Fragment detection was performed using an automated capillary ABI 310 Genetic Analyser and analysed using the GeneScan 3.1 Analysis Software (Applied 
Biosystems). The GeneScan software takes the raw data generated by the Genetic Analyser and determines the size of the fluorescently-labelled DNA fragments by comparing them to fragments contained in a size standard. It also quantifies the fragments at each size by measuring the amount of fluorescence emitted.

For each profile determination, a $2 \mu \mathrm{l}$ aliquot of the digested DNA had $10 \mu \mathrm{L}$ deionised formamide (Applied Biosystems) and $1 \mu \mathrm{L}$ size standard added before loading. The size standard used was Tamra 500 (Applied Biosystems). Run module parameters were set to: 10 second injection time at $15 \mathrm{kV}$ and 45 minutes run time at $60^{\circ} \mathrm{C}$.

The ABI 310 Genetic Analyser detects fluorescently labelled fragments using an argonion laser. Each DNA preparation is brought into contact with a cathode electrode and one end of a glass capillary filled with Performance Optimised Polymer $4 \%$, or POP-4 (Applied Biosystems). An anode electrode at the other end of the capillary is immersed in buffer. A portion of the DNA preparation enters the capillary as current flows from the cathode to the anode (electrokinetic injection). The cathode end of the capillary is then placed in buffer (Applied Biosystems) and current is applied again to initiate electrophoretic movement of the DNA fragments along the capillary. When the fragments reach a detector window in the capillary coating, the argon-ion laser excites the fluorescent dye labels. The fluorescence emitted from the dyes is collected by a CCD camera and the data captured and interpreted by the inbuilt software, which calculates the size and quantity of fragments from retention time and fluorescence intensity, respectively, at each point (Applied-Biosystems, 1998). A standard matrix file is used to analyse the data. The size standard and DNA being analysed have different coloured fluorescent dyes attached, so this file is used to correct for spectral overlap between the different colours. The matrix file is generated from a separate 
matrix run, generated every time a new run module parameter is set, and contains information about how much of the collected light falling on a filter is due to the intended light emission and how much is contaminating light.

To reduce turn-around time and ensure correct operation, the Genetic Analyser is maintained and operated as a service by a single person at ESR Ltd. Digested DNA preparations were delivered to the operator who ran the samples through the Genetic Analyser and made the results available as digital files for analysis and size calling.

\subsubsection{Results Analysis}

Fragment size calling was done using the Local Southern method (Southern, 1979). Local Southern calling uses the two DNA size standards on either side of a peak to call its size and is the most accurate of the size calling methods available with the GeneScan software (Kaplan and Kitts, 2003). The range used for size calling was set at 75-490 bp. The data generated by the GeneScan software can be displayed as graphical electropherograms (e.g., Figure 3.2) or as numerical data.

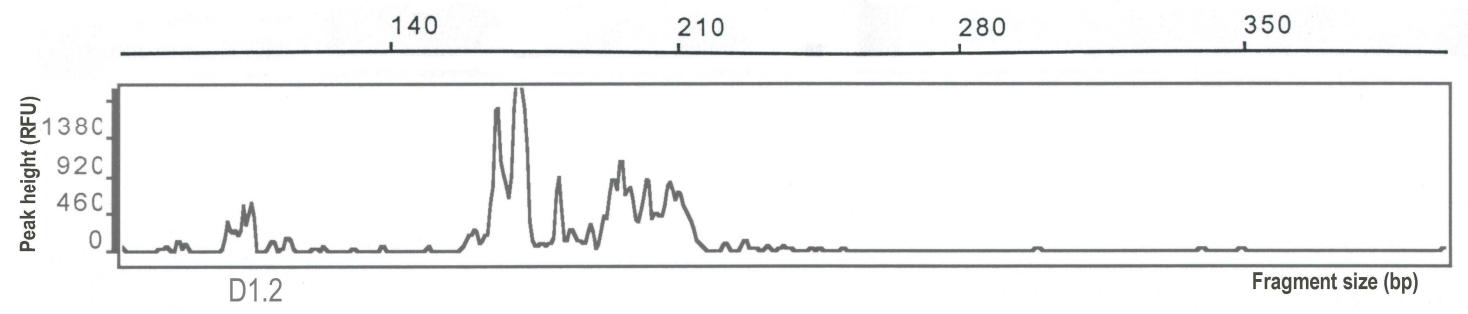

Figure 3.2. Example of graphically displayed T-RFLP profile data. The DNA fragment size in base pairs is shown along the $x$ axis, and the peak height (or number of fragments at each size) is shown on the $y$ axis in relative fluorescence units.

Electropherograms were printed and the data copied into and saved in electronic spreadsheets for data analysis. Each comparison was performed by first aligning the spreadsheet data and then calculating a similarity index value for each pair of profiles. 
Originally this was done manually, by aligning matching fragment size data points next to each other and leaving blank cells where a fragment occurred in only one sample. Two fragments sizes were considered to be the same if they were within 1 base pair of each other. If two fragments within a sample fell within this $1 \mathrm{bp}$ range, then the one closest to the machine called size in the other sample was considered to be a match (e.g., Table 3.1).

\begin{tabular}{|c|c|c|c|c|}
\hline \multicolumn{2}{|c|}{ Sample A } & \multicolumn{2}{|c|}{ Sample B } & \multirow[b]{2}{*}{ Table. 3.1. Example of spreadsheet alignment of two } \\
\hline $\begin{array}{l}\text { Fragment } \\
\text { size }\end{array}$ & $\begin{array}{c}\text { Peak } \\
\text { height }\end{array}$ & $\begin{array}{c}\text { Fragment } \\
\text { Size }\end{array}$ & $\begin{array}{c}\text { Peak } \\
\text { height }\end{array}$ & \\
\hline- & - & 82.9 & 123 & sample data sets. Fragment peaks were considered to be \\
\hline 85.74 & 77 & - & - & \\
\hline 88.24 & 103 & 88.21 & 61 & the same size if they were within one base pair of each \\
\hline 90.53 & 314 & 90.47 & 172 & other. The circled values are an example where two \\
\hline- & - & 91.66 & 58 & \\
\hline - & - & 97.45 & 62 & fragment sizes in profile B could potentially match with \\
\hline 102.82 & 312 & 102.75 & 209 & the $118.85 \mathrm{bp}$ peak in profile $A$. As the $118.73 \mathrm{bp}$ peak in \\
\hline 103.76 & 201 & 103.56 & 90 & 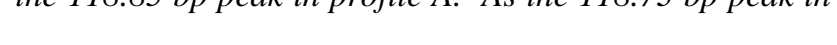 \\
\hline 104.6 & 254 & 104.59 & 144 & profile $B$ is closer in size to 118.85 than $119.25 \mathrm{bp}$, the \\
\hline 106.29 & 756 & 106.13 & 315 & \\
\hline 111.07 & 131 & - & - & former was considered to be the best match. \\
\hline 112.57 & 78 & 112.37 & 50 & \\
\hline 113.43 & 181 & - & - & \\
\hline 116.45 & 010 & 416.28 & 225 & \\
\hline 118.85 & 240 & 118.73 & 79 & \\
\hline & & 119.25 & 68 & \\
\hline
\end{tabular}

A computer programme that can rapidly perform multiple comparisons was developed as part of the profiling modification and is discussed in section 5.4.1. It aligns the data and calculates a similarity index value for each pair of profiles. The comparison indices tested are outlined in sections 4.3.4.3 and 5.4.2. Only fragments between 100 and 450 base pairs in size were included in the analysis, as this is the range in which fragments can be accurately sized using the Local Southern calling method. A minimum fluorescence unit or peak height cut off value was arbitrarily set at 100 relative fluorescence units (rfu). Peaks below this height were excluded from analysis to eliminate noise interference. 


\section{TECHNICAL SURVEY OF ANALYTICAL METHODOLOGY}

\subsection{Introduction}

A major part of this research project was further development of the basic soil profile comparison methodology into a reliable and reproducible procedure. To gain an understanding of the procedures involved in the current method and test the potential of soil bacterial DNA profiling, a mock forensic case scenario was set up.

Some problems were apparent at the outset of this exercise. These were primarily associated with extracting and amplifying DNA from soil samples. In particular, there were concerns that some samples might contain PCR inhibitors. Therefore, in addition to the soil samples collected from the mock forensic scenario, some other soil samples were also obtained that might be expected to be especially difficult to profile. These were included in order to see if it would be possible to improve the profiling success rate for difficult samples. These samples were collected from under a decomposing human cadaver at the University of Tennessee's Anthropology Research Facility. They were expected to be difficult to profile because of the presence of large quantities of organic compounds released from the decomposing body into the underlying soil. These compounds include breakdown products of proteins, lipids, carbohydrates, and volatile fatty acids, among others, many of which have been shown to inhibit PCR (Wilson, 1997). The nature and actions of PCR inhibitors are discussed more fully in section 5.2 of Chapter 5. 


\subsection{Aims}

The aim of the mock homicide scenario and decomposition sample trial was to use samples collected in a realistic forensic context to test and improve the methodology of Horswell et al. (2002).

\subsection{Methods}

\subsubsection{Mock Homicide Scenario Setup}

A mock homicide crime scenario was set up with the help of the forensic scientists employed by ESR Ltd. The scenario involved a victim being attacked in a suburban garden (scene one), wrapped in a sheet and relocated, using a vehicle, to a second location (scene two) where the victim was dumped, still wrapped in the sheet. The mock scenario allowed collection of soil samples of realistic size on materials encountered in real case-work situations. By acting out a struggle between a victim and an assailant, soil stains were made on clothing and shoes in the positions and quantities that could reasonably be expected in a real forensic case.

At scene one (the suburban garden), a struggle between the 'victim' and the 'assailant' was enacted (Figure 4.1). The victim was mock strangled while on her back and struggled in this position, resulting in soil stains on the elbows and back of her clothing and dislodging soil with her shoes. The assailant acquired soil stains on the knees of his overalls. The assailant then rolled the victim onto a cotton fabric sheet, wrapped the body, and dragged it across the grass (resulting in soil stains on the sheet) to a vehicle parked on a nearby driveway. The assailant removed the overalls covering his clothing at this point and left them in the vehicle. 


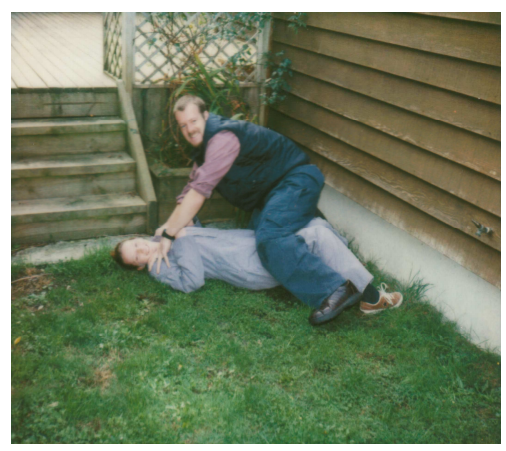

Figure 4.1. Assailant attacking victim at scene one.

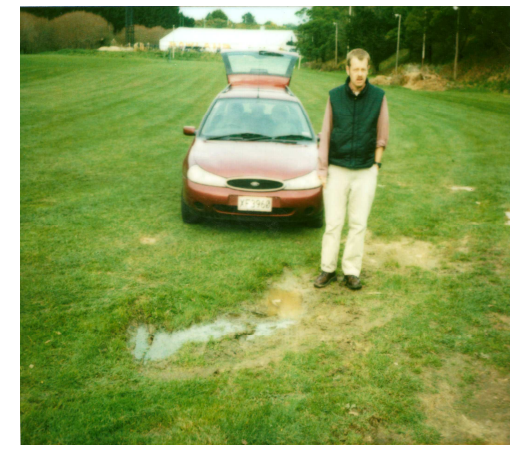

Figure 4.2. Assailant and vehicle at scene two.

At the second location (a nearby sports field), the assailant reversed the vehicle through a muddy puddle onto a grassed area (Figure 4.2). The victim was removed from the vehicle and dragged across a muddy patch of grass where the body was left, still wrapped in the sheet.

\subsubsection{Sample Collection}

Soil samples were collected at both scenes. At scene one, soil was collected from patches of earth where the mock attack took place (Figure 4.3). Sample sites included the areas of earth that were disturbed by the victim's shoes and elbows during the struggle, and fabric impressions that were likely to have been caused by the assailant's knees. Samples collected at the second scene were from entry and exit tyre prints (Figure 4.4), a fabric drag impression and a shoeprint left by the assailant at the scene.

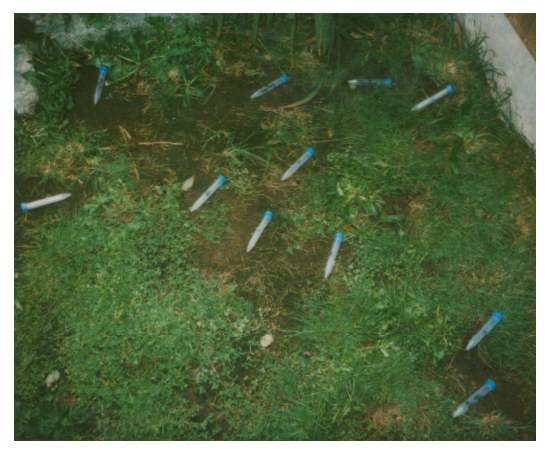

Figure 4.3. Sample sites at scene one marked with collection tubes.

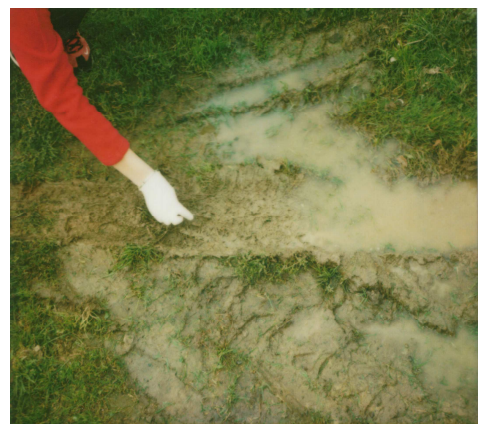

Figure 4.4. Sampling of tyre print at scene two. 
Soil from each scene was collected as outlined in section 3.2.1. The victim's and assailant's overalls and shoes were taken to the forensic laboratory at ESR Ltd., Kenepuru Science Centre for examination and soil collection. Stains found on the knees of the assailants overalls, the elbow of the victim's sleeve and soil on the sheet that the victim was wrapped in were collected and processed as described in section 3.2.1. Several samples were also collected from the vehicle used to transport the victim and included: mud on the left front wheel-arch and side of the vehicle directly behind the wheel, the left front tyre, the brake pedal and a small clod of soil found in the driver's footwell (see Figure 4.5).

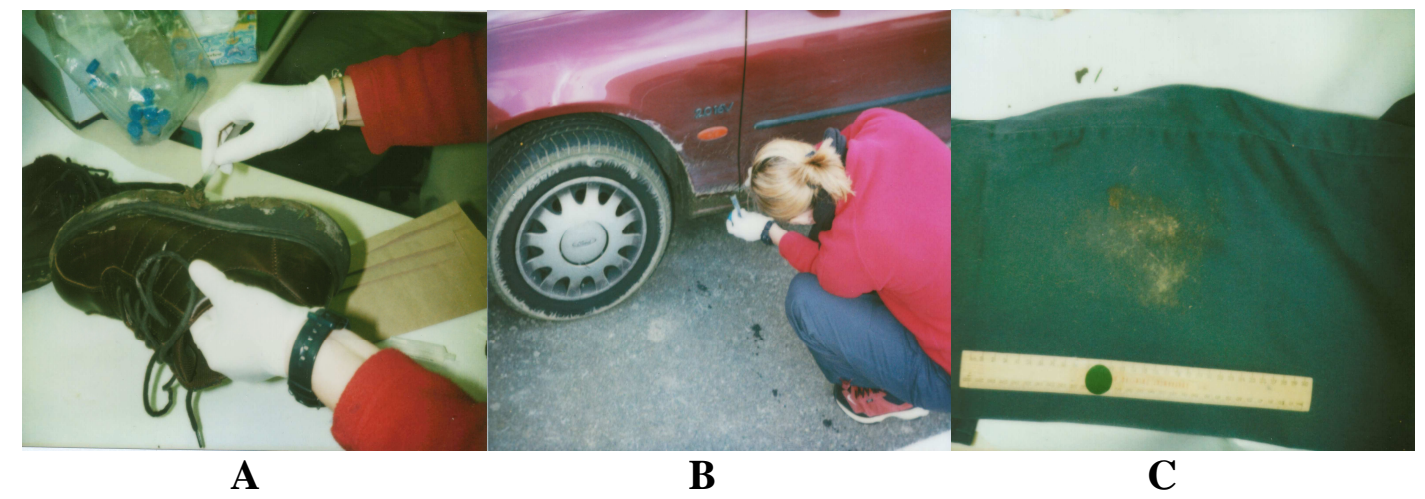

Figure 4.5. Collection of samples from assailant's right shoe (A), from the vehicle side (B) and the assailant's clothing $(C)$.

Thirty-two samples were collected in total (Table 4.1). Fifteen of these samples were selected for further processing on the basis that they would most likely link the suspect, victim and vehicle to either scene. For example, the shoeprint and soil from both of the suspect's shoes were chosen as these might link the suspect with scene two. Similarly, soil from both the victim and assailant's clothing, as well as from disturbed patches of earth were profiled, as these may link both people to the first scene. In forensic casework it is usual that numerous samples are collected at a crime scene. It is always judged prudent to collect too many, rather than to find out later that there are too few. 
Samples that are judged to have potential to offer the most information are processed first. The other samples are processed later if required. Here, many samples were initially collected from the homicide scenario, so that if more information was to be required at a later date, then extra samples were in storage and available for processing.

\begin{tabular}{|c|c|c|}
\hline Sample No. & Scene & Sampled from \\
\hline 1 & 1 & Soil (under victim's sleeve ?) \\
\hline 2 & $\mathbf{1}$ & Soil (under victim's shoe?) \\
\hline 3 & 1 & Soil (under assailant's knee?) \\
\hline 4 & 1 & Soil (under assailant's foot?) \\
\hline 5 & 1 & Soil (under assailant's foot?) \\
\hline 6 & 1 & Soil (under victim's shoe?) \\
\hline 7 & 1 & Soil (under victim’s back?) \\
\hline 8 & 1 & Soil (under victim's back?) \\
\hline 9 & 1 & Soil (under victim's back?) \\
\hline 10 & 1 & Soil (under victim's back?) \\
\hline 11 & 1 & Soil (?) \\
\hline 14 & $\mathbf{1}$ & Soil - fabric impression \\
\hline 15 & 2 & Shoeprint \\
\hline 16 & 2 & Fabric dragmark \\
\hline 17 & 2 & Tyre Impression (entry) \\
\hline 18 & 2 & Tyre Impression (exit) \\
\hline 19 & 2 & Vehicle - wheel arch left front \\
\hline 20 & 2 & Vehicle - tyre left front \\
\hline 21 & 2 & Vehicle - driver's footwell (brake pedal) \\
\hline 22 & 2 & Vehicle - driver's footwell (clod of soil) \\
\hline 23 & 2 & Vehicle - behind wheel arch left front side \\
\hline 24 & 2 & Assailant's right shoe - swab from shoe rim \\
\hline 25 & 2 & Assailant's left shoe - side of sole and tread \\
\hline 26 & 2 & Assailant's right shoe - side of sole and tread \\
\hline 27 & 1 & Sheet - mudstain on outside \\
\hline 29 & 1 & Victim's right shoe - heel \\
\hline 30 & 1 & Victim's left shoe - sole \\
\hline 31 & 1 & Victim's overalls - left sleeve \\
\hline 32 & 1 & Victim's overalls - shakings \\
\hline 33 & 1 & Sheet - grass stain on outside \\
\hline 34 & 1 & Assailant's overalls - right knee stain \\
\hline 35 & 1 & Sheet - shakings from inside \\
\hline
\end{tabular}

Table 4.1. Samples collected from the homicide scenario scenes. The 15 samples selected for immediate profiling are in bold print. Samples 27-35 relate to scene one but were collected last from items taken to the laboratory. 


\subsubsection{Decomposition Samples}

A group of five soil samples collected from under a decomposing body at the University of Tennessee's Anthropology Research Facility (refer section 7.1) were also used in this methodological survey. Each sample was collected at a different stage of decomposition, encompassing fresh, bloat, decay, dry and a control sample collected before the body was placed on the soil. These stages are discussed further in Chapter Seven. These samples were collected between December 1988 and October 1989 as part of a study collecting data on volatile fatty acid, and anion and cation release during decomposition (Vass et al., 1992). The samples were stored in a freeze-dried state.

\subsubsection{Soil DNA Profiling Method}

The general method that was used for profile generation is outlined in Chapter Three. The DNA polymerases and PCR recipes used in this experiment are outlined below, as is the similarity index used.

\subsubsection{AmpliTaq Gold DNA Polymerase}

AmpliTaq Gold DNA Polymerase Mastermix (Applied Biosystems, Australia) was chosen for use with the mock homicide scenario and decomposition samples because of its chemical hot start capability, which increases specific product yield. This polymerase is chemically modified, so that when the chemical moiety is attached to the enzyme, the polymerase is inactive. When optimal annealing temperatures are reached, the moiety is cleaved, activating the enzyme. It had previously been identified as successful for PCR amplification of DNA from soil samples (J Horswell, ESR Ltd., pers. comm.). The Amplitaq Gold Mastermix contained AmpliTaq Gold DNA Polymerase $(0.05 \mathrm{U} / \mu \mathrm{L})$, dNTPs $(400 \mu \mathrm{M}$ each), Gold Buffer $(30 \mathrm{mM}$ Tris/HCl $\mathrm{pH}$ 8.05, $100 \mathrm{mM} \mathrm{KCl})$ and $\mathrm{MgCl}_{2}(5 \mathrm{mM})$. 
Six positive control PCR reactions were run, additional to the 15 samples. These consisted of five randomly chosen soil samples spiked with 20 ng Escherichia coli genomic DNA, and one reaction with only E. coli DNA. A negative (reagent) control was also run. The spiked samples are valuable when it is suspected that PCR inhibitors, co-extracted with the DNA, may be present. For example, if neither the spiked nor unspiked samples amplify successfully, this indicates that PCR inhibitors capable of blocking the reaction may be present. If the spiked samples amplify but the unspiked do not, this suggests that there may be another problem with the sample, such as degraded template DNA. The PCR recipe is shown in Table 4.2 and the thermocycling regime in Table 4.3 .

\begin{tabular}{|l|l|}
\hline \multicolumn{1}{|c|}{ Component } & Volume/Amount \\
\hline AmpliTaq Gold Mastermix & $25 \mu \mathrm{L}$ \\
Primers: & \\
F63 FAM & $10 \mu \mathrm{m}$ \\
R1389 & $10 \mu \mathrm{m}$ \\
Template DNA & $20 \mathrm{ng}(1-22 \mu \mathrm{L})$ \\
$\mathrm{H}_{2} \mathrm{O}$ & Variable (to total $50 \mu \mathrm{L})$ \\
\hline Total volume & $50 \mu \mathrm{L}$ \\
\hline
\end{tabular}

Table 4.2. AmpliTaq Gold PCR recipe.

\begin{tabular}{|l|c|c|}
\hline Initial Denaturation & Time & Temperature \\
3 Step Cycling & $10 \mathrm{~min}$ & $94^{\circ} \mathrm{C}$ \\
Denaturation: & $1 \mathrm{~min}$ & $94^{\circ} \mathrm{C}$ \\
Annealing: & $1 \mathrm{~min}$ & $55^{\circ} \mathrm{C}$ \\
Extension: & $2 \mathrm{~min}$ & $72^{\circ} \mathrm{C}$ \\
Number of Cycles & 30 & \\
Final Extension & $10 \mathrm{~min}$ & $72^{\circ} \mathrm{C}$ \\
\hline
\end{tabular}

Table 4.3. AmpliTaq Gold thermocycling regime. 


\subsubsection{HotStarTaq DNA Polymerase}

HotStarTaq DNA Polymerase Mastermix (Qiagen) was also used during profiling of the homicide scenario and decomposition samples when AmpliTaq Gold polymerase was found to have limited success with DNA from soil (see section 4.4.2). The PCR recipe used is outlined in Table 4.4, and the thermocycling regime in Table 4.5. The Mastermix contained: 2.5 units of HotStarTaq DNA Polymerase, PCR buffer (Tris·Cl, $\left.\mathrm{KCl},\left(\mathrm{NH}_{4}\right)_{2} \mathrm{SO}_{4}, 15 \mathrm{mM} \mathrm{MgCl}_{2} ; \mathrm{pH} 8.7\left(20^{\circ} \mathrm{C}\right)\right)$ and $400 \mu \mathrm{M}$ of each dNTP.

\begin{tabular}{|l|l|}
\hline Component & Volume/Amount \\
\hline HotStarTaq Mastermix & $25 \mu \mathrm{L}$ \\
Primers: & \\
F63 FAM & $10 \mu \mathrm{m}$ \\
R1389 & $10 \mu \mathrm{m}$ \\
Template DNA & $20 \mathrm{ng}(1-22 \mu \mathrm{L})$ \\
$\mathrm{H}_{2} \mathrm{O}$ & Variable (to total $50 \mu \mathrm{L})$ \\
\hline Total volume & $50 \mu \mathrm{L}$ \\
\hline
\end{tabular}

Table 4.4. HotStarTaq DNA polymerase PCR recipe.

\begin{tabular}{|l|l|l|}
\hline Initial Denaturation & $15 \mathrm{~min}$ & $95^{\circ} \mathrm{C}$ \\
Denaturation: & $1 \mathrm{~min}$ & $94^{\circ} \mathrm{C}$ \\
Annealing: & $1 \mathrm{~min}$ & $55^{\circ} \mathrm{C}$ \\
Extension: & $1 \mathrm{~min}$ & $72^{\circ} \mathrm{C}$ \\
Number of Cycles & 30 & \\
Final Extension & $10 \mathrm{~min}$ & $72^{\circ} \mathrm{C}$ \\
\hline
\end{tabular}

Table 4.5. HotStarTaq thermocycling regime.

\subsubsection{Similarity Index}

Sorenson's Similarity Index (Sorenson, 1948) was used to determine the level of similarity between two sample profiles (Figure 4.6). This is the similarity index used in 
the T-RFLP analysis option on the Ribosomal Database Project II website (Maidak et al., 1999) and was also used by Horswell et al. (2002). An index value of 1 indicates an exact match between two profiles, and a value of zero, no similarity.

$$
\begin{aligned}
& S I=\frac{2 n(A B)}{n(A)+n(B)} \\
& \text { SI = Sorenson's Similarity Index } \\
& n(A B)=\text { Number of matching peaks } \\
& n(A)=\text { Number of peaks in profile A } \\
& n(B)=\text { Number of peaks in profile B }
\end{aligned}
$$

Figure 4.6. Sorenson's Similarity Index is calculated as the number of matching peaks in both profiles divided by the average number of peaks in the two profiles being compared.

\subsection{Results}

The processing of the samples collected during the homicide scenario raised some technical issues with the methodology. Many steps had to be repeated with modifications to enable progression to the next step. For example, when PCR inhibitors prevented successful amplification the first time, the PCR step was repeated using a different Taq polymerase. These modifications are noted where applicable.

\subsubsection{Soil Recovery and DNA extraction}

The amount of soil recovered from the shoes, clothing and vehicle varied in the mock homicide scenario. When less than $0.5 \mathrm{~g}$ was recovered, the whole sample was used for DNA extraction. The amount of soil used for DNA extraction for each sample is recorded in Table 4.6. 
DNA was obtained from all samples tested using the FastDNA SPIN kit for soil, even from samples smaller than the standard $0.5 \mathrm{~g}$. The range of total DNA amounts extracted from the soil samples was wide, ranging from 2600 to $61000 \mathrm{ng}$ (Table 4.6). The lowest yields corresponded to the smallest amounts of soil used in the extraction, but if the samples were above $0.2 \mathrm{~g}$ in size, the yield of DNA was not proportional to the sample size.

\begin{tabular}{|c|c|c|c|}
\hline Sample No. & Object & $\begin{array}{l}\text { Soil used in } \\
\text { extraction (g) }\end{array}$ & $\begin{array}{l}\text { Total DNA } \\
\text { extracted } \\
\text { (ng) }\end{array}$ \\
\hline & Scene 1 & & \\
\hline 1 & Soil (a) & 0.5 & 12800 \\
\hline 2 & Soil (b) & 0.5 & 42150 \\
\hline 3 & Soil (c) & 0.5 & 28050 \\
\hline 14 & Soil (d) & 0.5 & 8450 \\
\hline 29 & Victim right shoe heel & 0.16 & 2600 \\
\hline 31 & Victim overalls sleeve soil stain & 0.11 & 4100 \\
\hline \multirow[t]{2}{*}{34} & Assailant overalls knee soil stain & 0.19 & 5550 \\
\hline & Scene 2 & & \\
\hline 15 & Shoe print & 0.5 & 23150 \\
\hline 18 & Tyre Print & 0.5 & 61000 \\
\hline 19 & Vehicle left front wheel arch & 0.28 & 39000 \\
\hline 20 & Vehicle left front tyre & 0.31 & 37900 \\
\hline 22 & Vehicle driver's footwell & 0.5 & 31450 \\
\hline 23 & Vehicle left front side & 0.24 & 21600 \\
\hline 25 & Assailant left shoe & 0.38 & 33450 \\
\hline \multirow[t]{2}{*}{26} & Assailant right shoe & 0.4 & 28200 \\
\hline & Decomposition & & \\
\hline D1 & Control & 0.5 & 16700 \\
\hline D2 & Fresh & 0.5 & 14350 \\
\hline D3 & Bloat & 0.5 & 23400 \\
\hline D4 & Decay & 0.5 & 30850 \\
\hline D5 & Dry & 0.5 & 29050 \\
\hline
\end{tabular}

Table 4.6. The amount of soil used for DNA extraction and the amount of DNA extracted. 
The DNA solution extracted from all samples was dark brown in colour, suggesting that coloured substances, probably humic acids, had been co-purified.

\subsubsection{Amplification}

The initial PCR amplification using the standard protocol was successful for all of the samples derived from scene two (the sports field). None of the scene one and decomposition samples, however, gave PCR products, with the exception of three of the five extra reactions that were spiked with E. coli DNA (Table 4.7). When run on an agarose gel, however, two of the spiked reaction products gave a notably weaker positive result (Appendix 2.2).

Because PCR products were gained for some of the scene two E. coli spiked samples and not the un-spiked counterparts, it was concluded that the DNA extracted from scene one samples was probably of low quality or degraded, and that there was insufficient template DNA to give a PCR product. It was also proposed, however, that this result could be explained by the action of co-extracted PCR inhibitors such as humic acids (see section 4.5 for discussion).

Performing the PCR reactions again using AmpliTaq Gold DNA polymerase yielded the same result, with only scene two samples amplifying. The PCR products gained were cleaned with the QIAquick PCR Purification Kit as detailed in Chapter 3. 


\begin{tabular}{|c|c|c|c|c|c|}
\hline \multicolumn{2}{|l|}{ Sample } & \multicolumn{2}{|c|}{ AmpliTaq Gold } & \multicolumn{2}{|c|}{ HotStarTaq } \\
\hline & & Unspiked & Spiked Control & Unspiked & Spiked Control \\
\hline Number & Scene One & & & & \\
\hline 1 & Soil (a) & $\mathrm{N}$ & - & $\mathrm{Y}$ & - \\
\hline 2 & Soil (b) & $\mathrm{N}$ & Weak Y & $\mathrm{Y}$ & $\mathrm{Y}$ \\
\hline 3 & Soil (c) & $\mathrm{N}$ & - & $\mathrm{Y}$ & - \\
\hline 14 & Soil (d) & $\mathrm{N}$ & - & $\mathrm{Y}$ & - \\
\hline 29 & Victim's right shoe & $\mathrm{N}$ & Weak Y & $\mathrm{Y}$ & $\mathrm{Y}$ \\
\hline 31 & $\begin{array}{l}\text { Victim overalls sleeve soil } \\
\text { stain }\end{array}$ & $\mathrm{N}$ & $\mathrm{N}$ & $\mathrm{N}$ & $\mathrm{N}$ \\
\hline \multirow[t]{2}{*}{34} & $\begin{array}{l}\text { Assailant overalls knee soil } \\
\text { stain }\end{array}$ & $\mathrm{N}$ & $\mathrm{N}$ & $\mathrm{Y}$ & $\mathrm{Y}$ \\
\hline & Scene Two & & & & \\
\hline 15 & Shoe print & $\mathrm{Y}$ & - & $\mathrm{Y}$ & - \\
\hline 18 & Tyre print & $\mathrm{Y}$ & $\mathrm{Y}$ & $\mathrm{Y}$ & $\mathrm{Y}$ \\
\hline 19 & Vehicle left front wheel arch & $\mathrm{Y}$ & - & $\mathrm{Y}$ & - \\
\hline 20 & Vehicle left front tyre & $\mathrm{Y}$ & - & $\mathrm{Y}$ & - \\
\hline 22 & Vehicle driver's footwell & $\mathrm{Y}$ & - & $\mathrm{Y}$ & - \\
\hline 23 & Vehicle left front side & $\mathrm{Y}$ & - & $\mathrm{Y}$ & - \\
\hline 25 & Assailant left shoe & $\mathrm{Y}$ & - & $\mathrm{Y}$ & - \\
\hline \multirow[t]{2}{*}{26} & Assailant right shoe & $\mathrm{Y}$ & - & $\mathrm{Y}$ & - \\
\hline & Decomposition & & & & \\
\hline D1 & Control & $\mathrm{N}$ & - & $\mathrm{Y}$ & - \\
\hline D2 & Fresh & $\mathrm{N}$ & - & $\mathrm{N}$ & - \\
\hline D3 & Bloat & $\mathrm{N}$ & - & $\mathrm{N}$ & - \\
\hline D4 & Decay & $\mathrm{N}$ & - & $\mathrm{Y}$ & - \\
\hline D5 & Dry & $\mathrm{N}$ & - & $\mathrm{Y}$ & - \\
\hline
\end{tabular}

Table 4.7. PCR amplification success using AmpliTaq Gold DNA Polymerase Mastermix and

HotStarTaq DNA Polymerase Mastermix. $Y=P C R$ successful, $N=P C R$ unsuccessful, - = not performed.

Because of the limited number of successful PCR reactions, the DNA extraction and amplification steps were identified as part of the methodology requiring further development. All of the above samples were PCR amplified using a different Taq polymerase, HotStarTaq DNA Polymerase (Qiagen). This proved to have better success rates with DNA templates from soil samples and enabled the profiling methodology to be continued. The HotStarTaq polymerase successfully amplified all but one sample 
from the homicide scenario (scenes one and two), and two of the five decomposition samples (Table 4.7). The homicide scenario sample that did not produce a PCR product was that obtained from the victim's overalls sleeve soil stain (sample number 31 ). This sample is the one that had the smallest amount of soil and the second lowest total extracted DNA yield (Table 4.6).

\subsubsection{DNA Quantitation}

The amount of PCR product generated by each successful reaction using the AmpliTaq Gold polymerase was relatively low. After the DNA wash step, less than $150 \mathrm{ng}$ of purified DNA was recovered. The digestion step required $150 \mathrm{ng}$ of DNA, so analysis was not continued from this point. The PCR reactions that were successful using HotStarTaq DNA Polymerase did yield sufficient product for cleaning and restriction enzyme digestion, so analysis was continued for these samples.

\subsubsection{Restriction Enzyme Digestion}

The restriction enzyme digestion of the PCR products appeared to work well. A small aliquot of digested DNA $(3 \mu \mathrm{L})$ from each sample was run on a $2 \%$ agarose gel (Appendix 1.3) to check that the digestion worked before proceeding to the next step. Numerous bands of different sized DNA could be seen for each sample, indicating that successful digestion of the PCR products had occurred. Later analysis with the Genetic Analyser confirmed that the choice of restriction enzyme was sound, with a sufficient

number of different sized terminal restriction fragments being generated for comparison. 


\subsubsection{Fragment Detection \& Profile Generation}

The initial DNA end-fragment detection and community DNA profile generation was successful using the Genetic Analyser and Genescan software. Peaks over 100 rfu were present in all of the profiles generated. As the homicide scenario and decomposition samples were the first group to be profiled, it was difficult to know whether the number of peaks and the relative fluorescence unit levels were high enough for successful comparison. The total number of peaks within the $100-450 \mathrm{bp}$ range and the number of these over the minimum inclusion threshold of $100 \mathrm{rfu}$ are tabulated in Table 4.8. The total number of peaks present in each profile ranged from 3 to 32 , with between 1 and 20 over the minimum analysis inclusion threshold of $100 \mathrm{rfu}$.

The cumulative peak height or total fluorescence in profiles (including only peaks between 100 - 450 bp in size) varied between samples, as is shown in Table 4.8. The homicide scenario sample collected from the victim's right shoe (sample 29) gave the lowest amount of extracted DNA (Table 4.6), and it also had the lowest number of peaks over $100 \mathrm{bp}$ and the lowest cumulative peak height (Table 4.8). However, for the other samples, there does not appear to be any identifiable relationship between the amount of soil used for extraction, peak number or cumulative fluorescence (Table 4.8). The tyre print (sample 18), for example, had the third lowest DNA yield for all the samples that amplified, but had the fifth highest total number of peaks. The differences between profiles in the number of peaks and cumulative fluorescence may be caused by variations in the uptake of DNA between samples by the Genetic Analyser. The presence of ions in the digested DNA solution can interfere with the uptake of DNA using electrokinetic injection because of preferential injection of higher charge-to-mass molecules (for example, $\mathrm{Cl}^{-}$ions). This was identified as an issue that needed to be addressed in method development. 


\begin{tabular}{|c|c|c|c|c|}
\hline \multicolumn{2}{|c|}{ Sample } & \multirow{2}{*}{$\begin{array}{c}\text { Total no. } \\
\text { peaks in } \\
\text { profile } \\
\text { between } \\
\text { 100-450 bp } \\
15\end{array}$} & \multirow{2}{*}{$\begin{array}{c}\text { No. peaks } \\
\text { between 100-450 } \\
\text { bp and over } \\
\mathbf{1 0 0} \text { rfu. } \\
10\end{array}$} & \multirow{2}{*}{$\begin{array}{c}\text { Cumulative peak } \\
\text { height (rfu) }\end{array}$} \\
\hline 1 & Soil at scene 1 (a) & & & \\
\hline 2 & Soil at scene 1 (b) & 19 & 12 & 6414 \\
\hline 3 & Soil at scene 1 (c) & 10 & 5 & 4588 \\
\hline 14 & Soil at scene 1 (d) & 3 & 3 & 2208 \\
\hline 29 & Victim right shoe & 7 & 1 & 612 \\
\hline 34 & $\begin{array}{l}\text { Assailant overalls knee soil } \\
\text { stain }\end{array}$ & 9 & 4 & 3001 \\
\hline 15 & Shoe print scene 2 & 29 & 20 & 5691 \\
\hline 18 & Tyre print scene 2 & 27 & 14 & 4917 \\
\hline 19 & Vehicle left front wheel arch & 19 & 7 & 2058 \\
\hline 20 & Vehicle left front tyre & 24 & 13 & 4418 \\
\hline 22 & Vehicle driver's footwell & 21 & 8 & 2449 \\
\hline 23 & Vehicle left front side & 31 & 14 & 4973 \\
\hline 25 & Assailant left shoe & 32 & 17 & 5728 \\
\hline 26 & Assailant right shoe & 29 & 12 & 4266 \\
\hline D1 & Decomposition Control & 20 & 10 & 3292 \\
\hline D4 & Decomposition Decay & 26 & 17 & 10667 \\
\hline D5 & Decomposition Dry & 23 & 13 & 8837 \\
\hline
\end{tabular}

Table 4.8. Total number of peaks and number of peaks over 100 fluorescence units, as well as the cumulative peak height for homicide scenario and decomposition samples.

The electropherograms generated from DNA successfully amplified by PCR using the HotStarTaq polymerase are shown in Figures 4.7, 4.8 and 4.9. Scene two sample profiles displayed more diversity with more peaks present than in the scene one profiles. Scene one sample profiles appear to have fewer but higher peaks than those from scene two. Visually, the profiles from the two scenes appear to have distinct patterns, with the scene one samples tending to have two or three dominant peaks around $200 \mathrm{bp}$ in size and the scene two profiles typically having large peaks at 171 and $197 \mathrm{bp}$. 

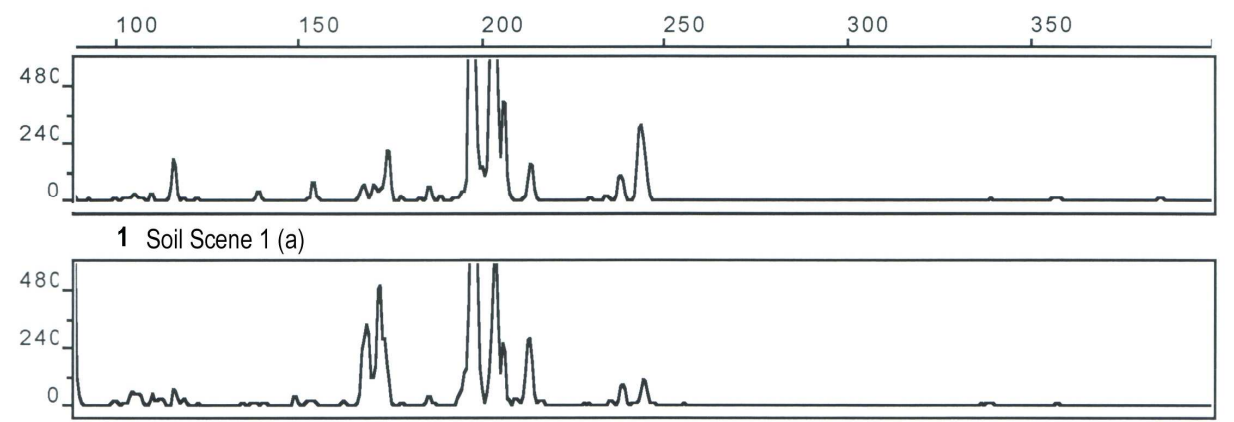

2 Soil Scene 1 (b)
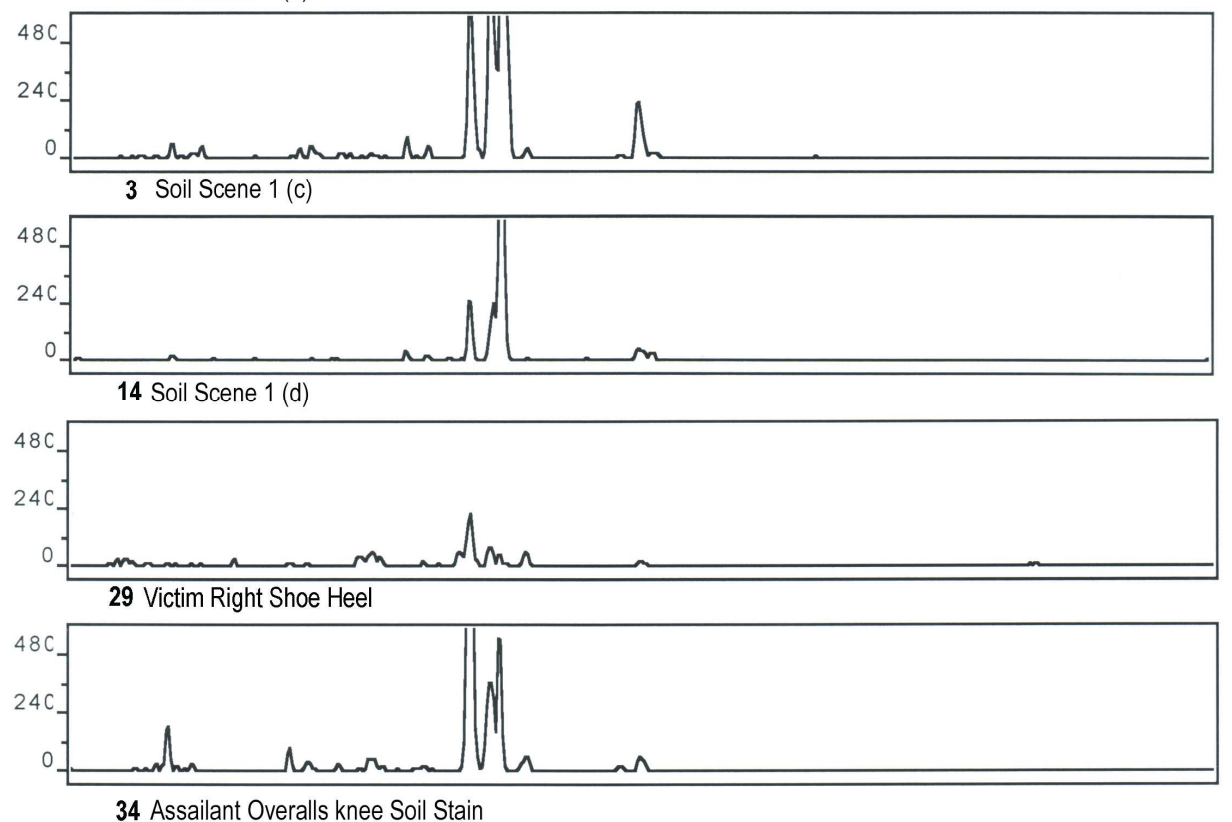

Figure 4.7. Profiles from samples that originated from scene one of the homicide scenario.

The two samples with the lowest total fluorescence (sample 29, victim's right shoe heel from scene one and sample 19, vehicle left front wheel arch from scene two) gave electropherograms that were much lower than those from the other samples (Figures 4.7 and 4.8). Both had peaks that were higher than the 100 rfu cut-off value, although the victim right shoe heel had only one. Profiles with many peaks are desirable to provide greater discrimination between soils. Samples with few peaks could be excluded from comparisons if it was felt that they were not adequate. Alternatively, re-profiling of the sample could be attempted, although better quality profiles may not necessarily be obtained. 

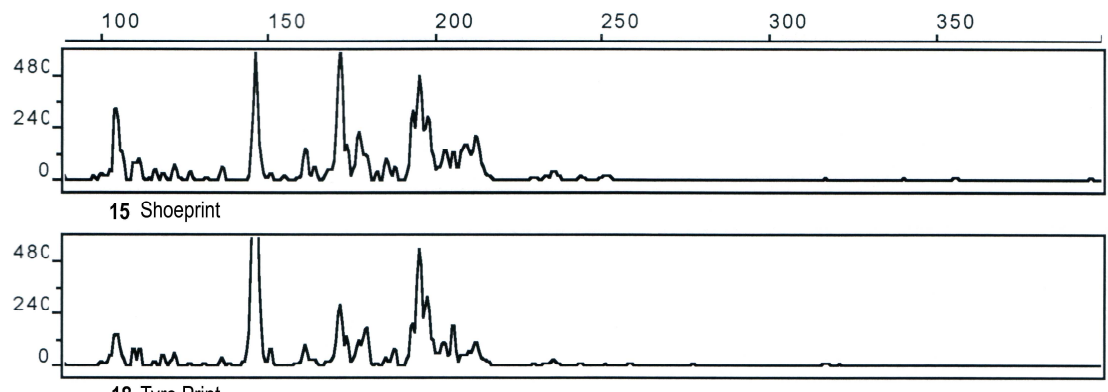

18 Tyre Print
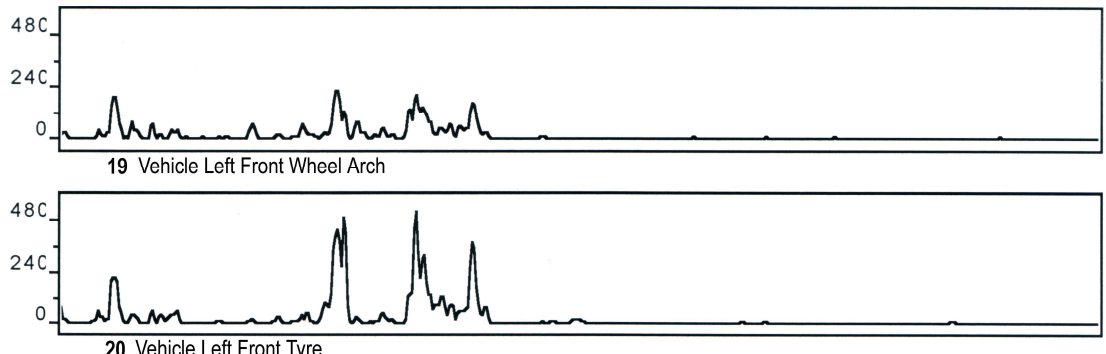

20 Vehicle Left Front Tyre

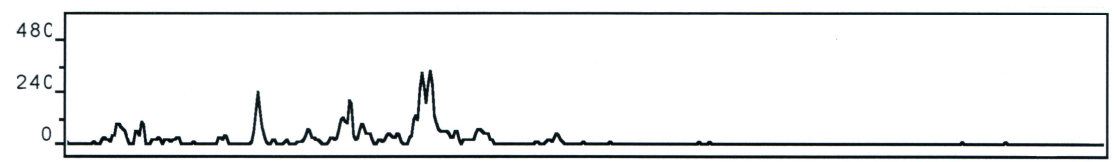

22 Vehicle Driver's Footwell

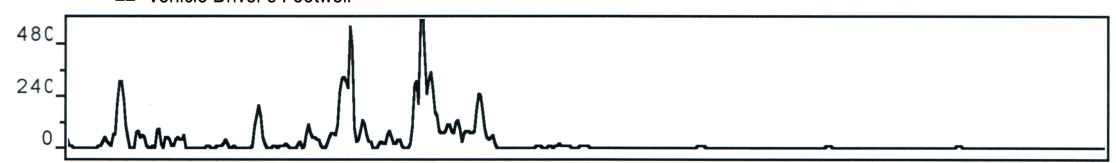

23 Vehicle Left Front Side

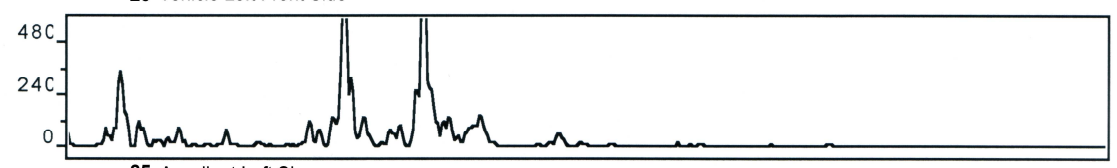

25 Assailant Left Shoe

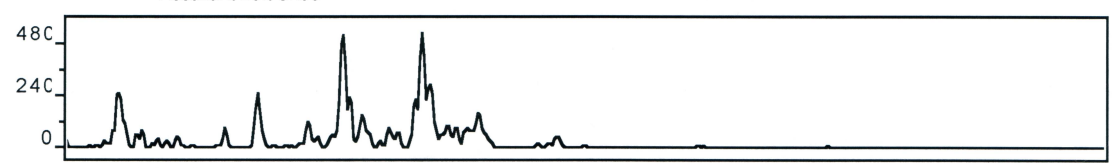

26 Assailant Right Shoe

Figure 4.8. Profiles from scene two of homicide scenario.
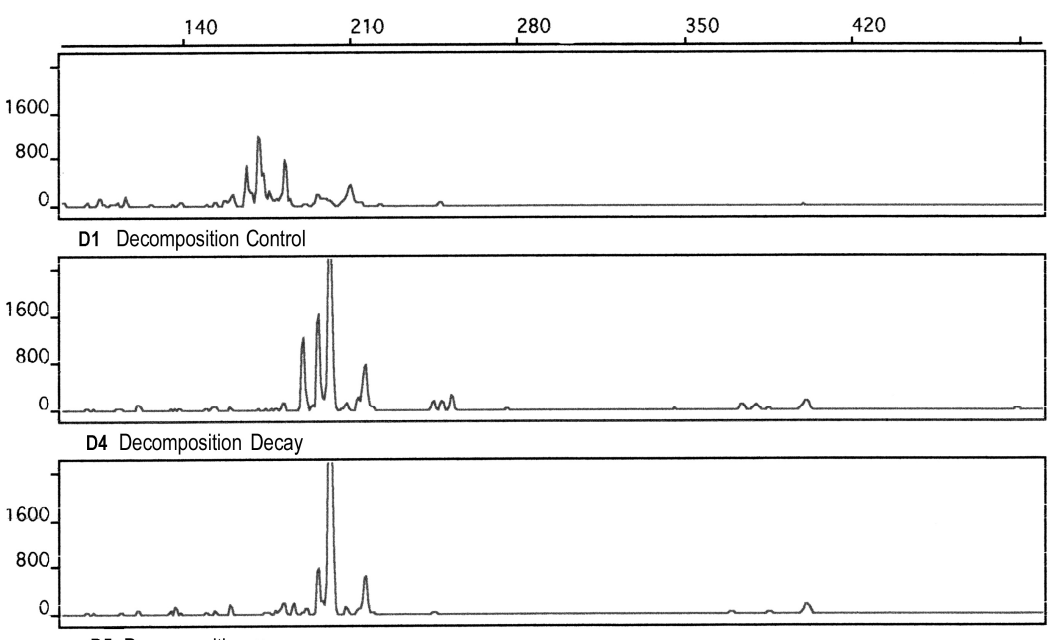

D5 Decomposition Dry

Figure 4.9. Profiles from successfully amplified decomposition samples. 


\subsubsection{Data Analysis}

The first major problem encountered with data analysis of the homicide scenario and decomposition sample profiles was the time-consuming and error-prone process of manually aligning data points. Hours were spent aligning the group of profiles against each other and then counting up the number of peaks and calculating the Sorenson's Index. It was quickly decided that an automated analysis approach would be needed to handle the large number of samples that would be processed for this project. If the technique is to be used for routine forensic casework, data analysis needs to be rapid and accurate.

The second issue to arise was the comparison index used. The samples that were collected from the same scene appeared, on average, to be only a little more similar to each other than to samples collected from the other scene (Table 4.9). The mean Sorenson's Similarity index value for samples collected from scene one compared with other scene one samples was $0.47 \pm 0.19(n=15)$. For scene two samples the mean was $0.67 \pm 0.10(n=28)$, and when samples from different scenes are compared, the mean was $0.25 \pm 0.14(n=40)$. Some samples that were expected to have similar profiles due to their common origin site gave high similarity index values, while others gave much lower results. For example, soil samples 1 and 2 from scene one were collected only centimetres apart, and by visual comparison the two profiles look fairly similar (Figure 4.7), but they give a Sorenson's similarity index of only 0.36. It is possible that the simplicity of the Sorenson's Index makes it sensitive to small changes in the bacterial community. This suggested that alternative comparison indices needed to be investigated. 


\begin{tabular}{|l|l|l|l|l|l|l|l|l|l|l|l|l|l|}
\hline & $\mathbf{1}$ & $\mathbf{2}$ & $\mathbf{3}$ & $\mathbf{1 4}$ & $\mathbf{2 9}$ & $\mathbf{3 4}$ & $\mathbf{1 5}$ & $\mathbf{1 8}$ & $\mathbf{1 9}$ & $\mathbf{2 0}$ & $\mathbf{2 2}$ & $\mathbf{2 3}$ & $\mathbf{2 5}$ \\
\hline 1 Soil at scene 1 (a) & & & & & & & & & & & & & \\
\hline 2 Soil at scene 1 (b) & 0.36 & & & & & & & & & & & & \\
\hline 3 Soil at scene 1 (c) & 0.53 & 0.47 & & & & & & & & & & & \\
\hline 14 Soil at scene 1 (d) & 0.46 & 0.40 & 0.75 & & & & & & & & & & \\
\hline 29 Victim right shoe & 0.18 & 0.15 & 0.33 & 0.50 & & & & & & & & & \\
\hline 34 Assailant overalls knee soil & 0.57 & 0.38 & 0.67 & 0.86 & 0.4 & & & & & & & & \\
\hline 15 Shoe print scene 2 & 0.20 & 0.44 & 0.32 & 0.17 & 0.10 & 0.25 & & & & & & & \\
\hline 18 Tyre print scene 2 & 0.33 & 0.46 & 0.32 & 0.24 & 0.13 & 0.22 & 0.77 & & & & & & \\
\hline 19 Vehicle left front wheel arch & 0.24 & 0.53 & 0.17 & 0.2 & 0.00 & 0.00 & 0.52 & 0.67 & & & & & \\
\hline 20 Vehicle left front tyre & 0.26 & 0.64 & 0.22 & 0.13 & 0.14 & 0.24 & 0.60 & 0.67 & 0.70 & & & & \\
\hline 22 Vehicle driver's footwell & 0.22 & 0.40 & 0.15 & 0.18 & 0.22 & 0.17 & 0.57 & 0.64 & 0.67 & 0.48 & & & \\
\hline 23 Vehicle left front side & 0.33 & 0.54 & 0.32 & 0.24 & 0.13 & 0.22 & 0.76 & 0.79 & 0.67 & 0.74 & 0.64 & & \\
\hline 25 Assailant left shoe & 0.22 & 0.48 & 0.18 & 0.1 & 0.11 & 0.19 & 0.65 & 0.58 & 0.58 & 0.67 & 0.48 & 0.71 & \\
\hline 26 Assailant right shoe & 0.27 & 0.5 & 0.24 & 0.13 & 0.15 & 0.25 & 0.75 & 0.77 & 0.74 & 0.72 & 0.70 & 0.92 & 0.76 \\
\hline
\end{tabular}

Table 4.9. Sorenson's Similarity Index for homicide scenario samples. Samples highlighted in yellow are from scene 1 and those in blue, scene 2.

The Sorenson's Similarity Index values calculated for comparisons between the decomposition samples are shown in Table 4.10.

\begin{tabular}{|l|c|}
\hline Samples & \multicolumn{1}{l|}{$\begin{array}{l}\text { Sorenson's } \\
\text { Index }\end{array}$} \\
\hline Control (D1) \& Decay (D4) & 0.21 \\
\hline Control (D1) \& Dry (D5) & 0.29 \\
\hline Decay (D4) \& Dry (D5) & 0.53 \\
\hline
\end{tabular}

Table 4.10. Similarity Index values between decomposition sample profiles.

The degree of similarity indicated by the Sorenson's Index values (Table 4.10) is very low between the control and the two other profiles. It is also quite low between the decay and dry stage profiles. By looking at the electropherograms (Figure 4.9), there is a distinct difference between the control and the other two profiles, which is perhaps not reflected by the similarity index values. 


\subsection{Discussion}

The experiment described in this chapter provided a good opportunity to test the bacterial community profiling technique developed by Horswell et al. (2002) and identify, through the use of realistic forensic soil samples, the strengths and weaknesses of the protocol. The exercise proved to be highly successful, with two major areas of concern highlighted.

Perhaps the most important issue was the failure of eight of the 20 DNA extracts to generate PCR products using AmpliTaq Gold polymerase. Soil is known to be a difficult substrate to amplify DNA from, because of the presence of inhibitors, particularly humic acids (Tsai and Olson, 1992a; Chandler et al., 1997b; Wilson, 1997). Humic acids are soil components that are readily extracted under alkaline conditions and are thought to be inhibitory to PCR reactions (Tsai and Olson, 1992b). They are mixtures of polyphenolic substances produced during the degradation of plant material (Kreader, 1996a) and are known to give the DNA solution extracted from environmental samples a brown hue (Yeates et al., 1998). The failure to generate PCR products from the template DNA from some of the samples indicated that the DNA extracted from the soil samples may have been degraded, and the brown colouration of the DNA solution suggests inhibitors may also have been present in the DNA extracts, which may have further retarded PCR amplification. A change of polymerase from AmpliTaq Gold to HotStarTaq increased the number of samples from which PCR product was obtained, but some PCR reactions still failed, suggesting that additional investigation and development was required in the areas of DNA extraction and amplification. This relative success may be facilitated by HotStarTaq being able to amplify DNA from a more degraded template than could AmpliTaq Gold. It may also 
be less affected by PCR inhibitors such as humic acids. The template DNA in the spiked reactions may have acted as a sink for the humic acids, so that when the $E$. coli DNA was added, there was sufficient template for the reaction to proceed to some extent. This explanation is supported by the weaker positive electrophoresis signal generated by the spiked samples.

The second area of concern highlighted was the data analysis, particularly the manual calculation of comparison indices, and the need to explore the use of different comparison indices. Repetitive and time-consuming manual data analysis runs the risk of introducing calculation errors and severely restricts the number of calculations that can be performed. One of the main reasons for developing this molecular soil comparison technique is rapidity. If the subsequent analysis is time-consuming, the technique loses much of its appeal to the forensic community. Since numerous comparisons were expected to be calculated during the course of this research, and would be required in forensic case-work, it became apparent that an automated approach was required. Recognition that the Sorenson's Index might not be optimal (section 4.4.6) for accurately comparing different profiles also indicated that any automated calculation programme would require a degree of flexibility to allow for development of the comparison methods.

This analytical methodology review also, importantly, identified a number of areas where further investigation was required. The mock homicide scenario samples were all profiled immediately after collection, (i.e. no storage was required). The decomposition samples however were freeze dried immediately after collection and stored for 14 years before extraction. The difficulty in amplifying these samples may have been a result of this treatment, raising the need to determine whether different 
storage techniques affect the bacterial population or the success of PCR. A standard storage method would certainly need to be developed for actual case situations when the police would be collecting and storing the soil samples before analysis.

The failure of the victim sleeve soil stain sample (number 31) to amplify (for gel photo see Appendix 2.2) indicated that some forensic soil samples might be too small to successfully profile, as this sample contained the smallest amount of recovered soil. Determination of the minimum amount of soil required for a successful profile is also required. As this sample was a stain on fabric, the ability to recover enough soil from fabric stains will be important. Fabrics have different properties, and some may be more difficult to recover soil from than others. If the soil recovery levels are too low for profiling, the technique would not be practical for soil comparisons using stains. Soil stained clothing is often encountered in forensic casework so the inability of the technique to utilise these would be an important limitation.

This review also confirmed that bacterial community variation between soil samples from the same and different sites, and variation introduced through the profiling methodology, need to be investigated and quantitated. The variation between samples from the same site was high, suggesting that soil bacterial communities might vary considerably over short distances. The possibility that variation is introduced through the methodological procedures must also be considered and determined before the technique can be routinely used for case-work. 


\section{METHOD DEVELOPMENT}

\subsection{General Introduction}

The mock homicide scenario and decomposition samples described in Chapter 4 were effective for demonstrating the potential of soil bacterial community DNA profiling as a forensic tool. The experiment in Chapter 4 also highlighted some important issues and problems with the basic methodology that could limit its usefulness in forensic casework. It must be noted that method development was performed throughout the duration of the experimental work described in this thesis as new problems with the methodology were encountered. The improvements made to the methodology throughout the whole project are described in this chapter. Each step of the general experimental protocol described in Chapter 3 was tested and reviewed in Chapter 4, and some modifications to the methodology were made to enable profiles to be obtained. This chapter explains all the further modifications and alternatives sought to optimise each step and to increase the rate of success in obtaining soil DNA profiles. The most problematic steps in the protocol, DNA extraction and PCR amplification, and profile generation and analysis, were identified in Chapter 4 and these became the primary focus of later development work. Other areas of uncertainty were also identified and resolved, including the best method/conditions for soil storage and the minimum amount of soil required to produce a profile. A much improved, more reliable protocol was developed through this process which enables successful profiling of a larger proportion of soil samples.

The following section, 5.2, describes the problems associated with PCR amplification of DNA templates extracted from soil, and discusses the extra methodological steps that were tested to resolve these issues. Sections 5.3 and 5.4 deal with fragment detection 
and generation, and data analysis procedures and the steps taken to improve these areas. Section 5.5 describes the experiment performed to determine the best storage conditions for soil samples, and section 5.6 covers the other, more minor improvements made to the methodology, such as in the DNA quantitation step. Section 5.6 also details experiments performed to determine the minimum amount of soil required to generate a profile, to improve sample homogenisation, and whether sufficient soil can be recovered from clothing stains to generate a DNA profile of the soil bacterial community.

\subsection{Factors Affecting Amplification}

\subsubsection{Review of PCR Inhibition}

The failure to consistently generate PCR products was a major problem with the existing methodology (section 4.4.2). Amplification of 16S rDNA targets from scene two of the homicide scenario described in Chapter 4 (section 4.3.1) but not scene one when using AmpliTaq Gold DNA polymerase, was the first evidence of this problem. However, switching to HotStarTaq vastly improved the success rate (Table 4.9). Improving the success rate for amplification was an important part of the method development because failure of the PCR reactions was ultimately identified as the biggest barrier to successful profiling.

Inhibition of PCR by contaminating substances in the DNA extracts is not only a problem in soil molecular analysis, but is also widely recognised as a serious problem when working with other sources such as blood and food samples. A huge range of substances that can inhibit PCR have been identified, including haemoglobin, urea, heparin, various organic and phenolic components, glycogen, fats, humic acids, heavy metals, disposable laboratory glove powder, various detergents and laboratory reagents, 
and many as yet unidentified substances (Wilson, 1997). Inhibitors act by degrading or sequestering the nucleic acid template, or by inhibiting the polymerase enzyme. Nonspecific blocking of nucleic acid can be caused by cellular debris, proteins and polysaccharides, as they make the DNA unavailable to the polymerase enzyme. Some inhibitors may sequester $\mathrm{Mg}^{2+}$ ions which are a vital cofactor for polymerase (Satsangi et al., 1994).

Soil is known to contain substances which are inhibitory to PCR, and many studies have documented difficulty in amplifying DNA from microbes in soil (Kreader, 1996b; Vaneechoutte and Van Eldere, 1997; Kramer et al., 2002; Braid et al., 2003). Humic acids are the most commonly reported inhibitors in soil samples (Wilson, 1997), and are thought to interfere with polymerase/DNA interaction, possibly by bonding with the DNA or the polymerase enzyme (Young et al., 1993). They may also denature DNA by bonding to amides, or oxidising to form a quinone which covalently bonds to DNA and proteins (Young et al., 1993). Humic acids, and the related fulvic acids, are heterogenous complexes of organic residues that are resistant to decay. The precise chemical composition of humic and fulvic acids remains unknown, but many of their properties have been determined. A theoretical model of the chemical groups and structures likely to be found in humic acids is shown in Figure 5.1.

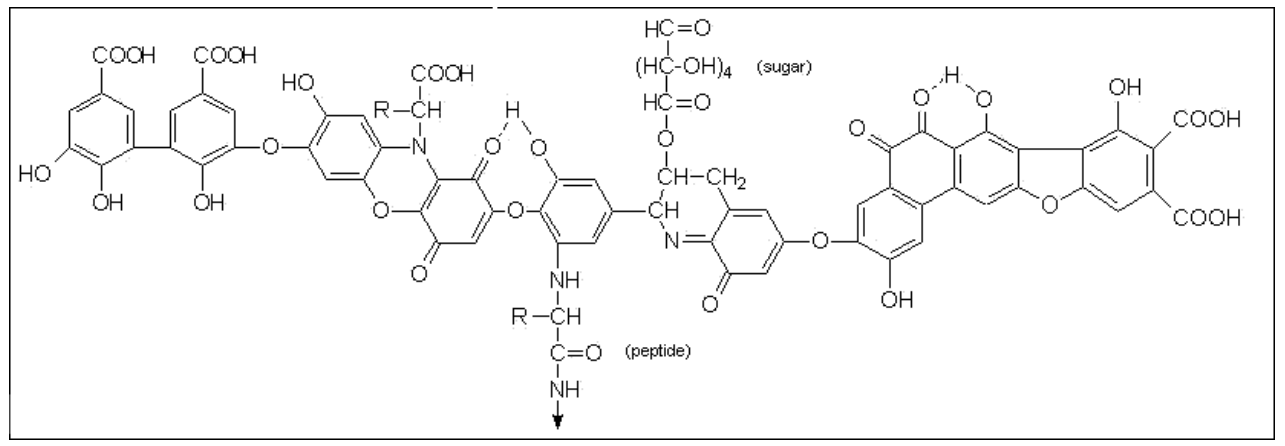

Figure 5.1. Hypothetical model structure of humic acid (Stevenson, 1982). 
Many substances originating from human clinical samples have also been found to have inhibitory actions on PCR. Soil samples collected from under decomposing bodies are likely to contain not only the endogenous soil derived PCR inhibitors such as humic acids, but also those released from the body. The use of PCR with template DNA from various clinical samples has enabled detection of a number of these body derived inhibitors, such as haemoglobin and its breakdown products, various other proteins, urea, $\mathrm{Ca}^{2+}$ and heparin (Wilson, 1997). The decomposition process, however, is likely to produce far more inhibitors than just these compounds as the body is broken down. Soil samples collected from under a decomposing body (Chapter 7 and section 4.4.3) often contained a white, waxy substance, much of which floated to the top of the sample during the early steps of the DNA extraction. This is likely to have been lipids, or fats, from the body. Lipids are sometimes converted into adipocere or 'grave wax' during decomposition of the body when conditions are favourable (usually moist, anaerobic conditions (Forbes et al., 2002)), so it is possible that some of this adipocere-like substance was also contributing to PCR inhibition.

Two approaches were used in an attempt to overcome the problem of PCR inhibition: improving the purity of the DNA used for PCR by removing contaminants, and optimising the PCR itself. Many different products and techniques were tried until a reliable combination was found.

\subsubsection{Improving DNA Template Purity}

One direct way of improving PCR success is to reduce co-extraction of inhibitory substances during the DNA extraction procedure. Ideally, the extracted DNA should be as pure as possible containing few, if any, co-extracted substances. The wide range of 
substances present in soil and the interactions that can occur between DNA, soil and cellular lysate components means the extraction process rarely extracts DNA alone. The presence of significant humic acid contamination can be detected visually, as they give the sample a brown hue. Many other contaminants in DNA preparations, however, cannot be detected so easily. Failure of the amplification reaction was often the only indication of low DNA purity.

To increase template DNA purity, a number of methods were tested. Extra steps were added to the FastDNA Spin Kit for Soil protocol which had previously been identified as effective and reliable ( $\mathrm{J}$ Horswell, ESR Ltd., pers. comm.). Efforts were concentrated primarily on improving this kit rather than duplicating work already completed, although two alternative extraction kits, the DNeasy Tissue Kit (Qiagen) and the tissue FastDNA Kit (QBIOgene) were also tested.

A panel of five soil samples were chosen to test the additional steps and alternative kits. All five of these samples had previously yielded large quantities of extracted DNA template, but the DNA templates had failed to amplify in all five instances (no PCR product was seen when run on an agarose gel). Repeating the extraction and amplification steps gave similar negative results. Three of these samples were collected from under decomposing cadavers at the University of Tennessee's Anthropological Research Facility (see section 7.3), while the remaining two were soil samples collected in New Zealand (Table 5.1). Test panel sample one was used in the survey of the analytical methodology in Chapter 4 (sample D3, Table 4.7). The other two decomposition samples were from the post mortem interval experimental work described in detail in Chapter 7 (section 7.3). 


\begin{tabular}{|c|l|}
\hline $\begin{array}{c}\text { Test Panel } \\
\text { Sample no. }\end{array}$ & Sample type \\
\hline TP-1 & Decomposition - Bloat stage (Sample D3, Table 4.7) \\
\hline TP-2 & Decomposition (body B, sample 13) \\
\hline TP-3 & Decomposition (body A, sample 19) \\
\hline TP-4 & NZ soil (Otaki) \\
\hline TP-5 & NZ soil (Lincoln) \\
\hline
\end{tabular}

Table 5.1. Soil samples used for DNA extraction method modification testing.

The New Zealand soil samples used were collected from Otaki and Lincoln as part of an unrelated soil study (provided by Dr Stephanie Watson, ESR Ltd.) but template DNA extracted from these samples repeatedly failed to amplify. These five test panel samples were all used to test most of the method modifications, although the sodium phosphate buffer (section 5.2.2.1.2) and cetyl tri-methyl ammonium bromide (section 5.2.2.1.3) steps were tested using only three decomposition samples (TP-1 and two other decomposition samples, D2 and D4, see Table 4.7). The two extraction kits (section 5.2.2.2) were tested using only two decomposition samples each (samples TP-2 and TP-3). One step, that was found to be successful, was tested further with additional soil samples. These samples were also collected at the University of Tennessee's Anthropological Research Facility, and are detailed in section 5.2.2.1.6.

\subsubsection{Extra Extraction Steps}

Eight extra steps were sequentially tested as additions to the existing DNA extraction protocol (section 3.2.2).

\subsection{Repeated Wash Steps}

Two wash steps in the FastDNA Spin Kit protocol (Appendix 1.1) were repeated during DNA extraction. It was hoped that by repeating wash steps, any residual soluble or loosely bound contaminants that may have been missed in the first wash would be 
removed. The repeated steps were: an extra salt/ethanol wash solution (SEW-M) wash step and an extra protein precipitating solution (PPS) wash (see FastDNA Spin Kit protocol - Appendix 1.1). Only one of the five test panel samples (TP-4) yielded a PCR product from the template DNA extracted using these additional washes (gel photo Appendix 2.4). These extractions yielded much less DNA than previous extractions from the same samples, suggesting that these extra washes may not be a suitable technique, as optimal DNA yields are desirable for obtaining representative profiles.

\subsection{Sodium Phosphate Buffer (SPB) Incubation}

Addition of an aqueous extraction step with sodium phosphate buffer (SPB) prior to DNA purification was tested. Clay and organic particles in soil (such as humic acids) are known to bind to extracellular DNA (Crecchio and Stotzky, 1998), but phosphate buffer provides an alternative group to bind the organic particle, leaving the DNA free in solution. Sodium ions bind the negative phosphate groups on the DNA molecules, further protecting them from binding with soil particles and assisting with DNA aggregation. The use of phosphate buffers is common in DNA extraction from soil (Miller et al., 1999). The protocol involved incubating the soil with sodium phosphate buffer (SPB) containing $120 \mathrm{mM} \mathrm{Na} 2 \mathrm{HPO}_{4} / \mathrm{NaH}_{2} \mathrm{PO}_{4}, 100 \mathrm{mM}$ EDTA, $5 \mathrm{M}$ D-sorbitol and $1 \%$ SDS. Soil $(0.5 \mathrm{~g})$ was mixed with $1.5 \mathrm{~mL}$ SPB buffer and the mixture incubated at $70^{\circ} \mathrm{C}$ for 1 hour and then centrifuged at $14,000 \times \mathrm{g}$ for 5 minutes (Cullen et al., 1998). The supernatant was removed and put through the FastDNA spin kit extraction protocol (Appendix 1.1). DNA yields obtained were similar to those obtained with the unmodified methods, although the extracts had a slight brown colouration, suggesting the presence of humic acids. The PCR amplification step was unsuccessful using the template DNA extracted from each of the five test panel samples (Appendices 2.3 and 2.4). 


\subsection{CTAB Extraction}

Cetyl tri-methyl ammonium bromide (CTAB) is a commonly used DNA extraction reagent that acts as a polysaccharide and protein precipitant at high concentrations of $\mathrm{NaCl}$ (Stewart and Via, 1993). Adding a CTAB step would remove excess protein or polysaccharide contaminants at an early stage of the extraction procedure.

The first three steps of the FastDNA Spin Kit procedure (Appendix 1.1) were followed. Soil (0.5 g) was added to $978 \mu \mathrm{L}$ sodium phosphate buffer and $122 \mu \mathrm{L}$ MT buffer. This mixture was subjected to the standard bead beating procedure (speed 5.5 for 90 seconds) before centrifuging at $14,000 \mathrm{x} \mathrm{g}$ for 30 seconds. The supernatant was removed to a clean tube and $150 \mu \mathrm{L} 5 \mathrm{M} \mathrm{NaCl}$ added for every $1 \mathrm{~mL}$ of supernatant. After vortex mixing, $100 \mu \mathrm{L} \mathrm{CTAB}$ buffer containing $10 \%(w / v)$ CTAB and $0.7 \mathrm{M}$ $\mathrm{NaCl}$ in $\mathrm{H}_{2} \mathrm{O}$ was added, followed by mixing and incubation at $65^{\circ} \mathrm{C}$ for 20 minutes. An equal volume of chloroform was then added, and the mixture vortexed and centrifuged for 15 minutes at $9000 \mathrm{x}$ g. The top aqueous layer was then removed and put through the remainder of the FastDNA Spin Kit procedure (Porteous et al., 1997).

The DNA extracts obtained from samples treated in this way had a strong brown colouration indicating substantial humic acid contamination. None of the extracted DNA templates were successfully amplified (Appendices 2.3 and 2.4).

\subsection{Proteinase $K$}

Proteinase $\mathrm{K}$ is a highly active proteolytic enzyme commonly used to remove contaminating proteins during DNA/RNA preparation. The first three steps of the FastDNA Spin Kit (Appendix 1.1) were followed. After the bead beating step, centrifugation and transfer of the supernatant to a new tube, proteinase K (Roche) was 
added to a final concentration of $1 \mathrm{mg} / \mathrm{mL}$. The mixture was incubated overnight at $56^{\circ}$ $\mathrm{C}$ and the proteinase $\mathrm{K}$ was then inactivated by heating to $95^{\circ} \mathrm{C}$ for 10 minutes (Porteous et al., 1994). The FastDNA Spin Kit protocol was then continued from step 4.

The five samples treated in this way yielded large amounts of DNA (ranging from $12200 \mathrm{ng}$ to $91500 \mathrm{ng}$ total in the $50 \mu \mathrm{L}$ elution volume) but amplification of the template DNA was not successful (Appendix 2.5). This confirmed that the inhibitors are not proteins, but other compounds. The DNA extracts all had a brown hue, suggesting that humic acid contamination was likely.

\subsection{Guanidine Thiocyanate}

The addition of a guanidine thiocyanate solution wash during the extraction procedure was suggested by QBIOGene, the manufacturers of the FastDNA Spin Kit for Soil (for protocol see Appendix 1.5). Guanidine thiocyanate is an extremely potent chaotropic agent that quickly denatures macromolecules and inactivates nucleases. Nucleic acids also bind efficiently to silica or glass particles in the presence of high guanidine thiocyanate (Boom et al., 1990).

The template DNA extracted from all five test panel samples did not amplify after this treatment (Appendix 2.4). The guanidine thiocyanate wash was suggested by QBIOGene as a specific means to prevent humic acid inhibition, so other inhibitors may not be removed as effectively. Two of the DNA extracts, however, had brown colouration which suggests that the humic acids were not removed by this wash step. 


\subsection{DNAzol}

DNAzol ${ }^{\circledR}$ (Invitrogen) is a "guanidine-detergent based lysing reagent" designed for the extraction of genomic DNA from a range of sample types. It enables selective precipitation of DNA from cell lysates (Chomczynski et al., 1997). Rather than use DNAzol alone to extract DNA from soil, DNAzol was tested as a cleaning step during extraction with the FastDNA Spin Kit, and was also tested as a wash step of previously extracted DNA. These protocols are given in Appendix 1.7.

When the DNAzol wash step was added during extraction, amplification was successful with template DNA from three samples (Appendix 2.8). Subsequent use of the DNAzol wash step with a further ten decomposition samples (Table 5.2) that had not previously yielded PCR product proved it to be very successful in reducing co-extraction of inhibitors, with template DNA extracted from eight of the ten samples successfully amplifying (Appendix 2.6). Washing of previously extracted DNA with DNAzol as a post extraction clean-up step did not facilitate successful amplification of target DNA extracted from any of the five samples (Appendix 2.7).

\begin{tabular}{|l|l|l|l|}
\hline Number & Sample name & Decomposition Experiment Samples from & PCR Success \\
\hline 1 & Bush 19 & Surface Exposure Decomposition (section 7.2) & + \\
2 & Bush 24 & Surface Exposure Decomposition (section 7.2) & + \\
3 & Grass 43 & Surface Exposure Decomposition (section 7.2) & + \\
4 & B3 & Human Cadaver Experiment (section 7.3) & - \\
5 & B7 & Human Cadaver Experiment (section 7.3) & + \\
6 & B19 & Human Cadaver Experiment (section 7.3) & - \\
7 & B22 & Human Cadaver Experiment (section 7.3) & + \\
8 & A21 & Human Cadaver Experiment (section 7.3) & + \\
9 & A22 & Human Cadaver Experiment (section 7.3) & + \\
10 & A29 & Human Cadaver Experiment (section 7.3) & + \\
\hline
\end{tabular}

Table 5.2. Ten extra decomposition samples used to test the DNAzol and plant DNAzol steps during extraction and PCR success of template DNA extracted from them using this added step. 
In light of this success, a variant of DNAzol designed for extraction of DNA from plant tissue was also tested. Plant DNAzol (Invitrogen) was used as a cleaning step during extraction (Appendix 1.8). As with the standard DNAzol, template DNA from eight of the ten extra samples amplified successfully, with the template DNA from the same two samples not amplifying (Appendix 2.9). Common PCR inhibitors from plant tissue include polysaccharides and polyphenols, mostly unidentified (Wilson, 1997). The DNAzol reagent contains a guanidine-detergent lysing solution, so a range of compounds including humic acids might be successfully removed. Decomposition samples that had white lipid-like substance present during the first few steps in the extraction successfully amplified using DNAzol, so the active ingredient might also remove lipid-derived PCR inhibitors.

\subsubsection{Alternative Extraction Kits}

Two extraction kits additional to the FastDNA Spin Kit for Soil were tested in the extraction of DNA from soil samples. The DNeasy Tissue Kit (Qiagen) and the FastDNA Kit (QBIOgene) were tested and the protocols suggested by the manufacturers followed, with adjustments made for working with soil (Appendices 1.9 and 1.10). The extracted DNA yields were high (from $12,010 \mathrm{ng}$ to $22,935 \mathrm{ng}$ total extracted DNA), but PCR failed to amplify DNA templates extracted using either kit (Appendix 2.7). Both kits gave DNA extracts contaminated with very strong brown colouration.

\subsubsection{Summary}

The results from the various modifications made to the extraction procedure are summarised in Table 5.3. The Plant DNAzol and standard DNAzol were equally successful in facilitating amplification of template DNA from the ten difficult 
decomposition samples. Plant DNAzol was chosen for incorporation into the routine extraction procedure based on economic factors.

\begin{tabular}{|c|c|c|c|c|c|c|c|c|}
\hline \multirow[t]{2}{*}{ Modification } & \multirow{2}{*}{$\begin{array}{l}\text { Range of DNA } \\
\text { yields (total ng in } \\
50 \mu l \text { of elution } \\
\text { buffer) }\end{array}$} & \multirow{2}{*}{$\begin{array}{l}\text { Colour of DNA } \\
\text { extract }\end{array}$} & \multicolumn{6}{|c|}{ PCR success for Test Panel samples } \\
\hline & & & 1 & 2 & 3 & 4 & 5 & Extra \\
\hline SEW-M / PPS repeat washes & $1,075-2,545$ & clear & - & - & - & + & - & ND \\
\hline SPB & $17,557-22,985$ & light brown & - & ND & ND & ND & ND & $0 / 2$ \\
\hline CTAB & $46,500-68,340$ & dark brown & - & ND & ND & ND & ND & $0 / 2$ \\
\hline Proteinase $\mathrm{K}$ & $12,200-91,500$ & light brown & - & - & - & - & - & ND \\
\hline Guanidine Thiocyanate & $37,670-56,175$ & brown & - & - & - & - & - & ND \\
\hline DNAzol during extraction & $22,850-61,340$ & clear & - & + & - & + & + & $8 / 10$ \\
\hline DNAzol after extraction & $14,375-59,100$ & clear/ light brown & - & - & - & - & - & ND \\
\hline Plant DNAzol during extraction & $18745-72,670$ & clear & - & + & - & + & + & $8 / 10$ \\
\hline DNeasy Tissue Kit & $12,010 \& 22,935$ & very dark brown & ND & - & - & ND & ND & ND \\
\hline FastDNA Kit (all tissue types) & $15,334 \& 19,456$ & very dark brown & ND & - & - & ND & ND & ND \\
\hline
\end{tabular}

Table 5.3. Summary of modifications to the extraction procedure. $A+$ indicates a positive amplification result, - indicates a negative result. ND indicates that those samples were not tested. The extra samples were further samples tested when some success was experienced with the test panel samples and details are included in the relevant sections.

\subsubsection{Optimisation of PCR}

As well as improving the purity of the template DNA, improvements to the PCR were also investigated. The choice of DNA polymerase is important because the various commercially available DNA polymerase enzymes vary in fidelity and specificity. Some DNA polymerases appear to be better able to cope with inhibitors and degraded DNA templates than others (Abu Al-Soud and Radstrom, 1998). Bovine serum albumin (BSA) was also tested as an additive to the PCR reaction, as it has been reported to facilitate amplification of contaminated template DNA preparations (Kreader, 1996b). 


\subsubsection{DNA Polymerases}

A total of three DNA polymerases were tested in addition to the original DNA polymerase, AmpliTaq Gold, for their ability to amplify DNA targets extracted from a variety of soil samples. As explained in the previous chapter (see section 4.3.4), HotStarTaq (Qiagen) was tested during the initial survey of methodology, after failure of AmpliTaq Gold to amplify DNA targets from a large proportion of the soil extracts. Two other DNA polymerases, FastStart DNA Polymerase (Roche) and Accuprime Taq DNA Polymerase (Invitrogen), were also tested to determine whether amplification success rates could be improved further. A selection of DNA extracts from soil samples collected at different sites, and extracts from various soil samples from under decomposing cadavers were used as templates. The template DNA from many of the samples had previously successfully amplified while the others had not amplified using either HotStarTaq or AmpliTaq Gold (sample details in sections 5.2.3.1.1 and 5.2.3.1.2). The three extra DNA polymerases tested were all hot start PCR enzymes. Using a hot start step tends to give cleaner products due to the reduction of non-specific primer binding and primer-dimer formation (Kaboev et al., 2000).

\subsection{FastStart DNA Polymerase}

FastStart DNA Polymerase (Roche) was the first of the extra DNA polymerases tested. Aliquots of DNA from 15 sample extractions were chosen to act as templates (Table 5.6). Five were obtained from decomposition samples from which template DNA had previously amplified successfully using HotStarTaq (positive controls), and five were decomposition samples from which template DNA had not amplified. The final five samples were homicide scenario samples from which template DNA had amplified using HotStarTaq, but only three of which had worked using AmpliTaq Gold (Table 
4.8). The PCR recipe used is outlined in Table 5.4, and the thermocycling regime in Table 5.5.

\begin{tabular}{|l|l|}
\hline Component & Volume/Concentration \\
\hline 10x PCR buffer & $5 \mu \mathrm{L}$ \\
FastStart Polymerase & $0.4 \mu \mathrm{L}$ \\
dNTPs & $200 \mu \mathrm{m}$ \\
Primers: & \\
F63 FAM & $10 \mu \mathrm{m}$ \\
R1389 & $10 \mu \mathrm{m}$ \\
Template DNA & $20 \mathrm{ng}($ variable volume) \\
$\mathrm{H}_{2} \mathrm{O}$ & Variable (to total $50 \mu \mathrm{L})$ \\
\hline Total volume & $50 \mu \mathrm{L}$ \\
\hline
\end{tabular}

Table 5.4. FastStart DNA Polymerase PCR recipe.

\begin{tabular}{|l|l|l|}
\hline Initial Denaturation & $4 \mathrm{~min}$ & $95^{\circ} \mathrm{C}$ \\
3 Step Cycling & & \\
Denaturation: & $30 \mathrm{sec}$ & $95^{\circ} \mathrm{C}$ \\
Annealing: & $30 \mathrm{sec}$ & $60^{\circ} \mathrm{C}$ \\
Extension: & $1.5 \mathrm{~min}$ & $72^{\circ} \mathrm{C}$ \\
Number of Cycles & 30 & \\
Final Extension & $7 \mathrm{~min}$ & $72^{\circ} \mathrm{C}$ \\
\hline
\end{tabular}

Table 5.5. FastStart DNA Polymerase thermocycling regime.

Template DNA from only three of the five previously successful decomposition samples amplified with FastStart DNA Polymerase. None of the five previously unsuccessful sample DNA templates gave products. All five of the homicide scenario sample DNA templates did amplify. These results are shown in Table 5.6 and a gel photograph is included in Appendix 2.10. 


\begin{tabular}{|l|l|l|l|}
\hline $\begin{array}{l}\text { Test panel } \\
\text { sample } \\
\text { number }\end{array}$ & $\begin{array}{l}\text { Sample used (numbering } \\
\text { from original experiment) }\end{array}$ & Previous PCR success & $\begin{array}{l}\text { PCR success using } \\
\text { FastStart DNA } \\
\text { Polymerase }\end{array}$ \\
\hline TP-1 & D1 (decomposition) & + & - \\
\hline TP-2 & A5 (decomposition) & + & + \\
\hline TP-3 & A37 (decomposition) & + & - \\
\hline TP-4 & B1 (decomposition) & + & + \\
\hline TP-5 & B21 (decomposition) & + & + \\
\hline & & & - \\
\hline TP-6 & D2 (decomposition) & - & - \\
\hline TP-7 & D3 (decomposition) & - & - \\
\hline TP-8 & A21 (decomposition) & - & - \\
\hline TP-9 & B5 (decomposition) & - & - \\
\hline TP-10 & B20 (decomposition) & - & \\
\hline & & & + \\
\hline TP-11 & 18 (homicide scenario) & + & + \\
\hline TP-12 & 22 (homicide scenario) & + & + \\
\hline TP-13 & 25 (homicide scenario) & + & + \\
\hline TP-14 & 1 (homicide scenario) & $+(-$ with AmpliTaq gold) & + \\
\hline TP-15 & 29 (homicide scenario) & $+(-$ with AmpliTaq gold) & + \\
\hline
\end{tabular}

Table 5.6. Results of FastStart DNA Polymerase PCR using template DNA from the test panel samples.

The failure to amplify the target DNA from the five samples that previously had amplified using HotStarTaq indicated that FastStart Taq was not as reliable for amplifying 'dirty' DNA extracts as HotStarTaq. Additionally, template DNA that was unsuccessful with HotStarTaq was not amplified by FastStart Taq, suggesting that its use was unlikely to provide any advantage.

\subsection{Accuprime Taq DNA Polymerase}

Accuprime Taq DNA Polymerase (Invitrogen) has anti-Taq DNA polymerase antibodies that inhibit polymerase activity and provide an automatic hotstart. Accuprime Taq was tested using five samples from which products had successfully been amplified using HotStarTaq, and five which had not. Only 10 reactions were performed as the amount of Accuprime Taq available was limited (Table 5.9). These 10 samples were a sub-set of the test panel used to test the FastStart DNA Polymerase 
(Table 5.6). The PCR recipe used is outlined in Table 5.7 and the thermocycling regime in Table 5.8.

\begin{tabular}{|l|l|}
\hline Component & Volume/Amount \\
\hline Buffer II & $5 \mu \mathrm{L}$ \\
Accuprime Polymerase & $1 \mu \mathrm{L}$ \\
Primers: & \\
$\quad$ F63 FAM & $10 \mu \mathrm{m}$ \\
R1389 & $10 \mu \mathrm{m}$ \\
Template DNA & $20 \mathrm{ng}$ (variable volume) \\
$\mathrm{H}_{2} \mathrm{O}$ & Variable (to total $50 \mu \mathrm{L})$ \\
\hline Total volume & $50 \mu \mathrm{L}$ \\
\hline
\end{tabular}

Table 5.7. Accuprime Taq DNA Polymerase PCR recipe.

\begin{tabular}{|l|l|l|}
\hline Initial Denaturation & $2 \mathrm{~min}$ & $94^{\circ} \mathrm{C}$ \\
3 Step Cycling & & \\
Denaturation: & $1 \mathrm{~min}$ & $94^{\circ} \mathrm{C}$ \\
Annealing: & $1.5 \mathrm{~min}$ & $60^{\circ} \mathrm{C}$ \\
Extension: & $7 \mathrm{~min}$ & $72^{\circ} \mathrm{C}$ \\
Number of Cycles & 30 & \\
\hline
\end{tabular}

Table 5.8. Accuprime Taq DNA Polymerase thermocycling regime.

The use of Accuprime Taq gave mixed results. Target DNA was successfully amplified in one instance where previously it had not (sample B20 from the decomposition study), but the target region from only three of the five successful test panel sample DNA extracts previously successful with HotstarTaq (decomposition sample A37 and homicide scenario samples 1 and 25) amplified (Appendix 2.11). This result suggested that Accuprime Taq could be advantageous in some situations, and may be worth trying if DNA extracts repeatedly fail to yield PCR products using other polymerases. The success with just one previously unsuccessful extract however did not warrant making a change from the currently used HotStarTaq. 


\begin{tabular}{|l|l|l|l|}
\hline $\begin{array}{l}\text { Test panel sample } \\
\text { number (from } \\
\text { section 5.2.3.1.1) }\end{array}$ & $\begin{array}{l}\text { Sample used (numbering } \\
\text { from original experiment) }\end{array}$ & $\begin{array}{l}\text { Previous PCR } \\
\text { success }\end{array}$ & $\begin{array}{l}\text { PCR success using } \\
\text { Accuprime Taq }\end{array}$ \\
\hline TP-1 & D1 (decomposition) & + & - \\
\hline TP-2 & A5 (decomposition) & + & - \\
\hline TP-3 & A37 (decomposition) & + & + \\
\hline TP-13 & 25 (homicide scenario) & + & + \\
\hline TP-14 & 1 (homicide scenario) & + & + \\
\hline & & & \\
\hline TP-6 & D2 (decomposition) & - & - \\
\hline TP-7 & D3 (decomposition) & - & - \\
\hline TP-8 & A21 (decomposition) & - & - \\
\hline TP-9 & B5 (decomposition) & - & - \\
\hline TP-10 & B20 (decomposition) & - & + \\
\hline
\end{tabular}

Table 5.9. Results of Accuprime Taq PCR using template DNA from the test panel samples.

\subsection{Summary of results for the DNA Polymerases tested.}

FastStart DNA polymerase and Accuprime Taq PCR results are summarised in Table 5.10. The success using each polymerase is compared with the success of PCR for the same sample DNA extracts using HotStarTaq DNA Polymerase.

\begin{tabular}{|l|c|c|}
\hline Polymerase & \multicolumn{2}{|l|}{ PCR success } \\
\hline & $\begin{array}{c}\text { Previously successful with } \\
\text { HotStarTaq }\end{array}$ & $\begin{array}{c}\text { Previously unsuccessful with } \\
\text { HotStarTaq }\end{array}$ \\
\hline FastStart & $8 / 10(80 \%)$ & $0 / 5(0 \%)$ \\
\hline Accuprime Taq & $3 / 5(60 \%)$ & $1 / 5(20 \%)$ \\
\hline
\end{tabular}

Table 5.10. Summary of alternative polymerase enzymes' PCR success in amplifying target DNA already tested with HotStarTaq.

\subsubsection{Bovine Serum Albumin}

Bovine serum albumin (BSA) is often used as an additive to PCR reactions to relieve inhibition (Wilson, 1997). It is a protein that stabilises labile enzymes such as restriction endonucleases, polymerases and ligases and hence is used extensively by molecular biologists. Kreader (1996) postulated that BSA may be able to scavenge a variety of inhibitory substances or provide an alternative substrate for them, thereby preventing their binding and inactivation of Taq DNA polymerase. Kreader (1996b) 
recommended the concentration range $200-400 \mathrm{ng} / \mu \mathrm{L}$ of $\mathrm{BSA}$ in PCR reactions and Abu Al-Soud and Radstrom (2000) supported a similar concentration of 0.4-0.6\% [wt/vol]. Others have had success with higher concentrations, up to $10 \mu \mathrm{g} / \mu \mathrm{L}$ (P. Carter, ESR Ltd., pers. comm.).

Bovine serum albumin (Invitrogen) was added to the PCR reactions of four DNA extracts from which PCR products had not previously been gained (Table 5.11).

\begin{tabular}{|c|c|}
\hline $\begin{array}{c}\text { Sample used (numbering from } \\
\text { original experiment) }\end{array}$ & Previous PCR success \\
\hline +ve control (E. coli gDNA) & + \\
\hline D1 & - \\
\hline D2 & - \\
\hline A21 & - \\
\hline B5 & - \\
\hline
\end{tabular}

Table 5.11. The test panel of samples used with BSA added to the PCR reaction.

BSA was added to a final concentration of $10 \mu \mathrm{g} / \mu \mathrm{L}(10 \mu \mathrm{L}$ of $50 \mu \mathrm{g} / \mu \mathrm{L}$ stock solution in a total of $50 \mu \mathrm{L}$ ). The $\mathrm{H}_{2} \mathrm{O}$ in each reaction tube was reduced to hold the volume constant at $50 \mu \mathrm{L}$ while allowing the addition of the BSA. A positive control (genomic E. coli DNA) also had BSA added at this concentration.

The addition of BSA to the PCR reactions facilitated successful amplification of template from one sample (sample D2) which previously had not amplified. This suggested that the routine addition of BSA could be advantageous. The positive control did not amplify when BSA was added, although a BSA-free positive control did (Appendix 2.6). This suggested that the BSA might be inhibiting the reaction in some way. The control reaction also appeared milky and mucous-like. A gel photograph of the PCR products is shown in Appendix 2.6. 
To determine the maximum concentration of BSA that can be added to a PCR reaction before inhibition of the reaction occurs, a series of concentrations of BSA were added to PCR reactions for the positive control and sample (D2). Final concentrations of $0.1,1$, 5 and $10 \mu \mathrm{g} / \mu \mathrm{L}$ were used. It was discovered that 10 and $5 \mu \mathrm{g} / \mu \mathrm{L}$ concentrations inhibited the positive control but 1 and $0.1 \mu \mathrm{g} / \mu \mathrm{L}$ allowed amplification to occur (Appendix 2.7). Template DNA from sample D2 successfully amplified at all BSA concentrations. Bovine serum albumin was added to all subsequent PCR reactions at a final concentration of $0.1 \mu \mathrm{g} / \mu \mathrm{L}$.

\subsubsection{Summary of Amplification Improvement Results}

Three of the method modifications tested to improve amplification of extracted template DNA were incorporated into the standard methodology. In the extraction procedure, the plant DNAzol cleaning step was chosen, because of the visually cleaner samples it produced and the increased PCR success rate. The HotStarTaq polymerase was included because of its high amplification success rate. Thirdly, BSA was routinely added to all subsequent PCR reactions.

The overall success rate for PCR following the incorporation of all three of these modifications is over $90 \%$. Some samples (particularly decomposition samples), still prove difficult to amplify target DNA from. Some samples require re-extraction of the DNA from the soil, or a second attempt at PCR. Therefore, while the modified methodology is an improvement on the original methods used, it is not always successful for all samples encountered. However, if decomposition samples are excluded, the PCR success rate is close to $100 \%$. 


\subsection{Fragment Detection and Profile Generation}

Bacterial community DNA profile generation using the ABI 310 Genetic Analyser was generally successful and relatively problem free. The procedure for loading samples and running the machine has been established by other projects using the machine at ESR Ltd. The only problem encountered with the generation of profiles was the surprise appearance of a small number of profiles with very low peaks and poor definition. These profiles occurred randomly in large batches of samples with the previous and subsequent profiles in the batch appearing normal. These poor quality profiles were a problem for data analysis, as their inclusion could severely distort results. They were easily identified by their low, smooth peaks which in some cases were not much more than a wavy base line (Figure 5.2).

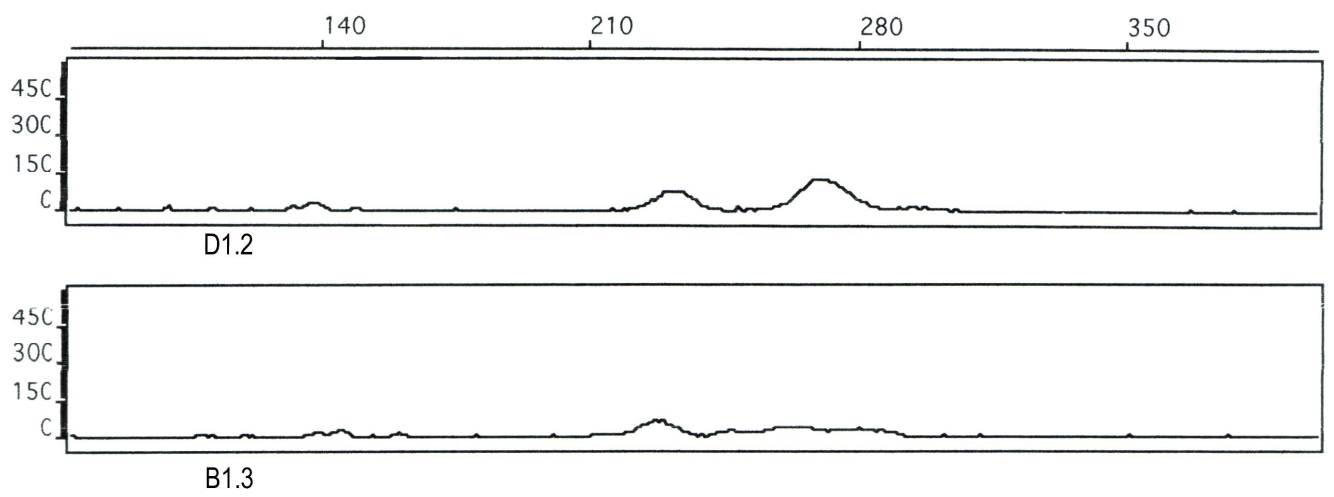

Figure 5.2. Two profiles that were identified as being of poor quality.

A number of possible causes of such poor quality profiles were identified, with the most likely being impurities in the DNA preparation that affected uptake of labelled DNA fragments into the capillary of the Genetic Analyser. The ABI 310 Genetic Analyser uses electrokinetic injection of DNA for capillary electrophoresis and the presence of inorganic ions can interfere with the uptake of DNA due to preferential injection of higher charge-to-mass ratio atoms or molecules (eg. $\mathrm{Cl}^{-}$ions). 


\subsubsection{Cleaning of Digested DNA}

Desalting the DNA preparation after enzymatic digestion has been shown to increase the uptake of DNA into the capillary of the Genetic Analyser, leading to higher fluorescent signals and more peaks being detected (Gruntzig et al., 2002). To determine whether this treatment might improve the quality of the profiles described above, the digested DNA fragments were put through a MinElute Reaction Cleanup Kit (Qiagen) to remove any residual enzyme or buffer salts which may have been interfering with DNA fragment uptake (for protocol see Appendix 1.11). After cleaning, the resulting profiles were much improved, with discrete peaks being detected from the DNA fragment preparations that had previously given poor quality profiles (Figure 5.3). The amount of fluorescent signal detected was markedly increased after the addition of this step, giving higher peaks on the profiles than those run previous. Time and cost restraints, however, prevented re-profiling of all the experimental samples that had already been profiled. All the PCR products from the Reproducibility and Spatial Variation experiment in Chapter 6 (the experiment where the poor quality profiles arose), however, were restriction enzyme digested, put through the MinElute cleanup column and re-profiled to ensure comparability between the resulting profiles.

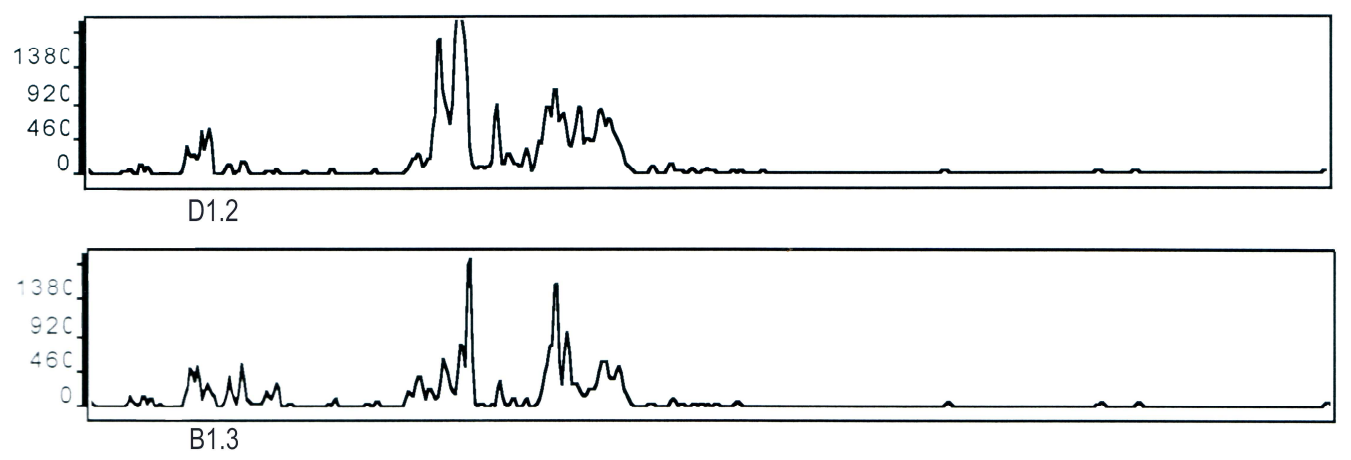

Figure 5.3. Profiles of two samples previously producing poor quality profiles. 


\subsection{Data Analysis of Profiles}

Major improvements were made in the data analysis procedure. A significant drawback to the original analysis method is that it was both time-consuming and error prone. Manual alignment of profile data and calculation of comparison indices for large groups of profiles is simply not practical. It was also realised that alternative comparison indices would need to be developed to replace the simplistic Sorenson's Index. If these were to prove more complex to calculate, then the process would become even less manageable. The following section describes the development of software that automatically aligns and compares profiles, using new indices, in order to eliminate the time consuming and error prone manual alignment process.

\subsubsection{Profile Wizard}

A new software programme, 'Profile Wizard', was developed specifically for storing and comparing T-RFLP data generated from soil samples for this project. It was designed in collaboration with a software developer for ESR. Profile data from different experiments are stored within separate databases, with information about each sample, such as date collected, soil type, location collected from and any additional facts (e.g. whether it is a control sample). In the screenshot shown in Figure 5.4, a data file for sample A32 is displayed. All the information held about the sample is displayed in the main window. To the right are the peak size and height data, and in the top window, these data are displayed graphically. 


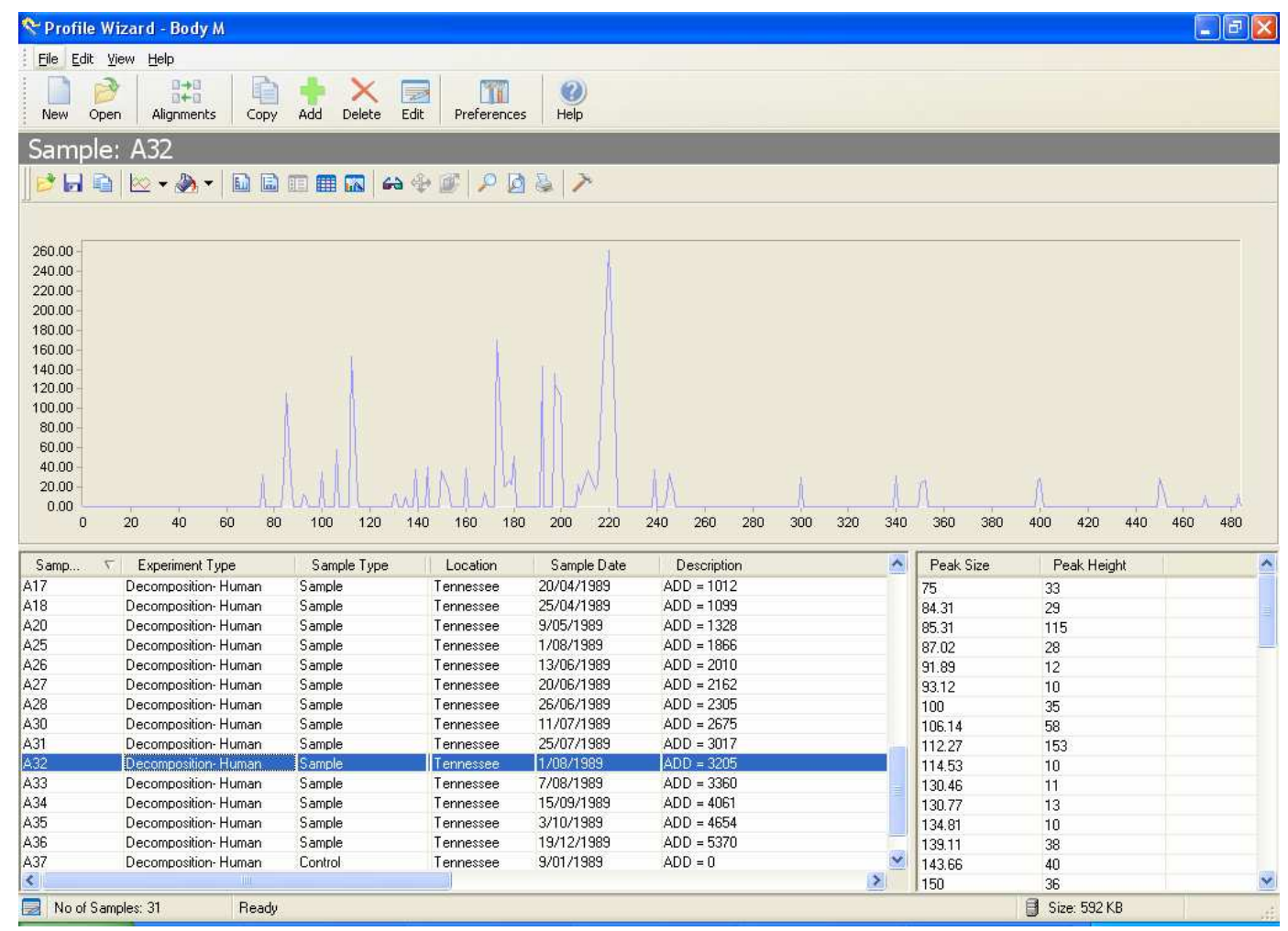

Figure 5.4. Screenshot of Profile Wizard displaying sample A32 data from

Body A of the decomposition study (Chapter 7).

The software also compares data for pairs of samples using similarity indices developed and tested for the project. The major advantage of having an automated calculation process is the ability to calculate multiple indices simultaneously in a single pairwise comparison. Profile Wizard allows all the selected samples within a given group to be compared against each other. These comparisons are displayed in the 'alignment' window and are saved automatically (Figure 5.5). The results can be exported to a spreadsheet or word processing programme for statistical analysis.

Profile Wizard was designed to be flexible and to allow comparison parameters to be set by the user. Limits can be placed on decision parameters and set which peaks are to be included in comparisons, such as the minimum peak height or the range of peak sizes. 


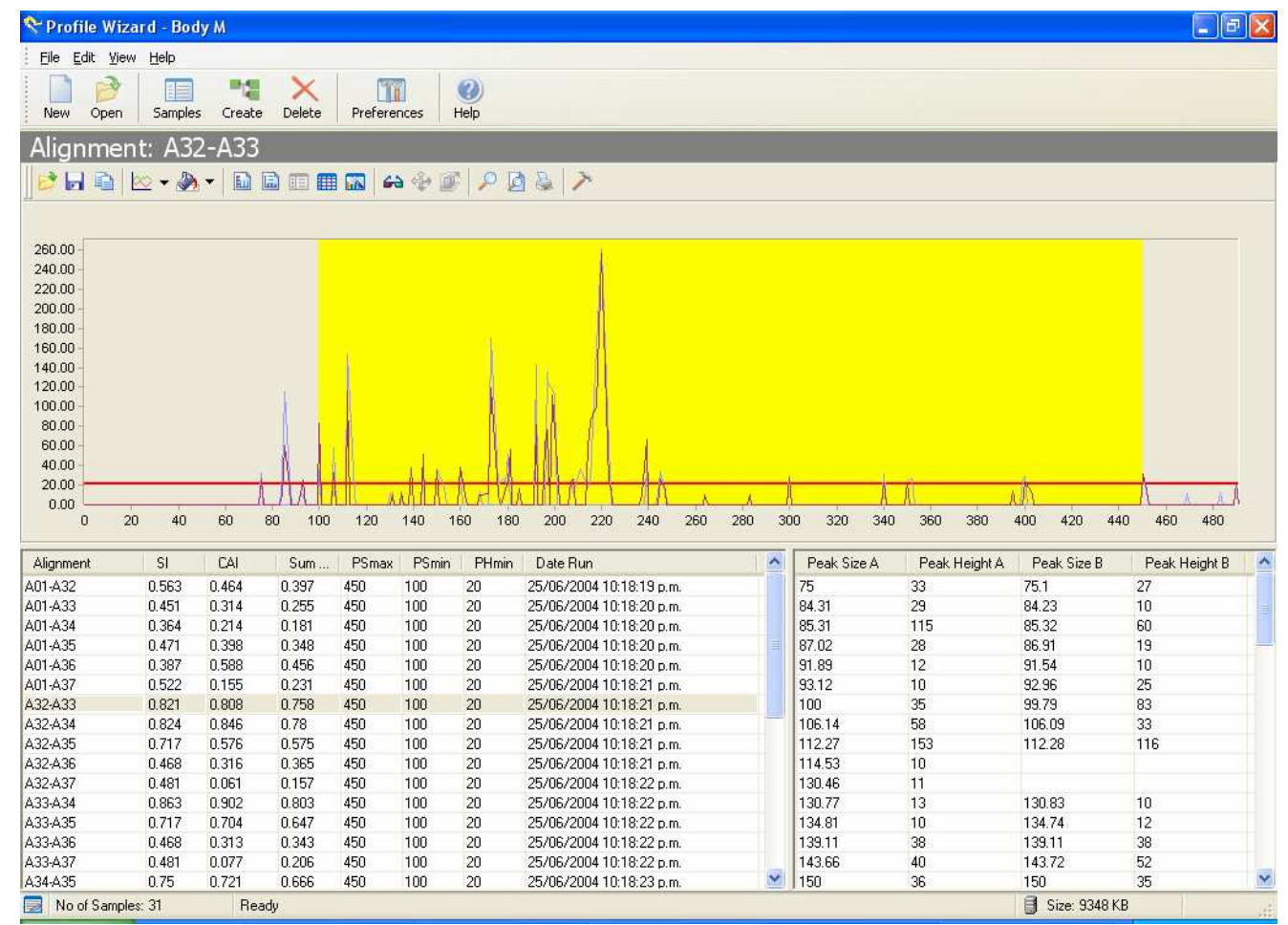

Figure 5.5. Screenshot of Profile Wizard displaying a comparison between two samples. The similarity index results are shown with the parameters of the comparison, along with the aligned data sets and a graphical display of the comparison. The highlighted region on the graph indicates the data inclusion parameters and the horizontal red line indicates the minimum fluorescence threshold set.

The development of Profile Wizard has facilitated the rapid and accurate comparison of sample data, allowing many more comparisons to be performed than would previously have been possible.

\subsubsection{Similarity Indices}

Sorenson's Similarity Index takes a very simple approach to calculating the similarity between two profiles. Peaks are either present or absent and fluorescence intensity (or peak height) is not taken into consideration. A very high similarity index value can be achieved if the same peaks are present in the two samples, although the same peaks may have very different heights. This is quite possible, as communities from similar soils or from nearby sites might have very similar populations, but in widely differing 
proportions. The problem created by differing proportions of bacterial ribotypes is particularly obvious when profiles have only a few peaks. Two profiles may look very different, but the Sorenson's Index indicates that they are very similar.

Another drawback to Sorenson's Index is that it weights all peaks equally, regardless of whether they are major peaks, accounting for a large percentage of the total fluorescence, or minor ones and only small contributors. Unavoidable experimental errors, such as small variations in the amount of template DNA put into a PCR are more likely to affect the presence or absence of minor peaks than the larger major peaks. Running duplicate profiles from a single sample might result in some minor peaks being present in one profile but not the other, while the majority of peaks remain constant. The absence of even these minor peaks will result in a disproportionately low similarity index value using the Sorenson's Index.

Sorenson's Index also relies heavily on the profiles being obtained from similar amounts of DNA. The total fluorescence of one profile can be lower than another despite best efforts to ensure that similar amounts of DNA are analysed. Differences in total fluorescence can have large effects on the Sorenson's Index values, particularly if smaller peaks in the lower sample begin to drop below the minimum peak height cut-off value.

For these reasons, alternative comparison indices to the Sorenson's Index were sought and tested. A good comparison index should weight peaks on their importance, and not allow minor peak variation to disproportionately affect overall similarity calculations. It should not be affected by differences in total overall fluorescence and should provide good discrimination between samples which are similar and those which are not. 
Finally, ideally, it should be relatively simple to understand and to explain to lay persons, such as those comprising a jury.

\subsubsection{Common Area Index}

Two alternative comparison techniques were tested using the homicide scenario data from Chapter 4. The first technique, the Common Area Index (CAI) was based on methods used by Daniels et al. (1998) for analysing microsatellite allele image patterns generated from DNA pools. It involved normalising the two data sets against each other to eliminate differences caused by variation in DNA amounts. The index takes into account the level of similarity of the area beneath the profile. This eliminates the simplistic presence/absence of peaks approach. The Sorenson's Index was replaced by the CAI early in method development for routine use, but alternative indices were continued to be sought in an attempt to find the best one.

To calculate the CAI between two samples, the highest peak in each profile is identified and set at $100 \%$. The heights of all other peaks in the profile are then expressed relative to this peak. For example, if the highest peak was $1200 \mathrm{rfu}$, this would become 100. If the next peak was $600 \mathrm{rfu}$, it would become 50, a peak of 120 would be 10 , etc. Two samples are then compared and the height difference between each peak in the two profiles is calculated and the squared height differences summed over all the peaks. This is then divided by the sum of the squares of the larger of the two heights. The given value is then subtracted from 1 to give the similarity index value. A value of one indicates very absolute similarity, and a value of zero, no similarity. The equation for calculating the CAI between two normalised profiles is shown in Figure 5.6. 


$$
\mathrm{CAI}=1-\left(\frac{\sum\left(A_{1}-B_{1}\right)^{2}}{\sum\left(\max \left(A_{1}, B_{1}\right)\right)^{2}}\right)
$$

Where $A=$ peak in sample $A$

and $B=$ peak in sample $B$

Figure 5.6. Equation for the Common Area Index calculation between two normalised data sets. A and $B$ refer to peaks within profiles $A$ and $B$, and $\max \left(A_{l}, B_{l}\right)$ refers to the larger of the two values.

\subsubsection{Peak Percentage Index}

The second comparison technique tested was based on the method developed by Collins et al. (2000), for determining total allele content differences of pooled DNA. The modified version was named the Peak Percentage Index (PPI). This index weights peaks on their importance to the profile i.e. reflecting the percentage of the total fluorescence detected. Like the CAI, this method eliminates differences between samples due to variation in total fluorescence.

To calculate the PPI, the combined heights of all the peaks in the sample are summed. The height of each peak is then divided by the combined height of all the peaks and multiplied by 100 to obtain the percentage of that sized fragment in the sample (the peak percentage). Two samples are then compared peak by peak and the absolute value of the difference of the peak percentages of the two pools is calculated. This number is divided by 2 to account for the fact that there are two samples being compared. The results for each peak in the samples are then summed, and this value is divided by 100 and subtracted from 1 to give the PPI. A value of one indicates sample profiles are the 
same, and a value of zero indicates no similarity. The equation for calculating the PPI is shown in Figure 5.7.

$$
\begin{gathered}
\text { PPI }=1-\left(\sum_{i=l}^{i=n} a b s\left(A_{1}-B_{1}\right) / 200\right) \\
\text { Where } A=\text { peak in sample } A \\
\text { and } B=\text { peak in sample } B
\end{gathered}
$$

Figure 5.7. Equation for the Peak Percentage Index calculation

\subsubsection{Similarity Index Choice}

The Homicide Scenario profiles were compared using all three of the available comparison indices: Sorenson's Index, CAI and PPI. The parameters set (as discussed in section 3.2.8) were: a size range of $100-450 \mathrm{bp}$, and a minimum height of $100 \mathrm{rfu}$. The calculations were performed using the Profile Wizard programme (section 5.4.1). The comparisons performed were divided into two groups: comparisons between samples collected from the same scene (i.e. scene one sample profiles vs. scene one sample profiles and scene two sample profiles vs. scene two sample profiles); and those between samples collected from different scenes (i.e. scene one sample profiles vs. scene two sample profiles). As shown in Figure 5.8, the mean similarity between samples taken from the same scene is much higher than between samples taken from different scenes. This difference is demonstrated by all three comparison indices although the greatest difference is displayed by the CAI. 


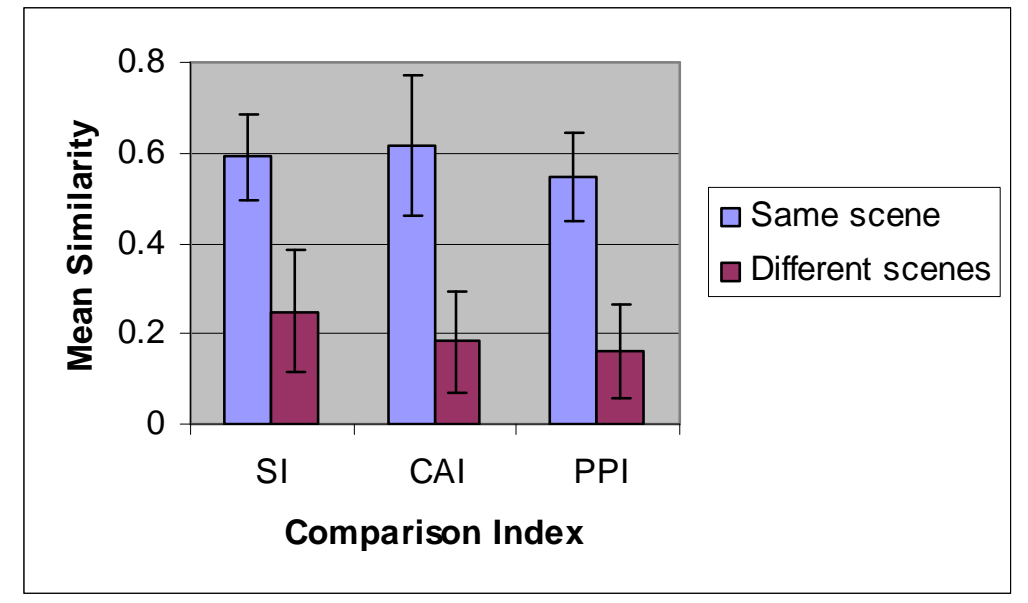

Figure 5.8. Mean similarity between samples collected at the same scene and at different scenes using the three comparison indices.

Because the Sorenson's Index has known limitations, particularly in its inability to take account of peak height variation, it was excluded from further consideration. The values given by the PPI and those given by the CAI were plotted on a scatter-graph to determine whether the two indices give similar values for comparisons between the same profiles. The correlation between the two indices is high with an $r^{2}$ value of 0.9 , and the equation is close to $\mathrm{y}=\mathrm{x}$ (Figure 5.9), suggesting that the choice of index used does not dramatically affect the result.

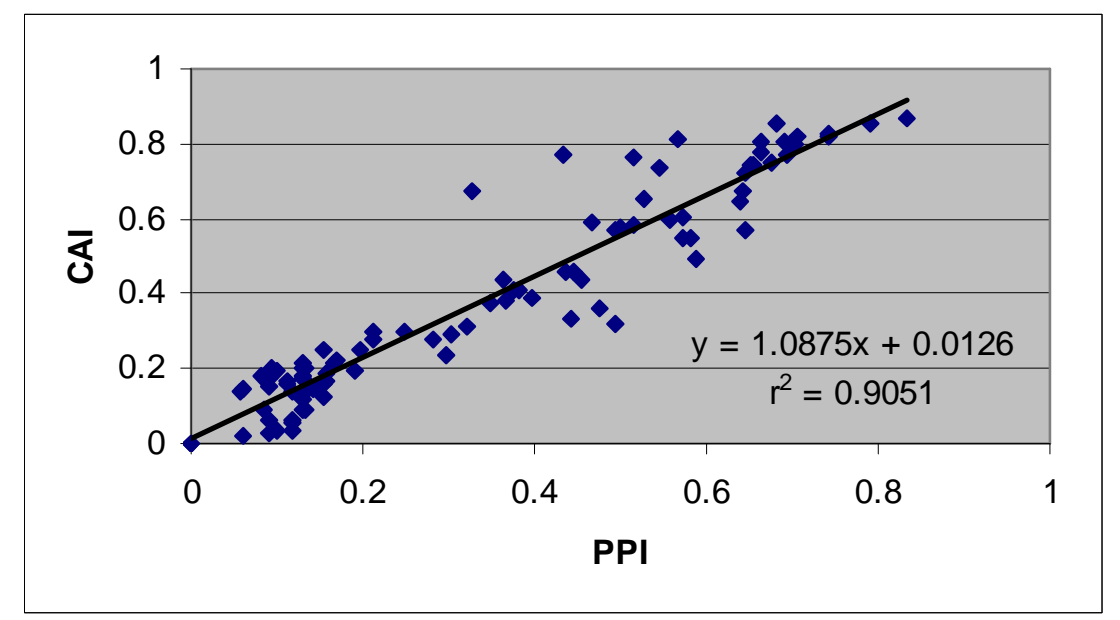

Figure 5.9. The correlation between the CAI and PPI values of the homicide scenario comparisons. 
The CAI gives slightly higher values than the PPI, and there are a few outliers where the CAI value is much higher than the PPI value between two profiles, but these outliers are comparisons between samples expected to be similar. In these cases, the CAI giving a higher value is desirable. Because the Peak Percentage Index showed no obvious advantage over the Common Area Index, the CAI, which had already been incorporated into the routine methodology, was continued to be used.

\subsection{Sample Storage}

An important issue to consider with regard to forensic casework is the effect that storage conditions prior to analysis may have on soil samples. Bacterial community profiling of a soil sample is equivalent to taking a 'snapshot' of the community at a particular point in time. If storage conditions allow the community to change, then the profile is not representative of the sample at the time of collection. The real possibility that bacterial communities might change during storage first arose when a number of samples needed to be re-analysed after storage for three months at $4^{\circ} \mathrm{C}$. Re-extraction of DNA from the samples yielded very low amounts of DNA (in the range of 400-1200 ng/g soil) for all samples, while fresh samples, extracted at the same time with the same procedure and the same batch of reagents, gave very high yields (32000 to $61000 \mathrm{ng} / \mathrm{g}$ ). An experiment was then performed to determine whether storage conditions affect both DNA yield and profiles obtained using that community DNA. A number of different storage conditions were examined: air drying, oven drying, freeze drying, and storage at $4^{\circ} \mathrm{C},-18^{\circ} \mathrm{C}$ and $-80^{\circ} \mathrm{C}$. These were selected based on their availability in most molecular biology laboratories. 


\subsubsection{Method}

A $500 \mathrm{~g}$ sample of fresh garden soil was collected from a private garden. The soil was homogenised on the day of collection by sieving with a $2 \mathrm{~mm}$ diameter mesh sieve and thorough mixing. It was then divided into portions of $2 \mathrm{~g}$ each. Three portions were used as control samples and the community DNA was extracted from these immediately. A further nine portions were put into storage immediately at $4^{\circ} \mathrm{C},-18^{\circ} \mathrm{C}$ and $-80^{\circ} \mathrm{C}$, with three replicates at each temperature. Three portions were also dried in each of the following ways:

1. Air dried - sample spread thinly and left in the laboratory at room temperature overnight.

2. Oven dried - sample spread thinly on a sterile oven-proof tray and warmed at $60^{\circ} \mathrm{C}$ until dry (approximately three hours).

3. Freeze dried - Sample frozen at $-80^{\circ} \mathrm{C}$ for three hours before processing in a freeze dryer overnight.

Samples that were air dried, oven dried and stored at $4^{\circ} \mathrm{C}$ were contained in sealed paper envelopes. This is the collection method most likely to be used by police officers in forensic casework, based on current collection practices for other types of evidence (S. Cordiner, ESR Ltd., pers. comm.). The freeze-dried samples were stored in the glass containers they were dried in, and the frozen samples were stored in plastic $50 \mathrm{ml}$ centrifuge tubes. The list of replicates, storage conditions and intervals are shown in Table 5.12 below. Small sub-samples $(0.5 \mathrm{~g})$ of each of the dried portions were profiled immediately after drying to assess the effect of the actual drying process on the bacterial community. Sub-samples were taken from all of the portions at one week and six weeks after collection, and profiles generated 


\begin{tabular}{|l|c|c|c|}
\hline Storage & Time 0 & 1 week & 6 weeks \\
\hline $4^{\circ} \mathrm{C}$ & - & 3 & 3 \\
\hline$-18^{\circ} \mathrm{C}$ & - & 3 & 3 \\
\hline$-80^{\circ} \mathrm{C}$ & - & 3 & 3 \\
\hline Air dried & 3 & 3 & 3 \\
\hline Oven dried & 3 & 3 & 3 \\
\hline Freeze dried & 3 & 3 & 3 \\
\hline Control & 3 & - & - \\
\hline
\end{tabular}

Table 5.12. The number of replicates profiled at each time period for each storage condition.

\subsubsection{Results}

Previous observations had suggested that storage conditions might affect the amount of DNA that could be successfully extracted from soil samples, but the yield of DNA extracted from all of the portions in this experiment were high, and within the normal range previously yielded by fresh soils $(\sim 12,000-100,000 \mathrm{ng} / \mathrm{g}$ soil $)$. Interestingly, the extracted DNA solutions stored at $4^{\circ} \mathrm{C}$ were 'dirtier' than the others after extraction, with a distinct yellow colour, suggesting possible contamination with humic acids, or other substances.

The profiles generated from each individual $2 \mathrm{~g}$ soil portion over the storage time were compared (Table 5.13). The first profile after drying or storage ( $\mathrm{t}=0$ or $\mathrm{t}=1$ week) from each portion was compared to a control profile to determine any immediate change caused by the storage or drying conditions. Profiles from $t=1$ week and $t=6$ weeks were then compared with the previous time profile to determine whether any further change to the community occurred over that time period. 


\begin{tabular}{|l|l|l|l|}
\hline Storage & Time 0 & 1 week & 6 weeks \\
\hline $4^{\circ} \mathrm{C}$ & - & $0.85 \pm 0.02$ & $0.86 \pm 0.03$ \\
\hline$-18^{\circ} \mathrm{C}$ & - & $0.80 \pm 0.01$ & $0.85 \pm 0.01$ \\
\hline$-80^{\circ} \mathrm{C}$ & - & $0.85 \pm 0.01$ & $0.84 \pm 0.01$ \\
\hline Air dried & $0.88 \pm 0.02$ & $0.83 \pm 0.02$ & $0.94 \pm 0.01$ \\
\hline Oven dried & $0.55 \pm 0.01$ & $0.86 \pm 0.02$ & $0.76 \pm 0.03$ \\
\hline Freeze dried & $0.81 \pm 0.02$ & $0.92 \pm 0.03$ & $0.90 \pm 0.04$ \\
\hline
\end{tabular}

Table 5.13. Mean CAI values ( $n=3)$ of stored samples compared with the previous time period profile.

The $t=0$ values were compared with a control profile (from fresh soil). The $t=1$ week profiles were compared back to the $t=0$ profiles for the dried portions, and to the control for the cold stored portions. The profiles at $t=6$ weeks were compared with the $t=1$ week profiles.

Profiles from the soil sample portions that were air and freeze dried showed high similarity to the control immediately after the drying process, with mean CAI values of 0.88 and 0.81 respectively. The cold stored portions (at $4{ }^{\circ} \mathrm{C},-18^{\circ} \mathrm{C}$ and $-80^{\circ} \mathrm{C}$ ) also showed little change in the bacterial community profiles after 1 weeks storage when compared back to the fresh soil control profile (with CAI values of $0.85,0.80$ and 0.85 ). The exception to these high similarities were the oven dried soil profiles which had a lower mean similarity index of 0.55 , and looked markedly dissimilar to the control and all other profiles (Figure 5.10).

When sub-sampled and profiled one week after the initial drying, the oven dried soil portions showed high similarity to the $\mathrm{t}=0$ profiles (mean CAI of $0.86 \pm 0.02$ ) suggesting that little further change occurred in the bacterial community during this time (Table 5.13). All other storage techniques also showed little change from the previous time-point profiles. 
Further sub-samples were taken from each soil portion and extracted five weeks later (at $\mathrm{t}=6$ weeks) and again, the portions showed high similarity to the previous ( $\mathrm{t}=1$ week) profiles. The storage method with the greatest difference between the $t=1$ week and $t=6$ week profiles (with $\mathrm{CAI}=0.76 \pm 0.03$ ) was oven drying. All other sample profiles had a mean CAI value of 0.83 or higher similarity to the previous time the soil portion was profiled.
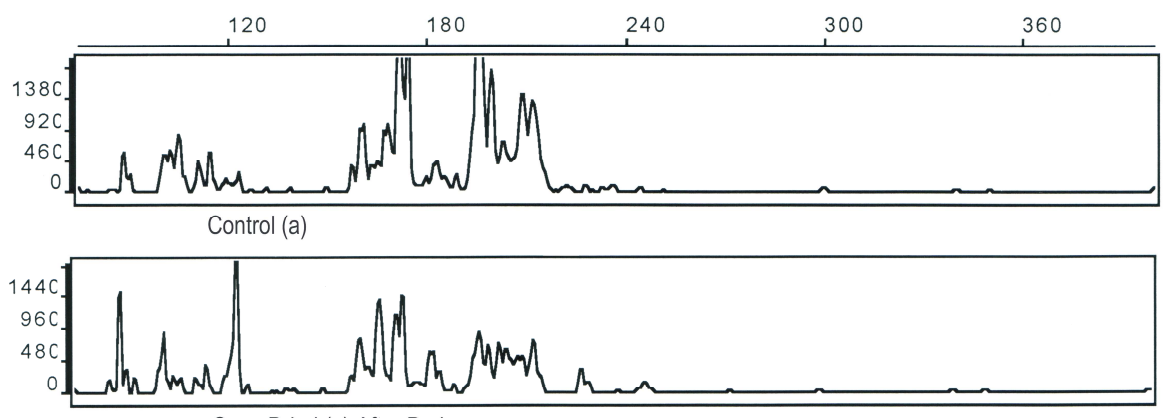

Oven Dried (a) After Drying

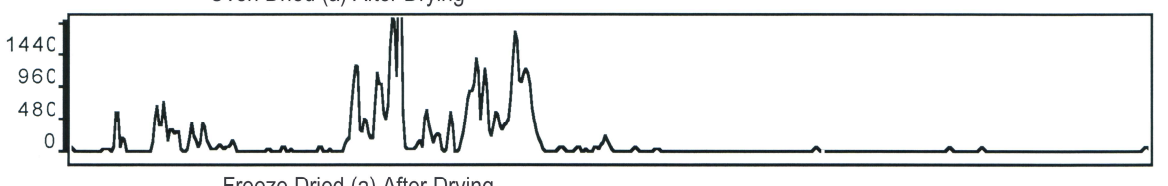

Freeze Dried (a) After Drying

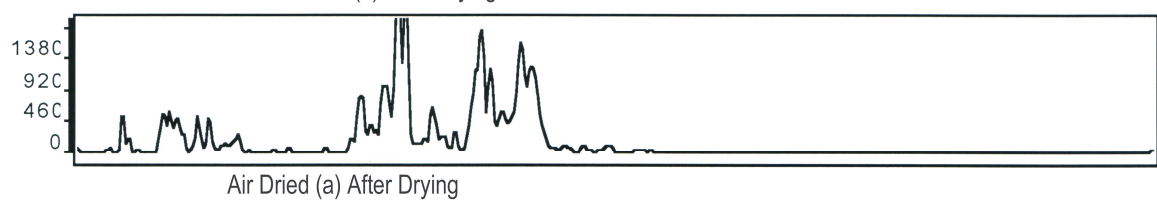

Figure 5.10. Profiles from: control, oven dried, freeze dried and air dried samples originating from the same soil.

The replicate soil sample portions that were oven dried had profiles that were very similar to each other, with a mean CAI of $0.97 \pm 0.01$. This suggests that the oven drying process was causing a real change in the bacterial community itself, or possibly on some other factor within the soil that affected how the DNA was preserved, extracted or amplified. All replicate portions stored in the same manner had profiles that were very similar, with the greatest variation being between the three control sample profiles (Table 5.14). 


\begin{tabular}{|l|l|l|l|}
\hline Storage & Time 0 & 1 week & 6 weeks \\
\hline $4^{\circ} \mathrm{C}$ & - & $0.95 \pm 0.01$ & $0.97 \pm 0.01$ \\
\hline$-18^{\circ} \mathrm{C}$ & - & $0.82 \pm 0.04$ & $0.95 \pm 0.01$ \\
\hline$-80^{\circ} \mathrm{C}$ & - & $0.92 \pm 0.03$ & $0.96 \pm 0.01$ \\
\hline Air dried & $0.94 \pm 0.01$ & $0.96 \pm 0.01$ & $0.98 \pm 0.01$ \\
\hline Oven dried & $0.97 \pm 0.01$ & $0.91 \pm 0.01$ & $0.93 \pm 0.03$ \\
\hline Freeze dried & $0.95 \pm 0.02$ & $0.96 \pm 0.01$ & $0.92 \pm 0.06$ \\
\hline Control & $0.76 \pm 0.16$ & - & - \\
\hline
\end{tabular}

Table 5.14. The mean CAI values (and standard deviation) between replicate profiles from each soil portion.

\subsubsection{Conclusion}

Storage at $4^{\circ} \mathrm{C}$ was chosen as the storage technique to be used for the remainder of the experimental work. This is a practical storage method for everyday laboratory handling, and it is also the most practical option for the New Zealand police, who are likely to be the ones collecting soil samples should the technique become a routinely used forensic tool. Storage at this temperature showed only small changes in the bacterial community in soil over time, with high mean CAI values between profiles generated over the storage time period of six weeks (Table 5.13). Air drying could also be used if access to refrigeration was not available, as this storage method also caused little change over time to the profiles generated from the soil. It would not be difficult for police officers to air dry a sample overnight before sealing it in a dry paper envelope. Ultimately, this may prove to be more practical than trying to ensure that correct refrigeration of samples always occurs. 


\subsection{Other Improvements}

\subsubsection{Restriction Enzyme Digestion}

The restriction enzyme digestion protocol (section 3.2.6) required some modification in response to the addition of the cleaning step (section 5.3.1) following digestion and prior to DNA fragment analysis with the Genetic Analyser. In order to keep the amount of DNA loaded on the Genetic Analyser constant from sample to sample (section 3.2.3), the amount of DNA digested was increased to allow for losses during the new postdigestion cleanup step. Through trial and error it was established that $500 \mathrm{ng}$ of $16 \mathrm{~s}$ PCR product DNA needed to be digested and cleaned up to reliably produce the $15 \mu \mathrm{L}$ of $10 \mathrm{ng} / \mu \mathrm{L}$ restriction fragments needed for analysis.

\subsubsection{Sample Homogenisation}

The issue of achieving repeatable soil sample homogenisation arose when examining which soil storage technique to use (section 5.5). In the storage experiment, a large single soil sample was divided into $2 \mathrm{~g}$ portions after being sieved and thoroughly mixed. These $2 \mathrm{~g}$ samples were randomly assigned to different storage conditions. Even after sieving and mixing, some variation was evident between the control replicates. Visual comparison of the profiles from the three control replicates shows clear differences (Figure 5.11). Variation was also evident in replicate extractions performed as part of the reproducibility experiment and this is outlined in Chapter 6. 

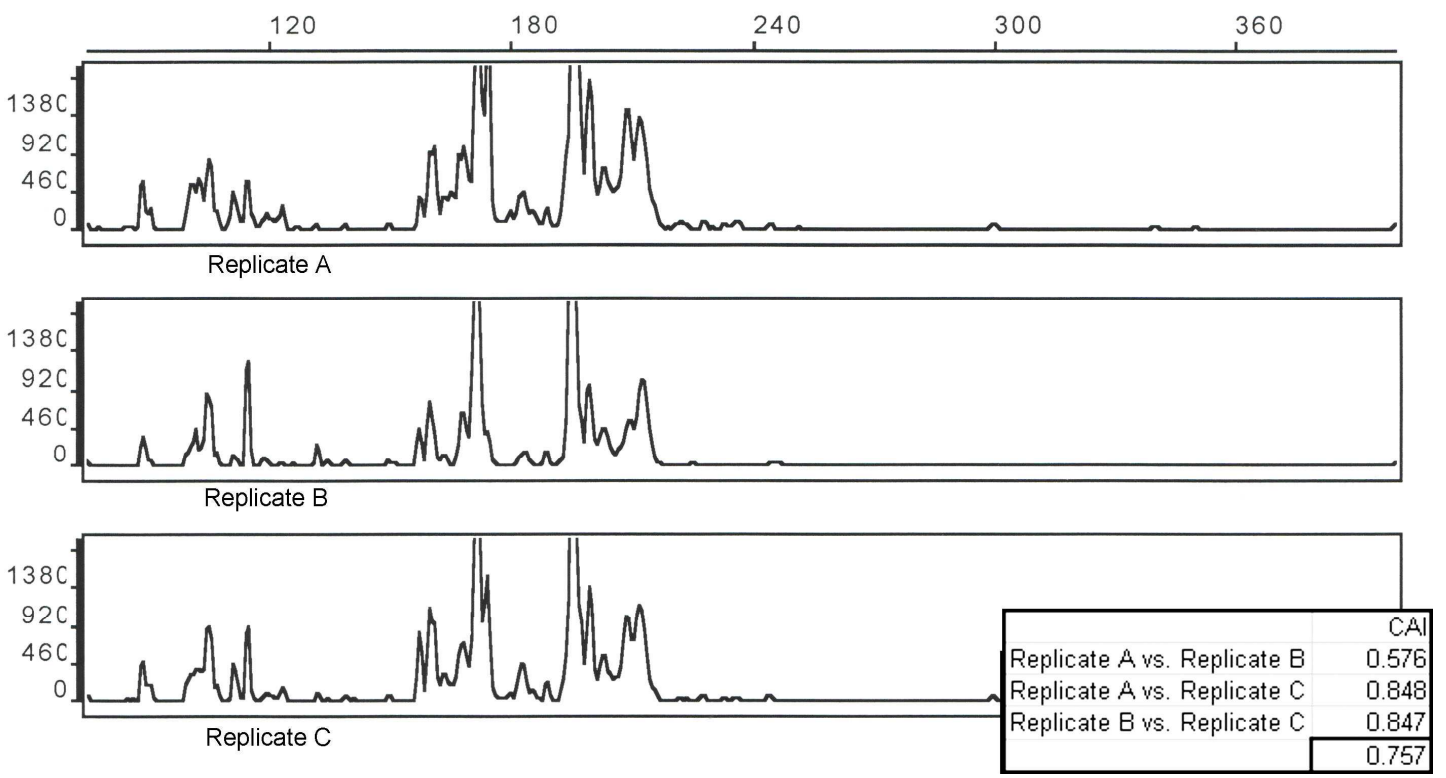

Figure 5.11. Profiles from the three replicate control samples from the storage experiment.

In an effort to reduce the level of variation seen between replicates, an additional step of homogenising sieved samples by grinding them in liquid nitrogen was tested.

\subsubsection{Method}

Ten grams of sieved soil was divided into 2 samples of $5 \mathrm{~g}$ each. One $5 \mathrm{~g}$ sample was ground in liquid nitrogen with a mortar and pestle. The other $5 \mathrm{~g}$ sample was mixed using a spatula. Three replicate extractions (using $0.5 \mathrm{~g}$ each) were carried out on each sample using the modified extraction protocol (as described in section 5.2.3.3). The resulting replicate sample profiles were then compared.

\subsubsection{Results}

Visually, some slight variation is apparent between the replicates in the two groups (Figures 5.12 and 5.13). When the CAI similarity index was calculated, the mean similarity between the samples ground in liquid nitrogen is slightly lower $(0.937 \pm 0.04)$ than the mean of the replicates that were not ground in liquid nitrogen $(0.984 \pm 0.02)$. 
This difference however is not large. The number of replicates also is not large $(n=3)$ but it appears that grinding the soil sample in liquid nitrogen does not reduce variation introduced through sampling.

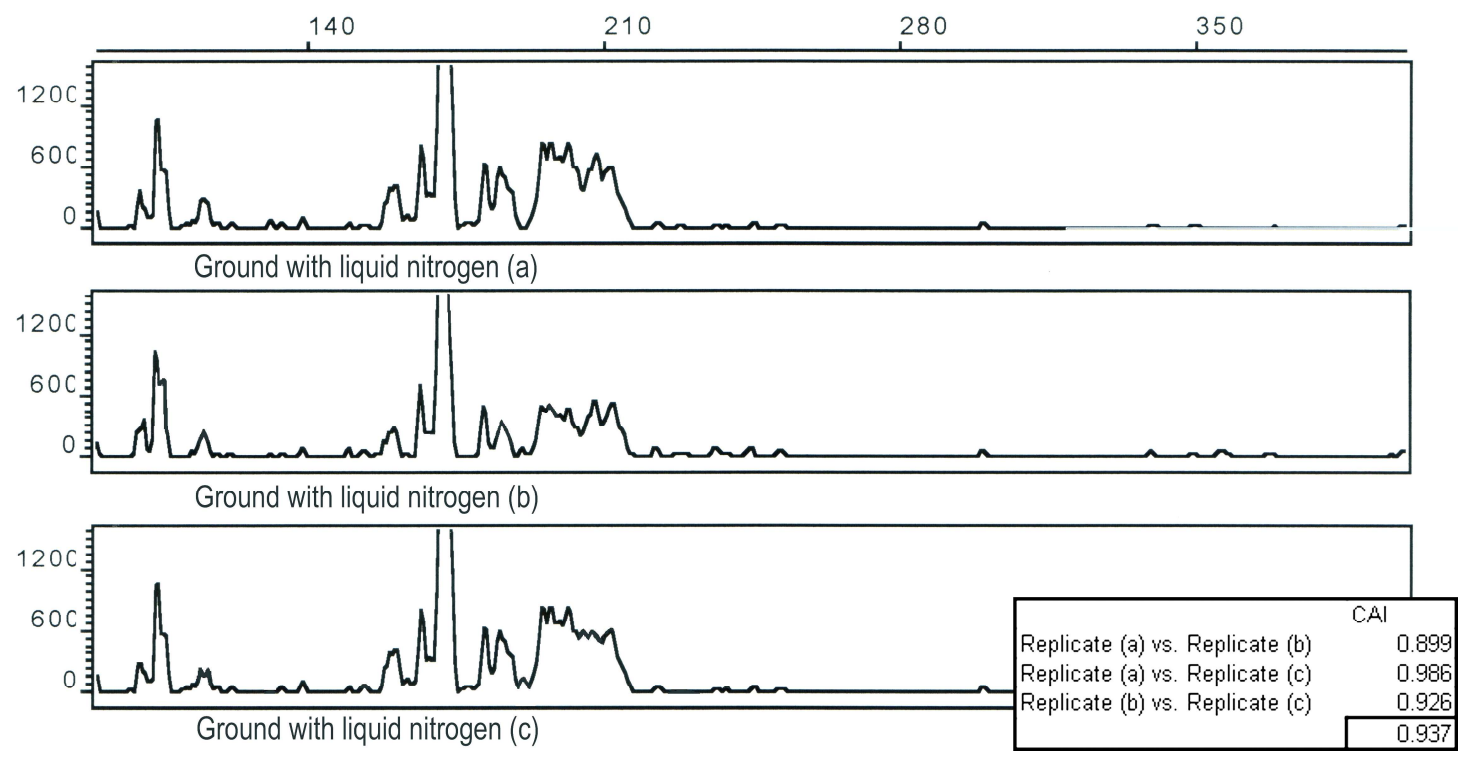

Figure 5.12. Profiles from the replicate sub-samples taken from the soil ground with liquid nitrogen.

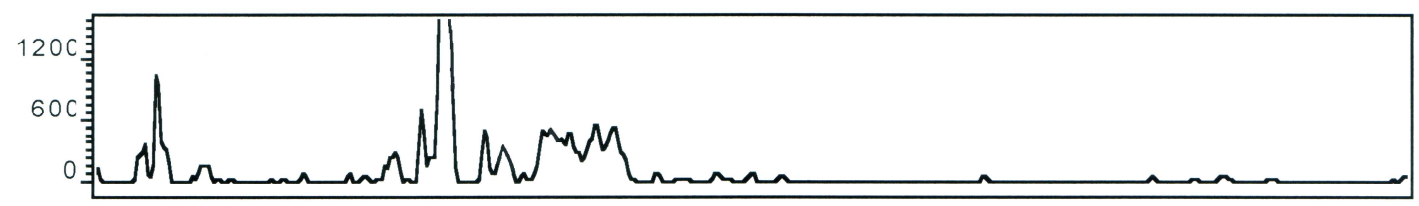

No liquid nitrogen grinding (a)

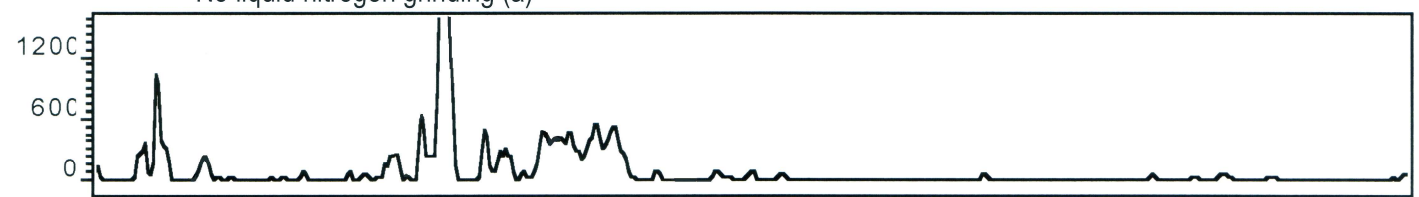

No liquid nitrogen grinding (b)

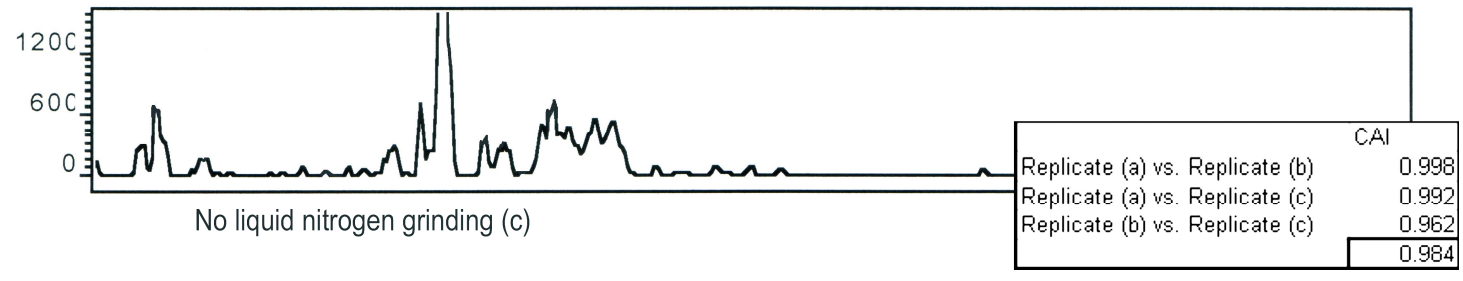

Figure 5.13. Profiles from the sub-samples taken from the soil sample not ground with liquid nitrogen. 


\subsubsection{Conclusion}

There was no apparent improvement in similarity between replicates when the soil was ground with liquid nitrogen before sub-sampling and extraction. It is preferable to keep the profiling methodology as simple as possible, so unless a clear advantage is demonstrated, a new step is not incorporated. Liquid nitrogen grinding, while not difficult, was not accepted as an additional step as it offered no clear advantage.

\subsubsection{Minimum Soil Sample Size Required to Generate a Profile}

The homicide scenario introduced the dilemma that forensic soil samples are sometimes likely to be smaller than the $0.5 \mathrm{~g}$ required for the standard DNA extraction protocol (section 3.2.2). The samples collected from items in the homicide scenario (see Table 4.1), included soil on clothing, shoes, a car tyre and a wheel-arch, and the amount of soil recovered from these ranged from $0.5 \mathrm{~g}$ to $0.11 \mathrm{~g}$. Therefore, an experiment was performed to determine the minimum amount of soil required for generation of a reliable profile.

\subsubsection{Method}

Fresh, sieved soil from Lincoln, New Zealand was weighed out into 0.5, 0.3, 0.2, 0.1, 0.05 and $0.01 \mathrm{~g}$ sample sizes. Using the improved extraction methodology (as summarised in section 5.2.3.3), DNA was extracted from each sample.

\subsubsection{Results}

Bacterial community DNA was extracted from samples of all sizes, indicating that the extraction methodology is capable of extracting template DNA from even very small $(0.01 \mathrm{~g})$ forensic soil samples, although the total amount of DNA extracted was greatly 
reduced in the $0.01 \mathrm{~g}$ sized sample compared with the other sample sizes (Figure 5.14). The DNA yield extracted decreased sharply from $89,570 \mathrm{ng}$ to $26,650 \mathrm{ng}$ when the amount of soil was reduced from $0.3 \mathrm{~g}$ to $0.2 \mathrm{~g}$. It continued to decrease with reduction in sample size down to $0.01 \mathrm{~g}$, but enough DNA (800 ng total) was recovered from the smallest sample to enable the profiling protocol to be continued (20 ng DNA total is required for PCR- see section 4.3.4.2).

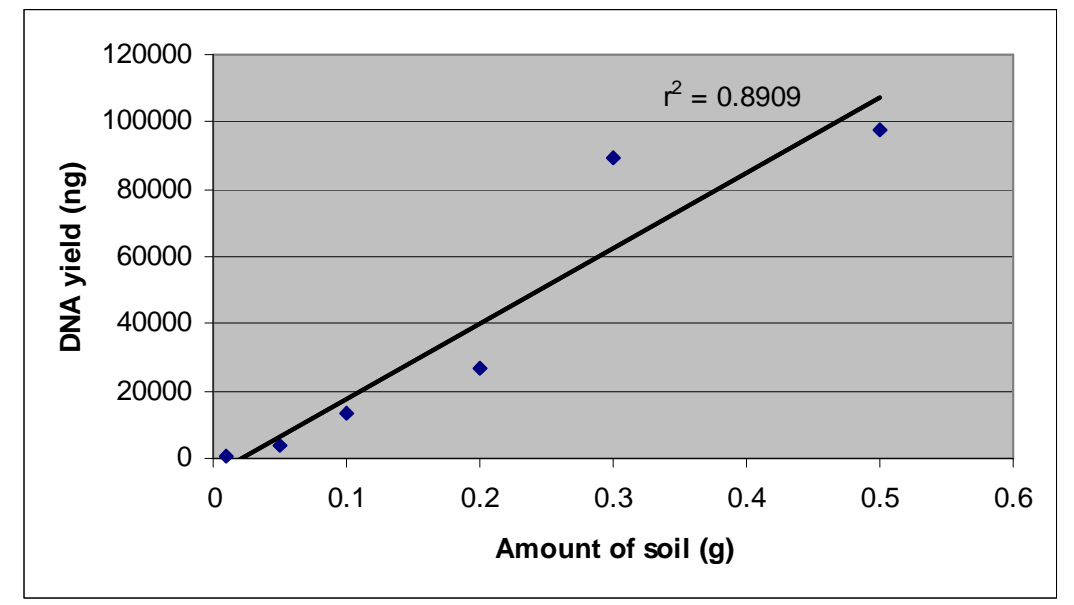

Figure 5.14. Amount of DNA recovered from soil samples of varying sizes.

Target DNA amplification was successful using the DNA extracted from the six different sized soil samples. The T-RFLP profiles generated using these PCR products were of good quality with high overall fluorescence and discrete peaks. Some minor variation is apparent between profiles (see Figure 5.15). These differences may be partly explained by variation introduced during the processing procedure, but error caused by the sample size is also likely to contribute to it. As seen in section 5.6.2, thorough homogenisation of soil samples is difficult to achieve. Microbes usually exist in soil in aggregates, or micro-communities within the greater sample (Stotzky, 1997). Unless homogenisation disrupts these aggregates, smaller samples are not likely to be 
representative of the wider soil community. Larger soil samples contain many of these individual aggregates, reducing sampling bias.
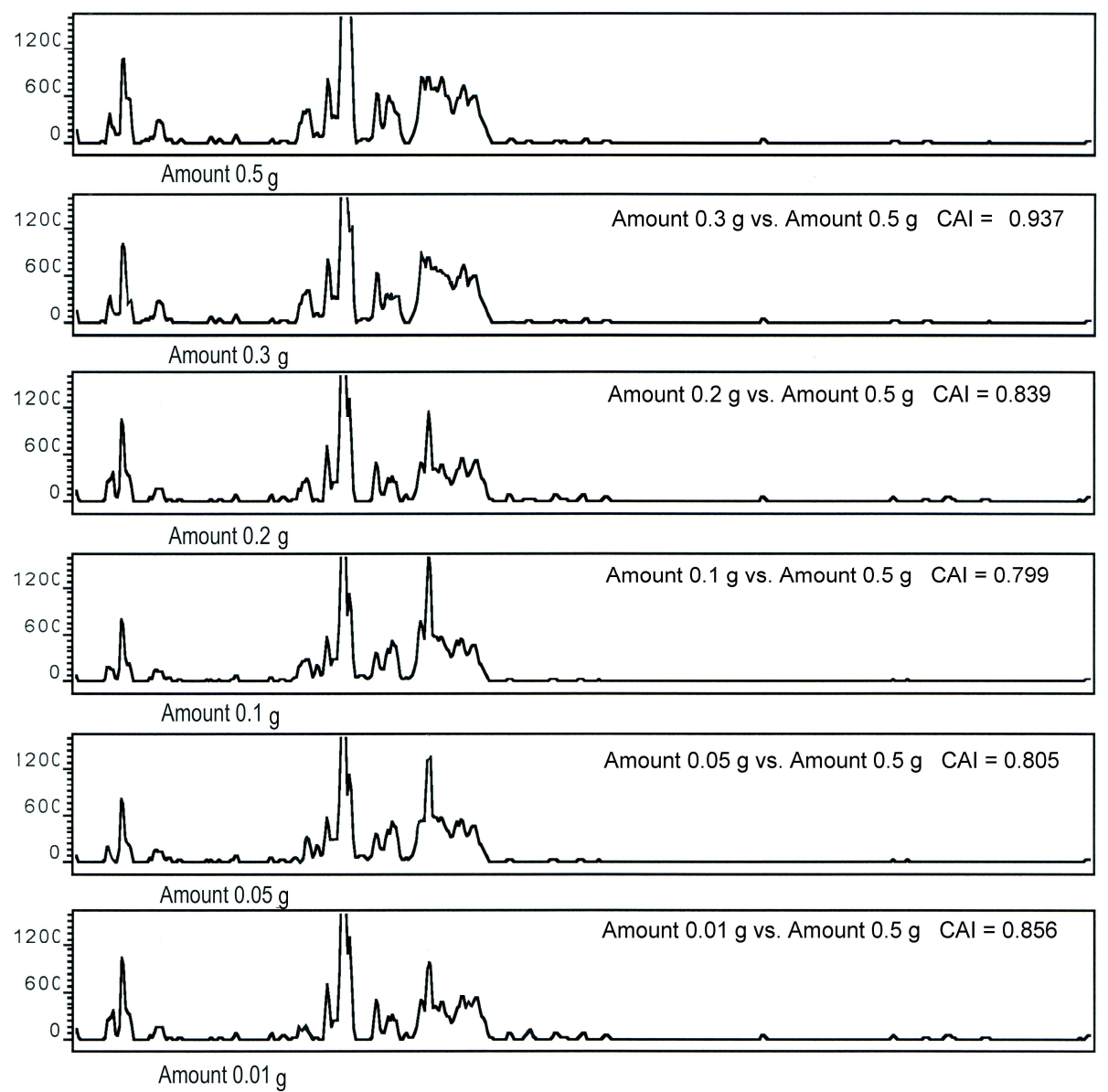

Figure 5.15. Profiles generated using different amounts of the same soil sample.

\subsubsection{Conclusion}

Soil samples as small as $0.01 \mathrm{~g}$ can be successfully profiled using the bacterial community DNA profiling system. It appears however that sampling variation might be introduced by extracting DNA from small amounts of soil. An important condition should be added to the profiling technique to reduce the introduction of variation: the same amount of carefully homogenised soil should be used for all profiles that are to be compared. If more than $0.3 \mathrm{~g}$ is available for DNA extraction, then at least $0.3 \mathrm{~g}$ should be used, as the amount of DNA recovered from $0.2 \mathrm{~g}$ was much lower, and is more likely to be influenced by microhabitats within the sample. How much of the variation 
seen in the above profiles can be attributed to the variation in sample size is unknown, but eliminating the 'amount variable' is a sensible precaution. The variation inherent in the profiling methodology itself is examined in Chapter 6.

\subsubsection{Soil Recovery from Fabrics}

In the homicide scenario, some of the lowest amounts of soil recovered were from stains on fabric. Following on from section 5.6.3 where the minimum sample size required was investigated, another experiment was designed to determine the amount of soil likely to be recovered from soil stains on various fabrics. In real forensic casework, the amount of soil in a soil stain is likely to vary considerably. Factors such as the pressure applied and moisture content of the soil are also likely to determine how much soil is transferred during contact. An 'average' sized stain was investigated in this experiment, one which is likely to occur by standing or kneeling on damp soil. The amount of soil in an average stain was estimated by creating stains on socks and denim jeans by walking and kneeling on damp soil.

\subsubsection{Method}

A selection of fabric types was chosen (Figure 5.16 and Table 5.15) that may commonly be encountered in forensic situations (B. Sutherland, ESR Ltd., pers. comm.). All clothing items were second hand, but were washed prior to use. Pieces of fabric $10 \times 10$ $\mathrm{cm}$ in size were cut from each item. 


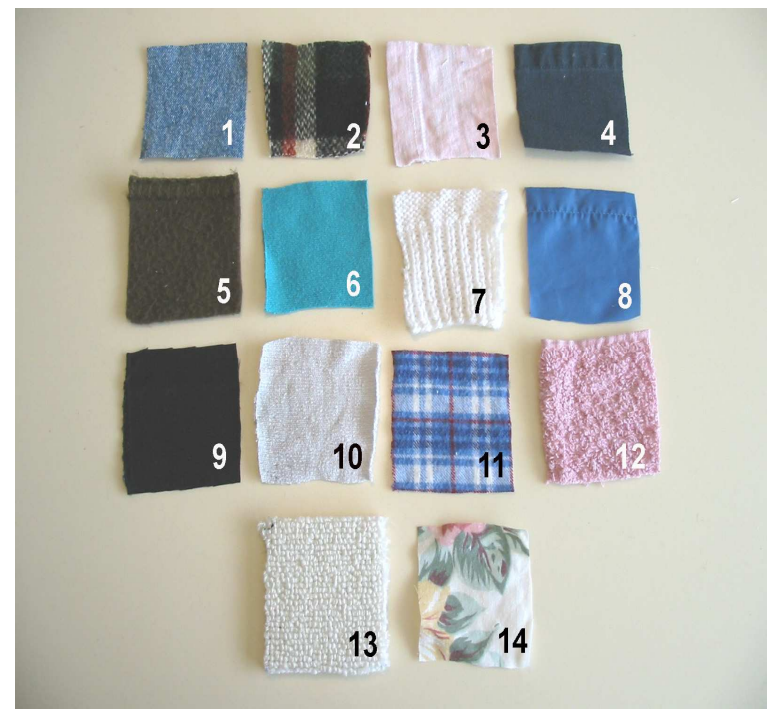

Figure 5.16. Fabric squares used for soil recovery

\begin{tabular}{|l|l|l|}
\hline & Fabric Type & $\begin{array}{l}\text { Clothing } \\
\text { Article }\end{array}$ \\
\hline 1 & Denim & Jeans \\
2 & Wool & Rug \\
3 & Cotton & T-shirt \\
4 & Heavy cotton & Overalls \\
\hline 5 & Polar fleece & Vest \\
6 & Sweat shirting & Track pants \\
7 & Knitted wool & Jersey \\
8 & Polyester & Rain jacket \\
\hline 9 & Polyester/rayon/spandex & Trousers \\
10 & Cotton/polyester & Sock \\
11 & Brushed cotton & Workshirt \\
12 & Flannel & Towel \\
\hline 13 & Wool & Carpet \\
14 & Thin cotton & Sheet \\
\hline
\end{tabular}

Table 5.15. Fabric items soil was applied to.

\section{experiment.}

Ten grams of soil was homogenised by sieving with a $2 \mathrm{~mm}$ sieve. Sterile $\mathrm{H}_{2} \mathrm{O}(1 \mathrm{~mL})$ was mixed into the soil to moisten it and enable it to adhere to the fabrics being tested. Using a metal spatula, $250 \mathrm{mg}$ of soil was then applied directly to each fabric square. The soil was rubbed in to the fabric using pressure as might be expected if transferring soil onto clothing by kneeling or standing on it. A typical stain is shown in Figure 5.17. A little extra sterile $\mathrm{H}_{2} \mathrm{O}$ was added to soil samples to enable them to adhere better to some fabrics. Fabrics were left overnight to allow the soil to dry onto them.

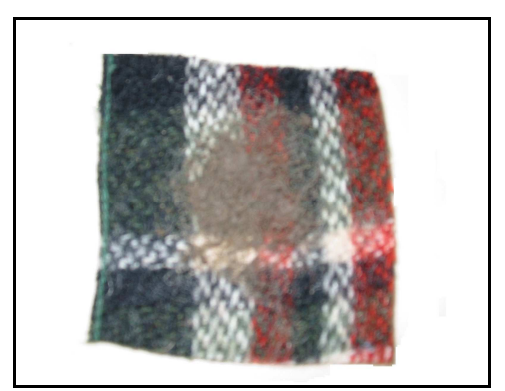

Figure 5.17. Example of a soil stain on a $10 \mathrm{~cm}^{2}$ square of fabric type 2. 
Each fabric square was then put into a sterile $50 \mathrm{~mL}$ centrifuge tube with $20 \mathrm{~mL}$ sterile $\mathrm{H}_{2} \mathrm{O}$. Each tube was shaken vigorously by hand to loosen soil from the fabric and then left to soak for two hours, with shaking every half hour. The fabric was then removed from the tube using clean gloves. Any soil still adhering to the fabric was scraped off using a sterile spatula. The remaining $\mathrm{H}_{2} \mathrm{O}$ was squeezed from the fabric and returned to the centrifuge tubes.

The soil suspensions were centrifuged for 5 minutes at $6000 \mathrm{rpm}$. Most of the supernatant was removed and discarded, leaving a small amount to allow resuspension of the soil pellet. The resuspended pellet was transferred to a microcentrifuge tube and centrifuged at 14,000 rpm for 2 minutes, and the supernatant removed completely. The pellets were left to air dry for 30 minutes under a bench lamp and then weighed.

\subsubsection{Results}

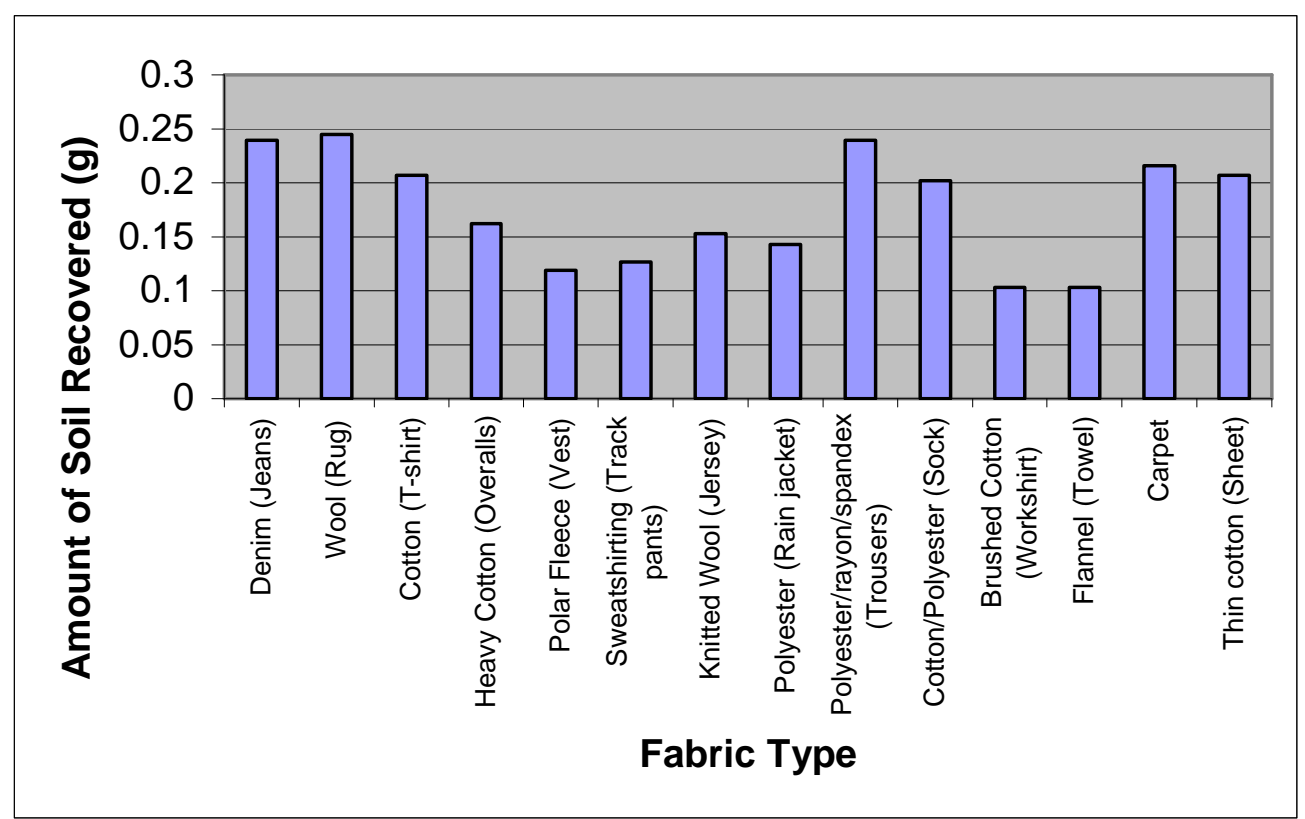

Figure 5.18. Amount of soil recovered from stains on various fabrics. 
The amount of soil recovered ranged from 0.103 to $0.245 \mathrm{~g}$ (Figure 5.18). This equates to $40-98 \%$ of the original soil applied. The figure for the woollen rug and wool carpet may be somewhat inflated due to wool threads being shaken loose and included in the recovered soil. For the denim and polyester/cotton/spandex, no visible fibres were included with the soil, suggesting that the majority of the soil stain can be recovered from these types of fabric. The more absorbent the fabric, the less soil seemed to be recovered. The flannel towel, brushed cotton and polar fleece gave the lowest recoveries.

\subsubsection{Conclusions}

Overall, the amount of soil recovered was acceptable for casework purposes, with over $0.1 \mathrm{~g}$ of soil recovered from each fabric type. A $0.1 \mathrm{~g}$ soil sample size was shown in section 5.6.4 to be more than adequate for producing a profile, although caution should be used when comparing a profile generated from such a small sample with one generated from a larger sample (see section 5.6.3). It can therefore be concluded that the fabric type affects the amount of soil that can be recovered from a stain, but for an average sized soil stain, enough soil can be recovered to produce a DNA profile.

\subsection{Conclusions}

A number of new developments were incorporated into the original profiling protocol described by Horswell et al. (2002). These changes are outlined in Figure 5.19. By including these modifications, the profiling methodology and analysis are more reliable and robust, producing good quality results more consistently, with over $90 \%$ of samples subsequently processed successfully profiling. 


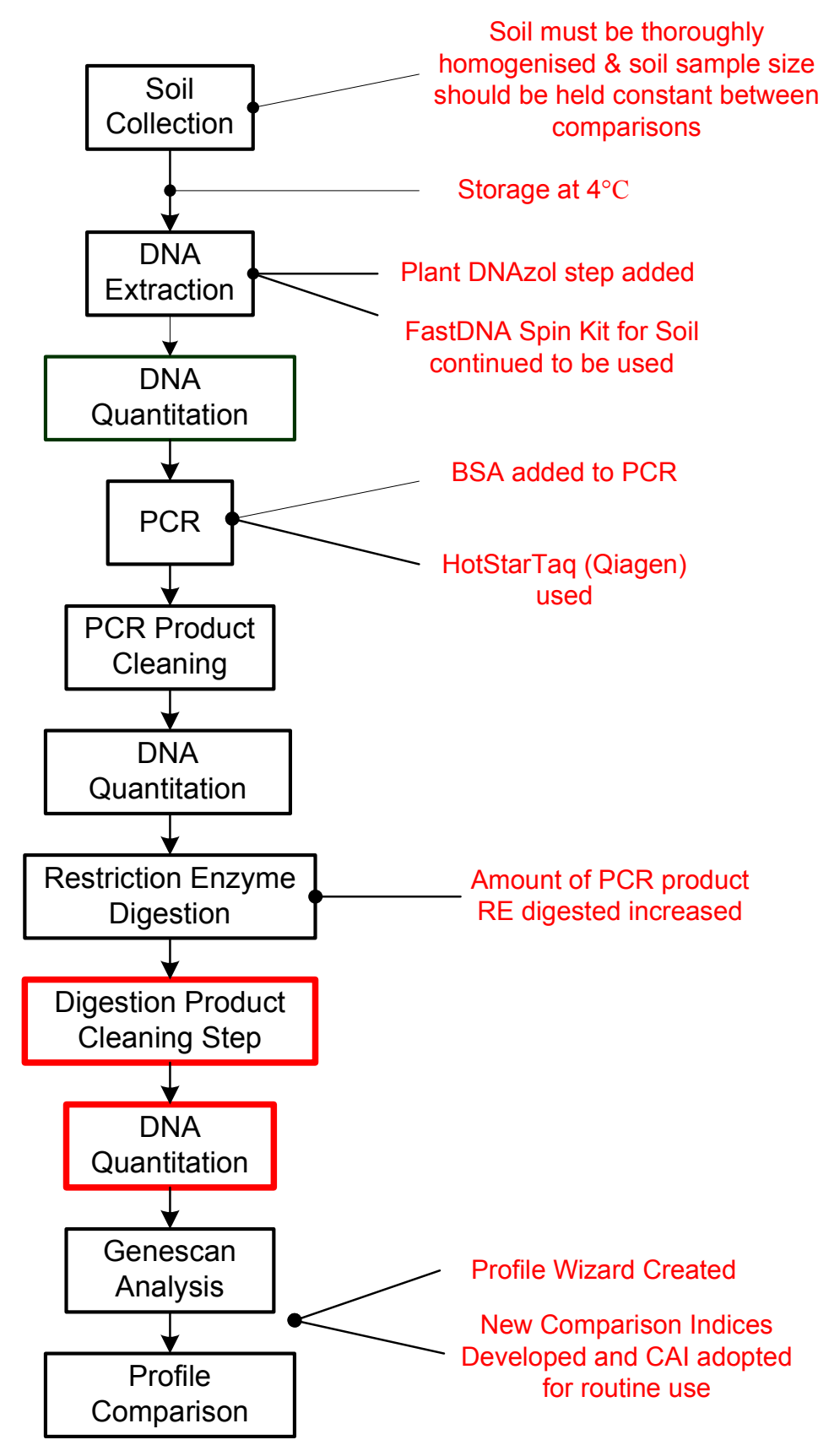

Figure 5.19. Changes made to the original methodology.

The amount of soil required to produce a quality bacterial community profile was investigated by profiling different amounts of the same soil (section 5.6.3). The profiles from all six sample sizes tested $(0.5,0.3,0.2,0.1,0.05$ and $0.01 \mathrm{~g})$ were all very similar, suggesting that sample sizes as small as $0.01 \mathrm{~g}$ can be successfully used. This is 
important as the sample sizes often encountered in forensic casework are around this size. By creating stains on a variety of fabric types (section 5.6.4), it was shown that a high percentage of the original soil in a stain on fabric can be recovered using the technique outlined in section 5.6.4.1. More than 0.1g was recovered from all fourteen fabric types tested. This demonstrates the potential the bacterial community DNA profiling technique has for utilising trace soil evidence.

Thorough homogenisation of the soil sample also emerged as an important factor for ensuring reproducibility of multiple profiles from a single sample. Sieving with a $2 \mathrm{~mm}$ diameter sieve did not achieve high reproducibility between profiles from replicate DNA extractions of soil in two separate experiments (sections 5.5 and 6.4.2.4). An experiment to determine whether grinding a soil sample in liquid nitrogen before subsampling from it would improve the reproducibility of the profile obtained was performed. The addition of the grinding step, however, did not offer any clear advantage, as the samples ground in liquid nitrogen and those not all displayed very high reproducibility between replicate profiles. When taking sub-samples from a large soil sample, all efforts should be made to homogenise the soil as well as possible by sieving, mixing and possibly grinding. It is also recommended that the same amount of soil be used for all extractions when profiles are to be compared.

Several storage methods were tested and found to be adequate for preservation of the bacterial community DNA from the time of collection until it is able to be profiled. The storage technique chosen for regular laboratory use was refrigeration at $4^{\circ} \mathrm{C}$. The mock homicide scenario soil samples were extracted immediately after collection so storage was not an issue, but for subsequent experiments, samples needed to be stored for various periods of time before DNA extraction. If the bacterial community profiling 
technique is to be used as a routine forensic application, a standard storage method is required, and $4^{\circ} \mathrm{C}$ is practical for those who collect the forensic soil samples, most likely New Zealand police personnel.

A variety of steps were tested, in order to improve the purity of the DNA extracted from soil samples. The most successful, in terms of facilitating PCR amplification of extracted target DNA was the inclusion of a DNAzol wash step (see 5.2.2.1.6) during the FastDNA Spin Kit for Soil extraction. Both DNAzol and Plant DNAzol were equally successful, so Plant DNAzol was chosen based on economic factors. This step was added into the existing methodology.

HotStarTaq DNA polymerase proved to be the most versatile DNA polymerase enzyme for amplification of template DNA extracted from soil samples. This was first incorporated into the profiling protocol when AmpliTaq Gold failed to amplify target DNA extracted from a number of the mock homicide scenario samples. It subsequently proved to be more reliable than two other polymerases tested (FastStart DNA Polymerase (Roche) and Accuprime Taq DNA Polymerase Invitrogen), as it seemed to be less affected by PCR inhibitors co-extracted with the DNA (see Table 5.9). The addition of BSA at a concentration of $0.1 \mathrm{mg} / \mathrm{mL}$ also proved effective for relieving inhibition. The combined use of the modified extraction technique, the HotStarTaq and BSA has led to a PCR success rate of around $90 \%$ in all subsequent experiments.

The addition of the MinElute Reaction Cleanup Kit step (section 5.3.1) following the restriction enzyme digestion led to greatly improved peak resolution and fluorescence intensity in the profiles. The kit removed any residual enzyme or buffer salts which 
may have been interfering with DNA fragment uptake to allow the Genetic Analyser to accurately detect the DNA fragments present.

The development of the Profile Wizard software programme enabled rapid and accurate calculation of comparisons between samples, as well as providing a database for storing data. Its implementation also allowed multiple comparison indices to be trialled. Eventually, Profile Wizard could form the basis of a New Zealand database for soils similar to the New Zealand human DNA databases.

The Common Area Index (CAI) was chosen as the comparison index for routine use, based on its meeting the criteria specified for a good comparison index (section 5.4.2). The CAI value is not over-influenced by variations in minor peaks and can account for differences in total fluorescence between profiles, unlike the previously used Sorenson's Index.

Overall, the changes made to the protocol resulted in a major improvement in PCR success, and in greatly improved profile generation. As the protocol was modified throughout the duration of the project, the quality and the PCR success rate varied between groups of samples. With all the modifications implemented, generation of a profile is successful for over $90 \%$ of the samples. This success rate includes decomposition samples which are more likely to prove difficult to amplify than soil samples without decomposition product contamination. For standard soil samples, the success rate is close to $100 \%$ when all the modifications are included in the protocol. 


\section{REPRODUCIBILITY AND SPATIAL VARIATION}

\subsection{Introduction}

The bacterial community based soil comparison technique relies heavily on the assumption that a soil bacterial community profile is representative of that soil sample and that any difference seen between samples is due to them originating from different physical locations. Previous studies, however, have identified that T-RFLP analysis results can be affected by the introduction of variation through the methodology itself, particularly as it involves numerous steps (Osborn et al., 2000). For forensic use, the technique needs to be reproducible, with minimal error introduced at each stage. Osborn et al. (2000) examined the reproducibility of T-RFLP analysis of soil samples, and investigated whether variation observed between samples could be partitioned and attributed to different stages in the methodology. A number of steps in the method described in Chapter 5 differ from those used by Osborn et al. (2000). Therefore, an approach similar to that used by Osborn et al. (2000) was taken in this chapter, to identify any systematic sources of variation. Reproducibility of the profiling technique is especially important, given its forensic application, as it must withstand detailed scrutiny if it is to be used in a court of law.

Also of importance when developing a forensic comparison technique, is some understanding of its power and limitations. It is widely accepted that the physical and chemical characteristics of soil vary greatly over short distances (Wood, 1995; Junger, 1996; Prosser, 1997; Stotzky, 1997), and it has been shown that soil bacterial communities also vary between different sites (Horswell et al., 2002; Zhou et al., 2002). The degree of variation in these communities between sample sites in close proximity, 
however, is not well established. It has been shown that microbial biomass and activity are spatially dependant at scales less than one metre in response to nutrient availability (Robertson et al., 1988; Smith et al., 1994), but variation in the actual community structure is less well known. A study performed by Cavigelli et al. (1995) suggested that spatial variation in a cultivated field was at the scale of individual soil aggregates or of the rhizosphere of individual plants. Using temperature gradient gel electrophoresis (TGGE), Felske and Akkermans (1998), determined that soil samples collected one metre apart had the same prominent bacteria present, but did not investigate the more minor variation, while Saetre and Baath (2000) showed that microbial variation in a forest environment is influenced by the location of trees and hence there is less spatial variation over small distances. Grundmann and Debouzie (2000) examined variation in $\mathrm{NH}_{4}{ }^{+}$and $\mathrm{NO}_{2}{ }^{-}$oxidising bacteria at millimetre intervals along $10 \mathrm{~cm}$ transects, and discovered that heterogeneity occurs even at this level. Spatial variation is an important factor to consider when comparing soil samples for forensic purposes, because if variation is high between sites in close proximity, sampling the exact spot where the sample in question originated from would be necessary to get a conclusive result. For example, soil from a shoe would need to be compared with that from the footprint itself, not just the general area. This could be difficult if only a general location is identified, and more exact information, such as disturbed soil or a footprint is not available. An advantage of high variation between sites in close-proximity is that small areas may be distinguished effectively. For example, if a suspect admits being in the general area (such as a garden) but denies standing in the flower-bed under the window, high spatial variation between these two area may effectively distinguish these two possibilities. If variation in soil bacterial communities is low over short distances, but higher in more geographically distinct areas, then linking a sample with a large area could be possible, such as in establishing that a suspect was in a particular neighbourhood. 
The potential uses of bacterial community DNA profiling of soil samples depends on its power of discrimination. In this chapter, a survey of the variation between samples collected at $10 \mathrm{~cm}$, at $10 \mathrm{~m}$ and at geographically distinct sites (i.e., more than $18 \mathrm{~km}$ apart) was made. For the technique to be accepted as evidence in a court of law, major studies assessing the statistical likelihood of incorrect matches / non-matches occurring would need to be performed. This magnitude is outside the scope of this project, so this part of the study has been designed to be a preliminary survey of spatial variation in bacterial communities at various levels, as well as the variation introduced by the methodology.

\subsection{Aim}

This experiment aimed to assess the reproducibility of the profiling methodology developed in Chapter 5 and to identify where, if any, erroneous variability was introduced during the profiling process itself. Spatial variation in soil bacterial communities was also investigated by comparing samples collected at set distances apart. The hypothesis tested was that soil bacterial communities vary greatly between different locations, and also, to a lesser degree, within a location.

\subsection{Methods}

Four sampling locations with similar vegetation were chosen. These were all grassed areas, but with different land uses and soil types that could potentially affect the bacterial community within the soil. These sites were also geographically separated with a distance of $18 \mathrm{~km}$ between the two nearest sites. Areas with similar vegetation were chosen because the plant species growing in a soil is thought to be one of the most 
important factors influencing bacterial population composition (see section 2.1.3.2.2). This is probably because different chemical cocktails of root exudates are released by different plants (Yang and Crowley, 2000). Grass covered sites are common in New Zealand, and outdoor crime scenes frequently involve such areas (B Sutherland, ESR Ltd., pers. comm.).

The sites chosen are shown in Figures $6.1-6.4$ and were: a site alongside the Hutt River, Lower Hutt, Wellington; a private backyard in Kelburn, Wellington; a recreational field behind the Kapi Mana darts club, Porirua; and a private backyard, Rotorua.

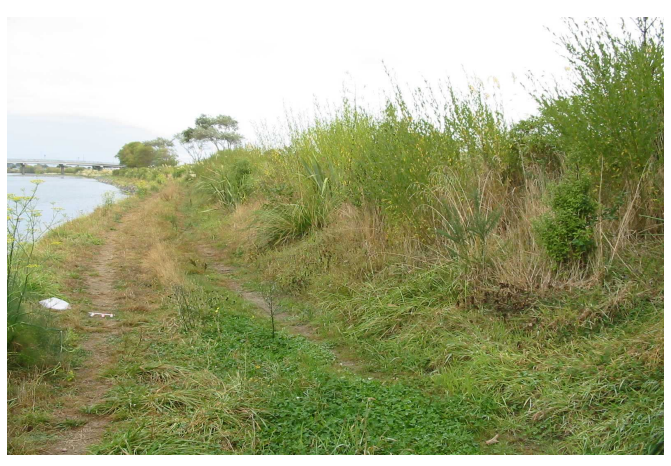

Figure 6.1. Location A: Hutt River Bank

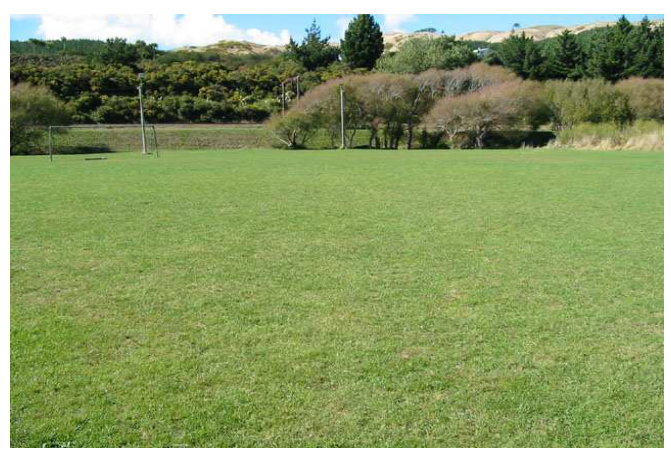

Figure 6.3. Location C: Porirua Field

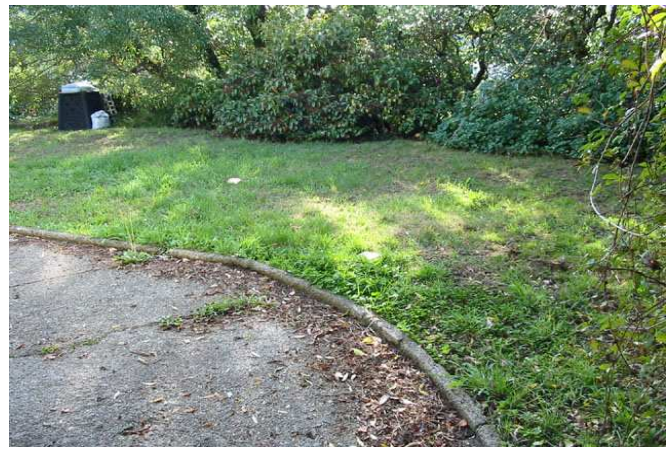

Figure 6.2. Location B: Kelburn Backyard

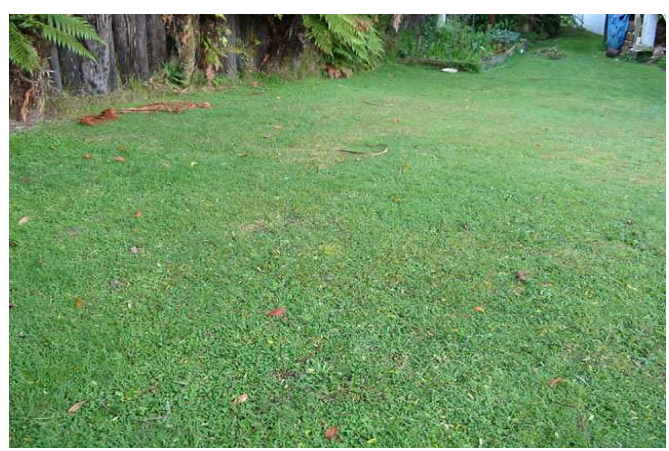

Figure 6.4. Location D: Rotorua Backyard 
The textural classification of each soil was determined using the "Feel" method described in Appendix 1.12 (Brady, 1974). The classifications are shown in Table 6.1.

\begin{tabular}{|l|l|l|}
\hline & Location & Soil Type \\
\hline A & Hutt River Bank & Fine sand \\
\hline B & Kelburn Backyard & Sandy loam \\
\hline C & Porirua Field & Silt \\
\hline D & Rotorua Backyard & Silt loam \\
\hline
\end{tabular}

Table 6.1. Location and classification of the four soils sampled.

\subsubsection{Sampling}

Within each location, three sites 10 metres apart were chosen for sampling. Three samples were collected from each site, $10 \mathrm{~cm}$ apart (see Figure 6.5). Sampling was performed as outlined in section 2.3.2. Samples were labelled according to the location (i.e. A, B, C or D) and the site (i.e. 1, 2 or 3). For example, the second sample collected from location A, site 2 would be labelled A2.2.

\section{Location A}

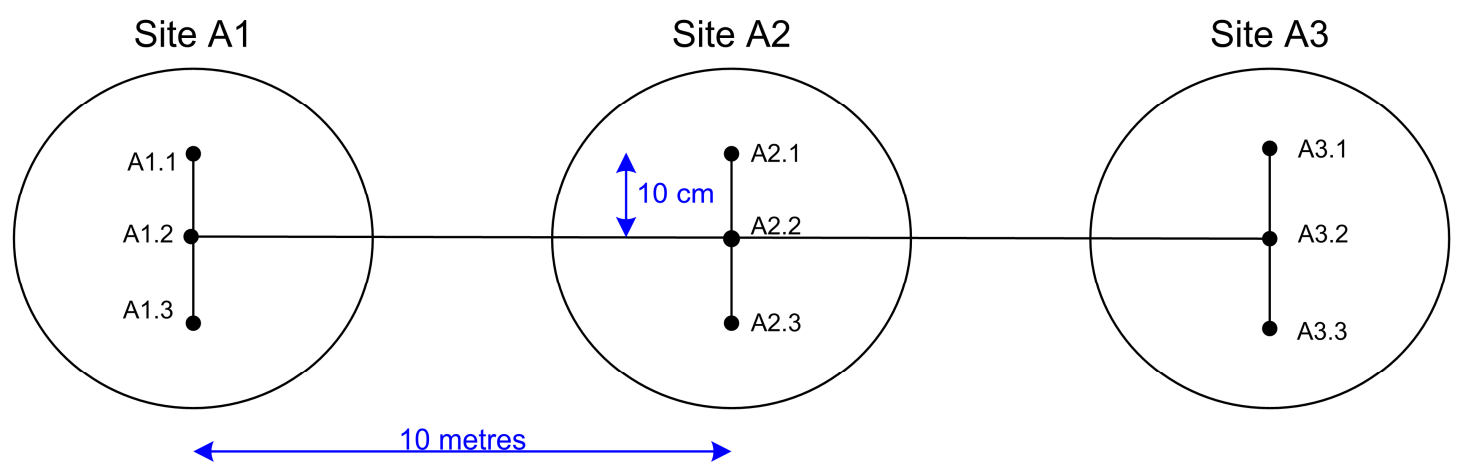

Figure 6.5. Example of the sampling plan for each location, showing location A. Three samples were collected $10 \mathrm{~cm}$ apart at sites spaced $10 \mathrm{~m}$ apart at each of the four locations. 


\subsubsection{Processing}

The soil bacterial community profiling methodology used was the refined protocol described in Chapter 5. The samples were originally processed without post-restriction digest cleaning (as described in section 5.3.1), but a number of profiles obtained were sub-optimal due to the Genetic Analyser failing to analyse the DNA (see section 5.3). The clean-up step was incorporated and the digested DNA from each sample was reanalysed. The clean-up step was found to dramatically improve the quality of the profiles generated (section 5.3.1). Inclusion of this step also increased the total fluorescence of the profiles and the peak distinction, generating more detailed, sharper profiles. Thus, all samples were reprocessed with this additional step in order to accurately compare profiles.

To test the reproducibility of each step of the methodology, one sample collected in the sampling procedure described above (section 6.3.1) was randomly chosen to undergo each step in the processing in triplicate (see Figure 6.6). Sample D2.2 had DNA extracted from it three separate times. One of these extractions was amplified in three separate PCR reactions. One amplification product was divided and digested with $A l u \mathrm{I}$ three separate times and then one digestion product was analysed on the Genetic Analyser in triplicate. This generated a total of nine profiles from sample D2.2, as shown in Figure 6.6, with extractions 1 and 3, PCRs 1 and 3, and digestions 1 and 3 each proceeding singly through to the Genetic Analyser and a profile being produced for each. 


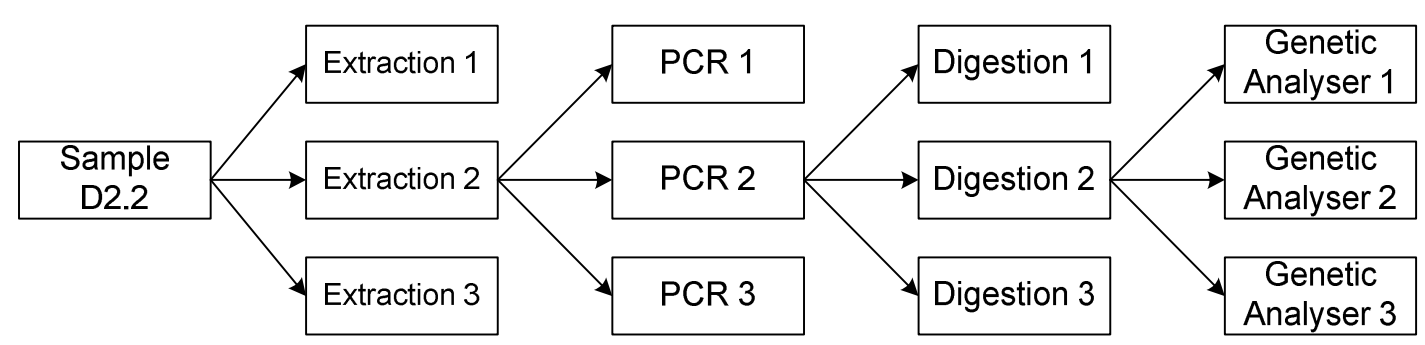

Figure 6.6. The processing procedure used to obtain replicates of each step.

The similarity index used to calculate the degree of similarity between profiles was the Common Area Index (CAI) as described in Section 4.4.2.1.

\subsection{Results}

Profiles were generated successfully for all samples collected. The results have been divided into the Spatial Variation experiment (section 6.4.1) and the Reproducibility experiment (section 6.4.2).

\subsubsection{Spatial Variation}

Comparisons were performed between profiles from samples collected $10 \mathrm{~cm}$ and 20 $\mathrm{cm}$ apart (Intra-site), 10 and $20 \mathrm{~m}$ apart (Inter-site) and between the un-related locations (Inter-location).

\subsubsection{Intra-site Similarity (10 cm Apart)}

The degree of variation between samples collected $10 \mathrm{~cm}$ apart differed between sites and locations (see Figure 6.7). The three individual samples collected at site A1, for example, showed high variation with a mean similarity index value of 0.512 and visually very different profiles (Figure 6.8). Another group from the same location, just 20 metres away, gave a mean similarity value of 0.952 , which suggests very similar profiles (Figure 6.9). The mean variation seen at all the sites (from all locations) was calculated to be $0.794 \pm 0.16$. The coefficient of variance was calculated to be $20.15 \%$. 


\begin{tabular}{|c|c|c|c|c|c|c|c|}
\hline \multicolumn{2}{|l|}{ Location A } & \multicolumn{2}{|l|}{ Location B } & \multicolumn{2}{|l|}{ Location C } & \multicolumn{2}{|l|}{ Location D } \\
\hline A1.1 vs. A1.2 & 0.524 & B1.1 vs. B1.2 & 0.907 & C1.1 vs. C1.2 & 0.910 & D1.1 vs. D1.2 & 0.581 \\
\hline A1.2 vs. A1.3 & 0.499 & B1.2 vs. B1.3 & 0.907 & C1.2 vs. C1.3 & 0.952 & D1.2 vs. D1.3 & 0.872 \\
\hline Mean & 0.512 & Mean & 0.907 & Mean & 0.931 & Mean & 0.727 \\
\hline A2.1 vs. A2.2 & 0.897 & B2.1 vs. B2.2 & 0.615 & C2.1 vs. C2.2 & 0.889 & D2.1 vs. D2.3 & 0.918 \\
\hline A2.2 vs. A2.3 & 0.854 & B2.2 vs. B2.3 & 0.613 & C2.2 vs. C2.3 & 0.858 & D2.2 vs. D2.3 & 0.623 \\
\hline Mean & 0.876 & Mean & 0.614 & Mean & 0.874 & Mean & 0.771 \\
\hline A3.1 vs. A3.2 & 0.946 & B3.1 vs. B3.2 & 0.840 & C3.1 vs. C3.2 & 0.622 & D3.1 vs. D3.2 & 0.801 \\
\hline A3.2 vs. A3.3 & 0.967 & B3.2 vs. B3.3 & 0.852 & C3.2 vs. C3.3 & 0.977 & D3.2 vs. D3.3 & 0.632 \\
\hline Mean & 0.957 & Mean & 0.846 & Mean & 0.800 & Mean & 0.717 \\
\hline Location mean & $0.781 \pm 0.21$ & Location mean & $0.789 \pm 0.14$ & Location mean & $0.868 \pm 0.13$ & Location mean & $0.738 \pm 0.14$ \\
\hline
\end{tabular}

Table 6.2 Common Area Index (CAI) similarity values between samples collected $10 \mathrm{~cm}$ apart.

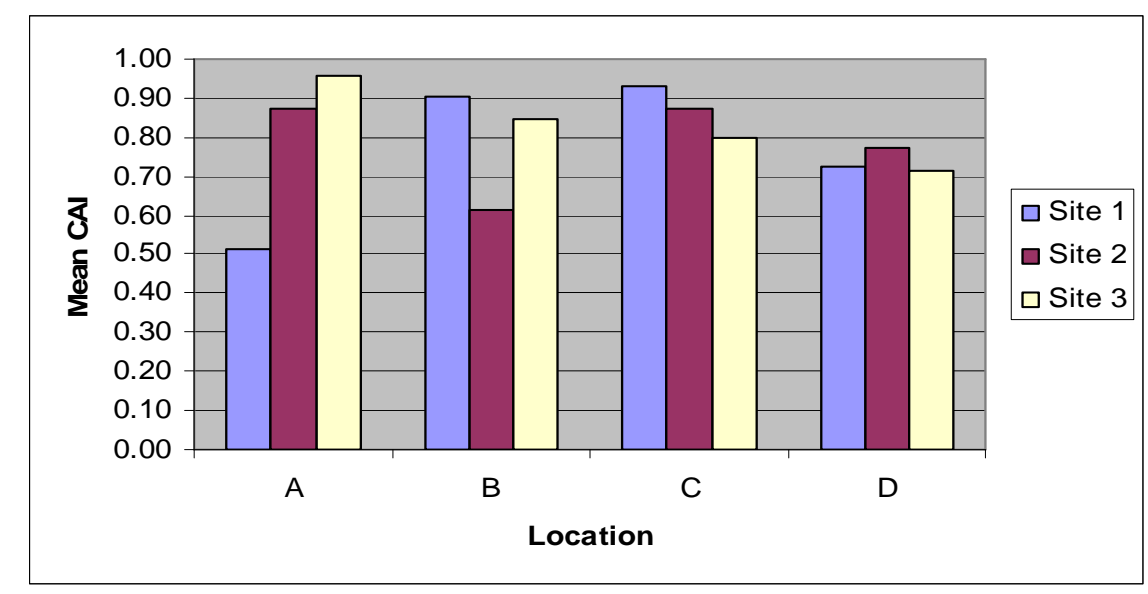

Figure 6.7. Mean CAI values for each group of samples $10 \mathrm{~cm}$ apart.
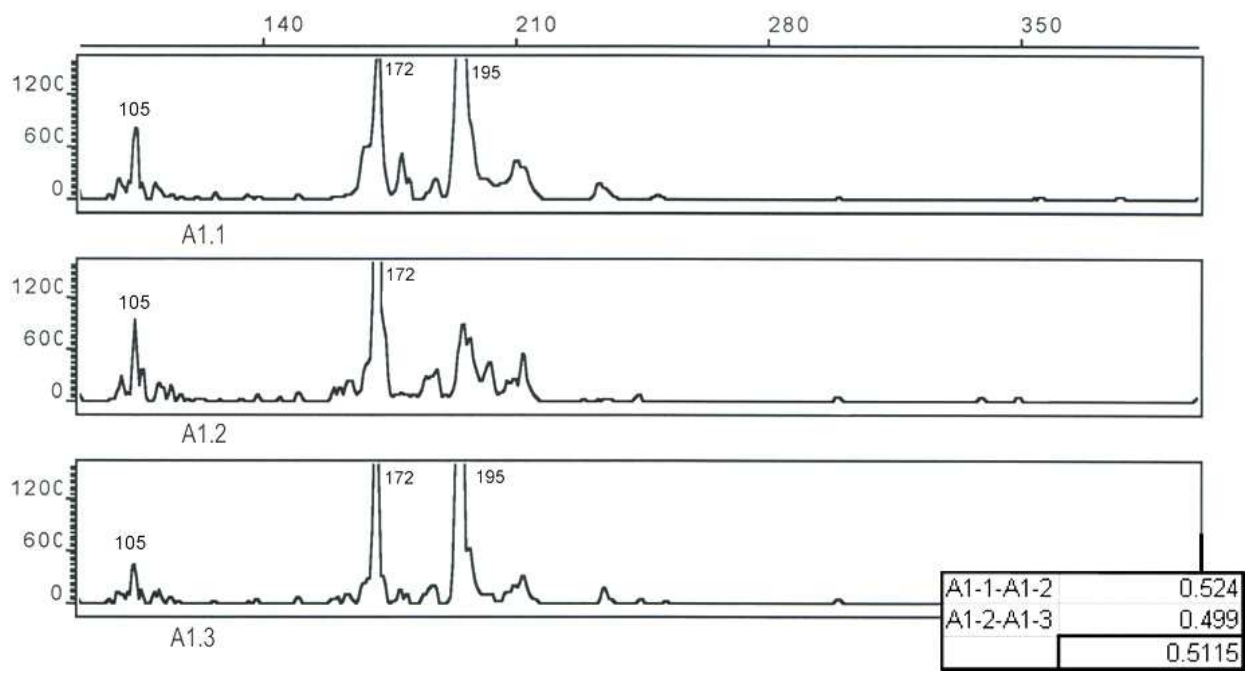

Figure 6.8. Profiles from samples A1.1 - A1.3, which display low similarity between samples collected $10 \mathrm{~cm}$ apart. 

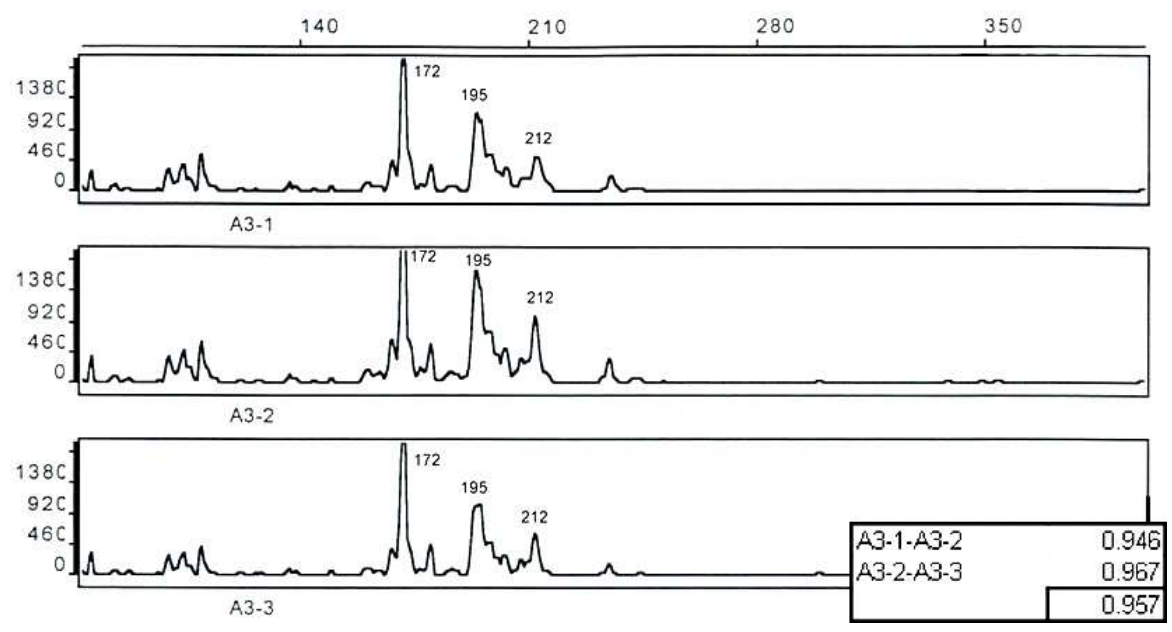

Figure 6.9. Profiles from samples A3.1 - A3.3, which display high similarity between samples collected

$10 \mathrm{~cm}$ apart.

\subsubsection{Intra-site Similarity (20 cm Apart)}

The sampling design of the experiment allowed comparisons to be made between samples $10 \mathrm{~cm}$ apart, and also $20 \mathrm{~cm}$ apart. The mean CAI value for samples collected $20 \mathrm{~cm}$ apart was $0.809 \pm 0.14$, and the coefficient of variance was calculated to be 17.30 $\%$. The individual values are shown in Table 6.3.

\begin{tabular}{|c|c|c|c|c|c|c|c|}
\hline Location A & $\mathrm{CAl}$ & Location B & $\mathrm{CAl}$ & Location C & $\mathrm{CAl}$ & Location D & $\mathrm{CAi}$ \\
\hline A1.1 vs. A1.3 & 0.543 & B1.1 vs. B1.3 & 0.924 & C1.1 vs. C1.3 & 0.913 & D1.1 vs. D1.3 & 0.702 \\
\hline A2.1 vs. A2.3 & 0.814 & B2.1 vs. B2.3 & 0.865 & C2.1 vs. C2.3 & 0.938 & D2.1 vs. D2.3 & 0.918 \\
\hline A3.1 vs. A3.3 & 0.943 & B3.1 vs. B3.3 & 0.883 & C3.1 vs. C3.3 & 0.664 & D3.1 vs. D3.3 & 0.598 \\
\hline \multicolumn{2}{|c|}{$0.767 \pm 0.20$} & \multicolumn{2}{|c|}{$0.891 \pm 0.03$} & \multicolumn{2}{|c|}{$0.838 \pm 0.15$} & \multicolumn{2}{|c|}{$0.739 \pm 0.16$} \\
\hline
\end{tabular}

Table 6.3. Common Area Index (CAI) similarity values between samples collected $20 \mathrm{~cm}$ apart.

\subsubsection{Inter-site Similarity (10 m Apart)}

The similarity between samples collected $10 \mathrm{~m}$ apart was calculated by finding the mean similarity between samples this distance apart at each site. Samples were compared along each $10 \mathrm{~m}$ transect e.g. sample A1.1 was compared with A2.1, and A2.1 was also compared with A3.1 (see Figure 6.10). Because the transects were only 
$10 \mathrm{~cm}$ apart, comparisons were also performed between samples from neighbouring transects e.g. A1.1 was compared with A2.2. These two samples, for example, are $10.0005 \mathrm{~m}$ apart, which, for the purposes of this experiment, is close enough to $10 \mathrm{~m}$.

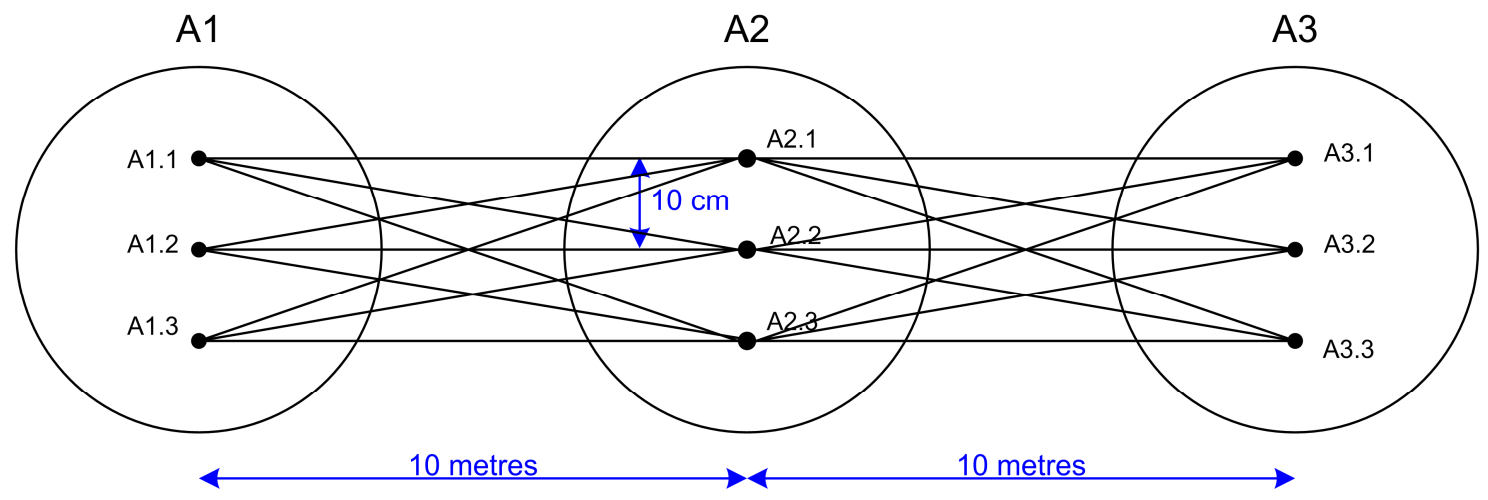

Figure 6.10. Example of the sites $10 \mathrm{~m}$ apart at each location and the comparisons that could be made between samples.

The mean CAI between samples $10 \mathrm{~m}$ apart over all four locations was calculated to be $0.741 \pm 0.10(\mathrm{n}=72)$. The coefficient of variance was calculated to be $13.50 \%$. The mean similarity of samples $10 \mathrm{~m}$ apart at each individual location is shown in Table 6.4. Location D showed slightly more variation at this level than the other sites.

\begin{tabular}{|l|l|}
\hline Location & $\begin{array}{l}\text { Mean Intra-Location }(10 \mathrm{~m}) \\
\text { Similarity }(\mathrm{n}=18)\end{array}$ \\
\hline $\mathrm{A}$ & $0.733 \pm 0.08$ \\
\hline $\mathrm{B}$ & $0.742 \pm 0.08$ \\
\hline $\mathrm{C}$ & $0.788 \pm 0.12$ \\
\hline $\mathrm{D}$ & $0.699 \pm 0.11$ \\
\hline
\end{tabular}

Table 6.4. CAI values for samples collected $10 \mathrm{~m}$ apart at each location. The mean for each location is calculated using the 18 comparisons shown in Figure 6.10. 


\subsubsection{Inter-site Similarity (20 m Apart)}

The mean CAI value for samples collected $20 \mathrm{~m}$ apart was $0.708 \pm 0.08$ and the coefficient of variance was calculated to be $11.30 \%$. The mean CAI values for each location are shown in Table 6.5.

\begin{tabular}{|l|l|}
\hline Location & $\begin{array}{l}\text { Mean Inter-Site }(20 \mathrm{~m}) \\
\text { Similarity }(\mathrm{n}=9)\end{array}$ \\
\hline $\mathrm{A}$ & $0.668 \pm 0.06$ \\
\hline $\mathrm{B}$ & $0.758 \pm 0.04$ \\
\hline $\mathrm{C}$ & $0.760 \pm 0.05$ \\
\hline $\mathrm{D}$ & $0.640 \pm 0.10$ \\
\hline
\end{tabular}

Table 6.5. CAI values for samples collected $10 \mathrm{~m}$ apart at each location.

\subsubsection{Inter-location Comparisons}

The mean inter-location CAI value was calculated by comparing each sample $(n=32)$ with every other sample collected at a different site, e.g., sample A1.1 was compared with each sample from sites B, C and D, as was A1.2, A1.3 etc. The mean from these between-location comparisons was then calculated to be $0.567 \pm 0.15$ with a coefficient of variance of $26.46 \%$. The mean similarities between individual locations are shown in Table 6.6. Location A has the lowest similarity to any of the other locations. The remaining three sites have a similarity to each other of between $0.662 \pm 0.09$ and 0.699 \pm 0.09 .

\begin{tabular}{|l|c|}
\hline Comparison & Mean CAI \pm SD \\
\hline A / B & $0.425 \pm 0.09$ \\
A / C & $0.462 \pm 0.09$ \\
A / D & $0.456 \pm 0.10$ \\
B / C & $0.695 \pm 0.06$ \\
B / D & $0.699 \pm 0.09$ \\
C / D & $0.662 \pm 0.09$ \\
\hline
\end{tabular}

Table 6.6. Mean CAI values for inter-location variation. 


\subsubsection{Reproducibility}

The soil bacterial community profiling technique was divided into four main steps where erroneous variability could be introduced by the methodology rather than by differences in the actual microbial community. Each step was performed in triplicate as shown in Figure 6.6. The results for each step are described in this section.

\subsubsection{Genetic Analyser}

The profiles for the replicate analyses on the Genetic Analyser and the comparison index values calculated when these are compared are shown in Figure 6.11.
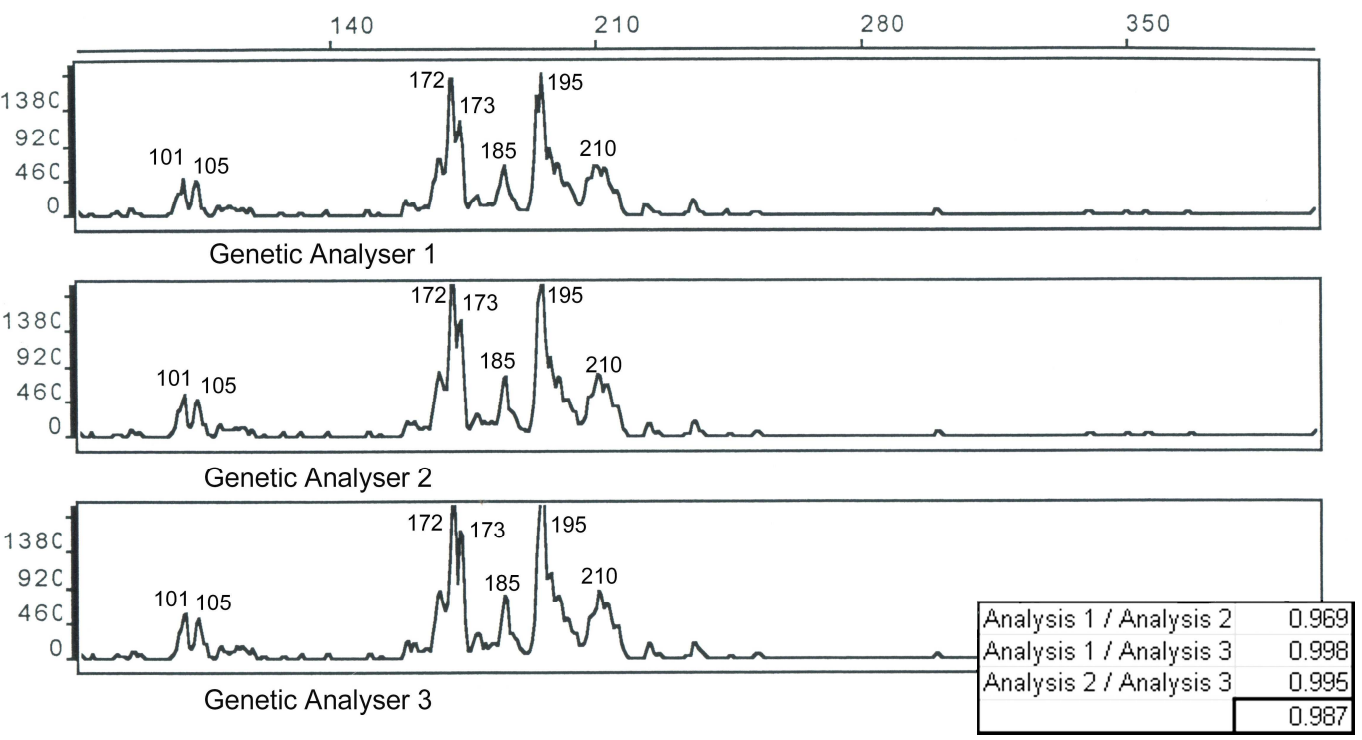

Figure 6.11. Genetic Analyser replicate profiles and CAI similarity index values.

The replicate runs on the Genetic Analyser were very similar with a similarity of 0.987 \pm 0.02 (with a coefficient of variance of $2.03 \%$ ). Some minor variation can be seen in the heights of the tallest peaks, 172 and 195 but the overall shape of the profiles is very similar in all three. The Genetic Analyser replicate runs should be expected to be highly reproducible because the process is automated with set conditions imposed. 


\subsubsection{Digestion}

The profiles for the replicate restriction enzyme digestions and the comparison index values calculated when these are compared are shown in Figure 6.12.

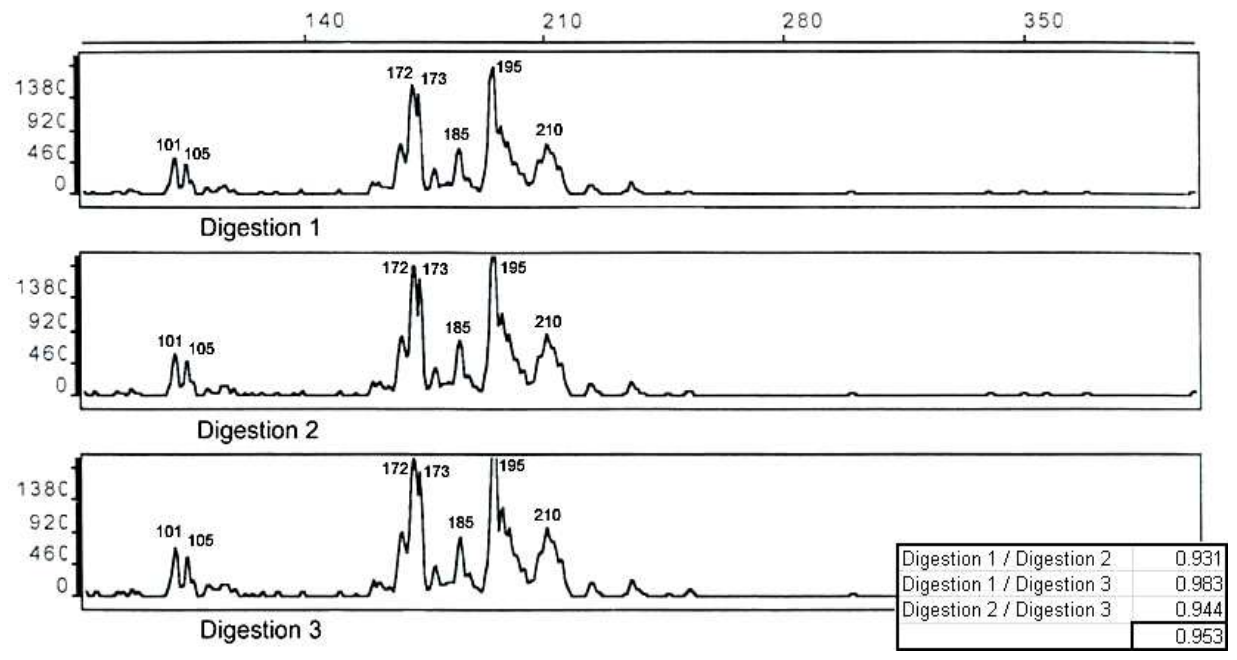

Figure 6.12. Digestion replicate profiles and CAI similarity index values.

The replicate digestions gave very similar profiles. The mean similarity index value between the three was $0.953 \pm 0.03$ (and a coefficient of variance of $3.15 \%$ ).

\subsubsection{PCR}

The profiles for the replicate PCR amplifications and the comparison index values calculated when these are compared are shown in Figure 6.13.
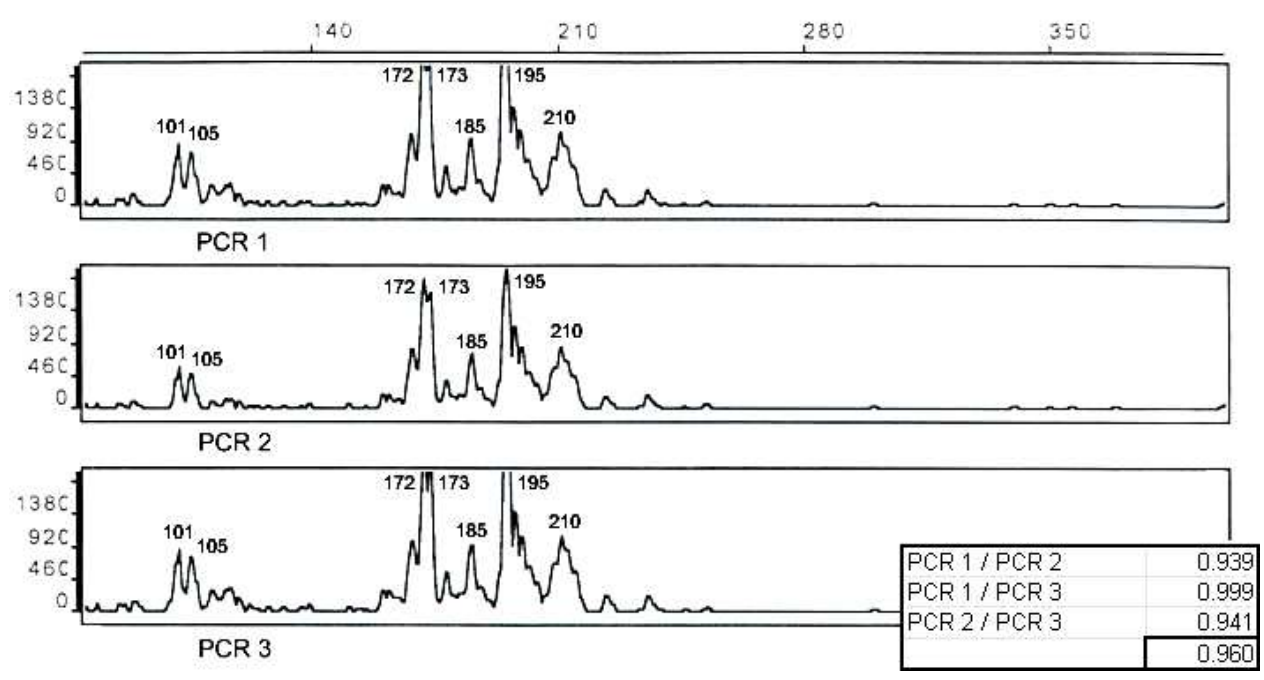

Figure 6.13. PCR replicate profiles and CAI similarity index values. 
The replicate PCR amplifications gave very similar profiles (mean CAI of $0.960 \pm$ 0.03). The coefficient of variance was calculated to be $3.13 \%$. The second profile appears to be slightly reduced in overall height, but this difference is taken into consideration by the Common Area Index.

\subsubsection{Extraction}

The profiles for the replicate DNA extractions and the similarity index values when these are compared are shown in Figure 6.14.

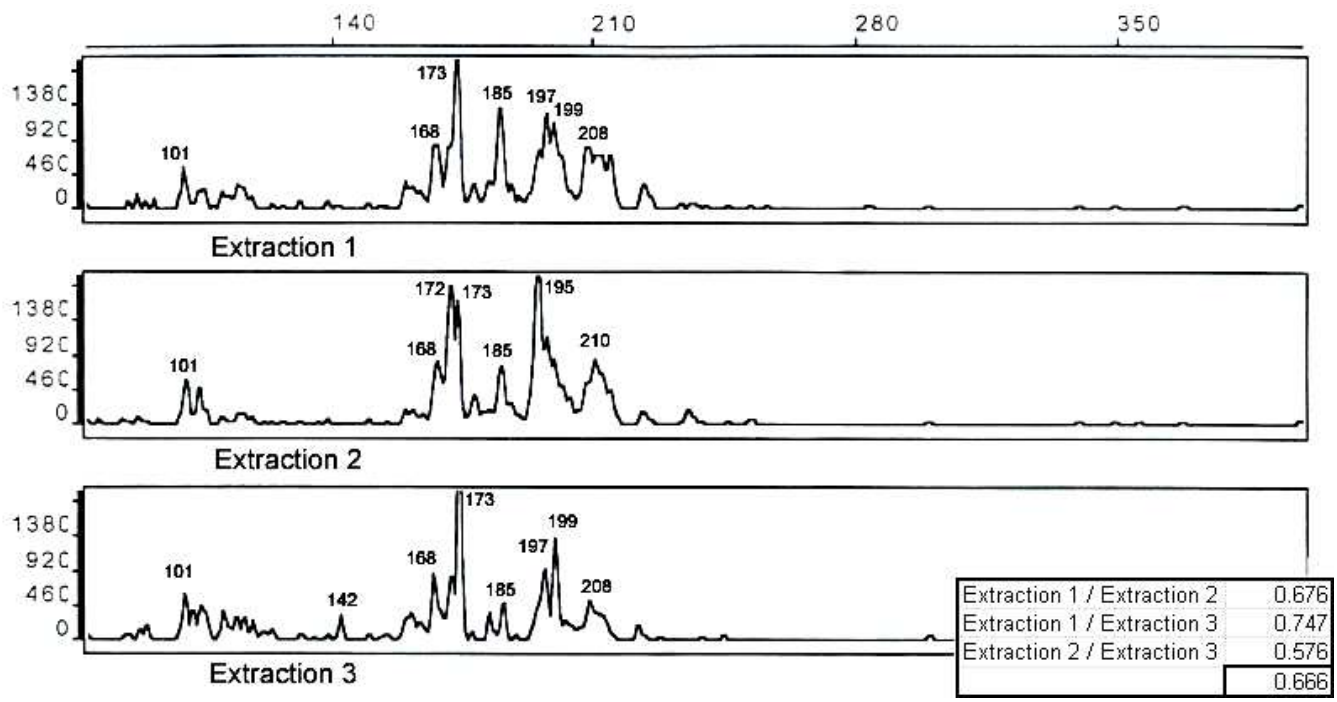

Figure 6.14. Extraction replicate profiles and CAI similarity index values.

The extraction replicates gave a mean CAI similarity index of $0.666 \pm 0.09$ with a coefficient of variance of $13.51 \%$. Visual comparison shows that the profiles display a lot of variation for replicates from the same soil sample. In extraction 2, a different peak is highest (195 bp) to that in extractions 1 and 3, where a peak at 173 bp is highest. 


\subsubsection{Summary of Results and Discussion}

The CAI similarity values for comparisons of samples from within and between locations and for replicates of each stage of the methodology are summarised in Table 6.7 .

\begin{tabular}{|l|c|c|}
\hline Level of Comparison & Mean CAI \pm SD & $\begin{array}{c}\text { Coefficient of } \\
\text { Variance }\end{array}$ \\
Inter-location & $0.567 \pm 0.15(\mathrm{n}=467)$ & $26.46 \%$ \\
Intra-location $20 \mathrm{~m}$ & $0.708 \pm 0.08(\mathrm{n}=36)$ & $11.30 \%$ \\
Intra-location $10 \mathrm{~m}$ & $0.741 \pm 0.10(\mathrm{n}=72)$ & $13.50 \%$ \\
Intra-location $20 \mathrm{~cm}$ & $0.809 \pm 0.14(\mathrm{n}=12)$ & $17.30 \%$ \\
Intra-location $10 \mathrm{~cm}$ & $0.794 \pm 0.16(\mathrm{n}=24)$ & $20.15 \%$ \\
\hline Between extractions & $0.666 \pm 0.09(\mathrm{n}=3)$ & $13.51 \%$ \\
Between PCRs & $0.960 \pm 0.03(\mathrm{n}=3)$ & $3.13 \%$ \\
Between digestions & $0.953 \pm 0.03(\mathrm{n}=3)$ & $3.15 \%$ \\
Between genetic analyser runs & $0.987 \pm 0.02(\mathrm{n}=3)$ & $2.03 \%$ \\
\hline
\end{tabular}

Table 6.7. Summary of the CAI values and Coefficient of Variance for the inter-location and intralocation sample comparisons and for replicates at each stage of the methodology.

The results from this pair of experiments offer some interesting insights into variation within soils and also the profiling methodology itself. The similarity between replicate genetic analyser runs, digestions and between PCRs appears to be high, suggesting that these stages of the methodology do not make significant contributions to the overall variation that can be apparent between profiles. The similarity values obtained between profiles from replicate DNA extractions, however, are much lower than for the other methodological steps (at CAI $=0.666)$. The similarity between the replicate extractions is actually lower than the similarity seen between samples from $10 \mathrm{~cm}, 20 \mathrm{~cm}, 10 \mathrm{~m}$ and $20 \mathrm{~m}$ apart. One of the extraction replicates (extraction 2 in Figure 6.14) is visually less similar than the other two profiles. Even if this profile is excluded, however, the remaining two profiles have a CAI of 0.747 , which is still much lower than the CAI 
values obtained from the PCR, digestion and Genetic Analyser replicates. This low similarity at extraction replicate level is in contrast to results obtained in a similar study performed by Osborn et al. (2000).

Osborn et al. (2000) evaluated the value and potential of T-RFLP analysis for bacterial community structure analysis, using a slightly different methodology to that used in this project. Their evaluation involved assessing the reproducibility of the method at each of the steps involved. One major methodological difference between that used by Osborn et al. (2000), and that used in the experiments presented here, is that polyacrylamide gel electrophoresis (PAGE) was used as the profiling method rather than the automated capillary system used in this project. The extraction methodology used by Osborn et al. (2000) also differed, with a lysozyme/C-TAB and phenol/chloroform extraction rather than the bead-beating based extraction used in this experiment. Different DNA polymerases were also used (Perkin-Elmer AmpliTaq versus Qiagen HotstarTaq), and Osborn et al. (2000) did not use a clean-up step after the digestion. In their study, replicate DNA extraction, PCR, and digests were performed, and intra-gel and inter-gel variation was assessed. By simple comparison of the number of common T-RFs present in two profiles, Osborn et al. (2000) showed that the greatest source of methodological variation was the uneven sample loading into the wells of a gel. This problem is circumvented in this project by using a capillary based Genetic Analyser system (ABI 310), which, being automated, eliminates human error. Some variation between injection amounts may occur, particularly if the DNA preparation contains contaminants that affect DNA uptake (see section 5.3), but this variation is expected to be small, and the high similarity seen between replicate injections $(0.987 \pm 0.02$, Figure 6.11$)$ supports this. 
Osborn et al. (2000) found that replicate DNA extractions, PCR amplifications and restriction enzyme digestions showed no more variability than that observed between gels. Of the three levels investigated, replicate PCRs showed the greatest variation. This result is in contrast to those presented here, where replicate extractions show the highest variability. Osborn et al. (2000), however, used a different extraction process to that described in this project. The amount of soil used to extract DNA from also differs between the two protocols and would almost certainly influence the variability between replicate extractions. Osborn et al. (2000) used $5 \mathrm{~g}$ sub-samples from a larger soil sample for each extraction, but here, only $0.5 \mathrm{~g}$ of soil was used. Ellingsoe and Johnsen (2002) showed that sample size affects the variation reported in DGGE analysis of 16S rDNA from soil. They extracted DNA from replicate soil sub-samples of four sizes $(0.01,0.1,1$ and $10 \mathrm{~g})$, all from a single, sieved soil. There was no significant variation between the $10 \mathrm{~g}$ replicates, but the variation seen in the DGGE profiles increased as the sample size decreased. This is likely to be caused by micro-heterogeneity or microhabitats within the greater soil sample. Osborn et al. (2000) may have overcome this problem by using a sample size of 5 g. Ellingsoe and Johnsen (2002) sieved their soil sample before the extraction sub-samples were taken, which suggests that homogenisation by sieving and thorough mixing (as was used in this project) is not adequate to disrupt micro-associations.

Other replicate extractions of $0.5 \mathrm{~g}$ samples performed as part of this project (see section 5.6.2), also displayed some variation $(\mathrm{CAI}=0.984)$ but not to anywhere near the degree shown between the replicate extractions described in this chapter $(\mathrm{CAI}=0.666)$. It may be that some soils are more easily homogenised than others, perhaps due to the chemical and physical characteristics of the soil, and that adequate homogenisation was particularly difficult to achieve for the sample used in this experiment. The presence of 
fine plant roots in samples could contribute to differences between sub-sample bacterial communities because of the high number of rhizobacteria associated with root surfaces, and even after sieving and mixing, these fine roots could remain in the sample. An attempt was made to improve homogenisation by grinding samples in liquid nitrogen (see section 5.6.2), but there was no discernible improvement achieved by adding this step and it was subsequently not incorporated into the routine methodology. Increasing the amount of soil used for DNA extraction, from $0.5 \mathrm{~g}$ to $1 \mathrm{~g}$ or even $5 \mathrm{~g}$ may reduce the amount of variation, although this practice would not be possible in many forensic situations, because the amount of soil recovered from items such as shoes can be small (less then $0.5 \mathrm{~g}$ ).

The high similarity observed between the replicate PCRs described in this chapter is an important finding (Figure 6.13), because the biases inherent in PCR (section 2.3.4.1) have been reported to affect the reproducibility of PCR based analyses. The bias of PCR selection (e.g., preferential primer binding) is unlikely to affect the reproducibility of profiles because the same template mixture is present in each reaction. The observation of Osborn et al. (2000) that replicate PCRs produced more variation than the replicate digestions or extractions, could be a result of PCR biases. However, it must be remembered that the greatest variation seen in the experiment was between gels. This intra-gel variation may account for any variation seen in replicates of earlier steps, as these would all be affected by the downstream intra-gel differences. The PCR components and conditions used, for example the choice of Taq polymerase and cycle programme, may also affect reproducibility of replicates. Osborn et al. (2000) used AmpliTaq polymerase while HotStarTaq was used in this experiment. The enzyme AmpliTaq Gold (an improved variant of AmpiTaq), was found to be less successful for amplifying DNA from some soil samples during method development (Chapter 5). 
HotStarTaq is thought to be more efficient at amplifying slightly degraded or contaminated DNA preparations (section 4.5), so it may also facilitate higher reproducibility between replicate PCRs.

The samples collected $10 \mathrm{~cm}$ apart at the same location (as shown in Figure 6.5) showed differing degrees of similarity (Figure 6.9). Some groups of samples were very similar while others gave visually very different profiles and low CAI values. The group of site samples that were most similar came from the same location, (A), that the most variable group also came from (sites A3 and A1, Figures 6.9 and 6.8). This difference between areas within a location shows that bacterial spatial heterogeneity in surface soils is highly variable. Some sites might be relatively homogeneous over a wide area, while others might vary over even very small distances. This is likely to be due to localised nutrient deposits (Stotzky, 1997). While all four locations sampled in this experiment were grass covered, there may have been very localised differences in vegetation. This is a definite possibility for location $\mathrm{A}$, as the sampling transect followed a popular walking track along the Hutt River. Location A is also a good example of a typical crime scene (S Cordiner, ESR Ltd., pers. comm.). Some areas were more exposed than others due to being trampled by walkers, and further localised nutrient deposits are probably contributed in this area by dog excrement and urine. The level of human activity at this location is likely to be higher than at the other three, although location $\mathrm{C}$ is a sports field and can also experience heavy use. Environmental factors such as topography, aspect and micro-climates at the locations were not investigated, but are also likely to influence the heterogeneity of the soil bacterial communities.

The samples collected $10 \mathrm{~cm}$ apart did not appear to be much more similar to each other than those collected $10 \mathrm{~m}$ apart. Soil bacterial heterogeneity did not seem to increase 
much with the greater local spatial separation. Location D had a lower mean spatial heterogeneity between sites spaced $10 \mathrm{~m}$ apart than the other three locations (see Table $6.2)$.

The similarity observed between samples from different locations was lower at $0.567 \pm$ 0.15 than that seen for intra-location comparisons, but the large standard deviation associated with this figure suggests that the degree of variation between sites is at least partly dependant on the specific sites. Three locations, B, C and D, were more similar to each other than any of them were to location A. This could be due to the more intensive use of this location by human and animal traffic, as well as the fact that this was probably the only site that was not sown with commercial grass seed (the other locations were all 'lawns'). The soil location A was classified as sand, and while locations $\mathrm{B}$ and $\mathrm{C}$ also had large sand components, A was by far the sandiest of these. Sand in soil decreases its ability to retain water against the pull of gravity, and hence very sandy soil is thought to be unable to support a large bacterial community (Stotzky, 1997). Location A, however, obviously contained a bacterial community, and was able to support the growth of vegetation. Because of its proximity to the Hutt River, this location experiences flooding from time to time, which could also influence the soil bacterial community.

\subsection{Conclusions}

Osborn et al. (2000) concluded that T-RFLP is a highly reproducible and robust technique for studying bacterial community structure. Although some variation was introduced by the methodology, the overall level was low. The results presented in this chapter, apart from the low similarity experienced between replicate extractions, 
support this conclusion. If sample size is indeed a major contributing factor, a change could be introduced to the profiling methodology whereby a larger sample size should be used if practically possible. As discussed in section 5.6.4, the soil sample sizes encountered in forensic case-work are often smaller than the $0.5 \mathrm{~g}$ of soil used in the modified standard protocol. It might be expected that very close matches between samples of $0.5 \mathrm{~g}$ or smaller and reference samples collected from, for example, a crime scene would not be likely because of sample size difference. This knowledge might influence the interpretation of such comparisons.

The level of variation between samples collected within a location, particularly at the 10 $\mathrm{cm}$ distance, suggests that discrimination between very close sites, such as between the lawn by a driveway and the lawn under a victim's window, may be possible. This introduces the requirement that when sampling a crime scene, samples must be collected from all small localised spots that are likely to be of importance. This means, for example, that the shoeprint itself must be sampled rather than just collecting a large reference sample from some other point in the garden. Thus, it would be prudent for investigators to collect many samples from any site at the crime scene where soil transfer to the suspect could have occurred.

The apparent degree of soil bacterial community heterogeneity between sites A-D, which have very similar vegetation, is slightly higher than variation within each site, but not by much. It is possible that, because bacterial communities are strongly influenced by the associated vegetation, these four sites exhibit a degree of similarity because of their similar plant cover. It might be that sites with different vegetation may be more dissimilar than those with common vegetation types, although this parameter was not investigated in this project. If this were true, then having different grassed site profiles 
showing some degree of similarity (while not being the same) presents a big advantage. If a sample from an unknown site gives a profile that is characteristic of a grassed site but different from, say, native bush, then the police may be able to focus their investigations on areas covered with grass.

In conclusion, it appears that with the possible exception of the replicate extractions, the profiling methodology is highly reproducible. Reconsideration of the sample size used for extraction or further investigation into more robust homogenisation techniques will probably enable this variation introduction to be minimised. Spatial heterogeneity of the bacterial community structure in soil is higher than the variation introduced by the methodology and the degree seems to vary between locations and also over smaller distances. These observations confirm the hypothesis that variation is exhibited both between and within locations although the degree of variation is similar. This study was successful as a preliminary survey of the degree of variation that might occur within a site and between different sites, as well as determining that the profiling method is highly reproducible at most steps, although further development of homogenisation techniques might be required to improve the reproducibility of the DNA extraction step. 


\section{POST MORTEM INTERVAL ESTIMATION}

\subsection{Introduction}

The microbiology associated with human body decomposition is not well understood. It is widely accepted that the decomposition process is complex, involving very large numbers and many species of microbes (Janaway, 1996; Vass, 2001). This chapter outlines how, for the first time, the micro-organisms associated with mammalian decomposition have been investigated using molecular biological techniques. Understanding this decomposition-associated microbiology may eventually lead to the development of a new technique to estimate the time elapsed since a person died, the post mortem interval (PMI). The overall aim of this section of the research was to determine whether changes in soil bacterial communities associated with decomposition could be visualised using the soil bacterial community profiling technique outlined in Chapter 5. The underlying hypothesis of this chapter is that, as decomposition progresses, a chain of bacterial succession will occur in response to the succession of organic compounds liberated from the body into the underling soil. These organic compounds are breakdown products of body constituents, and include macromolecules such as proteins, lipids and carbohydrates. Many soil bacterial species will grow and proliferate using these compounds as carbon and nitrogen sources, and this will alter the composition of the soil bacterial community. Also contributing to this bacterial community change is the body's natural microflora which is released into the soil when body fluids begin to be purged. Decomposition of human bodies occurs in a fairly predictable progression which has been well documented (Janaway, 1996; Gill-King, 1997; Forbes et al., 2002). It is likely that the changes that occur in the soil bacterial community over time are correlated with these documented stages. If this is so, then 
bacterial succession in the underlying soil may offer clues to the time elapsed since the person died.

Three groups of soil samples were used in this investigation. One group originated from under decomposing human cadavers, and the other two from studies using pig (Sus scrofa) carcasses; one with the pigs on the soil surface, and the other using buried pigs.

\subsection{Surface Exposure Decomposition Experiment}

\subsubsection{Introduction}

A study into post mortem interval estimation using entomological succession was performed in 2002 by University of Auckland student Terry Eberhardt as part of her MSc project. This project involved collection and analysis of insects colonising exposed decomposing pigs in different habitats. Ms Eberhardt collected soil samples for this study concurrently with her entomological studies.

The domestic pig (Sus scrofa) is used as a standard animal model for human decomposition because both animals undergo similar decomposition processes. A young domestic pig is roughly equivalent in size to the average human torso, and also has similar gastrointestinal fauna and skin to those of humans (Eberhardt, 2003).

\subsubsection{Aim}

The aim of this experiment was to determine whether changes in the soil bacterial community could be detected, using community DNA profiling, as decomposition progressed. Soil samples from under the pigs were collected over the course of 
decomposition. In addition, to normalise natural fluctuations in the bacterial community due to climatic conditions, control samples were taken from nearby, but not under the pigs.

\subsubsection{Methods}

For the entomological study, nine pigs were euthanised in accordance with University of Auckland ethics approval (AEC/02/2002/R13), which required the pigs to be dispatched humanely by a qualified person within the guidelines set by the University and the Ministry of Agriculture and Fisheries (Eberhardt, 2003). Soil was collected from under three of these pigs. Euthanasia was performed by rendering the animal unconscious with a captive bolt pistol followed by severing of the thoracic aorta. The pigs were killed at a commercial piggery, weighed and placed within double plastic bags for transport to the experiment site. The weight of each pig was recorded at the time of death. An average weight of $23 \mathrm{~kg}$ is recommended as the appropriate size comparison to the average human torso (Catts and Goff, 1992). The weights of the pigs ranged from 14.5 to $29 \mathrm{~kg}$.

\subsubsection{Decomposition Sites}

Three locations with different vegetation and soil types were chosen. These locations were an open grassy field, native bush and an area of sand dunes. The grass location was in Henderson, West Auckland and was on farm pasture intermittently grazed by sheep and cattle. The study sites at this location were on a western facing hillside covered in mixed grasses and exposed to the weather due to a lack of taller vegetation. 
The bush and sand locations were both within the Kaipara Weapons Range on Auckland's South Head Peninsula. The bush experimental site had a native vegetation community consisting predominantly of cabbage trees (Cordyline australis), manuka trees (Leptospermum sp.) and flax (Linum sp.). The ground covering was an organic layer of mainly leafy debris approximately $2-5 \mathrm{~cm}$ thick on top of sandy soil. The surrounding trees protected the site from exposure to the sun and the topography protected the site from excess wind.

The sand site was in a coastal sand dune area approximately $500 \mathrm{~m}$ from the ocean within the Kaipara Weapon's Range. The ground cover was sand with low shrubby vegetation that screened the area from view. The shrubs also afforded some protection from the sun and wind.

\subsubsection{Experimental Set-up}

Each pig carcass was dressed in a cotton T-shirt and underpants to simulate a partially clothed human homicide victim. A plasticised tape measure was placed round the abdomen of each carcass to monitor change in girth during decomposition. Three pigs were situated approximately $50 \mathrm{~m}$ apart at each site. The area where each pig was placed was enclosed by a chicken wire fence to prevent interference by scavengers. Each pig was also enclosed in a wire and mesh cage to enable it to be moved for sampling from underneath it, with minimal interference to the decomposition process.

\subsubsection{Sampling}

At each site, one pig was selected for the soil bacterial community profiling experiment. Two points under the pig were marked with golf tees. These were designated as 
decomposition sampling points A and B. Two control points, in an area adjacent to where the pig was positioned, were also marked. These were designated control sampling points A and B. These two sets of points, marked with sample collection tubes, can be seen at each site in Figures 7.1, 7.2 and 7.3.

Surface soil samples (approx. $2 \mathrm{~g}$ ) were collected by scraping the top $0.5 \mathrm{~cm}$ of the soil surface using a metal spatula sterilised with ethanol (refer to section 3.2.1 for more details). Soil samples were collected from each sampling point, adjacent to the golf tees, before the pigs were put in place. Rather than sampling from exactly the same point next to the golf tee, consecutive sample collections were performed a few centimetres apart to avoid sampling from different soil layers. Additionally, some samples were collected slightly further away due to adipocere formation near the golf tee marker. A sample collected where adipocere was located would likely have contained primarily pig tissue with little soil. Samples were stored in sterile $15 \mathrm{~mL}$ plastic centrifuge tubes, packaged, chilled, and sent to Wellington. Sampling was performed on five days over the course of decomposition, except for at the grass site where, in one instance, control samples were collected on a different day to the decomposition samples. In total, twenty samples were collected from each site, 10 control and 10 experimental, except for the bush site, where two control samples from one sampling day were accidentally combined, leaving only nine controls. 


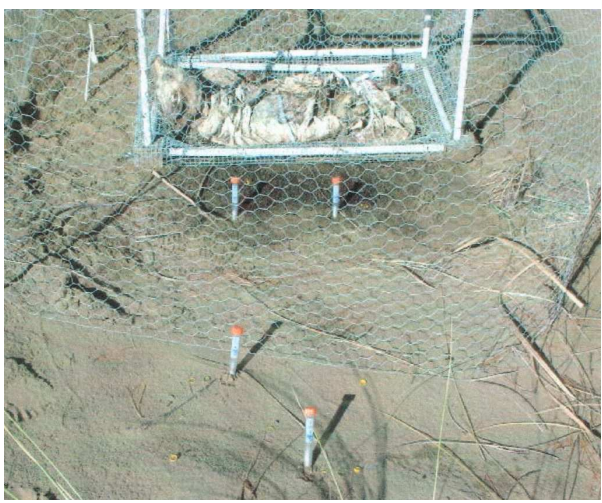

Figure 7.1. Experimental setup for the pig at the sand site.

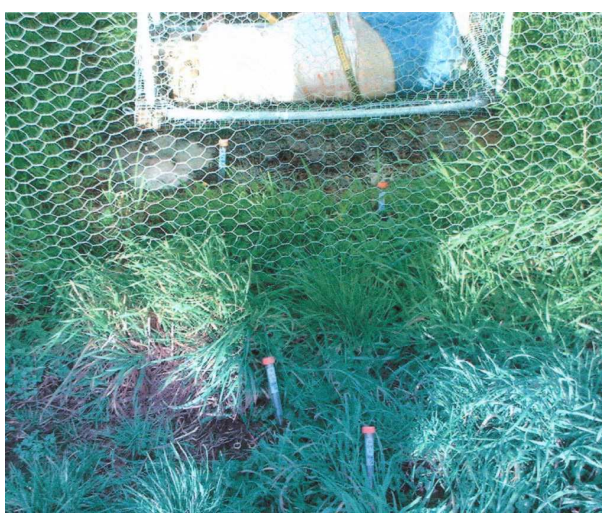

Figure 7.2. Experimental setup for the pig at the grass site.

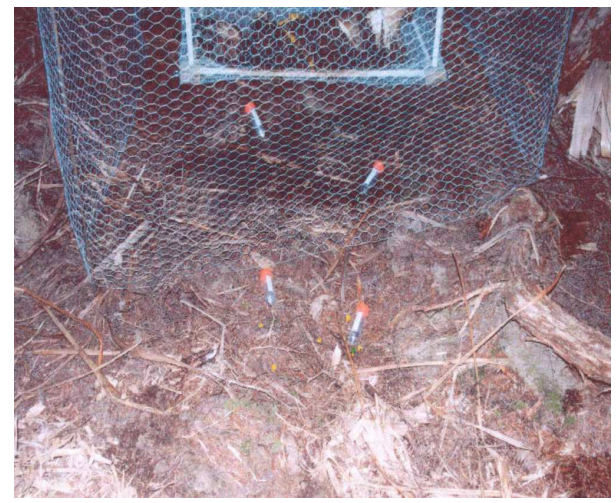

Figure7.3. Experimental setup for the pig at the bush site.

\subsubsection{Processing}

The samples were put through the basic profiling methodology outlined in Chapter 3. Because the methodology development outlined in Chapter 4 was an ongoing process, not all of the changes to the profiling methodology had been fully tested and adapted when the decomposition experiment samples were processed. The only change to the methodology from that originally developed by Horswell et al. (2002), as outlined in Chapter 3, was the use of HotStarTaq DNA polymerase (section 4.3.4.2) rather than AmpliTaq Gold DNA Polymerase. The groups of soil samples from each site were processed in two batches to make the handling of them manageable. 


\subsubsection{Results}

A bacterial community DNA profile could not be generated from 11 of the 59 soil samples processed, either due to an insufficient amount of DNA being extracted from the soil, or due to unsuccessful amplification of the template DNA. Six of the 10 sand control samples yielded little (less than $50 \mathrm{ng}$ total DNA in $50 \mu \mathrm{L}$ ), or no DNA. Attempts at re-extraction of DNA from these soil samples gave similar low or zero results. With one exception, template DNA extracted from all of the control samples from the bush and grass sites allowed target amplification, while the template DNA extracted from soil collected under the pigs proved only slightly more problematic, with only four from 30 not yielding PCR products. The success rates of the DNA extraction and PCR for the different groups is shown in Table 7.1. The samples from which DNA templates did amplify gave profiles with varying numbers (9-58) of peaks. The majority of profiles, however, had more than 20 peaks.

\begin{tabular}{|c|c|c|c|c|}
\hline & \multicolumn{3}{|c|}{ DNA extraction success } & PCR success \\
\hline Site & $\begin{array}{c}\text { Control } \\
\text { Samples }\end{array}$ & $\begin{array}{c}\text { Experimental } \\
\text { Samples }\end{array}$ & $\begin{array}{c}\text { Control } \\
\text { Samples }\end{array}$ & $\begin{array}{c}\text { Experimental } \\
\text { Samples }\end{array}$ \\
\hline Grass & $9 / 9$ & $10 / 10$ & $8 / 9$ & $9 / 10$ \\
\hline Bush & $10 / 10$ & $10 / 10$ & $10 / 10$ & $8 / 10$ \\
\hline Sand & $4 / 10$ & $10 / 10$ & $4 / 4$ & $9 / 10$ \\
\hline
\end{tabular}

Table 7.1 Success of the DNA extraction and PCR steps for controls and samples from the grass, bush and sand sites.

To determine the degree of bacterial community difference between the control and experimental soil samples, CAI similarity values were calculated between samples collected from the same sampling point, e.g., bush control point A samples were 
compared against each other and control point B samples against each other (Figure 7.4). These values are plotted against the time (in days) between the two samplings.

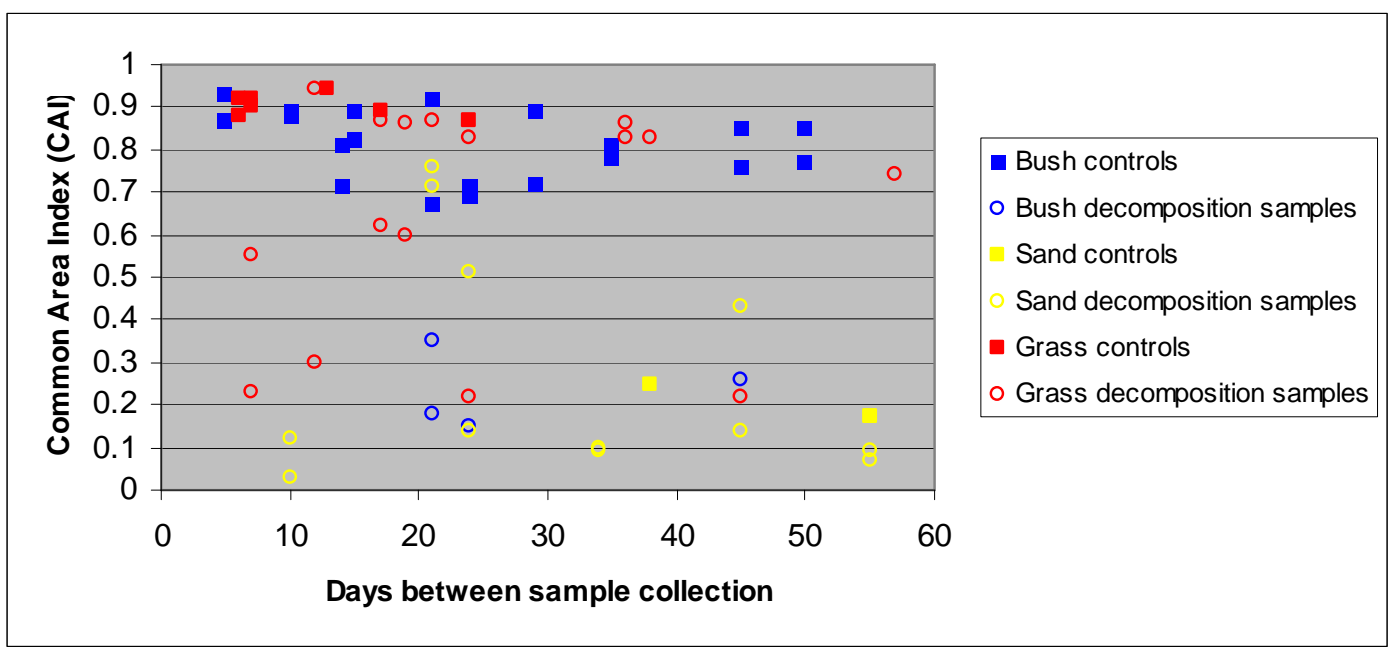

Figure 7.4. The CAI values between samples collected from the same sampling point over time.

The control samples from the three sites (filled squares in Figure 7.4) are clearly quite similar to each other, with high CAI values (with all except two values falling within the range of 0.67-0.94). The decomposition samples (unfilled diamond shapes), however, show much more variation, with CAI values ranging from 0.03 to 0.94 . The mean CAI values for the control samples were: at the bush site, $0.82 \pm 0.08$, grass, $0.86 \pm 0.07$ and sand, $0.208 \pm 0.05$. For the decomposition samples, the mean CAI values were: bush, $0.36 \pm 0.26$, grass, $0.60 \pm 0.26$ and sand, $0.22 \pm 0.26$. The coefficient of variance over all three sites was calculated to be $21.9 \%$ for the controls and $70.2 \%$ for the decomposition samples, showing that the profiles from the samples collected under the decomposing pigs are considerably more variable than those collected at the control sites nearby. The sand control samples, however, gave much lower CAI values than the bush and grass controls with the two values of 0.25 and 0.17 . The degree of similarity between any two samples does not appear to be correlated with the number of days that passed between samplings. 


\subsubsection{Discussion}

The results gained from this experiment were valuable for the preliminary insight they gave into the effect of mammalian decomposition on soil bacterial communities in three different environments. The number of samples which provided DNA of sufficient quantity and quality for PCR amplification was satisfactory (Table 7.1), considering that this experiment was performed before all the improvements to the extraction methodology (as described in Chapter 5) were implemented. The PCR reactions failed to give a product from the template DNA from only one control sample, versus four decomposition samples, suggesting that body-derived substances may have interfered to some extent with the PCR. Very little DNA was extracted from the sand site controls, which could be due to low bacterial numbers, due to poor water retention and a lack of soil development at this site (see section 2.1.3). Dune sands are typically in a preliminary stage of soil development, with the organic components not yet fully accumulated and matured. Such environments are not amenable to large bacterial populations.

The CAI values for the bush and grass sites (Figure 7.4) clearly show that the control site bacterial populations were more constant over time than were those at the sampling sites under the decomposing pig, with consistently high similarity. The extent of the variability displayed between successive sand control samples, however, was very high. Some temporal community variation is expected, as environmental microbial communities do fluctuate in response to seasonal changes (Mahasneh et al., 1984; Bardgett et al., 1999; Fisher and Triplett, 1999). For instance, Horswell et al. (2002) reported a Sorenson's Similarity Index value of 0.7 between soil samples collected eight months apart from the same New Zealand site. Because profiles were obtained for only four of the 10 sand controls, the comparisons may not have been representative. Those 
four control profiles, however, were very different from one another, with a mean similarity of $0.21 \pm 0.05$. Sands have very little capacity to retain water in dryer, warmer periods of the year (McLaren and Cameron, 1996), and, consequently, are subject to more severe seasonal drying and warming than are more developed or finely textured soils. This seasonal variation may promote substantial community fluctuations, accounting for the differences seen here. A small fluctuation occurring in a less complex community will have a greater proportional effect than a similar fluctuation in a larger community.

The decomposition samples from all three sites showed lower mean similarities than the equivalent control samples, as well as a coefficient of variance of $70.2 \%$. The fact that the degree of similarity varied widely is to be expected, as decomposition is a process in which breakdown products are released at different times and in different concentrations and combinations, all of which may affect the community differently, causing large scale community changes that are perhaps followed by periods of less significant change.

The surface exposure decomposition experiment results clearly show that decomposition has an observable effect on soil bacterial communities, and that these changes seen in soil bacterial communities under decomposing bodies are likely to be caused primarily by decomposition rather than by environmental conditions. Vass et al (1992) noted that the soil under a corpse is largely protected from rain, and that a heavy mucoid-like secretion produced by anaerobic fermentation binds the soil around the body, preventing significant rain penetration that could cause bacterial community changes in response. Some minor changes seen may be caused by seasonal fluctuations 
in bacterial communities, but decomposition is likely to be the cause of the more significant changes over time.

\subsection{Human Cadaver Experiment}

\subsubsection{Introduction}

The University of Tennessee's Anthropological Research Facility is a forensic research centre that studies human decomposition. Researchers use donated human corpses to simulate different decomposition situations in an attempt to aid forensic scientists in areas such as PMI estimation. Dr. Arpad Vass, a scientist based at Oak Ridge National Laboratories (ORNL) and associated with the Anthropological Research Facility, collected soil samples from under decomposing human bodies for analysis using our profiling technique.

\subsubsection{Aim}

This aim of this experiment was to establish whether changes in the soil bacterial community could be seen as decomposition of a human body progresses, using the improved soil DNA profiling technique developed as part of this project (Chapter 5). This was a preliminary investigation into the possibility of using the soil community profiling technique to aid estimates of post mortem intervals in forensic cases. 


\subsubsection{Methods}

\subsubsection{Facilities}

The Forensic Anthropological Research Facility is part of the Department of Anthropology at the University of Tennessee in Knoxville, and is situated in a secluded open-wooded area behind the University. Research at the facility centres around forensic aspects of decomposition and physical anthropology. The climate of the area is moderate, with an average annual temperature of $15^{\circ} \mathrm{C}$, ranging from around $-5^{\circ} \mathrm{C}$ in winter months up to $35^{\circ} \mathrm{C}$ in summer (Bass, 1997). The rainfall averages 127 to 152 $\mathrm{cm}$ per year, mostly falling in spring and early summer. During winter 5 to $10 \mathrm{~cm}$ of snow is the norm (Bass, 1997).

The facility is surrounded by an outside chain link fence with a wooden privacy fence about a metre inside. This keeps out large carnivores but opossums (Didelphis virginiana) and mice (Mus musculus) can occasionally get to the bodies. Birds can also access the area and often feed on insect larvae, but not usually on the decaying bodies themselves (Bass, 1997). The soil at the facility is a highly organic, fine, mixed thermic Typic Paleudalf (Vass et al., 1992). An area of the facility is shown in Figure 7.5.

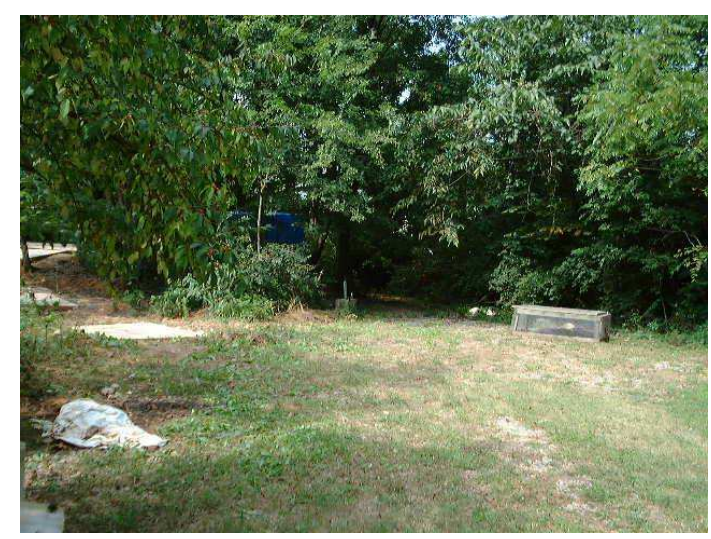

Figure 7.5. An area of the Anthropological Research Facility at the University of Tennessee. In the foreground on the left a body can be seen wrapped in fabric, and to the right rear of the photo, a body is left to decompose in a wire cage that prevents disturbance of the body by scavenging animals. 


\subsubsection{Experimental Design}

Five samples from under one body were analysed initially as a preliminary trial of the methodology (see Chapter 4). Several months later, Dr Vass sent samples collected from under seven further bodies to ESR Ltd. for analysis. These samples were collected between November 1988 and October 1989 as part of a study gathering data on volatile fatty acid, anion and cation release during decomposition (Vass et al., 1992). Seven unembalmed, unautopsied cadavers were placed on soil at the University of Tennessee Anthropological Research Facility at various times of the year. All bodies were placed in situ within 60 hours of death and were stored in morgue coolers until placement. Site selection for the placement of each body was random but with the stipulation that no other body had ever been placed within 10 metres of the site. The bodies were placed naked, face down, arms positioned to the side. Leaves and rocks were removed from under the bodies to allow ease of sampling but the soil was not disturbed, so as to simulate natural conditions. The site was in a wooded part of the facility, with a dense forest canopy.

During spring and summer months, soil samples were collected every three days, but during the autumn and winter months, when decomposition rate is slowed, sampling was performed weekly. The soil surface under the body, covered by the region from the pelvis to the shoulders of each corpse, was divided into equal areas so that, in sampling soil from 3 to $5 \mathrm{~cm}$ depth, each area yielded 10 grams of soil. Soil from three randomly selected areas was collected at each sampling. No area was sampled more than once. Bodies were briefly tilted sideways to enable sampling underneath, and soil was collected using a spatula and soil corer before the bodies were returned to their original position. 
The samples used for bacterial community DNA profiling were each weighed and placed in glass scintillation vials, frozen and then lyophilized for 24 hours. The samples were stored freeze-dried until required and were then sent to New Zealand.

Data on each body and each sample were recorded. This included the gender, race, age, height, weight, cause of death and date of death for each body. The date of soil sample collection and any visual change in decomposition stage were noted for the individual samples.

\subsubsection{Accumulated Degree Days}

Accumulated degree days (ADDs) are used to gauge of the progression of decomposition. Temperature greatly affects the rate at which human bodies decompose, so consideration of this factor is absolutely required when assessing the degree of decomposition. The four visually determined stages of decomposition (fresh, bloat, decay and dry) are not always easily distinguishable and generally, are a poor indicator of decomposition progression. Using ADDs allows more reliable decomposition progression measurement and also allows direct comparison of rates of decomposition occurring at different times of the year. The ADDs are determined by summing the average daily temperatures $\left({ }^{\circ} \mathrm{C}\right)$ for the period over which (in days) the corpse has been decomposing. For example, four days at an average daily temperature of $25^{\circ} \mathrm{C}(\mathrm{ADD}=$ 100) results in an equivalent decomposition state to 20 days at an average daily temperature of $5^{\circ} \mathrm{C}(\mathrm{ADD}=100)$.

Temperature data for calculating ADD were supplied by the USA National Weather Service (NWS). Minor adjustments to compensate for slight temperature differences between the nearest weather station and the body location were made by taking average 
temperature measurements at the site for at least a week. These values were compared to the NWS temperatures for the same period and an adjustment value calculated. These calculations were performed by scientists at the Anthropological Research Facility and made available for use in this study. This is the standard technique used in forensic investigations for calculating the ADD value for bodies found outdoors.

\subsubsection{Processing}

Samples from under two of the seven bodies, A (female) and B (male), were chosen to be profiled. The samples collected under these bodies covered the whole decompositional range from fresh to well past skeletonisation. Soil samples had been provided from only some of the decomposition stages for the remaining five bodies, and due to time and financial restraints, the two bodies which had samples from the widest time period, and could potentially provide the most information, were selected. Details of these bodies and the ADD period over which samples were collected are shown in Table 7.2.

\begin{tabular}{|l|l|l|l|l|l|l|l|l|l|}
\hline Body ID & Sex & Race & Age & Hgt $(\mathrm{cm})$ & Wgt $(\mathrm{kg})$ & $\begin{array}{l}\text { Cause of } \\
\text { Death }\end{array}$ & $\begin{array}{l}\text { Date of } \\
\text { Death }\end{array}$ & $\begin{array}{l}\text { No. of } \\
\text { samples }\end{array}$ & ADD range \\
\hline A & F & Caucasian & 59 & 160 & 44 & cancer & $28 / 11 / 1988$ & 37 & $0-5370$ \\
B & M & Caucasian & 51 & 182 & 62 & n.c. & $25 / 02 / 1989$ & 24 & $0-4214$ \\
\hline
\end{tabular}

Table 7.2. Details about the cadavers used in the human decomposition study.

Soil samples were processed $(0.5 \mathrm{~g})$ in batches of six or eight to keep the bench-work manageable. As the method development was ongoing throughout the duration of this experiment, the final modified version of the profiling methodology (as described in Chapter 5) was not used. This experiment was performed a number of months after the surface pig experiment described in section 7.2 , so the methodology had been modified 
to include the DNAzol wash step and BSA was routinely added to each PCR reaction (Chapter 5). The restriction enzyme digested DNA, however, was not put through the MinElute Reaction Clean-up Kit before analysis on the Genetic Analyser (section 5.3.1). This modification to the methodology was made after the human decomposition experiment was performed.

\subsubsection{Results}

Profiles were obtained from 31 of 37 samples from under body A, and 14 of 24 from under body B. Body A samples gave a progression of profiles from ADD 16 to ADD 5370, and from body B, from ADD 0 to ADD 3091.

It is obvious from the profiles that the soil bacterial community changed markedly over time, with profiles from samples from under both bodies showing major changes as time progressed. Even from early on, shifts in the dominant species occurred in both groups of profiles and many different peaks appeared and disappeared as time progressed (Figures $7.6-7.9$ ). The profiles are displayed in three groups per body: fresh, bloat/decay, and skeletonised/dry. The fresh stage is from body placement until the bloat stage was determined visually, and the bloat/decay stage from this point until skeletonisation occurred (usually around 1285 ADD). Although these stages can be difficult to determine visually, the division of the profiles roughly into these stages approximates times when major changes in substrate release from the body may have occurred, and aids in interpretation of the profiles. 


\subsubsection{Body A Profiles}

$\operatorname{Dod}=28-11-88$

210

280

350
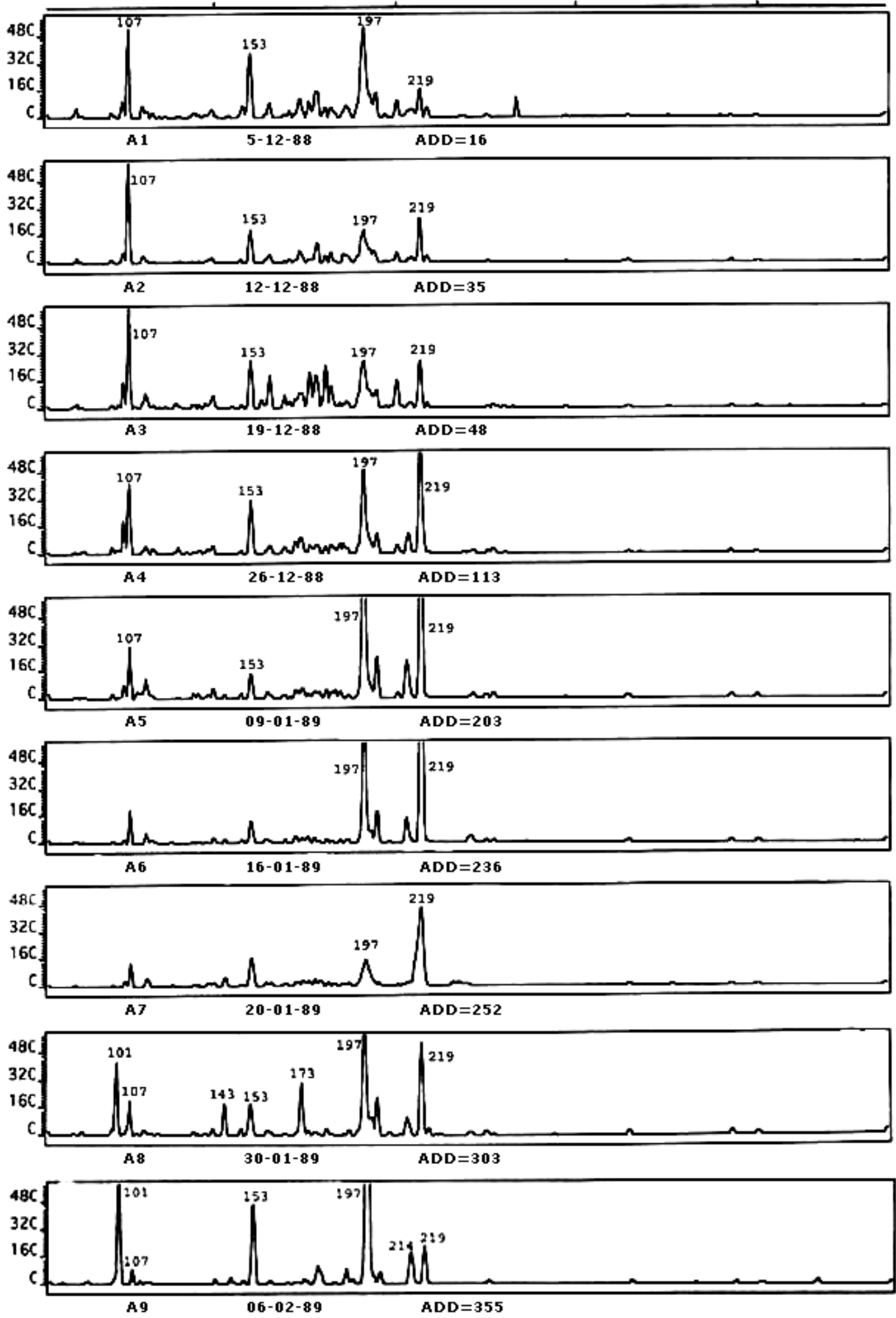

Figure 7.6. Profiles from samples collected at the fresh stage of body A (samples A1 - A9). 

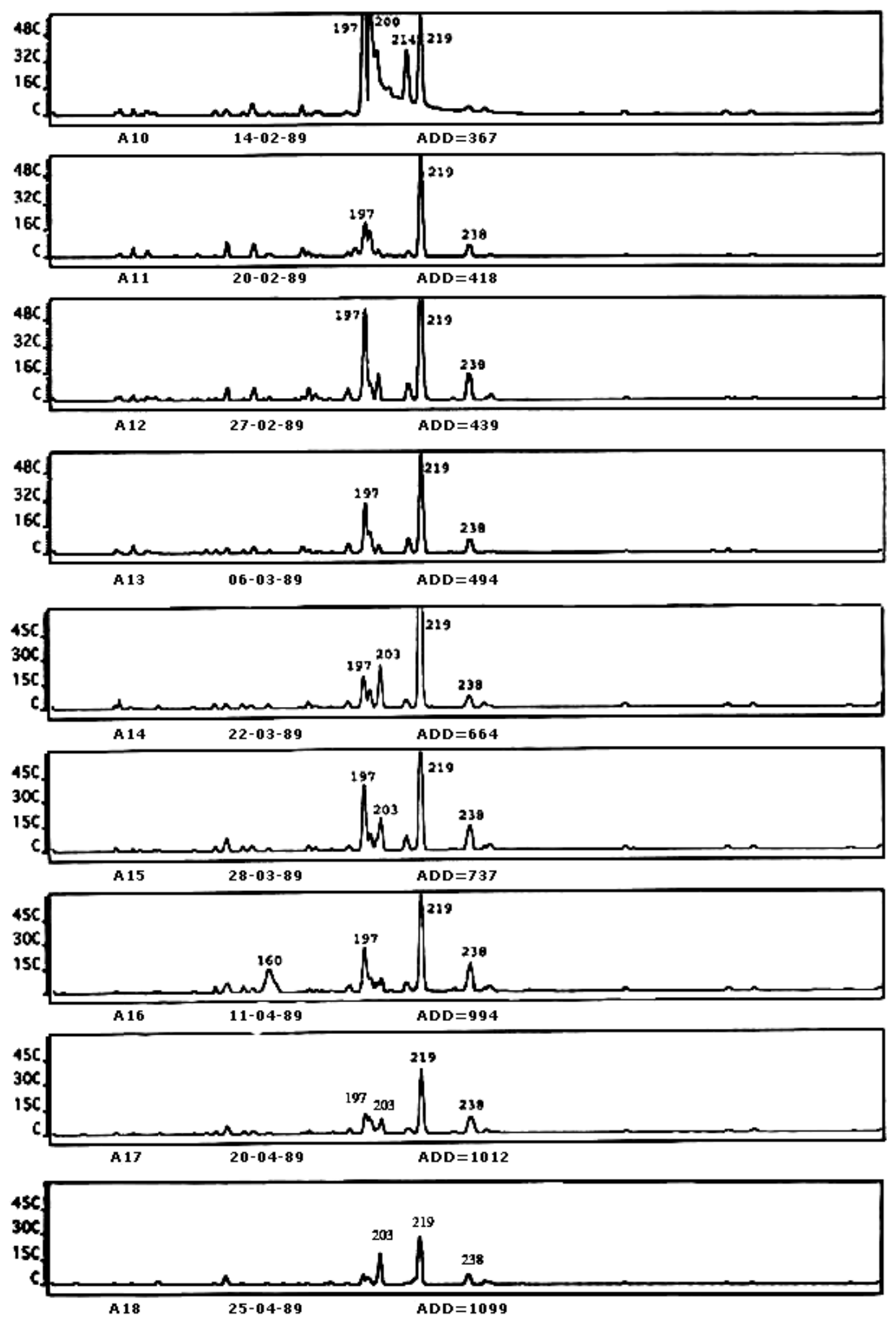

Figure 7.7. Profiles from samples collected at the bloat and decay stages of body A (A10-A18). 

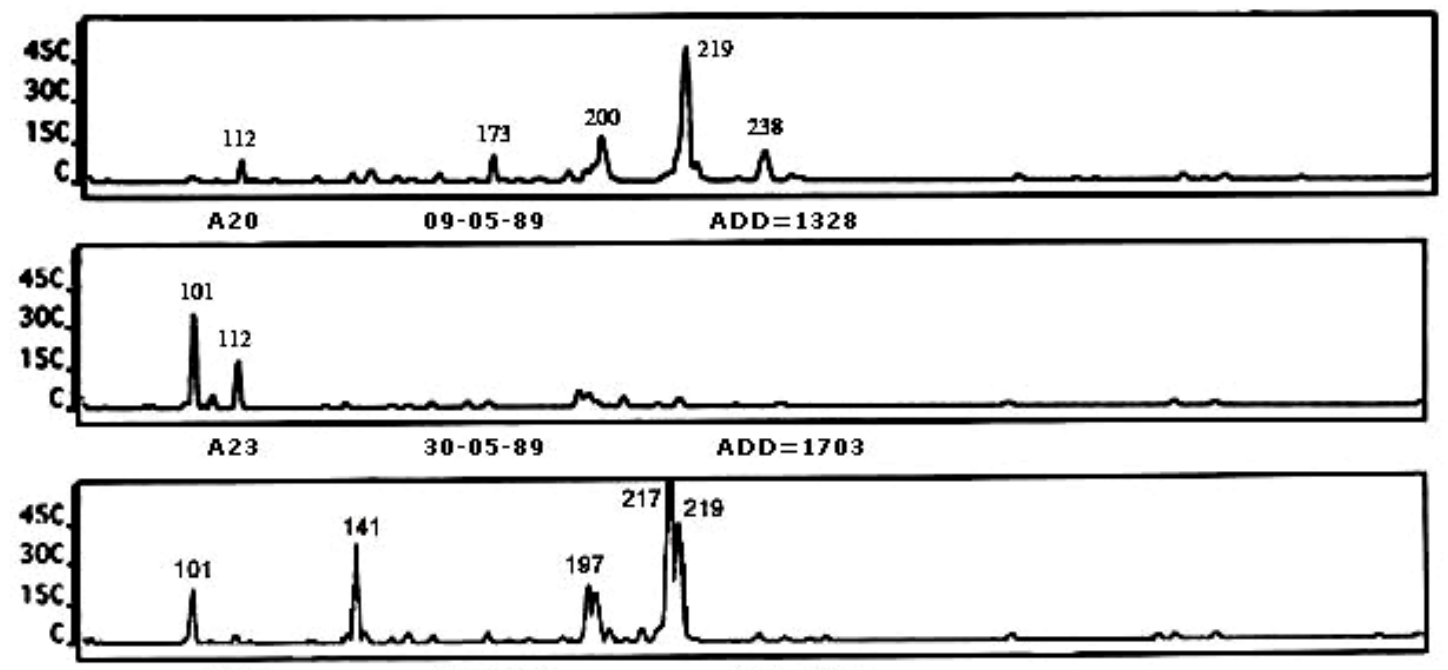
A24
02-06-89
$A D D=1775$
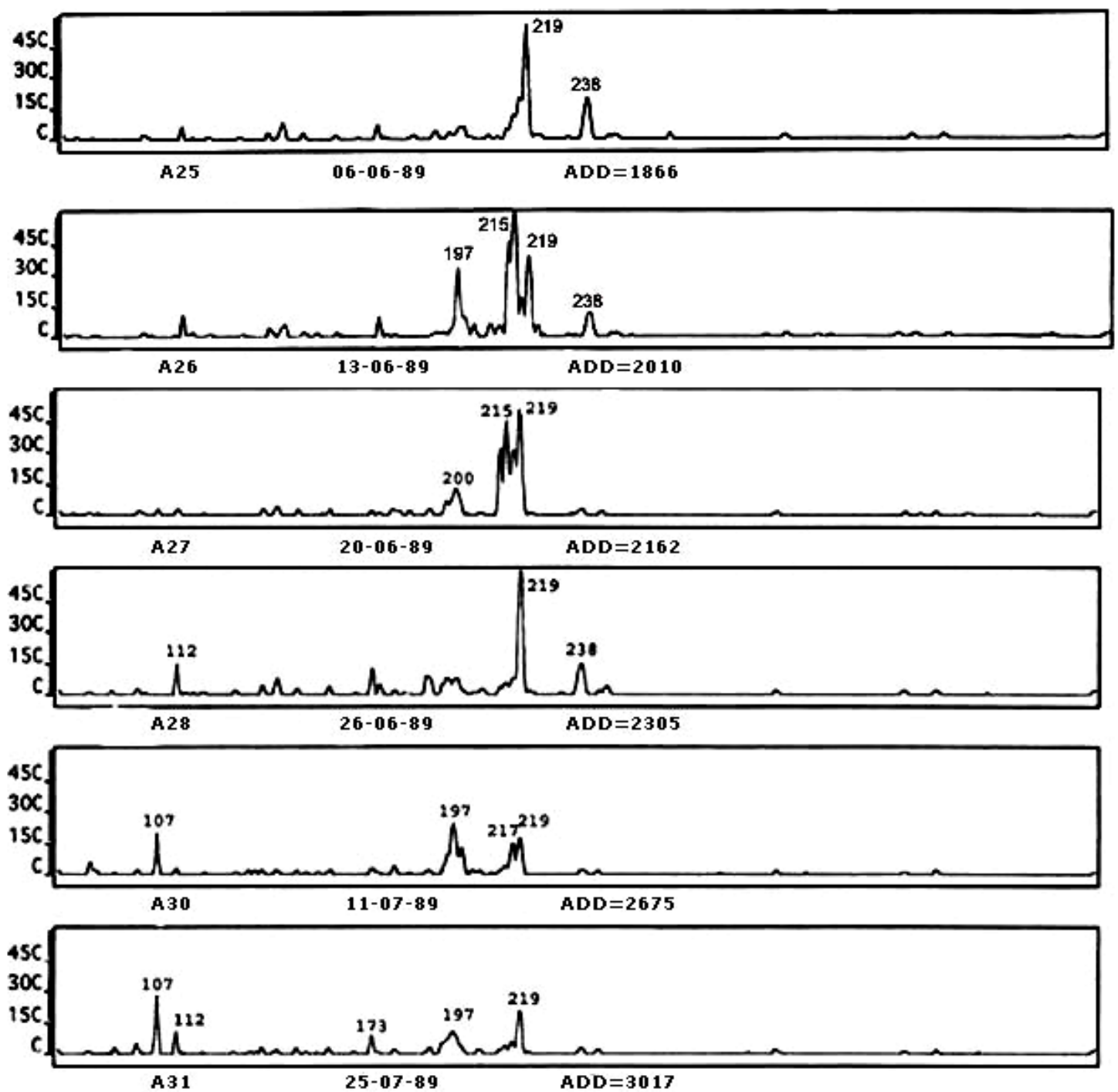

Figure 7.8. Profiles from samples collected at the dry stage of body A (A20 - A31). 

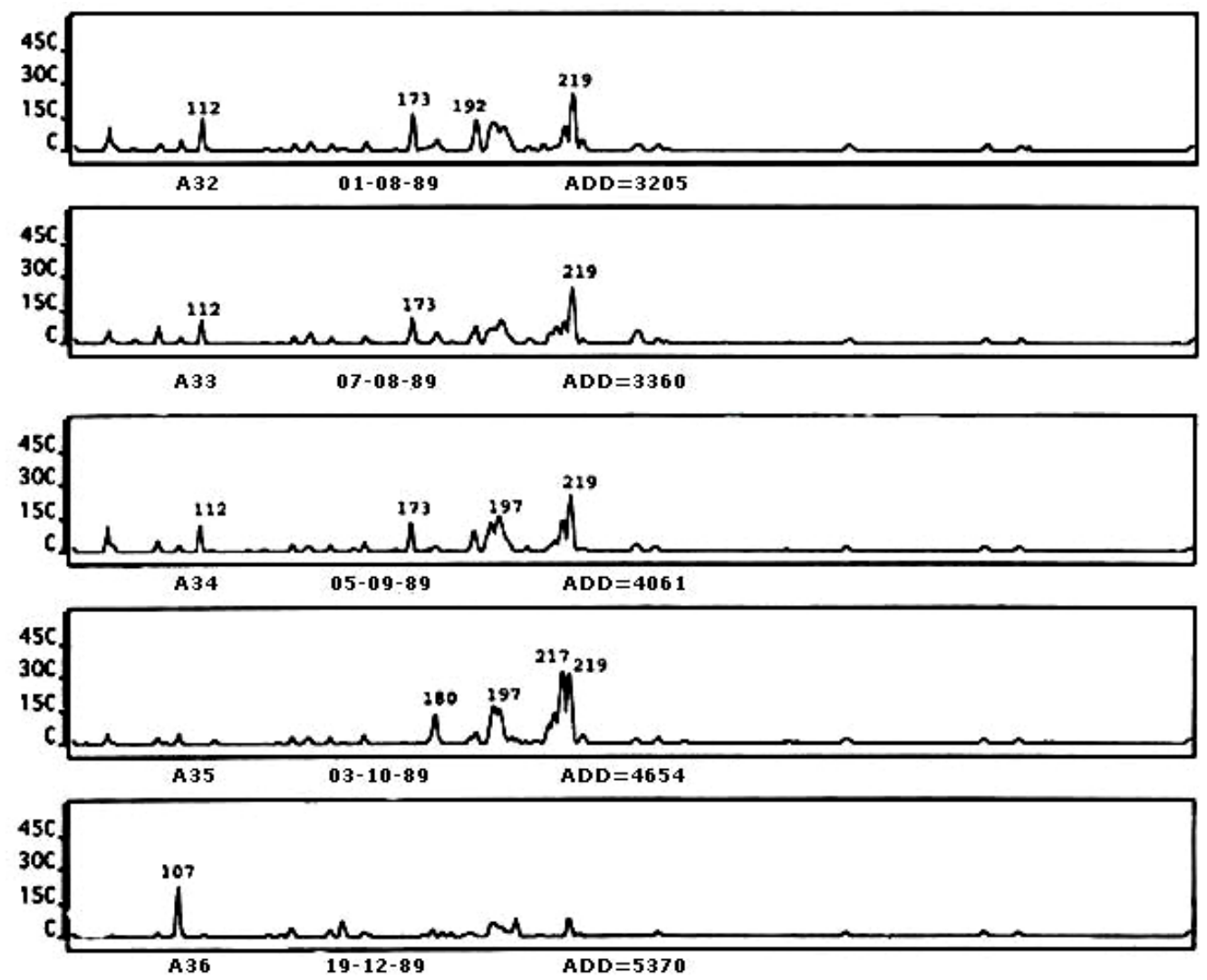

Figure 7.9. Profiles from samples collected at the dry stage of body A continued (A32 - A36).

The profiles of the soil bacterial community from under body A displayed the same major peaks, at constant proportions throughout the early fresh stage, until $\mathrm{ADD}=113$ when the 219 bp peak became dominant (Figure 7.6). The community showed high diversity at this point, with many peaks that were present in the initial sample profiles, such as those of 107 and 153 bp size, still being present. From ADD = 367 onwards, however, there was a reduction in diversity, with a few ribotypes completely dominating the community (Figure 7.7).

\subsubsection{Body B Profiles}

Because fewer profiles were generated from samples collected under body B than from under body A, the exact point at which change in the community first occurred was not discernible. $\mathrm{By}$ ADD $=528$ (Figure 7.11), the profile generated was clearly very 
different to that of the first (ADD $=0$, Sample B1, Figure 7.10). The dominant peaks seen in the initial profile were no longer present at $\mathrm{ADD}=528$, and new peaks at 197 and 219 bp size, appeared. The brief descriptions of visual changes in decomposition, which were provided with the samples, indicated that by $\mathrm{ADD}=528$, body $\mathrm{B}$ was well into active decay. Because of the gaps in the profile succession for body $\mathrm{B}$, it is not possible to determine whether community changes occurred at around the same ADD time point for both bodies.

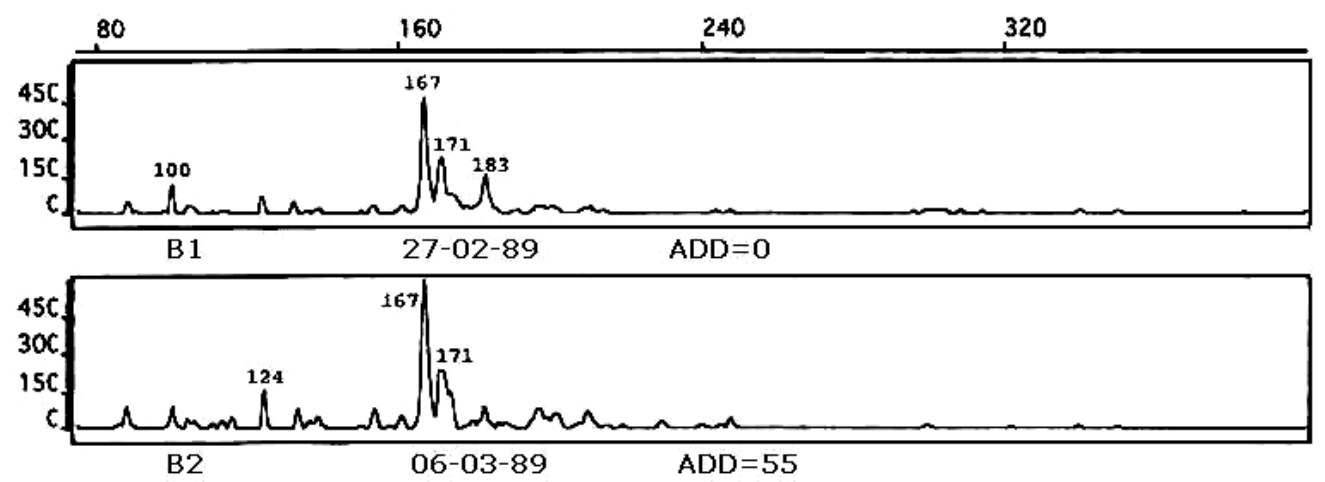

Figure 7.10. Profiles from fresh stage of body B (B1 \& B2).
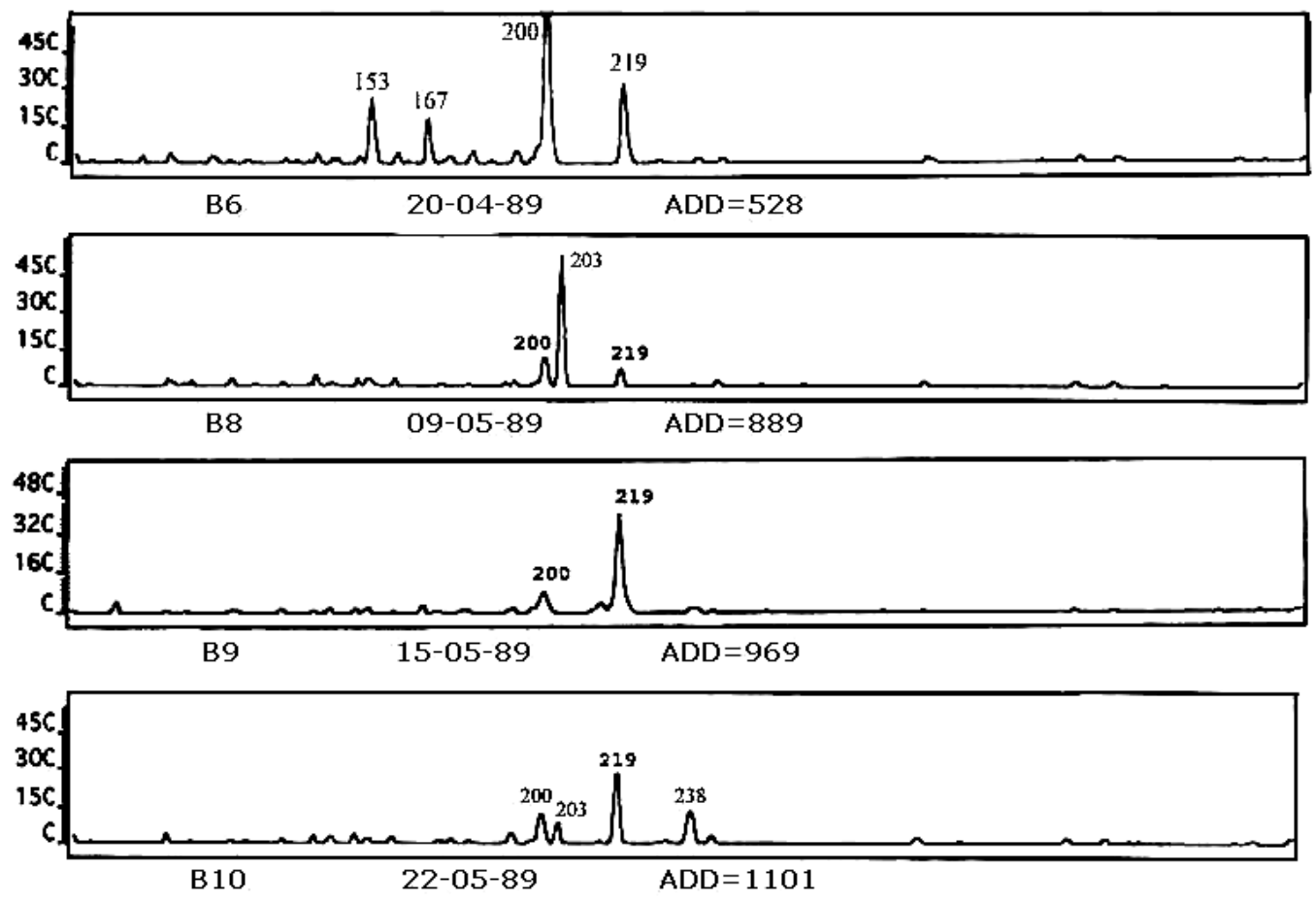

Figure 7.11. Profile from bloat/decay stage of body B (B6-B10). 

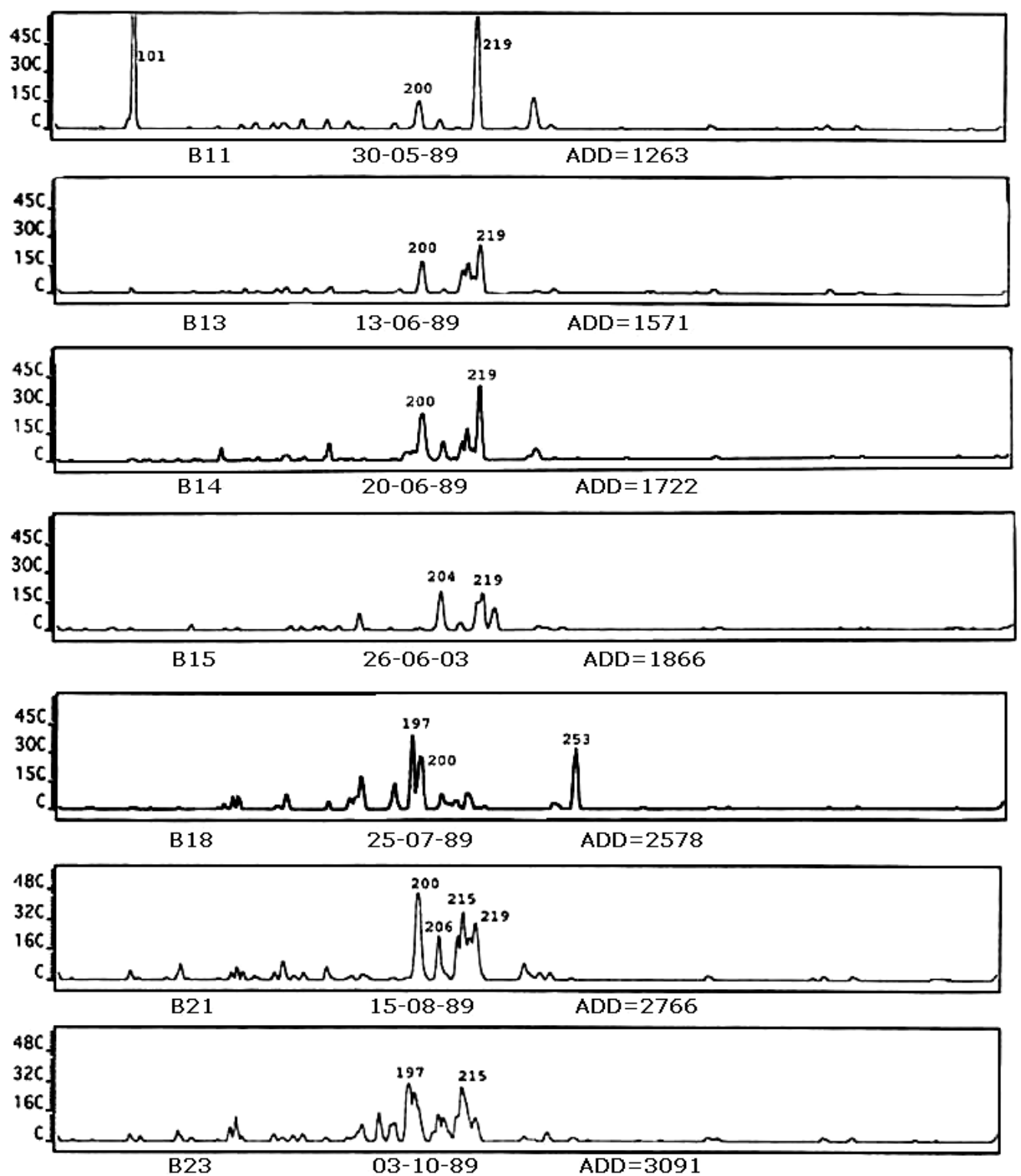

Figure 7.12. Profiles from dry stage of body B ( B11-B23).

\subsubsection{Control samples}

A control sample was collected for each body experiment, from a site a few metres away from the decomposition site. The control sample for body A was collected just over a month after the body was placed, and for body B, it was collected after four months. The profiles for these samples and the profile from the first sample collected from under each body are shown in Figures 7.13 and 7.14. 

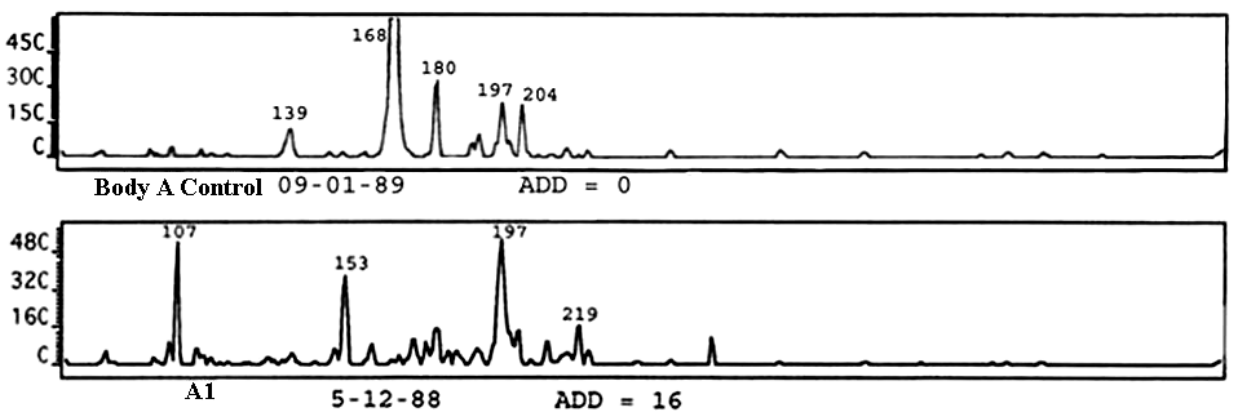

Figure 7.13. Profiles from the control sample collected near body A and the profile from the first sample collected from under the body, the day after body placement.
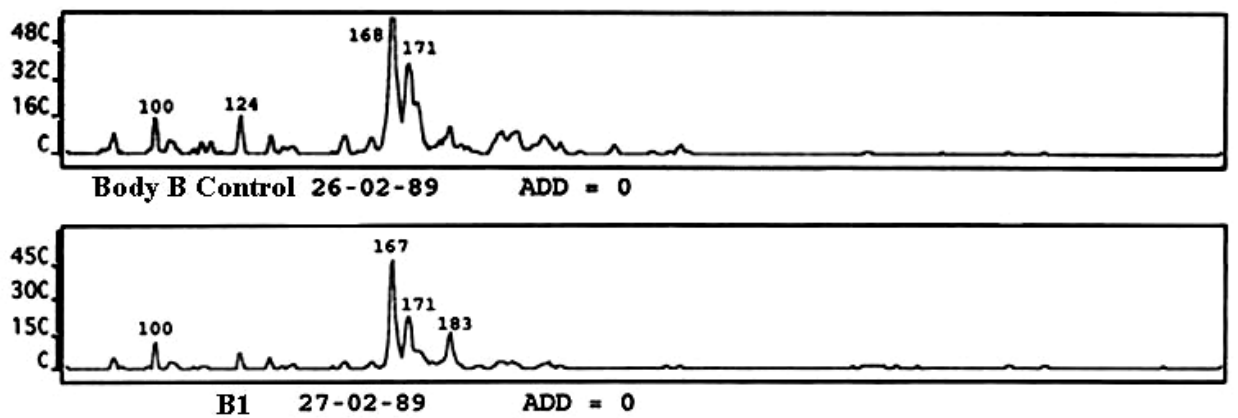

Figure 7.14. Profiles from the control sample collected near body $B$ and the profile from the first sample collected from under the body, the day of body placement.

The control sample profile for body B is very similar to the profile from the first sample collected from under the body, on the day of body placement (Figure 7.14) with a CAI of 0.824. However, the control profile for body A is markedly different from that of the first sample from under body A (collected the day after body placement), shown in Figure 7.13, with a CAI value of 0.155 . The body A control sample profile has dominant peaks at 168, 180, 197 and 204 bp size, whereas the largest peaks in the first few profiles from samples from under the body are 107, 197 and $153 \mathrm{bp}$.

\subsubsection{Changes in Diversity over the course of Decomposition}

It appears that bacterial diversity decreased under both bodies as decomposition progressed through the early stages (see Figures 7.6 - 7.12). The earliest profiles in 
both groups have several high peaks (from 3-8) which cover a wide range of fragment sizes $(107-257 \mathrm{bp})$. By $\mathrm{ADD}=418$ for body $\mathrm{A}$, and $\mathrm{ADD}=889$ for body $\mathrm{B}$, the profiles are dominated by a single large peak (219 bp for body A and 203 bp for body B) although smaller peaks are present. The number of peaks in each profile for body A is shown in Figure 7.15. Only peaks above 50 fluorescence units were included, to eliminate instrument noise interference. An initial decrease in the number of peaks can be seen, followed by a period of low diversity (ADD $367-664$ ), before the number becomes more variable.

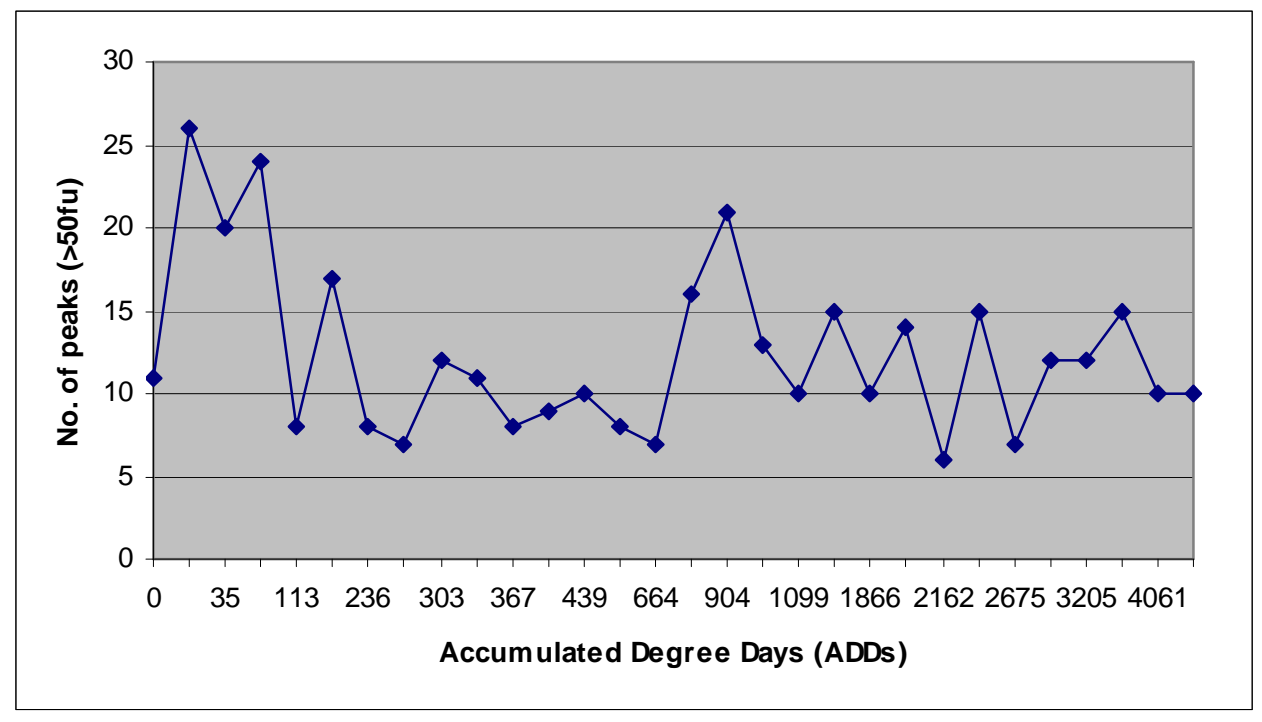

Figure 7.15. Number of peaks in body A profiles over time.

\subsubsection{Prominent Peak Identification}

A number of peaks appear to be prominent in profiles from both bodies, although a number of major peaks are also restricted to only one body or the other. The peak at fragment size 219 bp appears to be associated with the decomposition process in both sample groups. It is not present in the control profiles from either body (Figures 7.13 and 7.14), nor is it present at $\mathrm{ADD}=0$ for body $\mathrm{B}$ (Figure 7.14). It is present at $\mathrm{ADD}=$ 16 for body A, but is not a dominant peak (Figure 7.13). It quickly becomes dominant in both groups and persists throughout the duration of the sampling period, although it 
drops to be the second highest peak or even lower at some stages. The peak at $197 \mathrm{bp}$ also appears to be of some importance in both groups. It is prominent in many of the early body A profiles (Figures 7.6-7.9), before dropping away (around ADD=1012). In the body B profiles (Figures 7.10-7.12), it appears for shorter periods throughout decomposition, present in only one or two samples before disappearing again.

\subsubsection{Discussion}

Although most of the decomposition samples gave profiles, a number of these profiles were not of good quality, with few peaks present and/or low total fluorescence (e.g., A36 in Figure 7.9). This was most likely due to impurities remaining in the digested DNA preparation affecting the uptake of DNA by the Genetic Analyser. The MinElute reaction cleanup step was added specifically to eliminate this problem, but it was introduced after the human cadaver experiment had been performed (refer section 4.3). However, the profiles obtained do still clearly demonstrate that change was occurring in the soil bacterial community over time, which was the aim of this preliminary study. Use of the template DNA from the soil samples from under body B proved more difficult to amplify targets from than the DNA from samples from under body A. Thus, less than the full set of collected samples could be profiled for both bodies (Figures 7.10-7.12). The body B sample profiles also had lower total fluorescence and showed less diversity than those of samples from under body A, which could indicate that the digested DNA preparations from these samples contained more impurities that affected DNA uptake by the Genetic Analyser. 


\subsubsection{Causes of Bacterial Community Change}

There are two possible reasons for the observed community changes. The indigenous soil bacteria may be able to use the organic breakdown compounds released from the body as nutrients, and through competition, only the species that most effectively utilise these resources proliferate and come to predominate. Organic decomposition compounds are first released from bodies in the late fresh to early bloat stage when the gut microflora begin to break down the internal structures, and products begin to purge from the body openings. The amounts and types of compounds released increase dramatically when the trapped gases escape the body. Bloating subsides and is accompanied by heavy fluid drainage from the body cavity.

It is also possible that the body microflora released during decomposition enter the soil bacterial community and out-compete or simply overwhelm the soil bacteria. The early stages of decomposition involve a massive population expansion of the microflora, particularly those of the intestinal tract, which migrate throughout the body breaking down the organs. When the liquefied organs are purged from the body into the soil, the microfloral population is purged with them. Whether these bacteria would survive in the soil environment for long is unknown, particularly as many enteric microflora species are obligate anaerobes (such as Bacteroides and Clostridium). The environment directly under a body, however, might become anoxic enough to support anaerobic life due to the pooling and collection of liquid 'goo' from the body, which would also prevent growth of the indigenous aerobic soil bacteria. The human intestine does contain some facultative anaerobes, such as Escherichia, Enterobacter and Klebsiella, which may survive well in the organic, rich soil environment. It is likely that the soil community changes are caused by a combination of these two processes, with both 
indigenous soil bacteria and body microflora contributing to the communities, perhaps at varying times and to varying degrees.

The dramatic change in the bacterial community that is seen around the start of the bloat stage for both human bodies coincides with the beginning of organic compound release. It was at this stage $(\mathrm{ADD}=367$ for body $\mathrm{A}$ and $\mathrm{ADD}=528$ for body $\mathrm{B}$ ) when the most dramatic community changes occurred under both bodies. A smaller degree of community change could, however, be seen even earlier under body A, from around $\mathrm{ADD}=113$ (Figure 7.6). Because organic compound and microflora release was not expected to have begun by $\mathrm{ADD}=113$, this change might have been in response to influencing factors in the microbial habitat rather than nutrient/microflora release. When an object, such as a body, is placed on soil, the physical soil environment is changed. Sunlight is blocked from reaching the soil under the body, and any vegetation which might have been growing there. The vegetation cannot survive long without light and becomes a nutrient source for the soil bacteria. The rhizodeposits from the root structure would also cease, altering the bacterial community in this area. Body A was placed at the Anthropological Research Facility on 5 December 1988. This is during the winter in Tennessee, when temperatures often drop to below freezing, accompanied by snowfall. A body might act as effective protection from the snow for soil bacteria. The soil temperature under a body may even rise as insect activity increases. It has been documented that, in cold weather, water vapour has been seen rising from decaying bodies at the facility due to the warmth of the maggot mass (Bass and Jefferson, 2003). While the effects any of these environmental factors have on the bacterial community are likely to be small, these or similar small habitat changes caused by the presence of a body might contribute to the small changes in the profiles seen from very early in decomposition. 
The skeletonisation or dry stage of decomposition is known to begin around 1285 ADD and the profiles of samples collected during this stage are shown in Figures 7.8, 7.9 and 7.12. Although the drainage of body fluids into the underlying soil has ceased by this stage, the profiles from both bodies continued to show community change throughout the period sampled. It could be expected that, once decomposition is complete and there is no longer active nutrient release from the body, the soil bacterial community would begin to revert to the pre-decomposition structure. The soil environment would become oligotrophic once the nutrients from the body were all utilised and as the zymogenous species died off, they would in turn be used as a nutrient source. Body microflora would no longer survive and the indigenous soil bacteria would once again predominate. Sampling from under body A continued until ADD $=5370$, and for body $\mathrm{B}$ until $\mathrm{ADD}=4214$, which is well after skeletonisation in both cases. These final profiles were visually very different from those obtained at the start of decomposition, and CAI values calculated between the initial and final profiles (body $\mathrm{A}=0.57$ and body $\mathrm{B}=0.06$ ) show little indication of the communities returning to their original structures. This suggests that the bacterial community takes considerable time after decomposition ends to return to its original state. This could be because many organic compounds released from the body may not be degraded quickly in the soil. These compounds could then persist for a prolonged period with low levels of degradation occurring, providing a steady supply of breakdown products for bacteria to use as substrates. Alternatively, as bacterial species exhaust their usable carbon sources and die, other bacteria may in turn be able to use the dead cells for energy production. The physical and chemical characteristics of the soil are also likely to take some time to return to pre-decomposition conditions, because properties such as soil $\mathrm{pH}$ and ion balance can be altered by decomposition for some time (Vass et al., 1992). In addition, even skeletonised remains continue to be degraded by a process known as diagenesis. 
Inorganic components such as hydroxyapatite continue to leach from the bone for long periods (Gill-King, 1997) and, although microbes are not actively involved in this decay process, the bacterial community is still likely to be affected to some extent.

This persistence of change in the bacterial community structure could be important in forensic investigations. The estimation of PMI is more difficult once the body is skeletonised (Vass et al., 1992), making techniques which can help give more accurate estimation for this stage very valuable. If a bacterial community continues to be affected by the decomposition process for a long period after skeletonisation, then this might provide information on the time elapsed since death. Similarly, if a body were to be removed from the site of decomposition, the bacterial community is likely to continue to be affected by the compounds already in the soil and this could provide information about decomposition even in the absence of the body.

\subsubsection{Control Samples}

The control samples from both bodies A and B were very dissimilar to the profiles from the initial samples collected under each body. The control samples for body A had dominant peaks at 168, 180, 197 and 204 bp, whereas the first few profiles from under the body had dominant peaks at 107, 197 and 153 (Figure 7.13). The difference between the profile from the control sample for Body $\mathrm{A}$ and that from the initial decomposition sample was large, with a CAI value of 0.139 . It is unlikely that after one day, when the first sample was collected, the profile would have changed so dramatically. It is more likely that the control sample was not representative of the soil at the nearby site where the body was placed due to spatial variability (refer Chapter 6), although no two samples from the same location, or even different locations with 
similar vegetation examined in Chapter 6 gave such low similarity. It is possible that this control sample was collected in an area with very localised environmental conditions, where vegetation, shade or other factors strongly influenced the soil bacterial community. Although efforts were made to use sites on which bodies had not previously decomposed, it is possible that this control sample was collected from a site where the bacterial community had been affected by decomposition products at some point in time.

An important fact to consider when interpreting the results from the human cadaver experiment profiles is that control samples were not collected throughout the decomposition time period. A single control was collected either before body placement or from a site a few metres away from the body at a later date. A time series of control samples would allow determination of whether factors other than decomposition, such as rainfall and temperature affected the general community. However, as shown in the surface exposure decomposition experiment using pigs (section 7.2), the changes in controls are small when compared with the changes seen in the samples under the bodies. It is likely that decomposition is a major cause of the community changes observed, although environmental factors may also contribute.

Another factor that must be taken into account when interpreting soil bacterial community changes is the sampling method used. Because the samples were collected as part of another study, they were not collected from the same place under the body each time, but using a grid system under the torso to ensure that the same spot was not sampled more than once. This may be unfortunate, as the resident soil population can vary spatially (as shown in Chapter 6), and organic compound release might not be uniformly distributed across the area under the body. Compound and microflora release 
could be different around the upper torso area, compared with the lower abdomen. Therefore, the sampling method chosen may account for some differences seen between profiles. It is hoped that this effect might be negligible based on the knowledge that, during putrefaction, the gut microflora migrate throughout the body via the blood and lymph systems (Janaway, 1996) and will be purged fairly uniformly.

\subsubsection{Changes in Bacterial Community Diversity}

An observation was made earlier that diversity within the soil community appeared to decrease early in the decomposition process. As with the changes seen between the control sample and first decomposition sample profiles (see section 7.3.5.2), the release of microflora and organic compounds is unlikely to have begun at such an early time point, suggesting that other factors may also contribute to this change. A notable change in the bacterial communities of the soil under both bodies was the apparent shift to microbes with longer terminal-restriction fragments (T-RFs) early on, within the fresh and bloat stages (Figures 7.7 and 7.11). It is unlikely that the bacteria with longer TRFs have any selective advantage over those with shorter T-RFs, rather it is more likely that the bacterial species that came to dominate during decomposition happened to generate longer T-RFs.

\subsubsection{Identification of Prominent Peaks}

Two peaks, at 219 and $197 \mathrm{bp}$, were very prominent in many profiles from both bodies (Figures 7.6 -7.12). Because of their obvious importance in the soil bacterial community, an attempt was made to identify possible candidate bacteria that produce $\mathrm{T}$ RFs of these sizes, using a bioinformatics programme available on the Microbial Community Analysis 2 website (http://mica.ibest.uidaho.edu/cpa.php). This service, hosted by the University of Idaho, allows prediction of T-RFLP fragment lengths for 
microbes in its database. The database used is that from the Ribosomal Database Project. The conditions of the T-RFLP (the primers used and the restriction enzyme used) were entered and a list of fragment sizes was generated, along with the names of the organisms that are predicted to generate fragments of those lengths. Many different organisms are predicted to produce fragments of the same size in most instances (see Figure 7.16).

\begin{tabular}{|lllll|}
\hline Forward & Reverse & Accession no. & Locus & Organism \\
\hline 197 & 144 & AF173968 & S000002657 & Halomonas Variabilis \\
197 & 130 & AB021368 & S000006849 & Pseudomonas Elongata (T) \\
197 & 339 & AF114505 & S000000368 & Uncultured Gamma Proteobacterium DCM-ATT-2 \\
197 & 337 & Y18232 & S000007273 & Alteromonas Macleodii \\
197 & 337 & AF114507 & S000009535 & Uncultured Gamma Proteobacterium 400m-ATT-5 \\
197 & 337 & Y18231 & S000012319 & Alteromonas Macleodii \\
197 & 337 & AB015135 & S000012957 & Alteromonas Sp. \\
197 & 336 & AJ240914 & S000018216 & Uncultured Gamma Proteobacterium CHAB-IV-19 \\
197 & 337 & AJ310692 & S000020862 & Uncultured Proteobacterium \\
197 & 338 & AF513950 & S000088766 & Uncultured Alteromonadaceae Bacterium \\
197 & 337 & AF529061 & S000097416 & Alteromonas Marina \\
197 & 340 & AY027586 & S000101270 & Rhodococcus Opacus \\
197 & 73 & AJ318198 & S000019225 & Uncultured Bacteroidetes Bacterium \\
\hline
\end{tabular}

Figure 7.16. Example of results generated by the Microbial Community Analysis 2 website. This example shows species in the Ribosomal Database Project database predicted to generate a $197 \mathrm{bp}$ terminal fragment using the primers and enzyme chosen in this study.

The generation of common fragment sizes by many different bacterial species means that identifying and assigning fragments to individual species by simply predicting the fragment size is not possible. In addition, a huge number of species, particularly from soil, will not be represented in the database, because sequence data are not yet available for them. The database is continually upgraded as more $16 \mathrm{~S}$ sequence data become available, but, with only an estimated one percent of soil microbes having been 
cultured, and perhaps even fewer having been sequenced, the chance that a given profile peak is contributed by an unknown organism is high.

Another factor to consider is that variation has been reported to occur between true TRF length and observed T-RF length. The observed T-RF length size may be up to three or four base pairs in length different from the true T-RF size predicted from DNA sequence data (Kaplan and Kitts, 2003). This difference, known as T-RF drift, is positively correlated with T-RF size and negatively correlated with purine content. For forensic comparison purposes and for observing general changes in the bacterial community structure, T-RF drift is not an issue, as long as the level of drift is consistent between samples. It could, however, significantly affect identification of organisms contributing to an observed T-RF. For the peak at $197 \mathrm{bp}$, for example, organisms which are predicted to produce fragments from 193 to $201 \mathrm{bp}$ could all be included as possible candidates. This would lead to 156 candidate species rather than just the 13 predicted to give fragments of exactly $197 \mathrm{bp}$ (see Figure 7.16). Many bacterial species could be eliminated as candidates based on their known biology, e.g., those that were cultured from deep sea hydrothermal vents, although this type of information is not known for many database sequences.

A large number of organisms in the Ribosomal Database project database (1799 of 3065 listed) return predicted fragment sizes that are below our minimum detection limit of $100 \mathrm{bp}$. This confirms that the T-RFLP profiling technique may not be a definitive display of all the microbes in a community, but only an indicator which can be used to evaluate changes in a community. 


\subsubsection{Differences in Profiles from under Different Bodies}

It is apparent from comparing profiles from just the two groups of samples, body A and body $\mathrm{B}$, that individual bodies and/or environments produce different profiles, even when they are at the same stage of decomposition. Samples from body A had different community profiles, with at times, different peaks dominating to those in profiles obtained from samples from under body B. Both bodies were on the same type of soil and within a short distance of each other, but, it is obvious that some other factors were highly influential.

Environmental conditions specific to the area each body was placed in, such as exposure to the sun or rain, could have an effect on which bacteria are able to dominate a community. Another possible explanation is the inherent differences between the bodies themselves. The gut microflora found within the body is a complex community of several hundreds of species, and the particular species/sub-species present, and the combination of these, is unique to the individual (Upreti et al., 2004). People generally have their own distinct predominant species and sub-species combinations and these are retained even after drastic changes in the diet (Moore and Moore, 1995). Genetics may be a major determinant, as there is evidence that other body flora, such as periodontal flora are more similar in monozygotic than dizygotic twins (Moore et al., 1993). It is suspected that bacterial species released from the body contribute to the soil bacterial community and are responsible for some of the profile changes observed. If individuals have distinctly different gut microflora, then a unique combination of bacteria might be released from each body. Within the human gut, the vast majority of bacteria are obligate anaerobes, and some $30-40$ species predominate, meaning that although the combinations of microbes can vary from human to human, some bacterial species such as Clostridium, Bacteroides, Fusobacterium and Bifidobacterium are extremely 
common and play significant roles in the gut microfloral community (Upreti et al., 2004).

It must also be considered that every human body is slightly different from every other in biochemical composition. The proportions of body components, e.g. fat and muscle, are different in every individual. Obese individuals would release a greater proportion of breakdown products from lipids than someone with little body fat. This could affect the chemical composition of the soil habitat directly below a body, and may in turn influence the microbes which can proliferate in that environment. Fat and muscle proportions differ in males and females, suggesting that if such differences do affect the soil bacterial community changes during decomposition, then the gender of the deceased individual may need to be factored in. Knowing the pre-mortem weight of the individual may also aid in interpretation of results. In this study, one body was female (body A) and the other male (body B), and both could be considered to be underweight for their heights $(160$ and $182 \mathrm{~cm}$ ) at 44 and $62 \mathrm{~kg}$ respectively (Table 7.2), although for body A, this was likely due to the cancer which was the cause of death.

Because the bacterial succession from only two bodies is available for comparison, it is unwise to draw globally representative conclusions about the effects of individual microflora. It is presently unknown whether the community changes observed over time are caused by competition between indigenous soil bacteria, body microflora or a combination of both. Further research to establish the contribution of these two groups, as well as comparing data from more bodies would be required to soundly establish the processes occurring and the variables which contribute to differing bacterial communities. 


\subsection{Grave Burial Experiment}

\subsubsection{Introduction}

Victims of homicides are frequently found buried, often in shallow graves not more than one metre deep (Manhein, 1997). Buried bodies decompose at a slower rate than those left exposed on the surface, partly because of reduced access to the body by insects.

There is currently little known about the microbiological changes which occur in a grave in response to decomposition. Hopkins et al. (2000), investigated the soil biochemistry of pig graves that were part of a forensic homicide investigation and discovered that even after 430 days of burial the soil chemistry in the graves was significantly different from that of control soil. Microbial biomass was also elevated, and these factors together suggested that microbial activity was high and that decomposition was still occurring.

\subsubsection{Aim}

The aim of this experiment was to establish whether changes in the soil bacterial community could be detected in soil within a grave burial.

\subsubsection{Method}

In collaboration with the New Zealand Police Dog Training Centre, a pig was buried in a remote area of the Rimutaka Forest Park near Wellington on 14 July 2003. The Police use buried pig carcasses to train dogs in victim recovery. The grave was $50 \mathrm{~cm}$ deep, $2.2 \mathrm{~m}$ long and $60 \mathrm{~cm}$ wide (Figures $7.17 \& 7.18$ ). Control samples were collected from 
the side of the grave prior to placement of the pig carcass in the grave. These were taken from the top $5 \mathrm{~cm}, 5-10 \mathrm{~cm}, 10-20 \mathrm{~cm}, 20-30 \mathrm{~cm}, 30-40 \mathrm{~cm}$ and $40-50 \mathrm{~cm}$ depths.

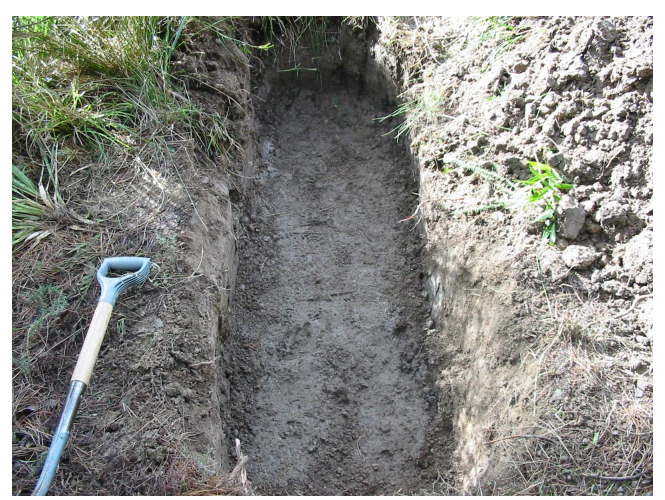

Figure 7.17. Empty pig grave.

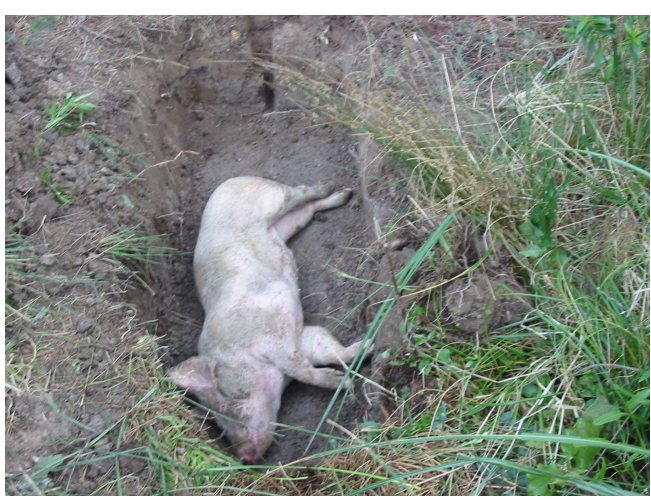

Figure 7.18. Pig in grave before burial.

Samples were collected from the grave 6 months later (16 January 2004) using an auger as shown in Figure 7.19. The grave was located using steel rod probes which can detect changes in soil density and compaction. The outline of the grave was determined based on the change in soil density. The vegetation at the site had regenerated where the soil had been disturbed, with similar plants such as grasses and small ferns covering the grave. There were, however, some patches of soil where vegetation had not regrown. There had been no disturbance of the grave.

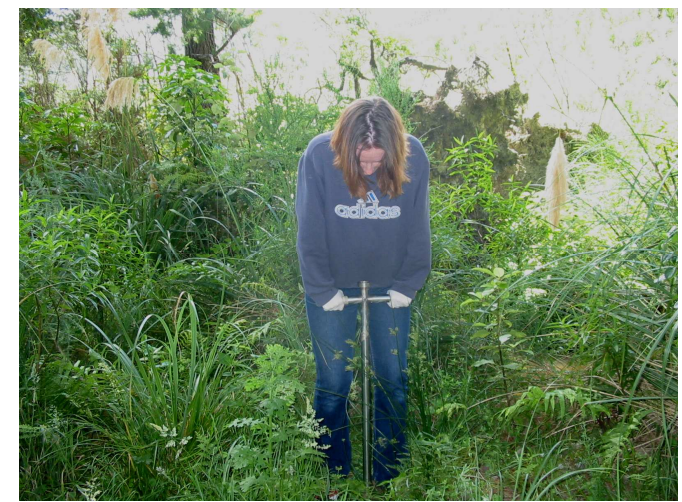

Figure 7.19. Investigator taking core samples of the grave using an auger.

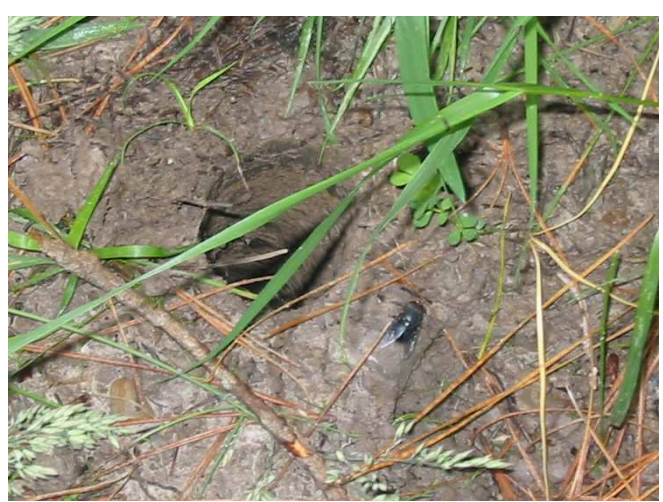

Figure 7.20. Flies were attracted to the opening in the grave created by the auger. 
A core sample was taken at two points in the grave (Figure 7.21). The auger was pushed through the pig remains to collect some of the underlying soil. The remains were easy to push an auger through by this stage, so decomposition had obviously progressed to the decay stage. Decay was still active as a strong smell of putrefaction was released with the penetration of the auger and flies were immediately attracted to the opening in the soil made by sampling (Figure 7.20). The core samples retrieved were divided in two and processed as either upper or lower grave samples. Only two divisions on the core sample were used because the soil compacted into a very small core which made accurate division into smaller sections difficult. The pig tissue provided a clear division between the upper and lower soils. Samples were collected in clean plastic bags, double-bagged, labelled and tied with rubber-bands.

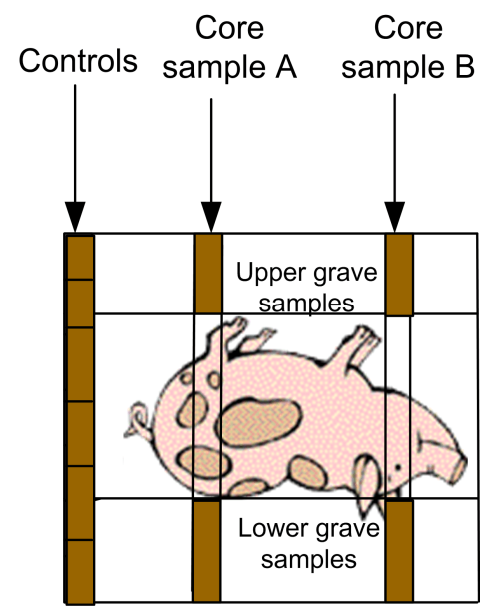

Figure 7.21. Diagram of grave sampling points.

Samples were processed using the improved methodology that included all the modifications discussed in Chapter 5. This was the final experiment performed during the course of the research for this thesis and was done after all the modifications to the methodology had been implemented. 


\subsubsection{Results}

The profiles produced for the control and grave samples were of good quality with numerous peaks present and high total fluorescence.

\subsubsection{Controls}

The control samples collected at increasing depths were remarkably similar to each other, with the only major community change occurring between the $5-10 \mathrm{~cm}$ and 10-20 cm samples (see Figure 7.22).
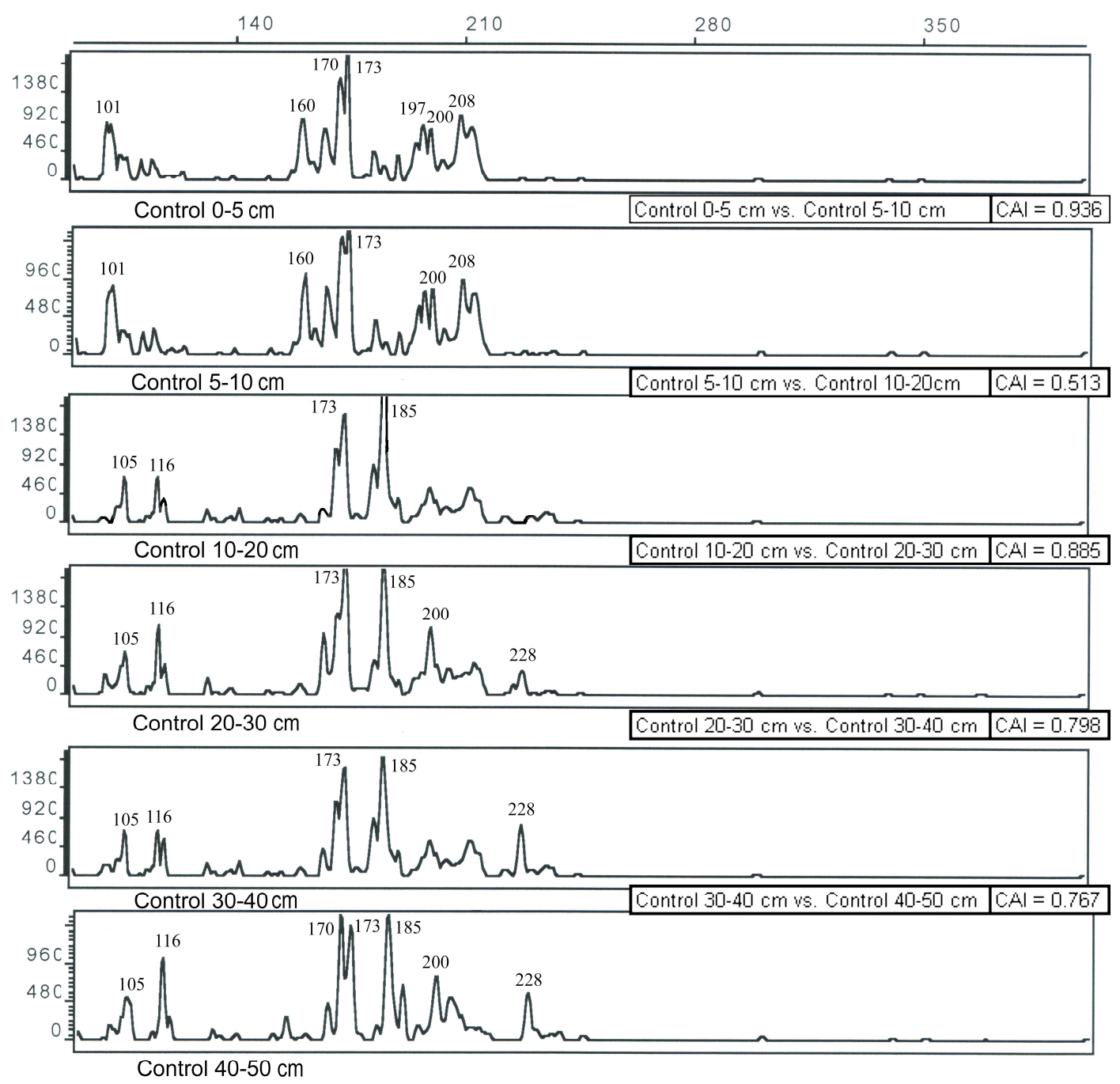

Figure 7.22. Profiles from control samples collected from the pig grave at the time of burial. 
The 0-5 and 5-10 cm sample profiles were different to those from the deeper samples, with the notable absence of the major peak at $185 \mathrm{bp}$ and a few more minor peaks such as at $105 \mathrm{bp}$ and $228 \mathrm{bp}$. These two samples also had additional peaks at $160 \mathrm{bp}$ and $101 \mathrm{bp}$ which were not present in the other profiles. The profiles from samples 10-20 $\mathrm{cm}$ and deeper were very similar to each other. The peaks at 185 and $228 \mathrm{bp}$ and those at 105 and $116 \mathrm{bp}$ represented important bacterial constituents in the community at these depths compared with the top $10 \mathrm{~cm}$, where they were either minor, or not present at all.

\subsubsection{Grave Samples}

The profiles for the soil samples collected from the grave after six months of burial are shown in Figure 7.23. The profiles from the two replicate samples from the top of the grave (Upper Grave A and Upper Grave B) were visually very similar, as were those from the two from the lower grave (Lower Grave A and Lower Grave B), although two peaks, at 153 and $190 \mathrm{bp}$, are present in the lower grave B profile but not in that from lower grave A. The CAI value for the two upper grave profiles is 0.972 and for the two lower grave profiles, 0.726. The mean CAI for the upper samples compared with the lower samples is 0.587 . 


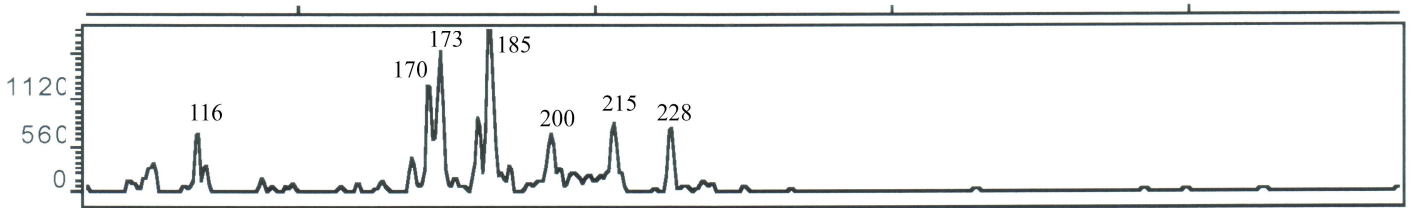

Upper grave A

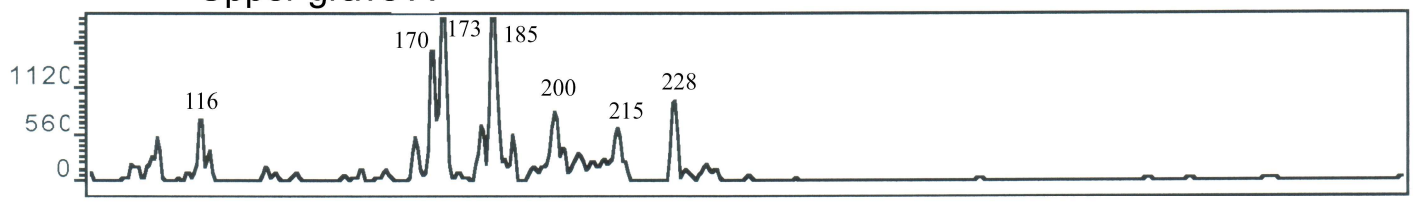

Upper grave B

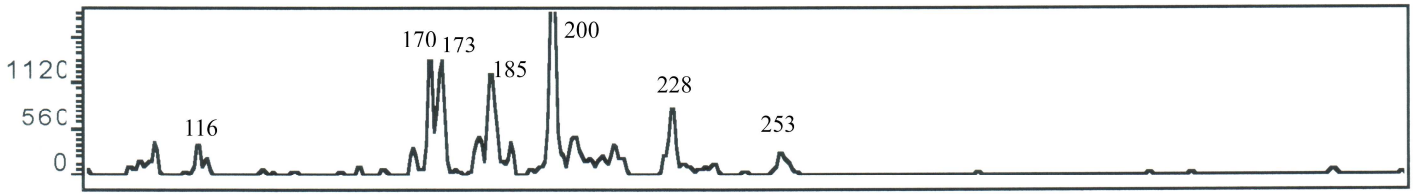

Lower grave A

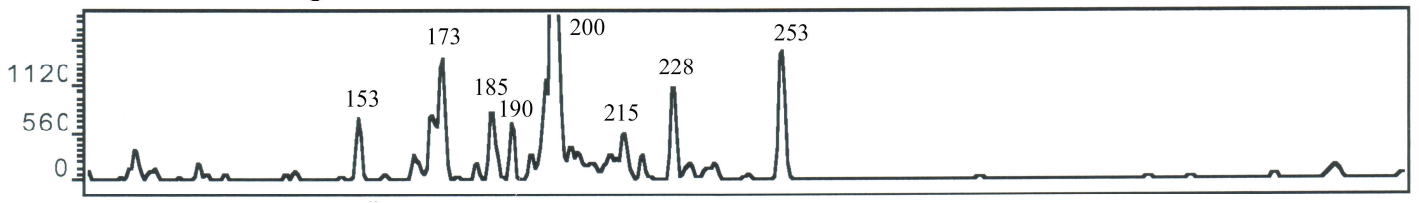

Lower grave $\mathrm{B}$

Figure 7.23. Profiles from samples collected from the pig grave after six months of burial.

\begin{tabular}{|l|l|}
\hline & CAI \\
\hline Upper Grave A vs. Upper Grave B & 0.972 \\
\hline Lower Grave A vs. Lower Grave B & 0.726 \\
\hline Upper Grave A vs. Lower Grave A & 0.686 \\
\hline Upper Grave B vs. Lower Grave B & 0.487 \\
\hline
\end{tabular}

Table 7.3. CAI comparison values for the profiles from samples collected from the pig grave after six months of burial.

The upper grave samples appeared to have very similar bacterial community structure to the control samples collected six months earlier, particularly the control samples from 10-20 $\mathrm{cm}$ and deeper (Upper grave A vs. Control 10-20 $\mathrm{cm} \mathrm{CAI}=0.813$ ). The $185 \mathrm{bp}$ peak does not appear in profiles from the control samples, until a depth of 10-20 cm, but is present in both upper grave profiles. Similarly, the 228 bp peak is also present in all 
of the profiles from the grave samples collected after six months of burial, but is only present in those from the deeper controls $(20-30 \mathrm{~cm}$ and deeper).

\subsubsection{Discussion}

The profiles generated from the control and grave samples were of high quality with numerous peaks present and high total fluorescence, which was reasonably uniform between samples. This reflects the use of the refined profiling methodology (refer Chapter 5).

Although the two upper grave samples were very similar to each other, and the two lower grave samples were also very similar to each other, there were some obvious differences between the profiles from the upper and lower grave samples. The lower grave is likely to change in response to decomposition because gravity would allow seepage of the body fluids downwards, but it is also possible that the bacterial community associated with the soil above the pig would also be influenced by decomposition. The profiles from the upper grave samples, however, are very similar to some of the control sample profiles, suggesting that decomposition has not appreciably affected the bacterial community in this region.

A large peak at $185 \mathrm{bp}$ was present in both the deep control samples $(10-20 \mathrm{~cm}$ and deeper), and the upper grave samples. This may be explained by the fact that, while the pig was being buried, the soil from different depths became mixed. Some of the deeper soil would have been returned to the top of the grave, thereby mixing the soil bacterial communities. Microbes that were associated with the deeper soil may have been able to survive in the new upper layer of the grave because of this mixing. Over time, as vegetation returns, the normal soil profile would be expected to re-develop and the 
bacterial populations revert to their previous structure. However, with only six months between the burial and the sampling, these processes might still be in progress.

Two DNA profile peaks were unique to the lower grave samples, suggesting that they may be specifically connected with the decomposition process. The peak at $253 \mathrm{bp}$ is seen in profiles from the lower part of the grave but is not found in profiles from any controls or the upper grave samples. A peak at $253 \mathrm{bp}$ also appears for the first time in the profile from sample B18 of the human decomposition study (Figure 7.12). The increase in size of the $200 \mathrm{bp}$ peak in profiles from the lower grave samples is also notable. Although present at constant proportions in the upper grave and control samples, the 200 bp ribotype becomes dominant in the lower grave samples. A peak at 200 also appeared in both the body A and body B profiles (section 7.3.4) at various times between $\mathrm{ADD}=367$ and $\mathrm{ADD}=2766$ (Figures 7.7, 7.8, 7.11 and 7.12) and although was the dominant peak in only one profile (B6, $\mathrm{ADD}=528$, Figure 7.11), it could represent a microbe released from the body, or a soil microbe that can proliferate in response to an increase of a certain nutrient, or possibly a combination of species from both.

In comparison with the human decomposition samples, the profiles from the grave do not exhibit a reduction in diversity, with only a few dominating peaks. The original soil community structure can still clearly be seen in the pig grave samples. This could be an important difference between surface decomposition and burial. Decomposition is slowed considerably by burial, due primarily to the inaccessibility of the body to insects, but also to lower temperatures below ground level. If insects colonise the body prior to burial, insect activity can occur, but if burial occurs before insect eggs can be laid on the body, decomposition is primarily a microbial process. Another important 
difference between burial and surface decomposition is that the buried environment can become very acidic, while the environment under surface decomposition can be basic due to the difference in oxygen availability in the two environments (A Vass, ORNL, pers. comm.). Soil $\mathrm{pH}$ was not determined in any of the decomposition experiments, so whether this previously-observed difference occurred and affected the bacterial communities is unknown.

Because decomposition is greatly slowed by burial, the soil bacterial community in the grave is unlikely to be impacted as strongly by organic compound or microflora release, as would occur in surface decomposition. If the release of body fluids is slow, species within the soil that can utilise the liberated compounds may proliferate, but perhaps not out-compete other members of the community. In the human cadaver experiment, where decomposition was on the soil surface, two or three ribotypes dominated and outcompeted all others, possibly because these species could most effectively utilise the vast quantities of organic compounds released into the underlying soil. Slower decomposition and compound release in a buried situation might prevent this strong competition. If, however, the changes seen in the surface decomposition soil bacterial communities are caused by the release of the body's microflora, the relationship between the indigenous soil microbes and the microflora might be affected by burial. The temperature in a grave is likely to be lower than at the surface, (with the exception of very cold winter periods) as sub-surface soils are generally less affected by the sun's heat (Blume et al., 2002; Fierer et al., 2003). Body microfloral bacterial species prefer temperatures around $37^{\circ} \mathrm{C}$, and when exposed to much lower temperatures, their metabolic activity is slowed. This reduced activity contributes to the slowed decomposition rates in cold buried environments, and may also prevent the microflora from significantly impacting the soil community in the grave. 
The control samples collected prior to burial of the pig also offer the opportunity to examine the change in bacterial community with increasing soil depth. The control sample profiles (Figure 7.22) show high similarity between the top two samples (0.92), collected from depths of $0-5 \mathrm{~cm}$ and $5-10 \mathrm{~cm}$. A large difference is seen between the 5$10 \mathrm{~cm}$ sample profile and the next lowest, at $10-20 \mathrm{~cm}$, with the disappearance of peaks, and the appearance of peaks not found in the upper two profiles. The samples from greater depths were all very similar to the $10-20 \mathrm{~cm}$ depth sample, having the same general profile shape and the same major peaks present. Bacterial numbers are known to decrease with increasing depth largely because the nutrient-rich rhizosphere, which supports dense bacterial populations, extends only as far as plant roots reach (Wood, 1995). The vegetation associated with this site was patchy, and primarily shallowrooted grass. The change in the community structure below $10 \mathrm{~cm}$ is likely to be caused by a decrease in rhizodeposits at this depth. Killham (1994) suggests that microbial diversity is lower in the rhizosphere region than in bulk soil because of the selective pressure applied by rhizodeposition. This reduced bacterial community diversity is not seen in the top soil profiles, as these two profiles actually appear to have slightly more diversity with a wider range of ribotypes represented.

Peaks that appeared to become more prominent in the samples from depths $10 \mathrm{~cm}$ and greater, particularly those at 105, 116, 185 and $228 \mathrm{bp}$, could be ribotypes from Grampositive bacteria and actinomycetes which have been found to be more numerous than Gram-negative bacteria in subsurface soils (Fierer et al., 2003), and can compete successfully in the nutrient deficient soil expected at this site (Burke et al., 2003). The homogeneity of the bacterial communities observed, as the depth increases, contrasts with results from other studies. These have shown that microbial communities change significantly even with small changes in soil depth (Blume et al., 2002; Fierer et al., 
2003; LaMontagne et al., 2003). LaMontagne et al. (2003), found that although subsurface soils have a different community structure to that of surface soils, the subsurface soil community tends not to change significantly with increasing depth. They also found that many of the same ribotypes were present in the surface and sub-surface soils, with the surface just having more diversity. This result is consistent with the findings presented here.

\subsection{Conclusions}

The aim of the experiments discussed in this chapter was to investigate whether body decomposition causes a successional change in the associated soil bacterial community over time. Part of this investigation involved determining whether soil samples collected from under a body at various stages of decomposition could be profiled using the soil bacterial community DNA profiling technique as developed in this project (Chapter 5). It was suspected that organic compounds released from the body might interfere with amplification of DNA targets, and this was confirmed early on for five of the original decomposition samples (see Chapter 4). Similar PCR inhibition problems were also encountered in the two surface decomposition studies (pig and human) outlined in this chapter. The development of the analytical methodology that was ongoing while these studies were performed ultimately led to high success rates (for example with the buried pig experiment, section 7.4). Due to cost and time restrictions, however, the soil samples from the surface exposure decomposition experiments were not analysed again using the improved methodology (Chapter 5). The profiles that were obtained using the less optimal methodology were sufficient to answer our preliminary research question, as to whether a succession of bacterial change occurs. The answer 
was clearly yes. Considerable changes occurred over the course of decomposition in all of the groups of samples.

Some bacterial community change was observed in the control samples from the pig surface exposure decomposition experiment, although the degree of change was relatively minor (Figure 7.4). These small changes were in contrast to the samples collected from under the pig carcasses, which displayed varying degrees of change over the course of decomposition. This suggested that while some variability is expected to occur in soil communities in response to season and weather patterns, the degree of change is unlikely to produce major profile shifts such as those exhibited in the samples collected during decomposition. Thus, it can be concluded that decomposition is primarily responsible for these major effects.

The human decomposition experiment produced some very interesting observations, particularly regarding the duration of change that the soil bacterial community experiences in response to decomposition. It appears from the experiments with bodies $\mathrm{A}$ and $\mathrm{B}$, that the community continues to change after skeletonisation occurs and nutrient/microflora release has ceased (Figures 7.9 and 7.12). This has important implications for PMI estimation, as establishing time since death is more difficult after skeletonisation has occurred (Vass et al., 1992).

Also evident from this preliminary work, is that while the modified profiling methodology was very successful in displaying the fact that change does occur over time, this profiling method alone may not be fully effective as a tool for post mortem interval estimation. The marked differences between individual bodies could impact the use of bacterial community profiling as a stand alone technique for helping to determine 
the PMI. Whether differences in individual human body microflora would significantly affect the soil bacterial community is unknown. This is because it has not yet been adequately established whether major changes are caused primarily by the release of the human associated microflora, or by fluctuations in the indigenous soil microbe population in response to organic compound release. It is possible that, rather than examining the peaks per se, the overall change in community structure might be most informative. To do this successfully, however, more informative molecular techniques are required. Further research is needed to understand the processes occurring in the bacterial community, and in identification of some of the major bacterial species involved in the decomposition process (see Future Directions section 8.1).

The grave burial experiment demonstrated that the decomposition process is greatly affected by burial. Six months after burial, the pig was obviously still in the active decay stage, and yet the bacterial community from both the upper and lower parts of the grave were still very similar to control samples collected at the time of burial. This suggests that the community profiles obtained from grave samples are likely to show different patterns of change to those found when bodies are placed on the surface. If the soil bacterial community DNA profiling technique is to be used for PMI estimation, studies will be needed to determine these differences.

This research has established that a succession of bacterial community changes does occur in soil, in response to decomposition, and that potential exists to use the information contained in the soil bacterial community for better estimating the post mortem interval in forensic cases. The soil bacterial community DNA profiling technique successfully demonstrated these changes and shows promise for the 
development of a PMI estimation tool, particularly if further research to investigate the effect of individual body microflora on the soil community during decomposition is performed. 


\section{GENERAL CONCLUSIONS}

The soil bacterial community DNA profiling technology developed and described in this thesis shows considerable potential as a forensic comparison technique, and also as a tool for investigating the complex bacterial community associated with human decomposition. The primary aim of this thesis was to establish the reliability and utility of using soil bacterial community DNA profiling, originally developed for forensic purposes by Horswell et al. (2002). While evaluating the original methodology (Horswell et al. 2002) through the use of a mock forensic homicide scenario (Chapter 4), it became apparent that some aspects required optimisation. The greatest impediment to successful profiling was a problem associated with the PCR step. Inhibitors co-extracted from the soil with DNA were blocking the PCR reaction. A series of additions and modifications were made to the original profiling methodology (Chapter 5), enabling quality profiles to be obtained from close to $100 \%$ of all subsequently tested samples. This figure falls to approximately $80 \%$ when soil samples collected from under decomposing bodies are profiled, as these samples are believed to contain PCR inhibitors that have no present understanding or remedy.

As part of the preliminary validation of the profiling technique, the reproducibility of the methodology was investigated, with each step of the protocol being performed in triplicate to determine the source of any introduced variability (Chapter 6). The greatest variability seen was between profiles generated from replicate extractions of the same soil sample, even after thorough homogenisation of the soil. This raised the issue of the soil sample size required to comprise a representative sample. Representative profiles were found to be successfully obtained from sample sizes as small as $0.01 \mathrm{~g}$ using the developed methodology (section 5.6.4), suggesting that the $0.5 \mathrm{~g}$ used routinely 
throughout the experimental work described in this thesis was ample to provide a representative profile. Soil sample homogenisation was found to be critical for reproducibility of the profiling technique, as sub-sampling from one soil sample generated different community profiles (section 6.4.2.1). An additional step of grinding the bulk sample in liquid nitrogen before sub-sampling is one possible solution, although a preliminary test of this method's effectiveness did not show any clear advantage to its inclusion (section 5.6.3). It was demonstrated that the amount of soil recovered from typical stains on various fabric types, such as those commonly encountered in forensic casework, was sufficient for use with the soil bacterial community DNA profiling technique (section 5.6.5). It was also determined that the optimal storage temperature for soil samples to prevent community change before profiling, is $4^{\circ} \mathrm{C}$ (section 5.5).

A preliminary investigation into spatial variation of bacterial communities using the soil DNA community profiling technique was performed. The differences between soil bacterial communities increased with distance. Samples spaced $10 \mathrm{~cm}$ apart had on average more similar bacterial communities than samples collected $10 \mathrm{~m}$ apart, which in turn were more similar than samples collected from distinct and un-related locations. It was also found that unrelated sites separated by large geographic distances, but with similar vegetation, showed a degree of similarity, although this was not high, with a mean CAI value of $0.567 \pm 0.15(n=486)$. It is likely that the vegetation present strongly impacts on the soil bacterial community and might even cause the soil to have a profile characteristic of that vegetation type. For example, grass-covered sites might give characteristic bacterial community profiles that are significantly different from the profiles obtained from soil samples taken from native bush or scrub-land. Characteristic vegetation type profiles could aid forensic investigators in a case where soil has been 
recovered, e.g., on a spade or on a suspect's clothing, but where the actual crime scene has not been located. A profile might indicate the type of area in which to concentrate investigations, e.g., native bush rather than rural pasture or suburban gardens. It remains to be determined whether different vegetation types have characteristic profiles, but even the ability to eliminate potential crime scene areas, based on such knowledge, offers a clear advantage for investigators of serious crimes.

An additional potential forensic application of the profiling technique is post mortem interval (PMI) estimation. A preliminary investigation into this application was performed as part of this project. The hypothesis was that a succession of changes would occur in the bacterial community in soil underlying a body, or surrounding a buried body, and that these changes could be seen in successive profiles generated using the soil bacterial community profiling technique. Prior to the work described in this thesis there had been little research into the microbiology associated with mammalian decomposition, and none on the associated succession of community changes. There is strong experimental evidence presented in this thesis that soil bacterial communities are strongly influenced by the decomposition of a body, in both surface and buried environments. Changes in the community continue to occur throughout the progression of decomposition, and with decomposition on the soil surface, the community structure remains altered for an extended period (a minimum of 4654 ADD), even after skeletonisation is reached.

In this thesis, forensic DNA profiling of bacterial communities in soil has been developed into a robust and reproducible technique which holds great potential for use as a routine analytical technique. The degree of variation detected and displayed between samples is high, and profiles can successfully be generated from samples of the 
size commonly encountered in forensic casework. With further validation work, this technique looks likely to be an asset to forensic scientists by making forensic soil analysis simple, reliable and routine. It offers the significant advantage of using equipment and concepts that are already available and in use in most forensic DNA laboratories world-wide. The reduction in cost and time required would enable soil recovered during forensic case-work to be utilised more routinely as evidence, and for more numerous but less serious crimes (such as burglaries) than the currently employed specialised soil comparison techniques allow.

\subsection{Future Directions}

The research presented in this thesis clearly demonstrates the potential for using molecular analysis of soil bacterial populations, in particular T-RFLP, as an analytical forensic technique. There is, however, the need for a comprehensive validation study that expands on the method development and preliminary validation work described in this thesis. This type of validation study is essential to prove the reproducibility and reliability of the technique for casework. This is required to enable it to withstand the detailed scrutiny it will face when used as evidence in a court of law. The proposed study would need to involve profiling a large number of samples from different sites, and determination of the statistical likelihood of false positives and false negatives occurring. The establishment of specific 'cut-off values' would also need to be addressed for the technique to be used evidentially. The CAI similarity index, developed as part of this thesis, provides an informative numerical value of the similarity between two samples, but specific CAI values which indicate a match or a mis-match between samples have not yet been determined. Data generated by a largescale validation study would provide a statistically sound base on which to make such 
recommendations, as well as determine the size and number of soil samples required for evidentially sound results. Statistical validation research is the logical next step in development of a molecular based bacterial forensic soil comparison technique.

Further development of the soil bacterial community profiling methodology may also be required, with variables such as the primer pair used in PCR and the restriction enzyme used for PCR product digestion investigated to determine those that produce the most discriminatory profiles. A primer pair that generates shorter PCR products from the 16S rDNA target may increase the chance of successfully amplifying degraded DNA, thereby providing greater profile variation. Similarly, both primers can be labelled with different fluorescent dyes to increase the number of T-RFs generated, providing more data for comparison if needed. The restriction enzyme $A l u \mathrm{I}$ was used in this study, but use of another enzyme, or combination of more than one, might also increase the number of T-RFs generated from a bacterial community. Although the primers and restriction enzyme used in this study enabled successful profiling with many different T-RFs generated, the potential to improve this output even further should be investigated.

The potential powers of the technique also need to be examined before it can be applied to forensic casework. It is recognised that soil comparisons based on the resident bacterial community of the sample could never be used as conclusive evidence of a crime in the way that human DNA profiling can be. Soil comparison evidence can only be used as associative evidence i.e., proving or disproving a link between a suspect and a victim, or an object, or a location. Soil bacterial community profiling has the potential to offer a wide range of evidential information. The technique is likely to enable basic comparison of two samples, such as those found on a suspect's shoe and a footprint at a 
crime scene, but may also help predict the location of a crime scene based on a soil sample on an item in the suspect's possession. The technique will probably be effective for distinguishing between unrelated soils, and so may help investigators disprove alibis, e.g., that the soil got on the suspect's clothing while playing rugby at a particular location, unrelated to the crime scene. Whether all of these potential applications will be feasible remains to be determined. The potential for obtaining, and feasibility of using, composite soil samples (e.g., soil collected from more than one location, such as may occur on footwear or vehicle tyres) must be ascertained. The homicide scenario experiment described in this thesis took a preliminary look at samples from shoes and vehicles and showed that if samples are collected from these items shortly after contact with the scene, then the profiles are very similar. If a vehicle, for example, has soil adhering to it before contact with the scene of interest, or, if the vehicle travels any distance in the time period between contact with the scene and sample collection, then the sample recovered may no longer be representative of the scene of interest. Such issues must be investigated thoroughly and potential problems resolved before application of the profiling technique to forensic casework.

The way the soil bacterial community profiling technique is used by forensic scientists will also depend strongly on the spatial variability of the soil bacterial communities. If soil varies significantly over short distances, the sampling strategy employed will be considerably different than if soils from all the gardens in a suburb have very similar bacterial community structure. These factors will need to be carefully investigated and evaluated as part of the statistical validation study.

The potential for using soil bacterial community DNA profiling as a PMI estimation tool was clearly demonstrated in this thesis. Although it was only a preliminary 
investigation into the soil bacterial community changes associated with decomposition, many avenues of potential research have been opened. The method described in this thesis is concerned only with the eubacterial population within the soil. The use of the 16S rRNA gene targets limits the target population to bacterial species, and the primer pair F63-R1389 specifically amplifies eubacterial DNA. By using primers targeting other members of the soil microflora, for example by using the fungal $18 \mathrm{~S}$ rRNA gene, additional community structure information may be elucidated and contribute further to both forensic soil comparison and decomposition microbiology applications. Similarly, research investigating bacterial groups with specific roles in soil, such as nitrogenfixing bacteria, could enable a more in-depth analysis of similarity between individual communities, and help to elucidate the microbial processes occurring in response to decomposition of a body. This type of research may require a combination of the molecular biological techniques such as community profiling and gene sequencing with more traditional microbiological and soil chemistry techniques. Identifying whether the bacterial species dominating the soil community during decomposition are indigenous to the soil or are gut microfloral species released from the body, and if possible, identifying the key bacterial players, is a logical progression from the research presented in this thesis. Identification of key microbes could eventually lead to development of an indicator species system for PMI estimation, where the presence, absence or combination of specific bacterial species in a soil sample could predict the stage of decomposition reached. The potential for further research into the area of human decomposition is great, and molecular microbial techniques, such as the T-RFLP based bacterial community profiling technique offer a new microbiological perspective. Such research could eventually offer significant help to death investigators, aiding in accurately estimating time since death or locating places where bodies have been removed from. 
Other molecular community analysis methods, such as microarray technology, could, in the future, offer alternatives to the T-RFLP based comparison system for both soil comparison and PMI estimation applications. The presence or absence of hundreds of key bacterial species in a soil sample could be determined rapidly using such technology. Currently, however, problems with annealing temperature differences between probes, and the cost of initial probe development are prohibitive, particularly for routine forensic analysis. Until such technology becomes readily available and affordable, T-RFLP offers the advantage of using equipment already available and currently in use in most forensic DNA laboratories world-wide. 


\section{REFERENCES}

Abu Al-Soud, W., Radstrom, P., 1998. Capacity of nine thermostable DNA polymerases to mediate DNA amplification in the presence of PCR-inhibiting samples. Applied and Environmental Microbiology, 64, 3748-3753.

Abu Al-Soud, W., Radstrom, P., 2000. Effects of amplification facilitators on diagnostic PCR in the presence of blood, feces, and meat. Journal of Clinical Microbiology, $38,4463-4470$.

Amann, R., Ludwig, W., 2000. Ribosomal RNA-targeted nucleic acid probes for studies in microbial ecology. FEMS Microbiology Reviews, 24, 555-565.

Amann, R.I., Krumholz, L., Stahl, D.A., 1990. Fluorescent-oligonucleotide probing of whole cells for determinative, phylogenetic, and environmental studies in microbiology. Journal of Bacteriology, 172, 762-770.

Amann, R.I., Ludwig, W., Schleifer, K.H., 1995. Phylogenetic identification and in situ detection of individual microbial cells without cultivation. Microbiological Reviews, 59, 143-169.

Amendt, J., Krettek, R., Niess, C., Zehner, R., Bratzke, H., 2000. Forensic entomology in Germany. Forensic Science International, 113, 309-314.

Andrasko, J., 1981. Soil. In: A. Maehly and L. Stromberg, (Eds.), Chemical Criminalistics. Springer-Verlag.

Applied-Biosystems, 1998. ABI Prism 310 Genetic Analyzer User's Manual.

Arnaldos, I., Romera, E., Garcia, M.D., Luna, A., 2001. An initial study on the succession of sarcosaprophagous Diptera (Insecta) on carrion in the southeastern Iberian peninsula. International Journal of Legal Medicine, 114, 156-162.

Australian-Museum. 2003. Decomposition [Online] http://www.deathonline.net.

Avaniss-Aghajani, E., Jones, K., Chapman, D., Brunk, C., 1994. A molecular technique for identification of bacteria using small subunit ribosomal RNA sequences. BioTechniques, 17, 144-146, 148-149.

Babapulle, C.J., Jayasundera, N.P., 1993. Cellular changes and time since death. Medicine, Science and the Law, 33, 213-222.

Bardgett, R.D., Griffiths, B.S., 1997. Ecology and Biology of Soil Protozoa, Nematodes, and Microarthropods. In: J. D. van Elsas, et al., (Eds.), Modern Soil Microbiology. Marcel Dekker, New York.

Bardgett, R.D., Lovell, C.R., Hobbs, P.J., Harvis, S.C., 1999. Seasonal changes in soil microbial communities along a fertility gradient of temperate grasslands. Soil Biology \& Biochemistry, 31, 1021-1030. 
Bass, W.M., 1997. Outdoor Decomposition Rates in Tennessee. In: W. D. Haglund and M. H. Sorg, (Eds.), Forensic Taphonomy: the Postmortem Fate of Human Remains. CRC Press, Boca Raton, FL.

Bass, W.M., Jefferson, J., 2003. Death's Acre: Inside the Legendary 'Body Farm' Time Warner Books UK.

Beauchamp, E.G., Hume, D.J., 1997. Aggricultural Soil Manipulation: The Use of Bacteria, Manuring and Plowing. In: J. D. van Elsas, et al., (Eds.), Modern Soil Microbiology. Marcel Dekker, New York.

Blume, E., Bischoff, M., Reichert, J.M., Moorman, T., Konopka, A., Tuco, R.F., 2002. Surface and subsurface microbial biomass, community structure and metabolic activity as a function of soil depth and season. Applied Soil Ecology, 20, 171181.

Bocaz-Beneventi, G., Tagliaro, F., Bortolotti, F., Manetto, G., Havel, J., 2002. Capillary zone electrophoresis and artificial neural networks for estimation of the postmortem interval (PMI) using electrolytes measurements in human vitreous humour. International Journal of Legal Medicine, 116, 5-11.

Boom, R., Sol, C.J., Salimans, M.M., Jansen, C.L., Wertheim-van Dillen, P.M., van der Noordaa, J., 1990. Rapid and simple method for purification of nucleic acids. Journal of Clinical Microbiology, 28, 495-503.

Borneman, J., Triplett, E.W., 1997. Molecular microbial diversity in soils from eastern Amazonia: evidence for unusual microorganisms and microbial population shifts associated with deforestation. Applied and Environmental Microbiology, 63, 2647-2653.

Brady, N.C., 1974. Some important physical properties of mineral soils. In: The Nature and Properties of Soils. Macmillan Publishing Co. Inc., pp. 48.

Braid, M.D., Daniels, L.M., Kitts, C.L., 2003. Removal of PCR inhibitors from soil DNA by chemical flocculation. Journal of Microbiological Methods, 52, 389393.

Broderick, N.A., Raffa, K.F., Goodman, R.M., Handelsman, J., 2004. Census of the Bacterial Community of the Gypsy Moth Larval Midgut by Using Culturing and Culture-Independent Methods. Applied and Environmental Microbiology, 70, 293-300.

Brown, A.G., Smith, A., Elmhurst, O., 2002. The combined use of pollen and soil analyses in a search and subsequent murder investigation. Journal of Forensic Sciences, 47, 614-618.

Bruce, K.D., 1997. Analysis of mer Gene Subclasses within Communities in Soils and Sediments Resolved Fluorescent PCR-Restriction Fragment Polymorphism Profiling. Applied and Environmental Microbiology, 63, 4914-4919.

Buckley, D.H., Schmidt, T.M., 2001. The Structure of Microbial Communities in Soil and the Lasting Impact of Cultivation. Microbial Ecology, 42, 11-21. 
Burke, R.A., Molina, M., Cox, R.J., Osher, L.J., Piccolo, M.C., 2003. Stable Carbon Isotope Ratio and Composition of Microbial Fatty Acids in Tropical Soils. Journal of Environmental Quality, 32, 198-206.

Buyer, J.S., Roberts, D.P., Russek-Cohen, E., 2002. Soil and plant effects on microbial community structure. Canadian Journal of Microbiology, 48, 955-964.

Carter, D.O., Tibbett, M., 2003. Taphonomic mycota: fungi with forensic potential. Journal of Forensic Sciences, 48, 168-171.

Castellano, M.A., Villanueva, E.C., von Frenckel, R., 1984. Estimating the date of dry bone remains. Journal of Forensic Sciences, 29, 527-534.

Catts, E.P., Goff, M.L., 1992. Forensic entomology in criminal investigations. Annual Review of Entomology, 37, 253-272.

Cavigelli, M.A., Robertson, G.P., Klug, M.J., 1995. Fatty acid methyl ester (FAME) profiles as measures of soil microbial community structure. Plant and Soil, 170, 99-113.

Cengiz, S., Sakul, O., 2001. Capillary Electrophoresis in Forensic Soil Analysis. Proceeding of American Academy of Forensic Sciences 2001; 53rd: B60.

Chander, K., Brookes, P.C., 1992. Synthesis of microbial biomass from added glucose in metal-contaminated and non-contaminated soils following repeated fumigation. Soil Biology and Biochemistry, 24, 613-614.

Chandler, D.P., Fredrickson, J.K., Brockman, F.J., 1997a. Effect of PCR template concentration on the composition and distribution of total community $16 \mathrm{~S}$ rDNA clone libraries. Molecular Ecology, 6, 475-482.

Chandler, D.P., Schreckhise, R.W., Smith, J.L., Bolton, H., 1997b. Electroelution to remove humic compounds from soil DNA and RNA extracts. Journal of Microbiological Methods, 28, 11-19.

Cheneby, D., Philippot, L., Hartmann, A., Henault, C., Germon, J., 2000. 16S rDNA analysis for characterization of denitrifying bacteria isolated from three agricultural soils. FEMS Microbiological Ecology, 34, 121-128.

Chomczynski, P., Mackey, K., Drews, R., Wilfinger, W., 1997. DNAzol®: a reagent for the rapid isolation of genomic DNA. BioTechniques, 22, 550-553.

Clark, M.A., Worrell, M.B., Pless, J.E., 1997. Postmortem Changes in Soft Tissues. In: W. D. Haglund and M. H. Sorg, (Eds.), Forensic Taphonomy: The Postmortem Fate of Human Remains. CRC Press, Boca Raton, FL, pp. 151-160.

Clayton, R.A., Sutton, G., Hinkle, P.S., Bult, C., Fields, C., 1995. Intraspecific variation in small-subunit rRNA sequences in GenBank: why single sequences may not adequately represent prokaryotic taxa. International Journal of Systematic Bacteriology, 45, 595-599. 
Coenye, T., Vandamme, P., 2003. Intragenomic heterogeneity between multiple 16S ribosomal RNA operons in sequenced bacterial genomes. FEMS Microbiology Letters, 228, 45-49.

Cole, S.T., Girons, I.S., 1994. Bacterial genomics. FEMS Microbiology Reviews, 14, 139-160.

Collins, H.E., Li, H., Inda, S.E., Anderson, J., Laiho, K., Tuomilehto, J., Seldin, M.F., 2000. A simple and accurate method for determination of microsatellite total allele content differences between DNA pools. Human Genetics, 106, 218-226.

Colmer, T.D., 2003. Aerenchyma and an Inducible Barrier to Radial Oxygen Loss Facilitate Root Aeration in Upland, Paddy and Deep-water Rice (Oryza sativa L.). Annals of Botany, 91, 301-309.

Conan Doyle, A., 1887. A Study in Scarlet.

Cox, R.J., Peterson, H.L., Young, J., Cusik, C., Espinoza, E.O., 2000. The Forensic Analysis of Soil Organic by FTIR. Forensic Science International, 108, 107-116.

Crecchio, C., Stotzky, G., 1998. Binding of DNA on Humic Acids: Effect on Transformation of Bacillus subtilis and Resistance to DNase. Soil Biology \& Biochemistry, 30, 1061-1067.

Croft, D.J., Pye, K., 2003. The potential use of continuous-flow isotope-ratio mass spectrometry as a tool in forensic soil analysis: a preliminary report. Rapid Communications in Mass Spectrometry, 17, 2581-2584.

Cullen, D.W., Nicholson, P.S., Mendum, T.A., Hirsch, P.R., 1998. Monitoring genetically modified rhizobia in fields using the polymerase chain reaction. Journal of Applied Microbiology, 84, 1025-1034.

Curl, E.A., Truelove, B., 1986. The Rhizosphere. Springer-Verlag, Berlin.

Damastri, C., Chiarini, L., Cantale, C., Bevivno, A., Tabacchioni, S., 1999. Soil type and maize cultivar affect the genetic diversity of maize-associated Burkholderia cepacia populations. Microbial Ecology, 38, 273-284.

Daniels, J., Holmans, P., Williams, N., Turic, D., McGuffin, P., Plomin, R., Owen, M.J., 1998. A simple method for analyzing microsatellite allele image patterns generated from DNA pools and its application to allelic association studies. Am J Hum Genet, 62, 1189-1197.

Diaz-Ravina, M., Acea, M.J., Carballas, T., 1994. Seasonal fluctuations in microbial population and available nutrients in forest soils. Biology and Fertility of Soils, $16,205-210$.

Donachie, S.P., Christenson, B.W., Kunkel, D.D., Malahoff, A., Alam, M., 2002. Microbial community in acidic hydrothermal waters of volcanically active White Island, New Zealand. Extremophiles, 6, 419-425. 
Dunfield, K.E., Germida, J.J., 2004. Impact of Genetically Modified Crops on Soil- and Plant-Associated Microbial Communities. Journal of Environmental Quality, 33, 806-815.

Eberhardt, T. 2003. A preliminary investigation into insect colonisation and succession on remains in New Zealand. MSc thesis, Auckland University.

Eberhardt, T., Elliot, D., 2004. Decomposition and Insect Succession. ANZFSS Conference, Wellington, NZ, March 29 - April 2, 2004.

Egert, M., Friedrich, M.W., 2003. Formation of Pseudo-Terminal Restriction Fragments, a PCR-Related Bias Affecting Terminal Restriction Fragment Length Polymorphism Analysis of Microbial Community Structure. Applied and Environmental Microbiology, 69, 2555-2562.

Ellingsoe, P., Johnsen, K., 2002. Influence of soil sample sizes on the assessment of bacterial community structure. Soil Biology \& Biochemistry, 34, 1701-1707.

Felske, A., Akkermans, A.D., 1998. Spatial Homogeneity of Abundant Bacterial 16S rRNA Molecules in Grassland Soils. Microbial Ecology, 36, 31-36.

Fierer, N., Schimel, J.P., Holden, P.A., 2003. Variations in microbial community composition through two soil depth profiles. Soil Biology \& Biochemistry, 35, 167-176.

Fisher, M.M., Triplett, E.W., 1999. Automated approach for ribosomal intergenic spacer analysis of microbial diversity and its application to freshwater bacterial communities. Applied and Environmental Microbiology, 65, 4630-4636.

Forbes, S.L., Stuart, B.H., Dent, B.B., 2002. The identification of adipocere in grave soils. Forensic Science International, 127, 225-230.

Frostegard, A., Tunlid, A., Baath, E., 1993. Phospholipid Fatty Acid Composition, Biomass, and Activity of Microbial Communities from Two Soil Types Experimentally Exposed to Different Heavy Metals. Applied and Environmental Microbiology, 59, 3605-3617.

Frostegard, A., Courtois, S., Ramisse, V., Clerc, S., Bernillon, D., Le Gall, F., Jeannin, P., Nesme, X., Simonet, P., 1999. Quantification of bias related to the extraction of DNA directly from soils. Applied and Environmental Microbiology, 65, 5409-5420.

Galloway, A., 1997. The Process of Decomposition: A model from the ArizonaSonoran Desert. In: W. D. Haglund and M. H. Sorg, (Eds.), Forensic Taphonomy: The Postmortem Fate of Human Remains. CRC Press, Inc.

Gerberth, V.J., 1996. Estimating Time of Death. In: Practical Homicide Investigation: Tactics, Procedures and Forensic Techniques, 3rd edition ed. Elselvier.

Gill-King, H., 1997. Chemical and Ultrastructural Aspects of Decomposition. In: W. D. Haglund and M. H. Sorg, (Eds.), Forensic Taphonomy: The Postmortem Fate of Human Remains. CRC Press, Boca Raton, FL, pp. 93-104. 
Goff, M.L., 2000. A Fly for the Prosecution: How Insect Evidence Helps Solve Crimes. Harvard University Press May 2000.

Grayston, S.J., Vaughan, D., Jones, D., 1996. Rhizosphere carbon flow in trees, in compariosn with annual plants: the importance of root exudation and its impact on microbial activity and nutrient availability. Applied Soil Ecology, 5, 29-56.

Griffin, D.M., 1972. The ecology of soil fungi. Chapman and Hall, Londan.

Griffiths, B.S., Bardgett, R.D., 1997. Interactions Between Microbe-Feeding Invertebrates and Soil Microorganisms. In: J. D. van Elsas, et al., (Eds.), Modern Soil Microbiology. Marcel Dekker, New York.

Grundmann, G.L., Debouzie, D., 2000. Geostatistical analysis of the distribution of $\mathrm{NH}_{4}{ }^{+}$and $\mathrm{NO}_{2}{ }^{-}$oxidising bacteria and serotypes at the millimeter scale along a soil transect. FEMS Microbiological Ecology, 34, 57-62.

Gruntzig, V., Stres, B., Ayala del Rio, H., Tiedje, J. 2002. Improved Protocol for TRFLP by Capillary Electrophoresis [Online]. Available by Ribosomal Database Project II http://rdp.cme.msu.edu/html/t-rflp_jul02.html.

Harris, D., 1994. Analyses of DNA extracted from microbial communities. In: K. Ritz, et al., (Eds.), Beyond the Biomass. Wiley-Sayce.

Heuer, H., Krsek, M., Baker, P., Smalla, K., Wellington, E.M., 1997. Analysis of actinomycete communities by specific amplification of genes encoding $16 \mathrm{~S}$ rRNA and gel-electrophoretic separation in denaturing gradients. Applied and Environmental Microbiology, 63, 3233-3241.

Höfle, M.G., Brettar, I., 1996. Genotyping of heterotrophic bacteria from the central BalticSea by use of low-molecular-weight RNA profiles. Applied and Environmental Microbiology, 62, 1383-1390.

Holben, W.E., Harris, D., 1995. DNA-based monitoring of total bacterial community structure in environmental samples. Molecular Ecology, 4, 627-631.

Hopkins, D.W., Wiltshire, P.E.J., Turner, B.D., 2000. Microbial characteristics of soil from graves: an investigation at the interface of soil microbiology and forensic science. Applied Soil Ecology, 14, 283-288.

Horrocks, M., Walsh, K.A.J., 1998a. Forensic palynology: assessing the value of the evidence. Review of Palaeobotany and Palynology, 103, 69-74.

Horrocks, M., Walsh, K.A., 1998b. Forensic palynology: assessing the value of the evidence. Review of Palaeobotany and Palynology, 103, 69-74.

Horrocks, M., Walsh, K.A., 1999. Fine Resolution of pollen patterns in limited space: differentiating a crime scene and alibi scene seven metres apart. Journal of Forensic Sciences, 44, 417-420.

Horrocks, M., Coulson, S.A., Walsh, K.A., 1998. Forensic palynology: variation in the pollen content of soil surface samples. Journal of Forensic Sciences, 43, 320323. 
Horswell, J., Cordiner, S.J., Maas, E.W., Martin, T.M., Sutherland, K.B., Speir, T.W., Nogales, B., Osborn, A.M., 2002. Forensic comparison of soils by bacterial community DNA profiling. Journal of Forensic Sciences, 47, 350-353.

Huang, L.N., Zhou, H., Chen, Y.Q., Luo, S., Lan, C.Y., Qu, L.H., 2002. Diversity and structure of the archaeal community in the leachate of a full-scale recirculating landfill as examined by direct $16 \mathrm{~S}$ rRNA gene sequence retrieval. FEMS Microbiol Lett, 214, 235-240.

Hugenholtz, P., Goebel, B.M., 2001. The Polymerase Chain Reaction as a Tool to Investigate Microbial Diversity in Environmental Samples. In: Environmental Molecular Microbiology: Protocols and Applications. Horizon Scientific Press, Wyndmondham, U.K.

Janaway, R.C., 1996. The decay of buried human remains and their associated materials. In: J. Hunter, et al., (Eds.), Studies in Crime: An Introduction to Forensic Archaeology. Batesford, London, pp. 58-85.

Jawetz, E., Melnick, J.L., Melnick, E.A., 1982. Review of Medical Microbiology. 15 ed, Lange Medical, Boston.

Junger, E.P., 1996. Assessing the Unique Characteristics of Close-Proximity Soil Samples: Just How Useful Is Soil Evidence. Journal of Forensic Sciences, 41, 27-34.

Kaboev, O.K., Luchkina, L.A., Tret'iakov, A.N., Bahrmand, A.R., 2000. PCR hot start using primers with the structure of molecular beacons (hairpin-like structures). Nucleic Acids Research, 28, e94.

Kaplan, C.W., Kitts, C.L., 2003. Variation between observed and true Terminal Restriction Fragment length is dependant on true TRF length and purine content. Journal of Microbiological Methods, 54, 121-125.

Killham, K., 1994. Soil Ecology. Cambridge University Press.

Kopczynski, E., Bateson, M., Ward, D., 1994. Recognition of chimeric small-subunit ribosomal DNAs composed of genes from uncultivated microorganisms. Appl. Environ. Microbiol., 60, 746-748.

Kowalchuk, G.A., Bruinsma, M., van Veen, J.A., 2003. Assessing responses of soil microorganisms to GM plants. Trends in Ecology and Evolution, 18, 403-410.

Kramer, F., Vollrath, T., Schnieder, T., Epe, C., 2002. Improved detection of endoparasite DNA in soil sample PCR by the use of anti-inhibitory substances. Veterinary Parasitology, 108, 217-226.

Kreader, C.A., 1996a. Relief of amplification inhibition in PCR with bovine serum albumin or T4 gene 32 protein. Appl Environ Microbiol, 62, 1102-1106.

Kreader, C.A., 1996b. Relief of amplification inhibition in PCR with bovine serum albumin or T4 gene 32 protein. Applied and Environmental Microbiology, 62, 1102-1106. 
LaMontagne, M.G., Schimel, J.P., Holden, P.A., 2003. Comparison of Subsurface and Surface Soil Bacterial Communities in California Grassland as Assessed by Terminal Restriction Fragment Length Polymorphisms of PCR-Amplified16S rRNA Genes. Microbial Ecology, 46, 216-227.

LaMontagne, M.G., Michel, F.C., Jr., Holden, P.A., Reddy, C.A., 2002. Evaluation of extraction and purification methods for obtaining PCR-amplifiable DNA from compost for microbial community analysis. Journal of Microbiological Methods, 49, 255-264.

Lee, D.H., Zo, Y.G., Kim, S.J., 1996. Nonradioactive method to study genetic profiles of natural bacterial communities by PCR-single-strand-conformation polymorphism. Applied and Environmental Microbiology, 62, 3112-3120.

Liesack, W., Janssen, P.H., Rainey, F.A., Ward-Rainey, N.L., Stackebrandt, E., 1997. Microbial Diversity in Soil: The Need for a Combined Approach using Molecular and Cultivation Techniques. In: J. D. van Elsas, et al., (Eds.), Modern Soil Microbiology. Marcel Dekker, New York.

Liu, W.T., Marsh, T., Forney, L.J., 1998. Determination of the microbial diversity of anaerobic-aerobic activated sludge by a novel molecular biological technique. Water Science and Technology, 37, 417-422.

Liu, W.T., Marsh, T.L., Cheng, H., Forney, L.J., 1997. Characterization of microbial diversity by determining terminal restriction fragment length polymorphisms of genes encoding 16S rRNA. Applied and Environmental Microbiology, 63, 45164522 .

Ludwig, W., Schleifer, K.H., 1994. Bacterial phylogeny based on 16S and 23S rRNA sequence analysis. FEMS Microbiology Reviews, 15, 155-173.

Lueders, T., Friedrich, M.W., 2003. Evaluation of PCR amplification bias by terminal restriction fragment length polymorphism analysis of small-subunit rRNA and mcrA genes by using defined template mixtures of methanogenic pure cultures and soil DNA extracts. Applied and Environmental Microbiology, 69, 320-326.

Lund, J.W.G., 1967. Soil Algae. In: A. Burges and F. Raw, (Eds.), Soil Biology. Academic Press, New York.

Mahasneh, A., Budour, S., Doddema, H., 1984. Nitrification and seasonal changes in bacterial populations in the rhizosphere of Suaeda and Anthrocnenum species growing in saline soils. Plant and Soil, 82, 149-154.

Maidak, B.L., Cole, J.R., Parker, C.T., Garrity, G.M., Larsen, N., Li, B., Lilburn, T.G., McCaughey, M.J., Olsen, G.J., Overbeek, R., Pramanik, S., Schmidt, T.M., Tiedje, J.M., Woese, C.R., 1999. A new version of the RDP (Ribosomal Database Project). Nucleic Acids Research, 27, 171-173.

Malgorn, Y., Coquoz, R., 1999. DNA typing for identification of some species of Calliphoridae. An interest in forensic entomology. Forensic Science International, 102, 111-119. 
Manhein, M.H., 1997. Decomposition Rates of Deliberate Burials: A Case Study of Preservation. In: W. D. Haglund and M. H. Sorg, (Eds.), Forensic Taphonomy: The Postmortem Fate of Human Remains. CRC Press, Inc.

Marchesi, J.R., Sato, T., Weightman, A.J., Martin, T.A., Fry, J.C., Hiom, S.J., Dymock, D., Wade, W.G., 1998. Design and evaluation of useful bacterium-specific PCR primers that amplify genes coding for bacterial $16 \mathrm{~S}$ rRNA. Applied and Environmental Microbiology, 64, 795-799.

Marschner, P., Crowley, D.E., Higashi, R.M., 1997. Root exudation and physiological status of a root-colonising fluorescent pseudomonad in micorrhizal and nonmycorrhizal pepper (Capsicum annum L.). Plant and Soil, 189, 11-20.

Marschner, P., Yang, C.H., Lieberei, R., Crowley, D.E., 2001. Soil and plant specific effects on bacterial community composition in the rhizosphere. Soil Biology \& Biochemistry, 33, 1437-1445.

Marsh, T., 1999. Terminal restriction fragment length polymorphism (T-RFLP): an emerging method for characterising diversity among homologous populations of amplification products. Current Opinion in Microbiology, 2, 323-327.

Marsh, T., Liu, W.T., Forney, L.J., Cheng, H., 1998. Beginning a molecular analysis of the eukaryal community in activated sludge. Water Science and Technology, 37, 455-460.

Marumo, Y., Yanai, H., 1986. Morphological Analysis of Opal Phytoliths for Soil Discrimination in Forensic Science Investigation. Journal of Forensic Sciences, 31, 1039-1049.

Marumo, Y., Sugita, R., Seta, S., 1995. Soil as evidence in criminal investigation. 11th Interpol Forensic Science Symposium, Japan.

McAlister, J.J., Smith, B.J., 1995. A Rapid Preparation Technique for X-Ray Diffraction

Analysis of Clay Minerals in Weathered Rock Materials. Microchemical Journal, 52, 53-61.

McLaren, R.G., Cameron, K.C., 1996. The Storage of water in soil. In: R. G. McLaren and K. C. Cameron, (Eds.), Soil Science. Sustainable Production and Environmental Protection. Oxford University Press, Auckland, pp. 71-104.

McPhee, J. 1996. Balloons of War. The New Yorker January 29, 1996 52-60.

Miethling, R., Wieland, G., Backhaus, H., Tebbe, C.C., 2000. Variation of microbial rhizosphere communities in response to crop species, soil origin, and innoculation with Sinorhizobium meliloti L 33. Microbial Ecology, 40, 43-56.

Mildenhall, D.C., 1990. Forensic palynology in New Zealand. Review of Palaeobotany and Palynology, 64, 227-234.

Miller, D.N., Bryant, J.E., Madsen, E.L., Ghiorse, W.C., 1999. Evaluation and optimization of DNA extraction and purification procedures for soil and sediment samples. Applied and Environmental Microbiology, 65, 4715-4724. 
Moore, W., Moore, L., 1995. Intestinal floras of populations that have a high risk of colon cancer. Appl. Environ. Microbiol., 61, 3202-3207.

Moore, W.E.C., Burmeister, J.A., Brooks, C.N., Ranney, R.R., Hinkelmann, K.H., Smibert, R.M., Moore, L.V.H., 1993. Investigation of the influences of puberty, genetics, and environment on the composition of subgingival periodontal floras. Infection and Immunity, 61, 2891-2898.

More, M.I., Herrick, J.B., Silva, M.C., Ghiorse, W.C., Madsen, E.L., 1994. Quantitative cell lysis of indigenous microorganisms and rapid extraction of microbial DNA from sediment. Applied and Environmental Microbiology, 60, 1572-1580.

Murray, R.C., 1982. Forensic examination of soil. In: R. Saferstein, (Ed.) Forensic science handbook. Vol. 1. Englewood Cliffs NJ: Prentice Hall.

Murray, R.C., Tedrow, J.C.F., 1992. Forensic geology. Prentice Hall, New Jersey.

Muyzer, G., de Waal, E.C., Uitterlinden, A.G., 1993. Profiling of complex microbial populations by denaturing gradient gel electrophoresis analysis of polymerase chain reaction-amplified genes coding for $16 \mathrm{~S}$ rRNA. Applied and Environmental Microbiology, 59, 695-700.

Myskowiak, J.B., Doums, C., 2002. Effects of refrigeration on the biometry and development of Protophormia terraenovae (Robineau-Desvoidy) (Diptera: Calliphoridae) and its consequences in estimating post-mortem interval in forensic investigations. Forensic Science International, 125, 254-261.

Nogales, B., Moore, E.R., Llobet-Brossa, E., Rossello-Mora, R., Amann, R., Timmis, K.N., 2001. Combined use of 16 S ribosomal DNA and 16S rRNA to study the bacterial community of polychlorinated biphenyl-polluted soil. Applied and Environmental Microbiology, 67, 1874-1884.

Omelyanyuk, G.G., Alekseev, A.A., Somova, N.G., 1999. The Possibility of Application of the Multisubstrate Testing Method in Soil Criminalistic Investigation. Proceedings of the15th International Association of Forensic Science.

Osborn, A.M., Moore, E.R., Timmis, K.N., 2000. An evaluation of terminal-restriction fragment length polymorphism (T-RFLP) analysis for the study of microbial community structure and dynamics. Environmental Microbiology, 2, 39-50.

Paget, E.L., Jocteur-Monrozier, L., Simonet, P., 1992. Adsorption of DNA on clay minerals: protection against DNase I and influence on gene transfer. FEMS Microbiology Letters, 97, 31-40.

Patra, D.D., Brookes, P.C., Coleman, K., Jenkinson, D.S., 1990. Seasonal changes of soil microbial biomass in an arable and a grassland soil which have been under uniform management for many years. Soil Biology \& Biochemistry, 8, 249-253.

Perry, W.L., Bass, W.M., Riggsby, W.S., Sirotkin, K., 1988. The autodegradation of deoxyribonucleic acid (DNA) in human rib bone and its relationship to the time interval since death. Journal of Forensic Sciences, 33, 144-153. 
Pickering, R.B., Bachman , D.C., 1996. The Use of Forensic Anthropology. CRC Press, Inc.

Porteous, L.A., Seidler, R.J., Watrud, L.S., 1997. An improved method for purifying DNA from soil for polymerase chain reaction amplification and molecular ecology applications. Molecular Ecology, 6, 787-791.

Porteous, L.A., Armstrong, J.L., Seidler, R.J., Watrud, L.S., 1994. An effective method to extract DNA from environmental samples for polymerase chain reaction amplification and DNA fingerprint analysis. Current Microbiology, 29, 301-307.

Prosser, J.I., 1997. Microbial Processes within the Soil. In: J. D. van Elsas, et al., (Eds.), Modern Soil Microbiology. Marcel Dekker, New York.

Querido, D., 1998. A preliminary investigation into postmortem changes in skinfold impedance during the early postmortem period in rats. Forensic Science International, 96, 107-114.

Querido, D., 1999. A preliminary study of changes in scalp impedance during the early post-mortem period in rats. Forensic Science International, 101, 123-130.

Raeside, J.D. 1974. Soils in Forensic Investigations. Department of Scientific and Industrial Research, NZ.

Ramirez-Saad, H.C., Sessitsch, A., Akkermans, A.D., 2003. Molecular diversity in the bacterial community and the fluorescent pseudomonads group in natural and chlorobenzoate-stressed peat-forest soil. Microbiological Research, 158, 47-54.

Ranjard, L., Poly, F., Nazaret, S., 2000. Monitoring complex bacterial communities using culture-independant molecular techniques: application to soil environment. Research in Microbiology, 151, 167-177.

Rappe, M.S., Giovannoni, S.J., 2003. The uncultured microbial majority. Annual Review of Microbiology, 57, 369-394.

Reysenbach, A., Giver, L., Wickham, G., Pace, N., 1992. Differential amplification of rRNA genes by polymerase chain reaction. Appl. Environ. Microbiol., 58, 34173418 .

Riley, M.S., Cooper, V.S., Lenski, R.E., Forney, L.J., Marsh, T.L., 2001. Rapid phenotypic change and diversification of a soil bacterium during 1000 generations of experimental evolution. Microbiology, 147, 995-1006.

Robertson, G.P., Huston, M.A., Evans, F.C., Tiedje, J.M., 1988. Spatial variability in a successional plant community: patterns of nitrogen availability. Ecology, 69, $1517-1524$.

Saetre, P., Baath, E., 2000. Spatial variation and patterns of soil microbila community structure in a mixed spruce-birch stand. Soil Biology \& Biochemistry, 32, 909917.

Satsangi, J., Jewell, D.P., Welsh, K., Bunce, M., Bell, J.I., 1994. Effect of heparin on polymerase chain reaction. Lancet, 343, 1509-1510. 
Schmidt, T.M., Delong, E.F., Pace, N.R., 1991. Analysis of natural microbial populations by ribosomal RNA sequences. Journal of Bacteriology, 173, 43714378.

Schwieger, F., Tebbe, C.C., 1998. A new approach to utilize PCR-single-strandconformation polymorphism for $16 \mathrm{~S}$ rRNA gene-based microbial community analysis. Applied and Environmental Microbiology, 64, 4870-4876.

Smalla, K., Wachtendorf, U., Heuer, H., Liu, W.T., Forney, L.J., 1998. Analysis of BIOLOG GN substrate utilisation patterns by microbial communities. Applied and Environmental Microbiology, 64, 1220-1225.

Smith, J.L., Halvorson, J.J., Bolton, H., 1994. Spatial relationships of soil microbial biomass and $\mathrm{C}$ and $\mathrm{N}$ mineralisation in a semi-arid shrub-steppe ecosystem. Soil Biology \& Biochemistry, 26, 1151-1159.

Sorenson, J., 1997. The Rhizosphere as a Habitat for Soil Microorganisms. In: J. D. van Elsas, et al., (Eds.), Modern Soil Microbiology. Marcel Dekker, New York.

Sorenson, T., 1948. A method of establishing groups of equal amplitude in a plant society based on similarity ofspecies content. Kongelige Danske Videnskabernes Selskab, 5, 1-34.

Southern, E.M., 1979. Measurement of DNA Length by Gel Electrophoresis. Analytical Biochemistry, 100, 319-323.

Srivastava, S.C., 1992. Microbial C, N and P in dry tropical soils: seasonal changes and influence of soil moisture. Soil Biology \& Biochemistry, 24, 711-714.

Stackebrandt, E., Goebel, B.M., 1994. Taxonmic note: A place for DNA-DNA reassociation and $16 \mathrm{~S}$ rRNA sequence analysis in the present species definition in bacteriology. International Journal of Systematic Bacteriology, 44, 846-849.

Stevenson, F.J., 1982. Humus chemistry: Genesis, composition, reactions. John Wiley and Sons., New York.

Stewart, C.N., Via, L.E., 1993. A rapid CTAB DNA isolation technique useful for RAPD fingerprinting and other PCR applications. BioTechniques, 14, 748-750.

Stotzky, G., 1997. Soil as an Environment for Environmental Life. In: J. D. van Elsas, et al., (Eds.), Modern Soil Microbiology. Marcel Dekker, New York.

Suberkropp, K., Gessner, M., Chauvet, E., 1993. Comparison of ATP and Ergosterol as Indicators of Fungal Biomass Associated with Decomposing Leaves in Streams. Appl. Environ. Microbiol., 59, 3367-3372.

Suzuki, M., Rappe, M.S., Giovannoni, S.J., 1998. Kinetic bias in estimates of coastal picoplankton community structure obtained by measurements of small-subunit rRNA gene PCR amplicon length heterogeneity. Applied and Environmental Microbiology, 64, 4522-4529. 
Suzuki, M.T., Giovannoni, S.J., 1996. Bias caused by template annealing in the amplification of mixtures of $16 \mathrm{~S}$ rRNA genes by PCR. Applied and Environmental Microbiology, 62, 625-630.

Svensson, A., Wendel, O., Fisher, B.A.J., 1981. Techniques of Crime Scene Investigation Elsevier North Holland, Inc.

Swift, B., Lauder, I., Black, S., Norris, J., 2001. An estimation of the post-mortem interval in human skeletal remains: a radionuclide and trace element approach. Forensic Science International, 117, 73-87.

Thien, S.J., 1979. A Flow Diagram for Teaching Texture-by-Feel Analysis. Journal of Agronomic Education, 8, 54-55.

Thorn, G., 1997. The Fungi in Soil. In: J. D. van Elsas, et al., (Eds.), Modern Soil Microbiology. Marcel Dekker, New York.

Thornton, J.I., 1986. Forensic soil characteristion. Forensic Science Progress, 1, 3-35.

Thornton, J.I., McLaren, A.D., 1975. Enzymatic Characterisation of Soil Evidence. Journal of Forensic Sciences, 20, 674-692.

Tiedje, J.M., Asuming-Brempong, S., Nusslein, K., Marsh, T., Flynn, S.J., 1999. Opening the black box of soil microbial diversity. Applied Soil Ecology, 13, 109-122.

Torsvik, V., Goksoyr, J., Daae, F.L., 1990. High diversity in DNA of soil bacteria. Applied and Environmental Microbiology, 56, 782-787.

Tsai, Y.L., Olson, B.H., 1992a. Rapid method for separation of bacterial DNA from humic substances in sediments for polymerase chain reaction. Applied and Environmental Microbiology, 58, 2292-2295.

Tsai, Y.L., Olson, B.H., 1992b. Detection of low numbers of bacterial cells in soils and sediments by polymerase chain reaction. Applied and Environmental Microbiology, 58, 754-757.

Tucker, R. 1999. Clay Minerals: Their Importance and Function in Soils Soil Fertility Note 13. NCDA \& CS Agronomic Division, Raleigh, NC, USA.

Ueda, T., Suga, Y., Yahiro, N., Matsuguchi, T., 1995. Remarkable N-2-fixing bacterial diversity detected in rice roots by molecular evolutionary analysis of nifH gene sequences. Journal of Bacteriology, 177, 1414-1417.

Upreti, R.K., Shrivastava, R., Chaturvedi, U.C., 2004. Gut microflora \& toxic metals: Chromium as a model. Indian Journal of Medical Research, 119, 49-59.

Van de Peer, Y., Chapelle, S., De Wachter, R., 1996. A quantitative map of nucleotide substitution rates in bacterial rRNA. Nucleic Acids Research, 24.

van der Maarel, M.J., Artz, R.R., Haanstra, R., Forney, L.J., 1998. Association of marine archaea with the digestive tracts of two marine fish species. Applied and Environmental Microbiology, 64, 2894-2898. 
van Heerden, J., Korf, C., Ehlers, M.M., Cloete, T.E., 2002. Biolog for the determination of diversity in microbial communities. Water SA, 28, 29-35.

Vaneechoutte, M., Van Eldere, J., 1997. The possibilities and limitations of nucleic acid amplification technology in diagnostic microbiology. Journal of Medical Microbiology, 46, 188-194.

Vass, A.A., 2001. Beyond the Grave - Understanding Human decomposition. Microbiology Today, 28, 190-192.

Vass, A.A., Bass, W.M., Wolt, J.D., Foss, J.E., Ammons, J.T., 1992. Time since death determinations of human cadavers using soil solution. Journal of Forensic Sciences, 37, 1236-1253.

Vass, A.A., Barshick, S.A., Sega, G., Caton, J., Skeen, J.T., Love, J.C., Synstelien, J.A., 2002. Decomposition chemistry of human remains: a new methodology for determining the postmortem interval. Journal of Forensic Sciences, 47, 542-553.

Walsh, S.J., 2004. Recent advances in forensic genetics. Expert Review of Molecular Diagnostics, 4, 31-40.

Ward, D.M., Weller, R., Bateson, M.M., 1990. 16S rRNA sequences reveal numerous uncultured microorganisms in a natural community. Nature, 345, 63-65.

Ward, D.M., Bateson, M.M., Weller, R., Ruff-Roberts, A.L., 1992. Ribosomal RNA Analysis of Microorganisms as They Occur in Nature. In: K. C. Marshall, (Ed.) Advances in Microbial Ecology. Vol. 12. Plenum Press, New York, pp. 219286.

Weller, R., Ward, D.M., 1989. Selective recovery of 16S rRNA sequences from natural microbia communities in the form of cDNA. Applied and Environmental Microbiology, 55, 1818-1822.

Whipps, J.M., 1997. Ecological Considerations Involved in Commercial Development of Biological Control Agents for Soil-Borne Diseases. In: J. D. van Elsas, et al., (Eds.), Modern Soil Microbiology. Marcel Dekker, New York.

Wikstrom, P., Andersson, A.C., Forsman, M., 1999. Biomonitoring complex microbial communities using random amplified polymorphic DNA and principal component analysis. FEMS Microbiological Ecology, 28, 131-139.

Wilson, I.G., 1997. Inhibition and Facilitation of Nucleic Acid Amplification. Applied and Environmental Microbiology, 63, 3741-3751.

Winogradsky, S., 1949. Methode dans la microbiologie du sol. Masson et Cie., Paris.

Woese, K., 1987. Bacterial Evolution. Microbiological Reviews, 51, 221-271.

Wood, M., 1995. Environmental Soil Biology. 2 ed, Chapman \& Hall, Glasgow.

Wuertz, S., Mergeay, M., 1997. The Impact of Heavy Metals on Soil Microbial Communities and their Activities. In: J. D. van Elsas, et al., (Eds.), Modern Soil Microbiology. Marcel Dekker, New York. 
Yang, C.H., Crowley, D.E., 2000. Rhizosphere microbial community structure in relation to root location and plant iron nutritional status. Applied and Environmental Microbiology, 66, 345-351.

Yap, W.H., Zhang, Z., Wang, Y., 1999. Distinct types of rRNA operons exist in the genome of the actinomycete Thermomonospora chromogenaand evidence for horizontal transfer of an entire rRNA operon. Journal of Bacteriology, 181, 5201-5209.

Yeates, C., Gillings, M.R., 1998. Rapid purification of DNA from soil for molecular biodiversity analysis. Letters in Applied Microbiology, 27, 49-53.

Yeates, C., Gillings, M.R., Davison, A.D., Altavilla, N., Veal, D.A., 1998. Methods for microbial DNA extraction from soil for PCR amplification. Biological Proceedings Online, 1, 40-47.

Young, C., Burghoff, R.L., Keim, L.G., Minak-Bernero, V., Lute, J.R., Hinton, S.M., 1993. Polyvinylpyrrolidone-agarose gel electrophoresis purification of polymerase chain reaction-amplifiable DNA from soils. Applied and Environmental Microbiology, 59, 1972-1974.

Zak, D.R., Holmes, W.E., White, D.C., Peacock, A.D., Tilman, D., 2003. Plant Diversity, Soil Microbial Communities and Ecosystem Function: are there any links? Ecology, 84, 2042-2050.

Zhou, J., Xia, B., Huang, H., Palumbo, A.V., Tiedje, J., 2004. Microbial Diversity and Heterogeneity in Sandy Subsurface Soils. Applied and Environmental Microbiology, 70, 1723-1734.

Zhou, J., Xia, B., Treves, D.S., Wu, L.Y., Marsh, T.L., O'Neill, R.V., Palumbo, A.V., Tiedje, J.M., 2002. Spatial and resource factors influencing high microbial diversity in soil. Applied and Environmental Microbiology, 68, 326-334. 


\section{Appendix 1: Method Protocols}

\section{A1.1 FastDNA ${ }^{\circledR}$ SPIN kit for Soil Protocol}

1. Add $500 \mathrm{mg}$ soil to the Tissue Matrix tube. Add $978 \mu \mathrm{L}$ Sodium Phosphate Buffer and $122 \mu \mathrm{L}$ MT Buffer.

2. Secure tubes in FastPrep Instrument and process for 90 seconds at speed 5.5.

3. Centrifuge Tissue Matrix tubes at $14000 \mathrm{x} g$ for 1 minute.

4. Transfer supernatant to a clean tube. Add $250 \mu \mathrm{L}$ PPS reagent and mix by shaking the tube by hand 10 times.

5. Centrifuge at $14000 \mathrm{x} \mathrm{g}$ for 5 minutes to pellet precipitate. Transfer supernatant to a clean $15 \mathrm{~mL}$ tube. Add $1 \mathrm{~mL}$ Binding Matrix Suspension to the supernatant.

6. Place on a rotator or invert by hand for 2 minutes to allow binding of DNA to matrix. Place tube in a rack for 3 minutes to allow settling of silica matrix.

7. Remove $500 \mu \mathrm{L}$ of supernatant being careful to avoid settled Binding Matrix. Discard supernatant. Resuspend the Binding Matrix in the remaining amount of supernatant. Transfer approximately $600 \mu \mathrm{L}$ of the mixture to a Spin Filter and centrifuge at $14000 \mathrm{x}$ g for 1 minute. Empty the catch tube and add the remaining supernatant to the Spin Filter and spin again.

8. Add $500 \mu \mathrm{L}$ SEWS-M to the Spin Filter and centrifuge at $14000 \times \mathrm{g}$ for 1 minute. Decant flow through and replace Spin Filter in catch tube. Centrifuge at $14000 \mathrm{x} \mathrm{g}$ for 2 minutes to "dry" the matrix of residual SEWS-M wash solution.

9. Remove Spin Filter and place in fresh kit-supplied Catch Tube. Air dry the Spin Filter for 5 minutes at room temperature.

10. Add $50 \mu \mathrm{L}$ DES and gently stir matrix on filter membrane with a pipette tip or vortex/finger flip to resuspend the silica for efficient elution of the DNA. Centrifuge at $14000 \mathrm{x} \mathrm{g}$ for 1 minute to transfer eluted DNA to Catch tube. DNA is now application ready. 


\section{A1.2 PicoGreen dsDNA Quantitation Kit Methodology}

1. Prepare the TE buffer from the kit by diluting $1 / 20$ in DNase/RNase free $\mathrm{H}_{2} \mathrm{O}$.

2. Using a black 96 well flat-bottomed (Nunc) plate, prepare standard solutions in the $1^{\text {st }}$ row of wells using the kit DNA standard stock $(100 \mu \mathrm{g} / \mathrm{mL})$ and TE buffer to a total volume of $100 \mu \mathrm{L}$. Prepare standards containing: $200 \mathrm{ng}, 100 \mathrm{ng}, 50 \mathrm{ng}, 25 \mathrm{ng}$, $12.5 \mathrm{ng}, 2.5 \mathrm{ng}, 1 \mathrm{ng}$, and $0.5 \mathrm{ng}$ total DNA.

3. Dilute samples $1: 100$ in TE buffer by adding $1 \mu \mathrm{L}$ of sample to a well and then 99 $\mu \mathrm{L}$ TE buffer.

4. Dilute the PicoGreen quantitation reagent 1:200 in DNase/RNase free $\mathrm{H}_{2} \mathrm{O}$, preparing $100 \mu \mathrm{L}$ for each well used including the standards and a blank well.

5. Add $100 \mu \mathrm{L}$ of diluted reagent to each well. Cover the plate with foil and mix gently. Leave to stand at room temperature for 5 minutes before reading with the fluorescence reader.

6. The excitation wavelengths are $485 \mathrm{~nm}$ and the emission $538 \mathrm{~nm}$.

7. Construct a standard curve using the readings from the standard solutions.

8. Use the standard curve and the sample values corrected for the blank value to calculate the amount of DNA present in each sample.

\section{A1.3 Gel Electrophoresis Protocol}

1. Prepare $400 \mathrm{~mL}$ of $2 \%$ agarose by mixing $8.0 \mathrm{~g}$ agarose powder with $400 \mathrm{~mL}$ of 0.5X TBE buffer (Tris-borate EDTA -diluted 1/20 from 10x TBE stock). Melt by heating in a microwave oven, shaking the bottle every minute until dissolved. Leave the agarose mix at room temperature to cool to around $56^{\circ} \mathrm{C}$.

2. When cooled, pour $50 \mathrm{~mL}$ of agarose into a casting tray and place a well comb.

3. Leave the gel to set for approximately 30 minutes.

4. When set, carefully remove the comb and place the gel, in its tray, inside the electrophoresis chamber. Pour enough $0.5 \mathrm{X}$ TBE buffer in the chamber to cover the gel.

5. Mix $3 \mu \mathrm{L}$ of each PCR reaction with $1 \mu \mathrm{L}$ loading buffer (40\% sucrose + bromophenol blue $0.25 \% \mathrm{w} / \mathrm{v}$ ) on parafilm and load into a well on the gel. Load $1.5 \mu \mathrm{L}$ of $100 \mathrm{bp}$ ladder (Invitrogen) into one well.

6. Attach the lid and power leads to the tank and apply a current of $115 \mathrm{~V}$. 
7. Run the electrophoresis for approximately 45 minutes or until the loading dye can be seen nearing the end of the gel. Switch off the current and remove the gel.

8. Immerse the gel in ethidium bromide $(10 \mathrm{mg} / \mathrm{mL})$ aqueous solution for approximately 10 minutes before removing and destaining in tapwater for approximately 10 minutes.

9. Visualise the bands using an ultraviolet light and a make a digital photographic record.

\section{A1.4 QIAquick PCR Purification Kit Protocol}

1. Add 5 volumes Buffer PB to 1 volume of the PCR reaction and mix. It is not necessary to remove mineral oil or kerosene.

2. Place a QIAquick spin column in a provided $2 \mathrm{~mL}$ collection tube.

3. To bind DNA, apply the sample to the QIAquick column and centrifuge for 3060 seconds.

4. Discard flow-through and place the QIAquick column back in the same tube.

5. Centrifuge the column for an additional 1 min at maximum speed.

6. Place QIAquick column in a clean $1.5 \mathrm{~mL}$ microfuge tube.

7. To elute DNA, add $50 \mu \mathrm{l}$ Buffer EB (10mM Tris-Cl, $\mathrm{pH} 8.5$ ) or $\mathrm{H}_{2} \mathrm{O}$ to the centre of the QIAquick membrane and centrifuge the column for 1 minute. Alternatively, for increased DNA concentration, add $30 \mu \mathrm{L}$ elution buffer to the centre of the QIAquick membrane, let the column stand for 1 min and then centrifuge.

\section{A1.5 Guanidine Thiocyanate Wash Methodology}

1. Prepare a Humic Acid Wash Solution by combining the following in a $1.5 \mathrm{ml}$ microcentrifuge tube:

$978 \mu$ l Sodium Phosphate Buffer

$122 \mu \mathrm{l}$ MT Buffer

$250 \mu 1 \mathrm{PPS}$ 
2. Mix well and spin at full speed for 1 minute. Transfer supernatant to new tube (2 $\mathrm{ml}$ or larger).

3. Add an equal volume of the 5.5 M Guanidine Thiocyanate solution and mix well.

4. After step 7 in the FastDNA ${ }^{\circledR}$ SPIN kit for Soil protocol, add $500 \mu$ l of Humic Acid Wash Solution to the SPIN filter.

5. Spin at $14,000 \mathrm{x} \mathrm{g}$ for 1 minute and empty catch tube.

6. Repeat washing process until silica returns to its original colour.

Continue with step 8.

\section{A1.6 Bovine Serum Albumin Dilutions}

To make a $50 \mu \mathrm{g} / \mu \mathrm{L}$ solution: add $0.05 \mathrm{~g}$ BSA to $1 \mathrm{~mL}$ sterile $\mathrm{H}_{2} \mathrm{O}$.

- $10 \mu \mathrm{L}$ into a $50 \mu \mathrm{L}$ reaction $=10 \mu \mathrm{g} / \mu \mathrm{L}$

- $5 \mu \mathrm{L}$ into a $50 \mu \mathrm{L}$ reaction $=5 \mu \mathrm{g} / \mu \mathrm{L}$

A $1 / 10$ dilution can be made of the $50 \mu \mathrm{g} / \mu \mathrm{L}$ solution $=5 \mu \mathrm{g} / \mu \mathrm{L}$

- $10 \mu \mathrm{L}$ into a $50 \mu \mathrm{L}$ reaction $=1 \mu \mathrm{g} / \mu \mathrm{L}$

- $1 \mu \mathrm{L}$ into a $50 \mu \mathrm{L}$ reaction $=0.1 \mu \mathrm{g} / \mu \mathrm{L}$

\section{A1.7 DNAzol Protocol}

\section{Extracted DNA wash}

1. Add $50 \mu \mathrm{l}$ of extracted DNA solution to $1 \mathrm{~mL}$ DNAzol and mix gently for two minutes.

2. Add $0.5 \mathrm{~mL} 100 \%$ ethanol and mix again.

3. Leave mixture at room temperature for 3 minutes.

4. Centrifuge sample for 2 minutes at $4000 \mathrm{~g}$.

5. Air dry DNA pellet and resuspend in $20 \mu \mathrm{l} \mathrm{H}_{2} \mathrm{O}$.

\section{Extraction with DNAzol step}

1. Add $0.5 \mathrm{~g}$ soil to lysing tube and follow the first steps of the FastDNA Spin Kit normal extraction protocol. 
2. After the first centrifugation step, transfer the supernatant to a clean tube and add $1 \mathrm{~mL}$ DNAzol. Mix gently for 2 minutes.

3. Add $0.5 \mathrm{~mL}$ of $100 \%$ ethanol and mix again.

4. Leave at room temperature for 3 minutes.

5. Centrifuge for 2 minutes at $4000 \mathrm{~g}$ - can be repeated if necessary.

Air dry the DNA pellet and resuspend in $100 \mu 1$ sodium phosphate buffer.

6. Follow the FastDNA kit protocol from step 4.

\section{A1.8 Plant DNAzol Protocol}

1. Add $0.5 \mathrm{~g}$ soil to the lysing tube and follow the protocol for normal extraction with the FastDNA Spin Kit for Soil.

2. After the first centrifugation step, transfer the supernatant to a clean tube and add $0.5 \mathrm{~mL}$ of Plant DNAzol. Mix gently a few times.

3. Add $0.4 \mathrm{~mL}$ of $100 \%$ ethanol and invert the mixture $6-8$ times.

4. Leave at room temperature for 5 minutes.

5. Centrifuge for 4 minutes at $4000 \mathrm{~g}$ - can be repeated if necessary.

6. Air dry the DNA/soil pellet and resuspend in $200 \mu$ l sodium phosphate buffer.

7. Follow the FastDNA kit protocol from step 4.

\section{A1.9 DNeasy DNA Extraction Kit Protocol}

(amended for use with soil)

1. In a $1.5 \mathrm{~mL}$ eppendorf tube, add $0.1 \mathrm{~g}$ of soil and $280 \mu \mathrm{l}$ Buffer ATL.

2. Add $20 \mu \mathrm{l}$ Proteinase $\mathrm{K}$, mix with a vortex mixer and incubate at $55^{\circ} \mathrm{C}$ overnight in a shaking waterbath.

3. In the morning add another $20 \mu$ Proteinase $\mathrm{K}$, vortex, and incubate at $55^{\circ} \mathrm{C}$ for 90 minutes.

4. Mix again for 15 seconds and add $200 \mu \mathrm{l}$ Buffer AL. Remix and incubate at $70^{\circ}$ $\mathrm{C}$ for 10 minutes.

5. Add $200 \mu \mathrm{l}$ of $100 \%$ ethanol and mix thoroughly. 
6. Transfer sample into a DNeasy spin column in a $2 \mathrm{~mL}$ collection tube and centrifuge at $8000 \mathrm{rpm}$ for 1 minute. Discard the flow through and collection tube.

7. Place the DNeasy spin column in a new $2 \mathrm{~mL}$ collection tube and add $500 \mu \mathrm{l}$ Buffer AW2. Centrifuge for 3 minutes at full speed to dry the membrane. Discard the flow through and collection tube.

8. Place the DNeasy spin column in a clean $2 \mathrm{~mL}$ microcentrifuge tube and pipette $200 \mu \mathrm{l}$ buffer AE directly onto the membrane. Incubate at room temperature for 1 minute and then centrifuge for a further minute at $8000 \mathrm{rpm}$ to elute the DNA.

9. Repeat the elution step as in step 8 .

\section{A1.10 FastDNA Kit Protocol}

(amended for use with soil)

1. Add $1 \mathrm{~mL}$ CLS-TC solution to $0.1 \mathrm{~g}$ of soil in a lysing matrix tube.

2. Homogenise the sample in a BeadBeater instrument for 30 seconds at speed 5 .

3. Leave the sample at room temperature for 1 hour and homogenise again for 30 seconds at speed 5 .

4. Pellet the debris by centrifuging for 5 minutes at $14,000 \mathrm{x}$ g. Transfer $600 \mu 1$ of supernatant to a clean microcentrifuge tube.

5. Add $600 \mu \mathrm{l}$ of binding matrix, mix gently and incubate for 5 minutes at room temperature. Centrifuge for 1 minute and discard the supernatant. Gently resuspend the pellet in $500 \mu \mathrm{SEWS}-\mathrm{M}$ and transfer to a spin filter.

6. Centrifuge for 1 minute, and then discard the contents of the catch tube. Centrifuge again for 1 minute to dry the matrix. Transfer the spin filter to a new catch tube.

7. Elute the DNA by resuspending the matrix in $100 \mu \mathrm{l}$ DES. It was left for 3 minutes and then centrifuged for 1 minute at $14,000 \mathrm{x}$ g to transfer the DES to the catch tube. This step was repeated to ensure maximum elution of DNA. 


\section{A1.11 MinElute Reaction Cleanup Kit (Qiagen)}

(Using a microcentrifuge)

1. Add 5 volumes of Buffer PB to 1 volume of the PCR reaction and mix. It is not necessary to remove mineral oil or kerosene. For example add $250 \mu \mathrm{L}$ of Buffer PB to $50 \mu \mathrm{L}$ PCR reaction (not including oil).

2. Place a MinElute column in a provided $2 \mathrm{~mL}$ collection tube in a suitable rack.

3. To bind DNA, apply the sample to the MinElute column and centrifuge for 1 min. For maximum recovery, transfer all traces of sample to the column.

4. Discard flow through and place the MinElute column back in the same tube.

5. To wash, add $750 \mu \mathrm{L}$ Buffer PE to the MinElute column and centrifuge for 1 minute.

6. Discard flow-through and place the MinElute column back in the same tube. Centrifuge the column for an additional $1 \mathrm{~min}$ at maximum speed. Important: Residual ethanol from Buffer PE will not be completely removed unless the flow-through is discarded before this additional centrifugation.

7. Place the MinElute column in a clean $1.5 \mathrm{~mL}$ microcentrifuge tube.

8. To elute DNA, add $10 \mu \mathrm{L}$ Buffer EB (10 mM Tris. $\mathrm{Cl}, \mathrm{pH} 8.5)$ or $\mathrm{H}_{2} \mathrm{O}$ to the centre of the membrane, let the column stand for 1 minute and then centrifuge for 1 minute. Important: Ensure that the elution buffer is dispensed directly onto the centre of the membrane for complete elution of bound DNA. The average eluate volume is $9 \mu \mathrm{L}$ from $10 \mu \mathrm{L}$ elution buffer volume. 


\section{A1.12 The 'Feel' Soil Characterisation Method}

Adapted from Thien (1979).

\section{Guide to Texture by Feel}

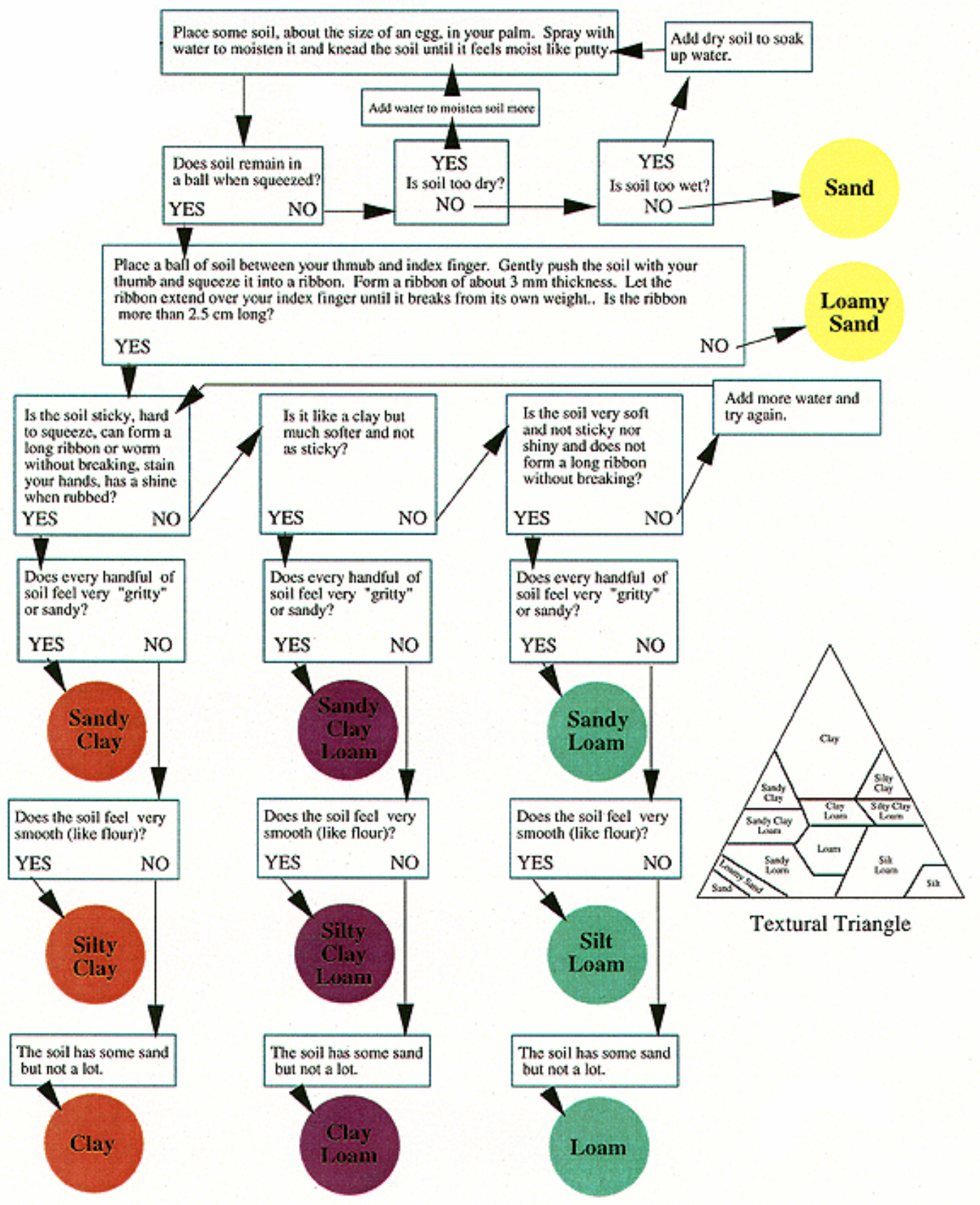




\section{Appendix 2: Gel Photos}

A2.1 Homicide scenario PCR with AmpliTaq Gold Taq Polymerase.

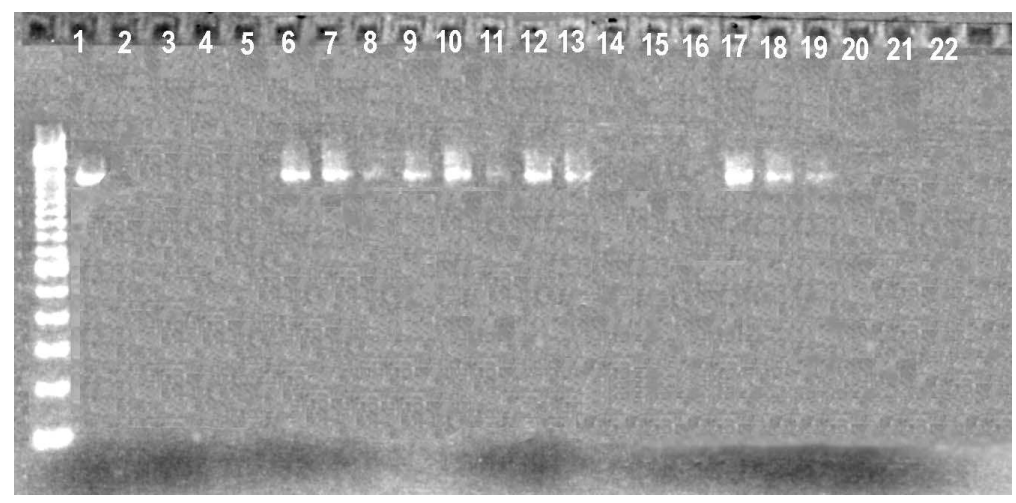

$1=$ Positive Control ( $\underline{\text { E.coli }} \mathrm{gDNA})$

$12=$ Assailant's left shoe

$2=$ Soil $(a)$ - scene 1

$3=$ Soil $(b)$ - scene 1

$4=$ Soil $(c)-$ scene 1

$5=$ Soil $(d)-$ scene 1

$6=$ Shoe print - scene 2

$7=$ Tyre print - scene 2

$8=$ Vehicle left front wheel arch

$9=$ Vehicle tyre

$10=$ Vehicle driver's footwell

$11=$ Vehicle left front side

$13=$ Assailant's right shoe

$14=$ Victim's right shoe heel

$15=$ Victim's overalls sleeve stain

$16=$ Assailant's overalls right knee stain

$17=$ Soil (b) spiked with $\underline{E}$. coli $g D N A$

$18=$ Shoe print spiked with E. coli $g D N A$

$19=$ Victim's right shoe heel spiked with E. coli gDNA

$20=$ Victim's overalls sleeve stain spiked with E.coli gDNA

$21=$ Assailant's overalls right knee spiked with E.coli gDNA

$22=$ Negative reagent control

\section{A2.2 Homicide scenario PCR with HotStarTaq DNA Polymerase.}

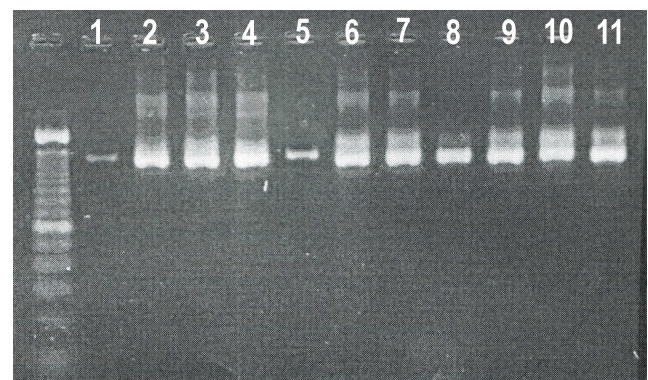

$\begin{array}{llllllllll}12 & 13 & 14 & 15 & 16 & 17 & 18 & 19 & 20 & 21\end{array} 22$

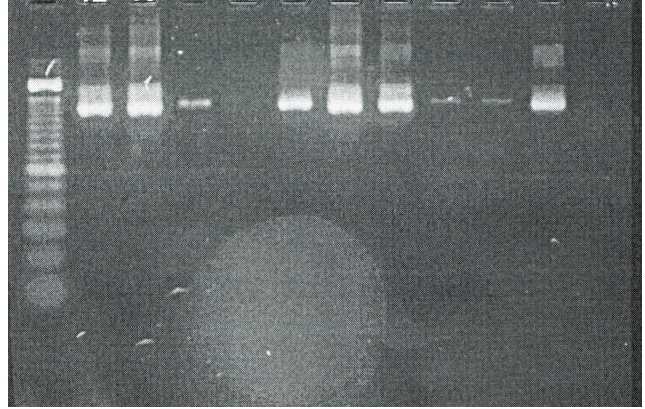

$1=$ Positive Control $($ E.coli $g D N A)$

$2=\operatorname{Soil}(a)-$ scene 1

$3=$ Soil $(b)-$ scene 1

$4=$ Soil $(c)-$ scene 1

$5=$ Soil $(d)$ - scene 1

$6=$ Shoe print - scene 2

$7=$ Tyre print - scene 2

$8=$ Vehicle left front wheel arch - scene 2

$9=$ Vehicle tyre - scene 2

$10=$ Vehicle driver's footwell - scene 2

$11=$ Vehicle left front side

$12=$ Assailant's left shoe

$13=$ Assailant's right shoe

$14=$ Victim's right shoe heel

$15=$ Victim's overalls sleeve stain

$16=$ Assailant's overalls right knee stain

$17=$ Soil $(b)-$ scene spiked with $E$.coli gDNA

$18=$ Shoe print - scene 2 spiked with $\underline{E}$.coli gDNA

$19=$ Victim's right shoe heel spiked with E.coli gDNA

$20=$ Victim's overalls stain spiked with $\underline{E}$.coli gDNA

$21=$ Assailant's overalls stain with E.coli gDNA

$22=$ Negative reagent control 


\section{A2.3 Extraction with CTAB and SPB steps PCR}

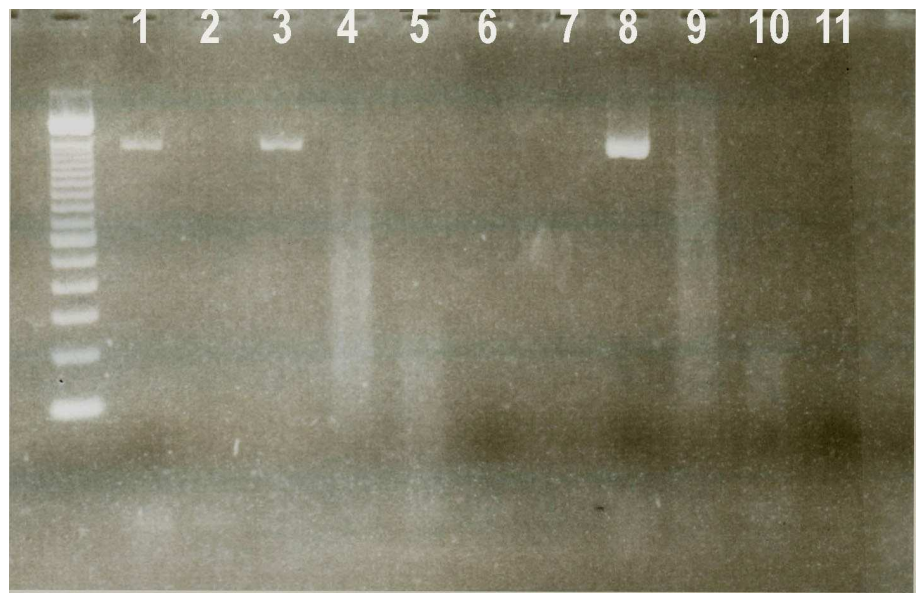

$1=$ Positive control ( F63FAM old primer)

$2=$ blank

3=Positive control (new FAM63

primer)

$4=$ SPB Test panel sample $1(D 3)$

$5=C T A B$ Test panel sample $1(D 3)$

$6=S P B$ sample $D 4$

$7=C T A B$ sample $D 4$

$8=$ Positive control (new unlabelled primer)

$9=$ SPB Test panel sample 1(D3)

$10=C T A B$ Test panel sample $1(D 3)$

$11=$ Negative (reagent) control

\section{A2.4 Repeated wash steps / guanidine thiocyanate / extra CTAB \& SPB}

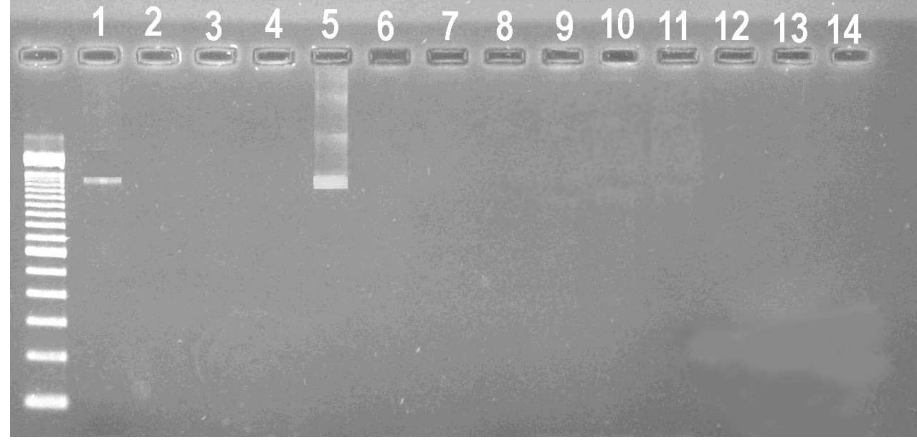

$1=$ Positive control $(\underline{\text { E.coli }} \mathrm{gDNA})$

$9=T P-3$ (guanidine thiocyanate)

$2=T P-1$ (extra SEWS wash)

$10=T P-4$ (guanidine thiocyanate)

$3=T P-2($ extra SEWS wash $)$

$11=T P-5$ (guanidine thiocyanate)

$4=T P-3$ (extra SEWS wash)

$12=S P B$ sample D4

$5=T P-4($ extra SEWS wash $)$

$13=C T A B$ sample $D 4$

$6=T P-5($ extra SEWS wash)

$14=$ Negative (reagent) control

$7=T P-1$ (guanidine thiocyanate)

$8=T P-2$ (guanidine thiocyanate)

\section{A2.5 Extraction with Proteinase K step}

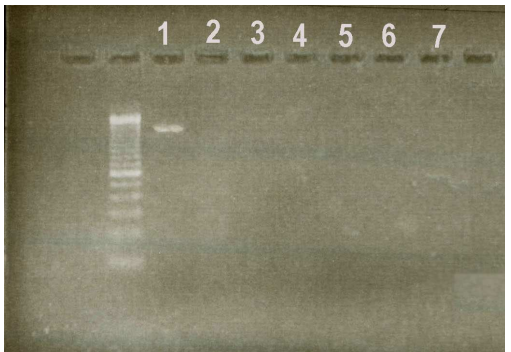

$1=$ Positive control $(\underline{\text { E.coli }}$ gDNA)

$2=$ Test panel sample 1

$3=$ Test panel sample 2

$4=$ Test panel sample 3

$5=$ Test panel sample 4

$6=$ Test panel sample 5

$7=$ Negative (reagent) control 


\section{A2.6 DNAzol after extraction / BSA}

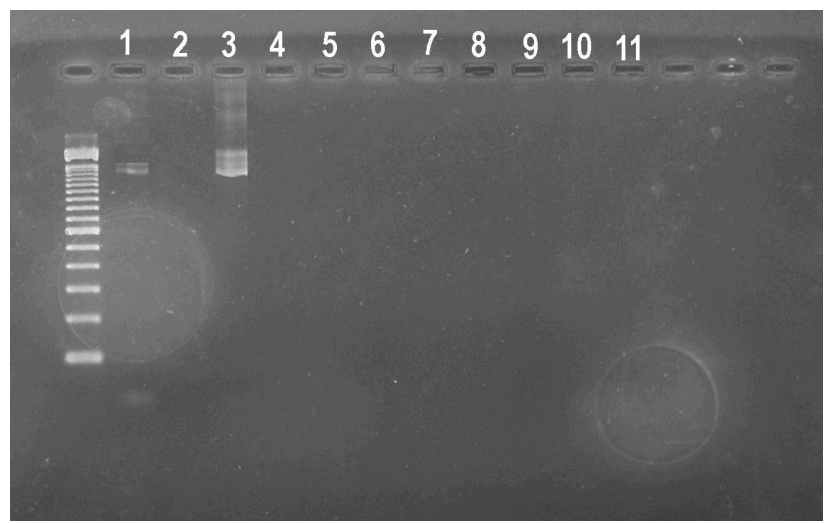

$1=$ Positive control( E.coli $g D N A)$

$2=D 1(B S A)$

$3=D 2(B S A)$

$4=A 21(B S A)$

$5=B 5(B S A)$

$6=$ Positive control (with BSA added)

$7=T P-1(D N A z o l)$

$8=T P-2(D N A z o l)$

$9=T P-3($ DNAzol $)$

$10=T P-4(D N A z o l)$

$11=T P-5(D N A z o l)$

$13=$ Negative (reagent) control

\section{A2.7 BSA / DNAzol during extraction}

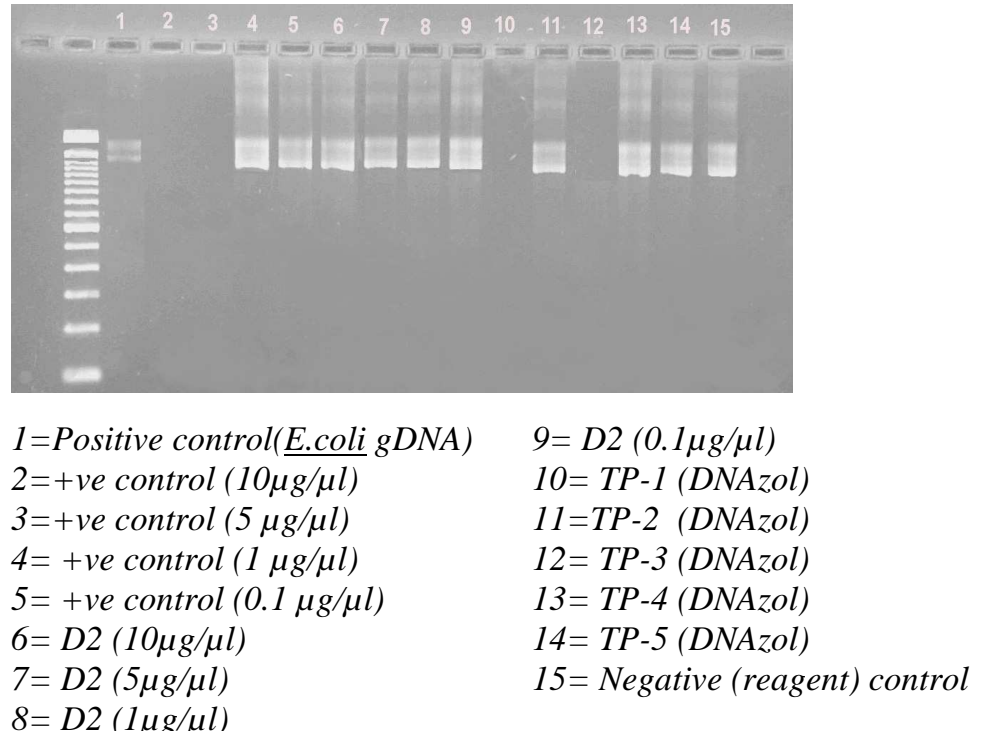

\section{A2.8 Extraction kits}

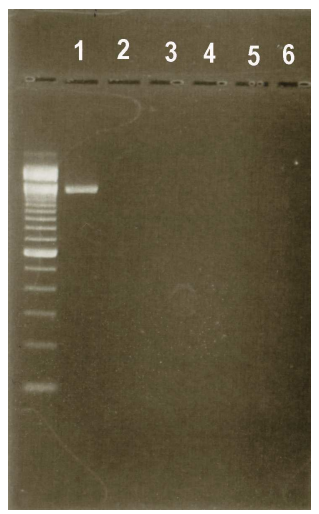

$1=$ Positive control(E.coli gDNA)

2= DNeasy Tissue Kit - Test panel sample 1

$3=$ DNeasy Tissue Kit - Test panel sample 2

$4=$ FastDNA Kit - Test panel sample 1

$5=$ FastDNA Kit - Test panel sample 2

$6=$ Negative (reagent) control 


\section{A2.9 DNAzol extra 10 samples}

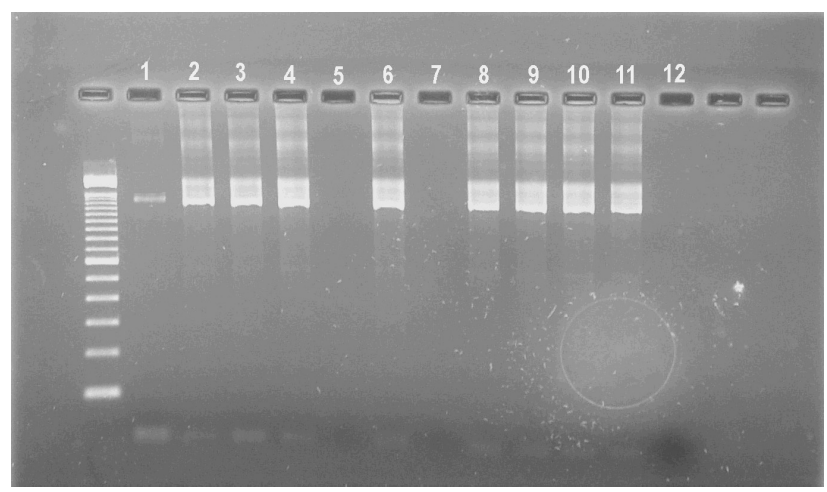

$1=$ Positive control( $\underline{\text { E.coli }}$ gDNA)

$2=$ Test sample1 (Bush 19)

$3=$ Test sample 2 (Bush 24)

$4=$ Test sample 3 (Grass 43)

$5=$ Test sample 4 (B3)

$6=$ Test sample 5 (B7)

$7=$ Test sample $6(B 19)$

$8=$ Test sample $7(B 22)$

$9=$ Test sample $8(A 21)$

$10=$ Test sample 9 (A22)

$11=$ Test sample 10 (A29)

$12=$ Negative (reagent) control

\section{A2.10 Plant DNAzol extra 10 samples}

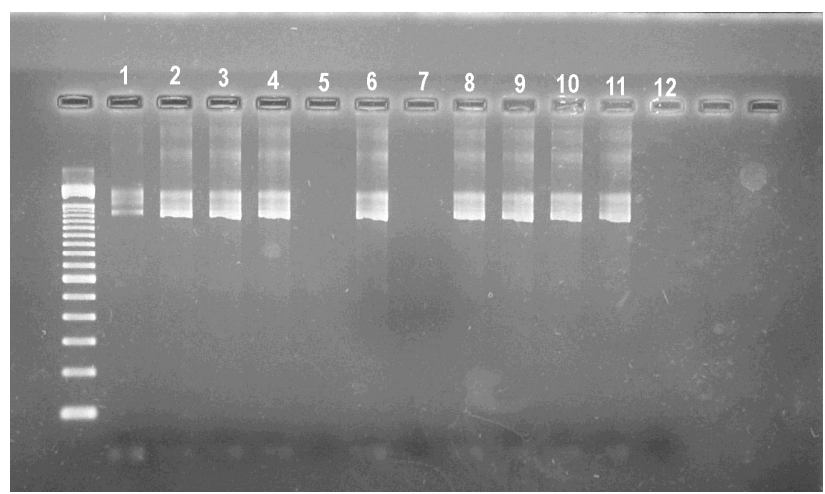

$1=$ Positive control $($ E.coli $g D N A)$

$2=$ Test sample1 (Bush 19)

$3=$ Test sample 2 (Bush 24)

$4=$ Test sample 3 (Grass 43)

$5=$ Test sample 4 (B3)

$6=$ Test sample $5(B 7)$

$7=$ Test sample $6(B 19)$

$8=$ Test sample 7 (B22)

$9=$ Test sample $8(A 21)$

$10=$ Test sample $9(A 22)$

$11=$ Test sample 10 (A29)

$12=$ Negative (reagent) control

\section{A2.11 FastStart DNA Polymerase}

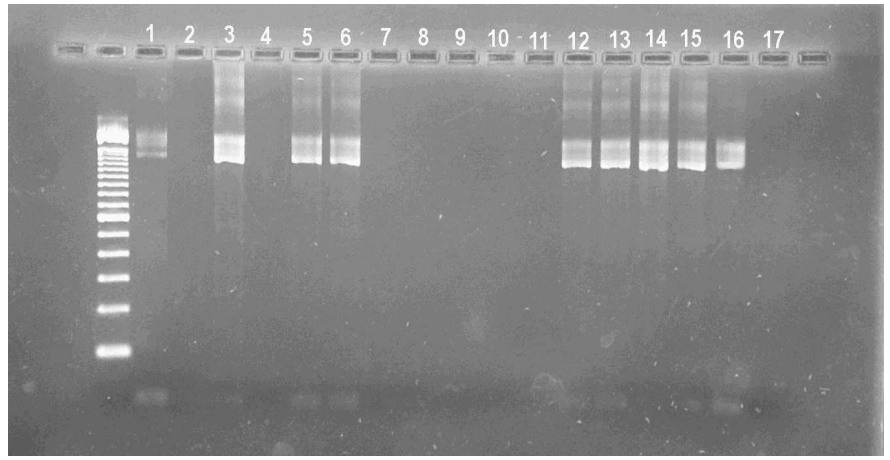

$1=$ Positive control(E.coli gDNA)

$10=T P-9$

$2=T P-1$

$11=T P-10$

$3=T P-2$

$12=T P-11$

$4=T P-3$

$13=T P-12$

$5=T P-4$

$14=T P-13$

$6=T P-5$

$15=T P-14$

$7=T P-6$

$8=T P-7$

$16=T P-15$

$9=T P-8$

$17=$ Negative (reagent) control 
A2.12 Accuprime Taq DNA Polymerase

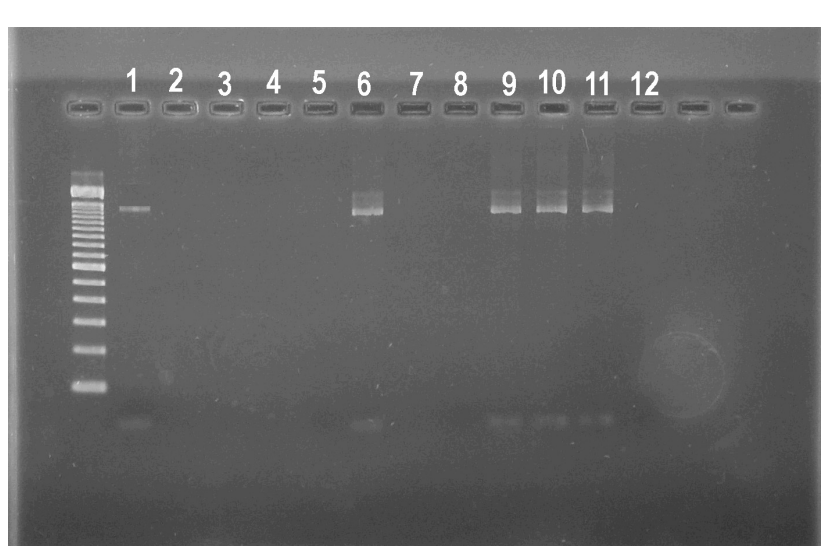

$1=$ Positive control( $\underline{\text { E.coli }}$ gDNA)

$2=T P-6(D 2)$

$3=T P-7(D 3)$

$4=T P-8(A 21)$

$5=T P-9(B 5)$

$6=T P-10(B 20)$

$7=T P-1(D 1)$

$8=T P-2(A 5)$

$9=T P-3(A 37)$

$10=T P-13$ (homicide 25)

$11=T P-14$ (homicide 1)

$12=$ Negative (reagent) control 